\title{
Behavioural patterns of two native Leiopelma frogs and implications for their conservation
}

\author{
Patricia Alejandra Ramírez Saavedra
}

\author{
A thesis submitted to \\ Victoria University of Wellington \\ in fulfilment of the requirement for the degree of \\ Doctor of Philosophy in Ecology and Biodiversity
}

Victoria University of Wellington

Te Whare Wānanga o te Ūpoko o te Ika a Māui

2017 
This thesis should be cited as follows:

Ramírez PA 2017. Behavioural patterns of two native Leiopelma frogs and implications for their conservation. Unpublished $\mathrm{PhD}$ thesis, Victoria University of Wellington, Wellington, New Zealand. 


\section{Abstract}

Amphibian populations are in general decline internationally. The current situation of amphibian populations highlights the urgent need for comprehensive information on species' ecology to better assess conservation and management strategies. Movement behaviour and microhabitat selection give insights into how amphibians use the environment and interact with their surroundings, and are essential to establishing their sensitivity to the global decline phenomenon and identifying the critical habitat features essential for their success. New Zealand native frogs (Anura: Leiopelmatidae, Leiopelma, nine species) were formerly distributed throughout New Zealand, but habitat modification and predation by introduced mammalian predators have influenced recent (Holocene) extinctions and declines, reducing the fauna to four species with major range reductions. All extant Leiopelma are classified as threatened both nationally and internationally, creating an urgent need for species-specific behavioural research to support conservation management. I investigated activity, movement behaviour and microhabitat use of L. archeyi and L. pakeka for better evaluation of long term population viability and improved husbandry in captivity. L. archeyi is the smallest of the Leiopelma species and has been able to cooccur with introduced predators (e.g. rats), whereas L. pakeka is the largest, and the only natural population is confined to a predator-free island. I used a fine-scale tracking technique (i.e. nontoxic fluorescent powders) to track L. archeyi and L. pakeka movements throughout their activity periods when on the surface in their natural habitats, Whareorino Forest and Maud Island, respectively, to obtain detailed information on their activity patterns, movement behaviour, and microhabitat and retreat site use. I investigated in more detail L. pakeka retreat sites by measuring the dimensions of the retreat site entrances (width, height and diameter) as well as the activity inside those retreat sites. Lastly, I used long-term frog survey data to examine the indirect impacts (i.e. behavioural changes) ship rats (Rattus rattus) may have on L. archeyi by studying the microhabitat use and home range of this species in an area with and without rat control within Whareorino Forest. L. archeyi had a longer activity period than L. pakeka with the former being active up to two hours after sunrise, but L. pakeka moved more and further than $L$. 
archeyi during their activity periods. Additionally, L. archeyi had a smaller home range compared to L. pakeka which suggests more prominent site fidelity and more sedentary behaviour in this species. Both species actively sought out specific microhabitats among the ones that were available, either to use during movement or to use as retreat sites, but those microhabitat types also differed between species. L. archeyi were more often found above ground level than L. pakeka and tended to use microhabitats that provided cover. L. archeyi preferred to use trees as retreat sites (roots, branches or trunk) whereas L. pakeka used trees (roots) and rocks. L. pakeka retreat sites had lower and more stable temperatures than outside retreats. Frogs were active inside retreats with no evidence of sleep behaviour for at least the first few hours of retreat use. In the rat control area, L. archeyi used more soil, leaf litter and ferns, and were also more likely to be found at ground level than frogs in the presence of higher numbers of rats. Abiotic factors also influenced movement patterns and microhabitat selection of both species, affirming water balance and thermoregulation are important drivers in frog behaviour. Behavioural attributes and small body size could be aiding in the persistence of $L$. archeyi in the presence of rats, and large body size and differences in behavioural attributes are likely to put L. pakeka at risk if rats were to reach their habitat. My findings inform on the ecology and behaviour of two Leiopelma species providing valuable information on their habitat requirements, which will enable more effective captive husbandry and better assessment of the appropriateness of translocation sites, aiding in their conservation management. 


\section{Resumen}

Internacionalmente, las poblaciones de anfibios están en declive. La situación actual de las poblaciones de anfibios resalta la urgente necesidad de más información sobre la ecología de especies para lograr una mejor evaluación de las estrategias de conservación y manejo. Los estudios de movimiento y selección de micro hábitat revelan cómo los anfibios usan el ambiente y cómo interactúan con su entorno, y son esenciales para establecer su sensibilidad al fenómeno global de declive y para identificar estructuras del hábitat que son críticas para su persistencia. Las ranas nativas de Nueva Zelanda (Anura: Leiopelmatidae, Leiopelma, nueve especies) se encontraban previamente distribuidas por toda Nueva Zelanda, pero la modificación del hábitat y la depredación por parte de mamíferos introducidos han influenciado las recientes (Holoceno) reducciones y extinciones de especies, reduciendo la fauna a cuatro especies con considerables reducciones en su rango de distribución. Todas las especies existentes de Leiopelma se encuentran clasificadas como en peligro, tanto nacional como internacionalmente, creando una urgente necesidad de más investigación acerca del comportamiento de estas especies para apoyar el manejo de su conservación. En esta tesis investigué los patrones de actividad, movimiento y uso del micro hábitat por parte de L. archeyi y L. pakeka para una mejor evaluación de su viabilidad poblacional a largo plazo y para mejorar su crianza en cautiverio. L. archeyi es la más pequeña de las especies de Leiopelma y ha sido capaz de coexistir con depredadores introducidos (e.g. ratas), mientras que L. pakeka es la más grande, y la única población natural de esta especie está confinada a una isla libre de depredadores. Utilicé una técnica de seguimiento a nivel de individuo (i.e. polvos fluorescentes no tóxicos) para seguir los movimientos de L. archeyi y $L$. pakeka durante su período de actividad estando en la superficie en sus hábitats naturales, Whareorino Forest y Maud Island, respectivamente, para obtener información detallada de actividad, movimiento y uso de micro hábitat y refugios. Investigué en más detalle los refugios de L. pakeka mediante la medición de las dimensiones de la entrada del refugio (ancho, alto y diámetro) como también de la actividad de las ranas en su interior. Finalmente, utilicé una base de datos de censos de ranas para examinar los impactos indirectos (i.e. cambios conductuales) 
que la rata negra (Rattus Rattus) podrían causar en L. archeyi, mediante el estudio del uso del micro hábitat y rango de hogar de esta especie en áreas con y sin control de ratas en Whareorino Forest. L. archeyi presentó un período de actividad más largo que L. pakeka, estando activa hasta dos horas después del amanecer, pero L. pakeka se movió más y más lejos que L. archeyi durante su período de actividad. Adicionalmente, el rango de hogar de L. archeyi fue más pequeño que el de L. pakeka, lo cual sugiere una mayor fidelidad de sitio y sedentarismo en la primera especie. Ambas especies utilizaron micro hábitats específicos dentro de los que se encontraban disponibles en su hábitat, ya sea usándolos durante su movimiento o como refugios, pero estos micro hábitats también difirieron entre ambas especies. L. archeyi se encontró más frecuentemente sobre el nivel del suelo que L. pakeka y tendió a utilizar micro hábitats que proveían de cobertura. L. archeyi prefirió el uso de árboles como refugio (raíces, ramas y tronco), mientras que L. pakeka utilizó árboles (raíces) y rocas. Los refugios de L. pakeka presentaron temperaturas menores y más estables que el ambiente. Los individuos de L. pakeka se encontraron activos dentro de sus refugios, sin evidencia de que éstos duerman por lo menos durante las primeras horas del uso del refugio. En el área con control de ratas, $L$ archeyi utilizó más tierra, hojarasca y helechos, y se encontró más frecuentemente a nivel del suelo que aquellas ranas en la presencia de un mayor número de ratas. Factores abióticos también influenciaron el movimiento y selección de micro hábitat en ambas especies, corroborando que el balance hídrico y la termorregulación son motores importantes en la conducta de estas ranas. Su conducta y pequeño tamaño corporal podrían estar ayudando en la persistencia de L. archeyi en la presencia de ratas, mientras que su mayor tamaño y diferente conducta podrían poner en riesgo a L. pakeka si las ratas llegaran a su hábitat. Mis resultados entregan información respecto a la ecología y conducta de dos especies de Leiopelma, proporcionando información invaluable respecto a sus requerimientos de hábitat, lo cual ayudará a mejorar su crianza en cautiverio y la selección de sitios de translocación apropiados, ayudando en el manejo de su conservación. 


\section{Acknowledgements}

So many people to thank and so little space...

I would like to start by thanking my supervisors, Nicky Nelson and Ben Bell, who guided me throughout my PhD studies from day one and who helped me to get where I am. Thank you for the endless help, advice and support you have given me. Special thanks go to Ben: thank you for going to Chile back in 2010 and for giving that little Chilean girl a chance!

The completion of this study would not have been possible without the contribution of many people. Many thanks to my excellent field assistants, Daniel Harvey, Marie Courteville, John Rynhart, Michael Lavery, and Kurt Villsen, who were essential to complete my fieldwork. I would also like to thank the New Zealand Department of Conservation/Te Papa Atawhai, Te Runanga o Ngati Kuia Charitable Trust and Kiritihere iwi group for granting me permission to work on Maud Island and Whareorino Forest. Special thanks to DOC Havelock office, Nio Mana, Stuart Burbidge, Chris Birmingham, Frank Higgott, Sue Caldwell, Piripi, and Heeni, who helped me have successful and enjoyable trips to Maud Island. I would also like to thank DOC Te Kutii office for providing me with valuable data for my thesis, and especially to Dave Smith, Abi Quinnell, Pete Bird, and Amanda Haigh, for their support and assistance before, during and after my trips to Whareorino Forest.

I was very lucky to share an office, at some point or another, with smart and fun people, who made of this experience a great one: Steph Price, Anna Carter (my stats saviour), Helen Taylor, Shanna Rose, Vaughn Stenhouse, Zöe Lennon, and Rosalynn Anderson-Lederer. Thanks also to the 'nonNicky’ students, Evan Brenton-Rule, Jess Russell and Yana Dobelmann, for being such great office mates, to Patrick Kavanagh for teaching me how to do circular stats in R, to Sue Keall for helping me sort out my gear for every single one of my field trips, and to Tanya Cornwell for taking me on my first frog adventure. I would also like to thank my friends, Olivia Vergara, Balám Jiménez, Kim 
Maxwell, and Lainie Antonio for their continuous support and friendship. My friends back home have also been present during this entire period, so I thank the many e-mails, skype sessions and messages we have exchanged since I have been here. Thanks also to Carezza Botto and Rodrigo Medel, for they were the ones who prepared me and helped me start this great journey.

I am very fortunate to have been welcomed by a beautiful Kiwi family here in New Zealand, and so I would like to express my gratitude to my in-laws, Lynne and Murray Biggs, who have given me love and support throughout these years, and to my beautiful fiancée, Raymond Biggs, whose continuous encouragement, patience, support, and love have meant everything to me. Many thanks also to Lynne for her editing assistance in one chapter, and to Ray for also editing one chapter and for helping me defeat Word and Excel. Finally, I would like to thank my Chilean family. I am eternally grateful to my parents and siblings who, even though far away, have been there for me every step of the way and without whom I would not have been able to do any of this. I would especially like to thank my sisters, Joche and Paz, for their enormous help sorting out my references and citations, and to my father, José Ramírez, for his invaluable help mapping out my froggies with GIS.

Funding for my PhD studies was provided by CONICYT-Becas Chile, and to them I am very grateful. I also obtained grants that supported different aspects of my research from Victoria University of Wellington (VUW) Faculty of Science, the Society for Research on Amphibians and Reptiles of New Zealand (SRARNZ) and the VUW Centre for Biodiversity and Restoration Ecology (CBRE). This research was carried out with approval from the Victoria University of Wellington Animal Ethics Committee (Permit No. 2013R8) and the New Zealand Department of Conservation (Permit No. 36895-FAU). 


\section{Agradecimientos}

Tanta gente a quien agradecer y tan poco espacio...

Quisiera comenzar agradeciendo a mis supervisores, Nicky Nelson y Ben Bell, quienes me guiaron durante mi doctorado desde el primer día y quienes me ayudaron a llegar donde estoy. Gracias por la infinita ayuda, consejos y apoyo que me han dado. Gracias especiales a Ben: igracias por haber ido a Chile en 2010 y por darle a esa pequeña chilena una oportunidad!

La finalización de este estudio no habría sido posible sin la contribución de mucha gente. Muchas gracias a mis excelentes ayudantes de terreno, Daniel Harvey, Marie Courteville, John Rynhart, Michael Lavery y Kurt Villsen, quienes fueron esenciales para completar mi trabajo. También quisiera agradecer al Departamento de Conservación (DOC) de Nueva Zelanda/ Te Papa Atawhai, a la Fundación Benéfica Te Runanga o Ngati Kuia y al grupo iwi Kiritihere por darme permiso para trabajar en Maud Island y Whareorino Forest. Gracias en especial a la oficina del DOC de Havelock, a Nio Mana, Stuart Burbidge, Chris Birmingham, Frank Higgott, Sue Caldwell, Piripi y Heeni, quienes me ayudaron a tener exitosas y agradables visitas a Maud Island. También quisiera agradecer a la oficina del DOC de Te Kuiti por entregarme una valiosa base de datos para mi tesis y especialmente a Dave Smith, Abi Quinnell, Pete Bird y Amanda Haigh, por su poyo antes, durante y después de mis visitas a Whareorino Forest.

Fui muy afortunada de compartir una oficina, en algún momento u otro, con gente inteligente y divertida quienes hicieron de ésta una experiencia muy buena: Steph Price, Anna Carter (mi salvadora estadística), Helen Taylor, Shanna Rose, Vaughn Stenhouse, Zöe Lennon y Rosalynn Anderson-Lederer. Gracias también a los 'no estudiantes de Nicky,' Evan Brenton-Rule, Jess Russell y Yana Dobelmann por ser muy buenos compañeros de oficina, a Patrick Kavanagh por enseñarme estadística circular en $\mathrm{R}$, a Sue Keall por ayudarme a organizar mis materiales de terreno en cada una de mis salidas y a Tanya Cornwell por llevarme a mi primera aventura 
ranística. También quisiera agradecer a mis amigos, Olivia Vergara, Balám Jiménez, Kim Maxwell, y Lainie por su continuo apoyo y amistad. Mis amigos en Chile también han estado presentes durante todo este período, por lo que agradezco los muchos e-mails, sesiones de Skype y textos que hemos intercambiado desde que estoy aquí. Gracias también a Carezza Botto y Rodrigo Medel, ya que ellos fueron quienes me prepararon y ayudaron a emprender este gran viaje.

Tengo la suerte de haber sido recibida por una bella familia Kiwi aquí en Nueva Zelanda, por lo que quisiera expresar mi gratitud hacia mis suegros, Lynne and Murray Biggs, quienes me han dado amor y apoyo durante todos estos años, y a mi bello novio, Raymond Biggs, cuyo continuo aliento, paciencia, apoyo y amor han significado todo para mí. Muchas gracias también a Lynne por ayudarme a revisar un capítulo, y a Ray por revisar otro capítulo y por ayudarme a derrotar a Word y Excel. Finalmente, quisiera agradecer a mi familia chilena. Estoy eternamente agradecida por mis padres y hermanos quienes, aun estando lejos, han estado ahí para mí en cada etapa de este camino y sin los que no habría podido hacer nada de esto. Quisiera agradecer en especial a mis hermanas, Joche y Paz, por su enorme ayuda con las referencias y citas de mi tesis, y a mi papá, José Ramírez, por su invaluable ayuda mapeando a mis ranitas con SIG.

El financiamiento para mis estudios de doctorado fue otorgado por CONICYT-Becas Chile y a ellos estoy muy agradecida. También obtuve becas que me apoyaron en distintos aspectos de mi investigación por parte de la Facultad de Ciencias de Victoria University of Wellington (VUW), de la Sociedad para la Investigación en Anfibios y Reptiles de Nueva Zelanda (SRARNZ) y del Centro de Biodiversidad y Restauración Ecológica de VUW (CBRE). Esta investigación fue aprobada por el Comité de Ética Animal de VUW (Permiso no. 2013R8) y el Departamento de Conservación de Nueva Zelanda (Permiso no. 36895-FAU). 


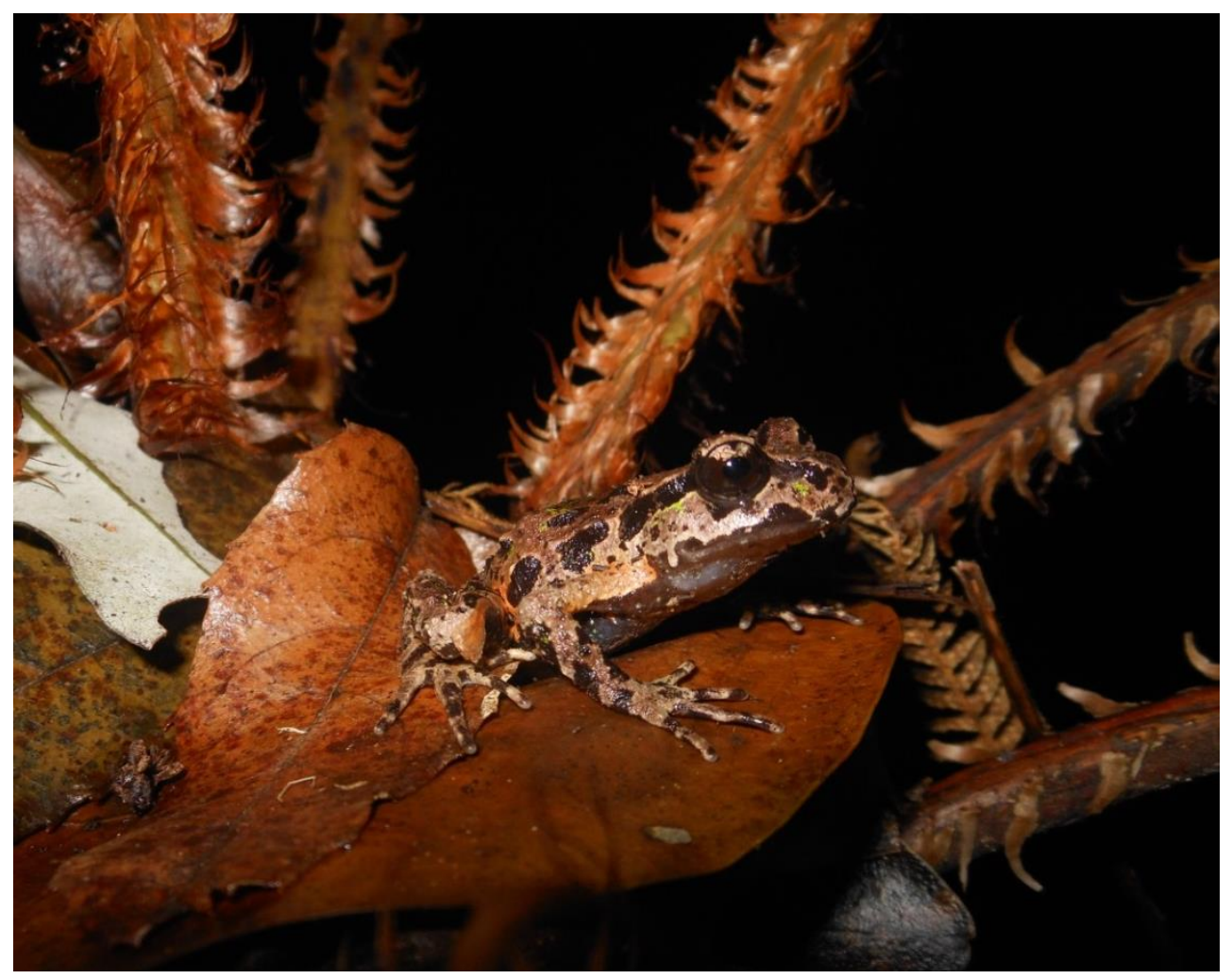

Leiopelma archeyi posing for a photo in Whareorino Forest. Photo: P.A. Ramírez Leiopelma archeyi posando para una foto en Whareorino Forest.

This thesis is dedicated to all my loved ones, and to those that have already left but that I'm sure I will see again.

Esta tesis está dedicada a todos los que amo, y a aquellos que ya partieron pero que estoy segura volveré a ver. 


\section{Table of contents}

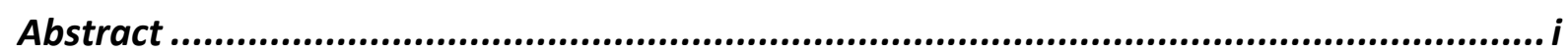

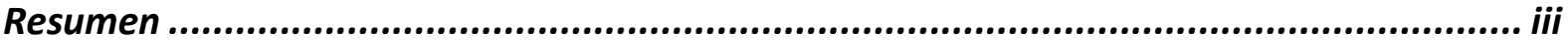

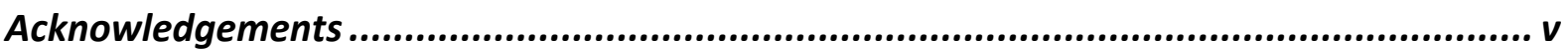

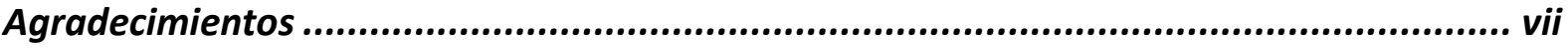

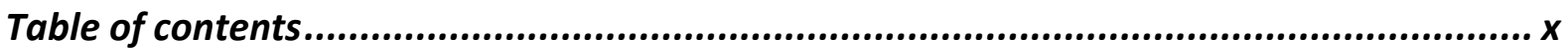

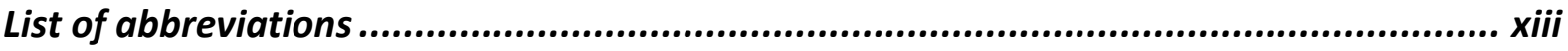

Chapter 1: General introduction............................................................................. 1

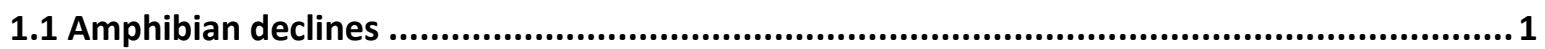

1.2 Behavioural studies for the conservation of amphibians ..................................................

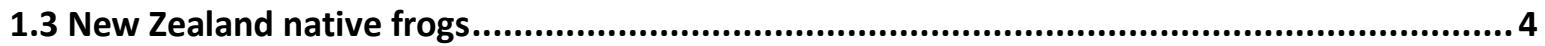

1.4 Leiopelma archeyi and Leiopelma pakeka: two contrasting terrestrial frogs .......................

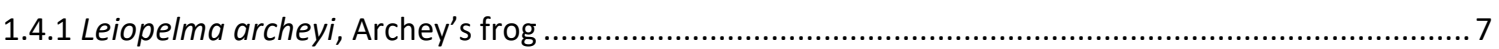

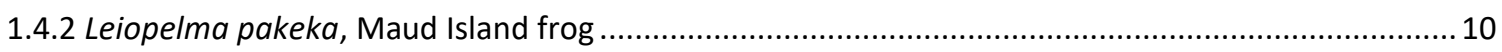

1.5 Behavioural studies for the conservation of $L$. archeyi and $L$. pakeka ................................ 12

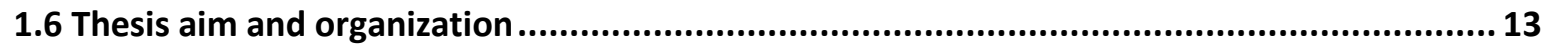

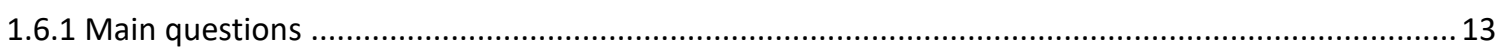

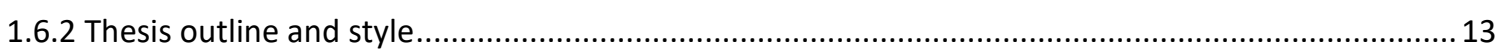

Chapter 2: Tracking a small cryptic amphibian with fluorescent powders ....................... 15

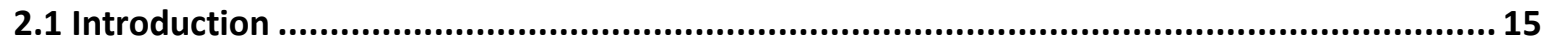

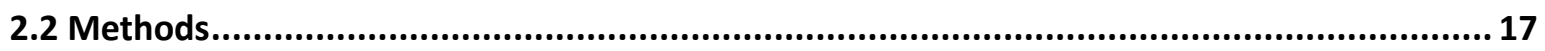

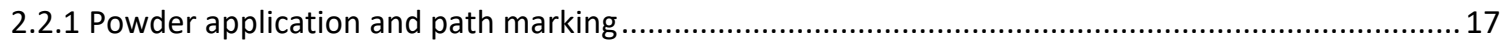

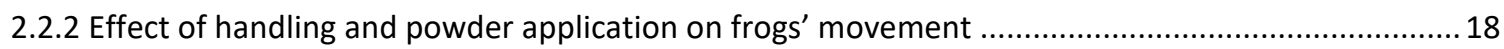

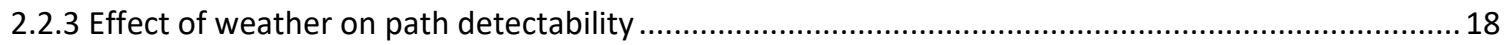

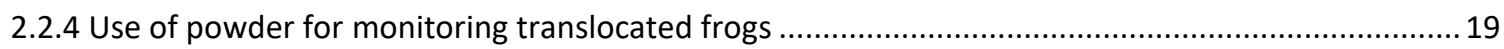

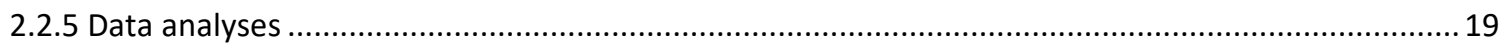

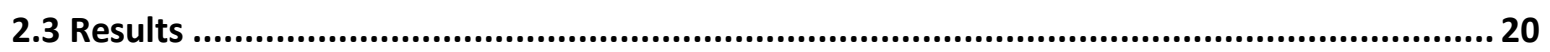

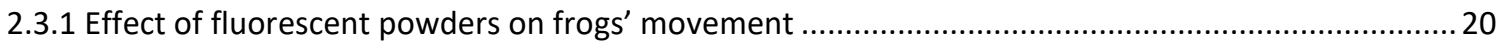

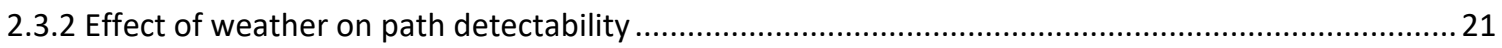

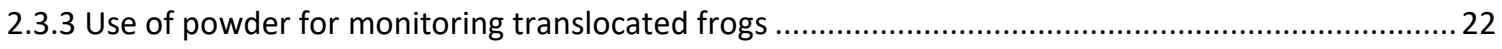

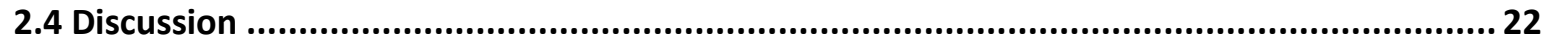

Chapter 3: Fine-scale movements of two Leiopelmatid frogs: Leiopelma archeyi and $L$.

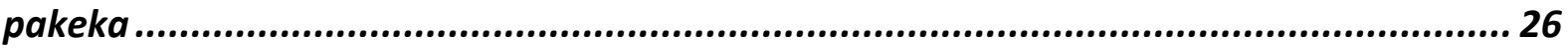

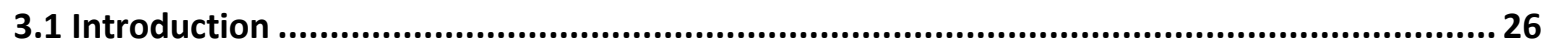

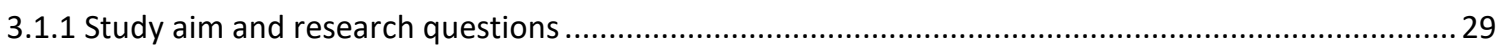

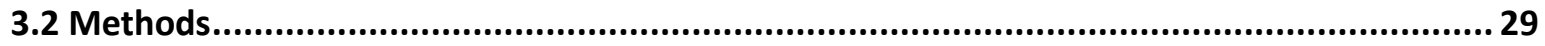

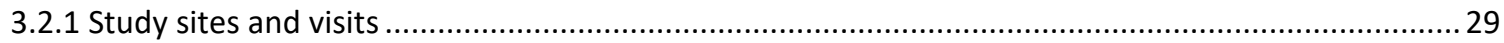

3.2.2 Tracking of frogs 


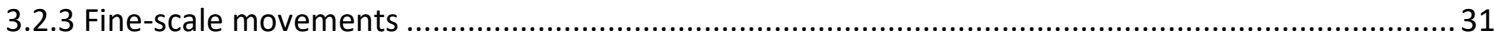

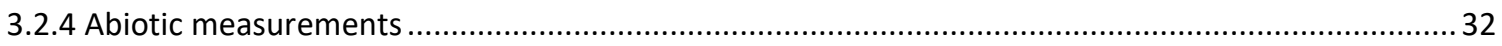

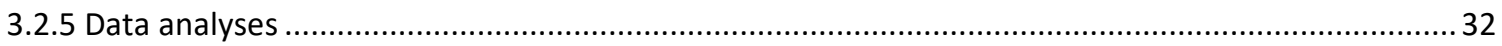

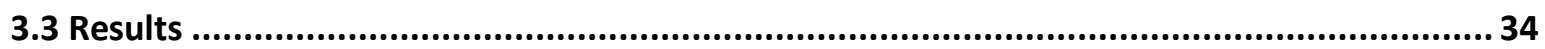

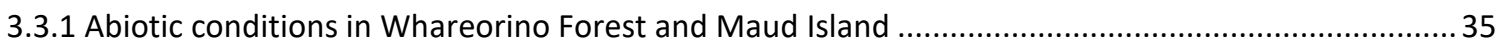

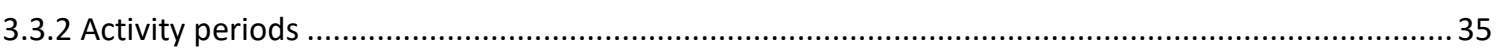

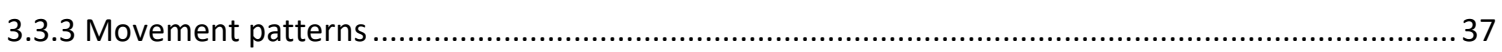

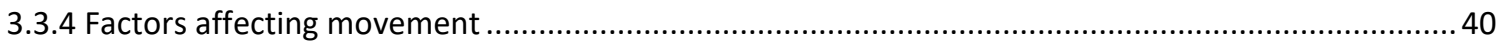

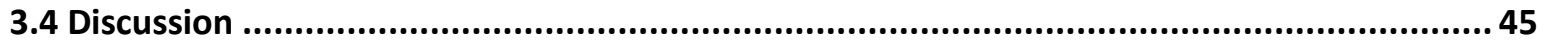

Chapter 4: Microhabitat use of Leiopelma archeyi and L. pakeka in their natural habitats49

4.1 Introduction

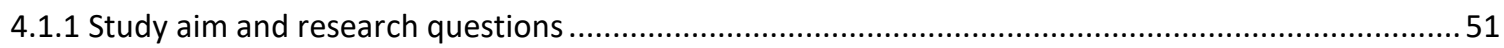

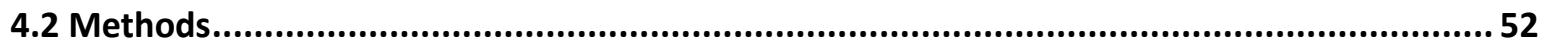

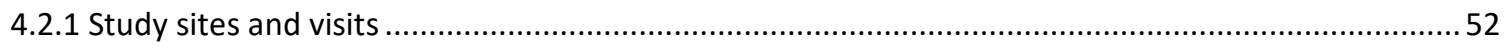

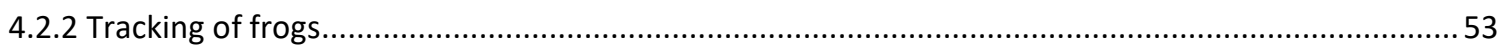

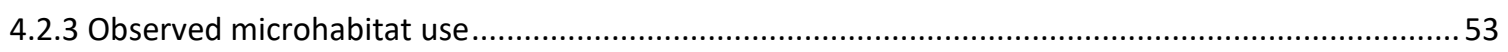

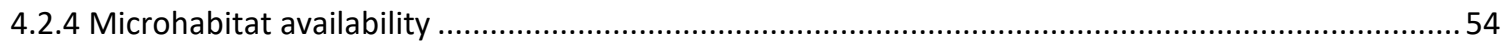

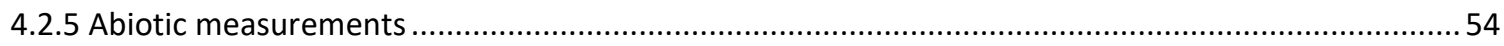

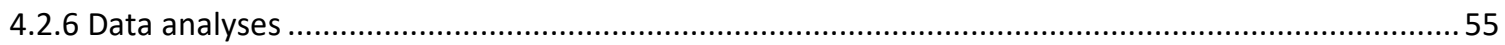

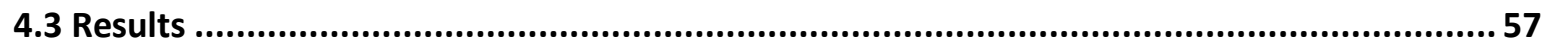

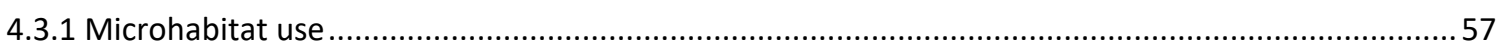

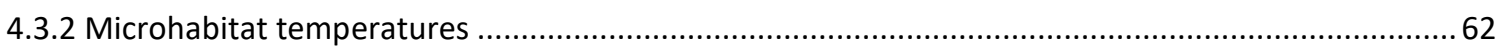

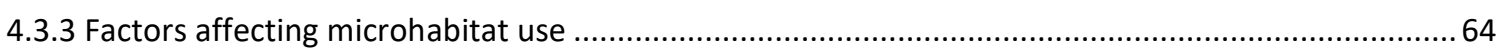

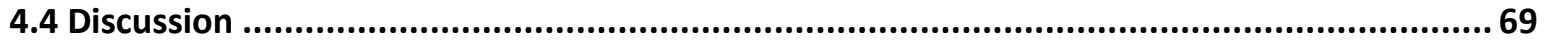

Chapter 5: Retreat site selection by Leiopelma archeyi and L. pakeka in their natural

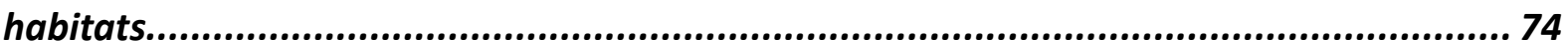

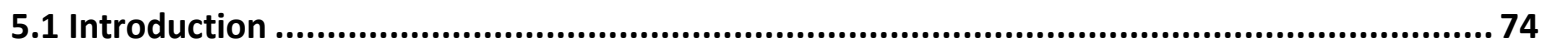

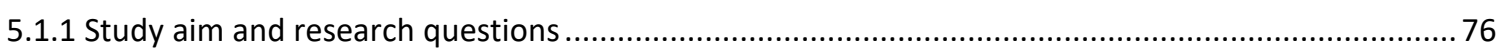

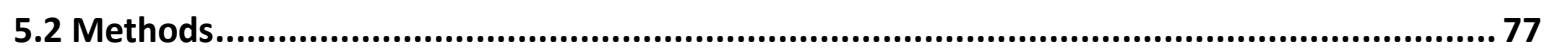

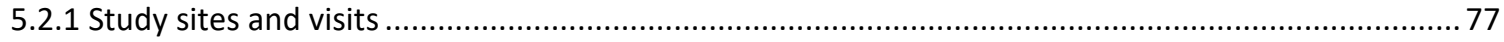

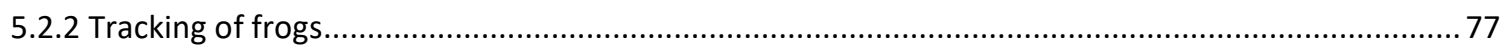

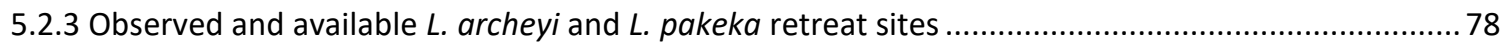

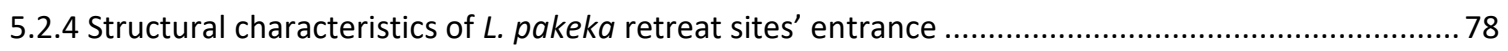

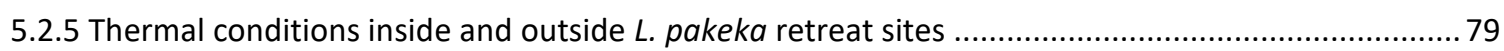

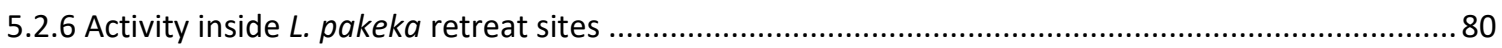

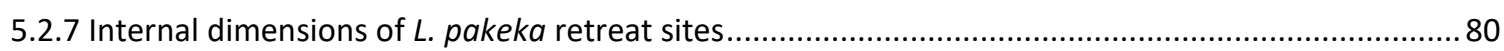

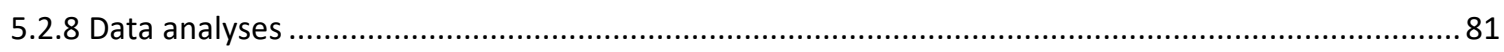

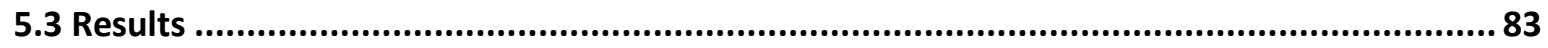

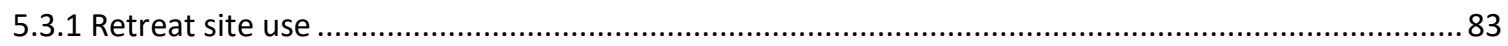

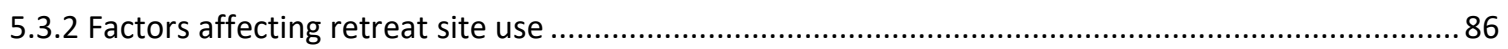

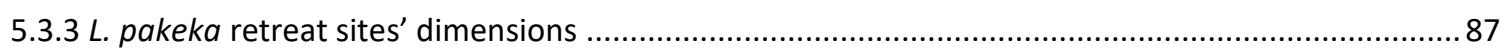

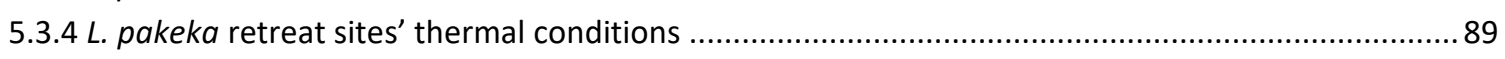

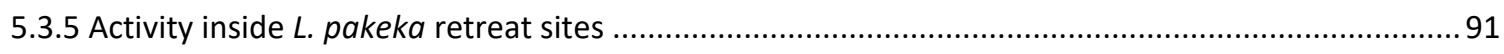

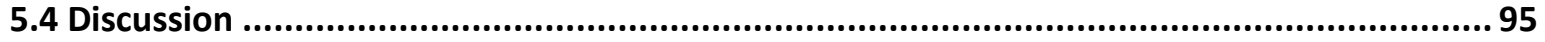


Chapter 6: Indirect effects of an introduced predator on a population of the native frog Leiopelma archeyi ....................................................................................... 102

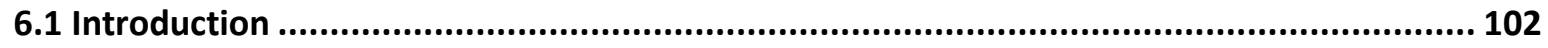

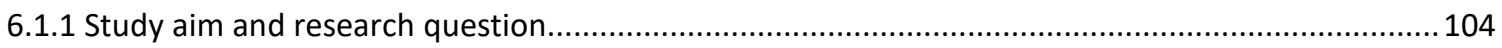

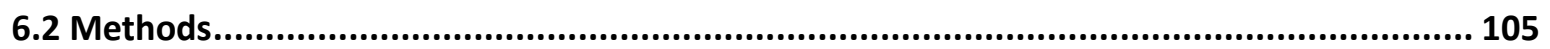

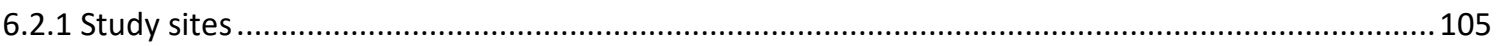

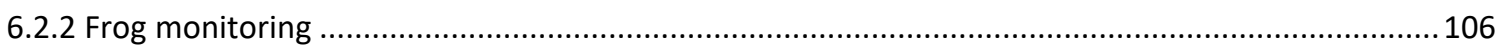

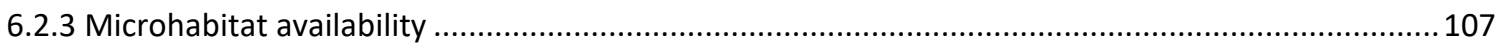

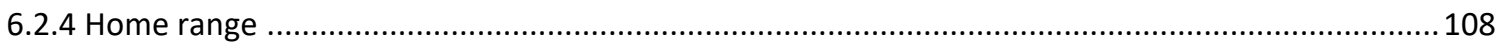

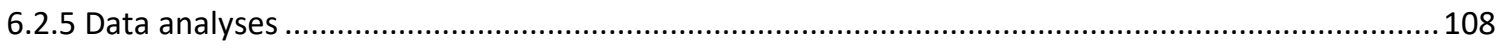

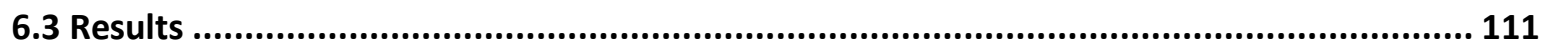

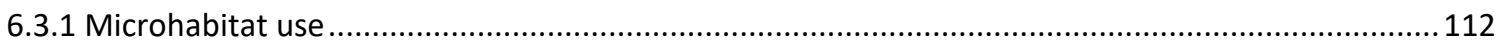

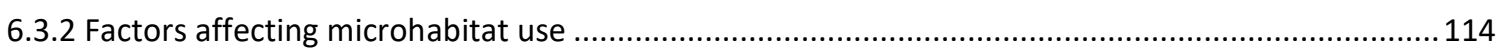

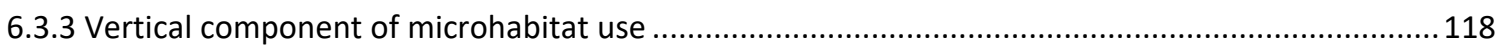

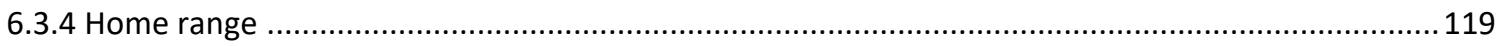

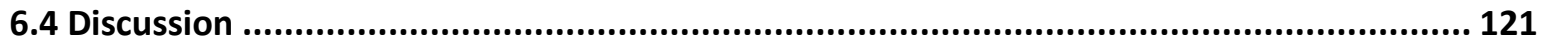

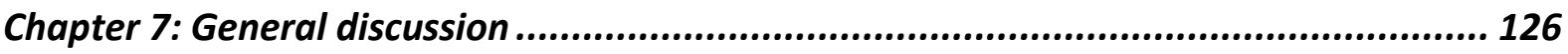

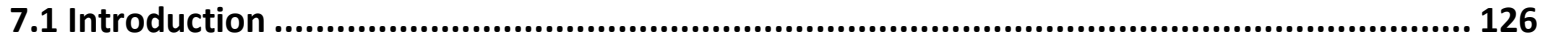

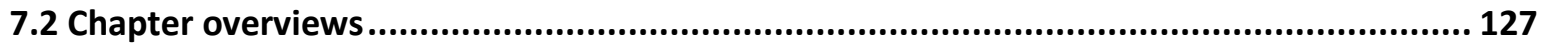

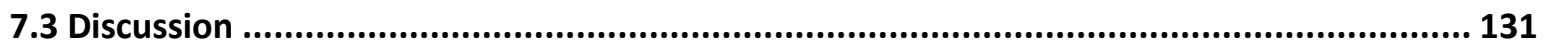

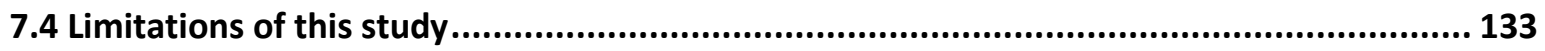

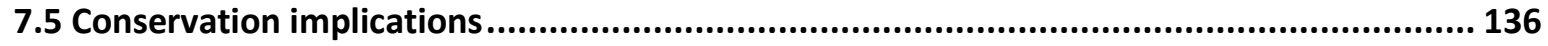

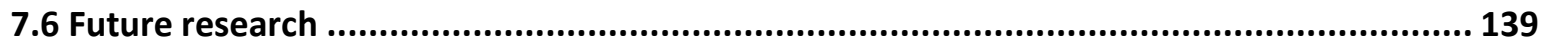

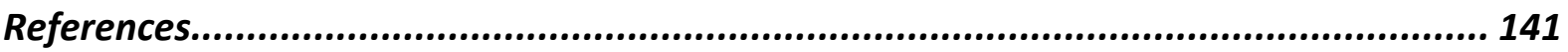

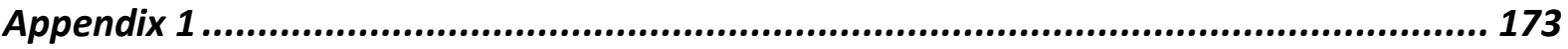

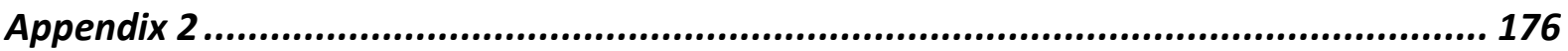




\section{List of abbreviations}

$\begin{array}{ll}\mathrm{AIC}_{\mathrm{c}} & \text { second-order Akaike's Information Criterion } \\ \triangle \mathrm{AIC}_{\mathrm{c}} & \text { delta AIC } \\ \mathrm{CI} & \text { confidence interval } \\ \mathrm{cm} & \text { centimetre } \\ { }^{\circ} \mathrm{C} & \text { degrees Celsius } \\ \mathrm{DOC} & \text { Department of Conservation } \\ \mathrm{EDGE} & \text { Evolutionarily Distinct and Globally Endangered Amphibians } \\ \mathrm{g} & \text { grams } \\ \mathrm{GLMMs} & \text { generalized linear mixed models } \\ \mathrm{h} & \text { hour } \\ \mathrm{IUCN} & \text { International Union for Conservation of Nature } \\ \text { ha } & \text { hectares } \\ \mathrm{k} & \text { number of parameters in AIC models } \\ \mathrm{km} & \text { kilometres } \\ \mathrm{m} & \text { metres } \\ \mathrm{MCP} & \text { minimum convex polygon } \\ \mathrm{mm} & \text { millimetres } \\ \mathrm{m}^{2} & \text { square metres } \\ \mathrm{nm} & \text { nanometre } \\ \mathrm{RH} & \text { relative humidity } \\ \mathrm{s} & \text { second } \\ \mathrm{SE} & \text { standard error } \\ \text { SVL } & \text { snout-vent length } \\ \text { VIF } & \text { variance inflation factor } \\ \text { vs } & \text { versus } \\ \mathrm{W}_{\mathrm{i}} & \text { cumulative Akaike weights } \\ & \end{array}$




\section{Chapter 1 \\ General introduction}

\subsection{Amphibian declines}

When the First World Congress of Herpetology took place in 1989, sufficient concern among herpetologists was raised for the National Research Council (United States) to sponsor a workshop in 1990 addressing the worldwide declines amphibians were experiencing (Barinaga 1990, Blaustein and Wake 1990, Wake 1991, 1998), with declines dating back to the 1970s in the Western United States and North-eastern Australia (Drost and Fellers 1996, Collins and Storfer 2003). There are over 7,600 known amphibian species (AmphibiaWeb 2017) and currently, from a total of 6,260 assessed species, $31.8 \%$ are globally threatened $(1,991$ species $)$ and $24.5 \%$ are data deficient (IUCN 2017). Thus, amphibians are far more threatened than mammals, reptiles and birds (20.8\%, 19.0\% and 13.2\%, respectively; IUCN 2017, BirdLife International 2013, Böhm et al. 2013) and they are, overall, in general decline (Green 2003, Stuart et al. 2004). The current rate of amphibian declines far exceeds past decline events experienced by this group (Bishop et al. 2012, Catenazzi 2015), and calculations using fuzzy arithmetic suggest that the current extinction rate of amphibians could be 211 times the background amphibian extinction rate, with the potential of being 45,474 times if species in imminent danger of extinction are included in these calculations (McCallum 2007). Worryingly, conservation efforts still remain insufficient to offset this (Hoffmann et al. 2010).

Amphibian declines are particularly concerning for two reasons. Amphibians are valuable indicators of environmental stress as their permeable skin and unshelled eggs are directly exposed to soil, water and sunlight, and therefore can easily absorb substances from the environment. They are also an important contribution to the trophic dynamics in many communities as they may act as predators, herbivores and prey, so their loss could affect other organisms (Blaustein 1994, Blaustein et al. 1994, Blaustein and Wake 1995). Several reviews 
addressing causes and consequences of these declines have been published (e.g. Blaustein and Wake 1995, Alford and Richards 1999, Blaustein and Kiesecker 2002, Storfer 2003, Beebee and Griffiths 2005, Hussain and Pandit 2012). Although in some cases major threats remain speculative or have not been conclusively demonstrated (Stuart et al. 2004), amphibian declines have been attributed to several possible causes. According to Collins and Storfer (2003), two classes of hypotheses can be propounded to explain these declines. Class I refers to hypotheses for which there is a good understanding of the basic ecological mechanisms underlying declines: introduced species, over-exploitation and land-use change. For class II hypotheses, global change (including climate change and UV radiation), contaminants and emerging infectious diseases, the understanding is poor but is improving. Mechanisms underlying amphibian population declines are complex and even though they have important effects in themselves, declines are also likely the result of interactions among biotic and abiotic factors that could be working synergistically to exacerbate adverse effects on amphibian populations (Alford and Richards 1999, Blaustein and Kiesecker 2002). Additionally, these causes can vary among species and localities which make this a challenging conservation issue to address (Bishop et al. 2012).

\subsection{Behavioural studies for the conservation of amphibians}

Although the study of the patterns of amphibian declines is important as a starting point for the development of management strategies, a full understanding of why species or populations decline is needed for the successful implementation of conservation and management strategies (Pittman et al. 2014). This highlights the urgent need for comprehensive information on species' ecology (Alford and Richards 1999, Bull and Hayes 2001, Lemckert 2004, Rowley and Alford 2007, Young et al. 2008). Population processes are largely mediated by the individuals within a population (Laskowski et al. 2015) with many ecological phenomena, such as population dynamics and distributions, having their roots in two individual behaviours: movement and habitat selection (Wiens et al. 1993, Lima and Zollner 1996, Clobert et al. 2009). These two 
behaviours can have important consequences on the reproduction, growth and survival of individuals and therefore, on the population as a whole. For this reason, fine-scale behavioural studies are an increasingly relevant and useful tool for species conservation (Buchholz 2007).

Fine-scale movement patterns and habitat selection can give insights into how amphibians use the environment and interact with their surroundings, and therefore, are critical in establishing their sensitivity to the global decline phenomenon and in identifying the habitat features that are essential for species to thrive (Hodgkinson and Hero 2001, Eggert 2002, Green 2003, Lemckert 2004, Birchfield and Deters 2005, Patrick et al. 2008). However, in order to fully understand these patterns of behaviour, it is necessary to incorporate the study of underlying factors that generate these patterns. A complex interplay of internal and external factors can have the potential to affect individuals' movement patterns and habitat use (Nathan et al. 2008, Clobert et al. 2009, Osbourn et al. 2014, Laskowski et al. 2015). External factors, such as microclimatic conditions, and internal factors, such as morphological attributes, can influence the internal states of ectotherms and the motion capacity of individuals, affecting their overall behavioural patterns (Duellman and Trueb 1994, Sinervo et al. 2006, Clobert et al. 2009, Peterman and Semlitsch 2013). Knowledge of these factors is important as they indicate the causal processes that mediate the behaviour of individuals, such as physiology maintenance or food search (Huey 1991, Clobert et al. 2009, Osbourn et al. 2014), and can reveal how species will respond to various current environmental concerns, such as climate change and habitat loss.

At a broader scale, the knowledge of animals' behaviour can help in the development of predictive models for understanding how species will modify their habitat use, movements, and distribution in the face of direct and indirect human disturbances (Blumstein and Fernández-Juricic 2004, Buchholz 2007, Nathan et al. 2008). To understand population dynamics it is, therefore, necessary to consider different temporal and spatial scales, integrating studies of an individual's behaviour into mechanistic models allowing for accurately scaling up of studies from an individual level to a population or landscape level (Wiens et al. 1993, Lima and Zollner 1996, Firle et al. 1998, 
Morales and Elner 2002, Revilla et al. 2004). Additionally, with incorporation of the factors affecting individual behaviour, population models can be further improved (Kearney and Porter 2009, Bogosian III et al. 2012). Overall, by investigating amphibians' movement and habitat selection, and the factors influencing their behavioural patterns, management and conservation strategies can be strengthened and species-specific strategies can be implemented where the protection of a given species is of high priority.

\subsection{New Zealand native frogs}

New Zealand native frogs belong to the genus Leiopelma (Anura: Leiopelmatidae), one of the two most basal living anuran genera along with Ascaphus (Holyoake et al. 2001, Roelants and Bossuyt 2005, Bell 2010), with recently described fossils dating their presence in New Zealand back to the Early Miocene period (Worthy et al. 2013). Nine Leiopelma species are formally recognized: four extant species, L. archeyi, L. pakeka, L. hamiltoni, and L. hochstetteri, and five extinct species: $L$. miocaenale, L. acricarina, L. markhami, L. waitomoensis and L. auroraensis (Worthy 1987, Bell et al. 1998, Holyoake et al. 2001, Worthy et al. 2013). Leiopelma synapomorphies include the presence of ventral inscriptional ribs, nine amphicoelous pre-sacral vertebrae, epipubic cartilages, low diploid chromosome numbers (18-22), absence of horny beaks in the larvae, tailwagging (caudalipuboischiotibialis) muscles in the adult, and the lack of a closed branchial chamber and spiracle (Stephenson 1955, Stephenson 1961, Green and Cannatella 1993, Bell and Wassersug 2003, Bell 2010). Other distinctive characteristics include round pupils and the lack of the tympanic membrane, Eustachian tubes, and vocal sacs (Stephenson 1961, Bell 1978, 2010).

Leiopelma species are cryptically-coloured and mostly nocturnal frogs that retreat under rocks and vegetation during daytime. Most extant species are terrestrial breeders, but L. hochstetteri is a semi-aquatic species. They are carnivorous and eat invertebrate prey (e.g. beetles, mites). They have endotrophic development with hatchlings completing development on the male's dorsum, except in L. hochstetteri where the hatchlings emerge as aquatic larvae without close association 
with the male. They are long-lived species, with some L. pakeka individuals living $>43$ years, and are K-selected (Stephenson and Stephenson 1957, Bell 1978, 1985b, 2010, B.D. Bell pers. comm., Newman 1990, Bell and Pledger 2010, Shaw et al. 2012, Bishop et al. 2013). Because of the lack of vocal sacks, they lack vocal choruses, although they can vocalize when handled (Bell 1978), but evidence suggests they can communicate through chemical signals (Lee and Waldman 2002, Waldman and Bishop 2004). Native predators include tuatara (Sphenodon punctatus; Newman 1977), the extinct laughing owl (Sceloglaux albifacies; Worthy and Holdaway 1994a), weka (Gallirallus australis), kiwi (Apteryx spp), fish, spiders, and large centipedes (Green 1988). Extant Leiopelma body lengths range from $<40 \mathrm{~mm}$ for the smallest species (L. archeyi) to $>51 \mathrm{~mm}$ for the largest (L. pakeka; Worthy 1987, Bell 1978, Newman 1990, Bell et al. 1998, Bishop et al. 2013). Recently extinct species were larger in body size (Worthy 1987). Currently, all four extant species are classified as threatened both nationally and internationally, ranging from Vulnerable to Critically Endangered (Newman et al. 2010, 2013, Bishop et al. 2013, IUCN 2017), and are protected under the New Zealand Wildlife Act 1953 (Bell et al. 2004a).

Subfossil bone deposits in limestone caves indicate that Leiopelmatid frogs were formerly common with representatives throughout New Zealand (Worthy 1987, Worthy and Holdaway 1994b; Fig. 1). However, the arrival of humans, beginning with the Polynesians in the thirteenth century AD (Wilmshurst and Higham 2004), and the subsequent habitat modification and predation due to the introduction of mammalian predators, are believed to be the primary drivers of the recent (Holocene) disappearance or decline of Leiopelma in New Zealand (Worthy 1987, Bell 1994, Towns and Daugherty 1994, Craig et al. 2000, Towns et al. 2003). All four extant species have suffered major range reductions, being limited to a few islands in the Marlborough Sounds, New Zealand's South Island, and to parts of the North Island mainland (Worthy 1987, Bell 1978, 1994, Towns and Daugherty 1994). The primary agent of the recent declines and extinctions of Leiopelma species is predation by introduced mammals (Bell 1994, Towns and Daugherty 1994, Craig et al. 2000, Towns et al. 2003, Bell 2010). New Zealand frogs evolved in the absence of predaceous mammals and as such, they lack the appropriate antipredator responses against them 
which may have made them vulnerable to these introduced predators (Worthy and Holdaway 2002, Gibbs 2006). As a defence mechanism, Leiopelma rely on camouflage and immobility. When disturbed or attacked they do not attempt to escape but instead they can adopt defensive postures by lowering their heads, raising their limbs and holding their bodies up in a rigid stiff-legged stance (Green 1988, Bell 2010). These antipredator strategies work best to dissuade vision-based predators, such as their native predators, but they are not adequate enough against scent-based mammalian predators. Introduced mammals have dramatically altered the composition and dynamics of New Zealand's native biota in general (McGlone 1989, Craig et al. 2000) and their effect on Leiopelmatid frogs are evident due to four main reasons: 1) recent historical extinction patterns coincide with first human arrival, 2) the relictual distribution of extant species with some isolated populations, 3) documented evidence of introduced species feeding on Leiopelma species, and 4) the survival and establishment of populations transferred into predator-free locations (Worthy 1987, Newman 1990, Bell 1994, Thurley and Bell 1994, Bell et al. 2004b, Lukis 2009, Bell and Pledger 2010, Bishop et al. 2013). Other threats proposed as agents of decline include disease, chemicals (e.g. biocides), illegal collections, and climatic change (Stuart et al. 2004, Bell 2010, Bishop et al. 2013). Due to their conservation status and ongoing threats, several management actions have been put in place to recover and protect these native species, including public advocacy, translocations, implementation of rodent control, captive breeding, and disease surveillance (Bishop et al. 2013). 


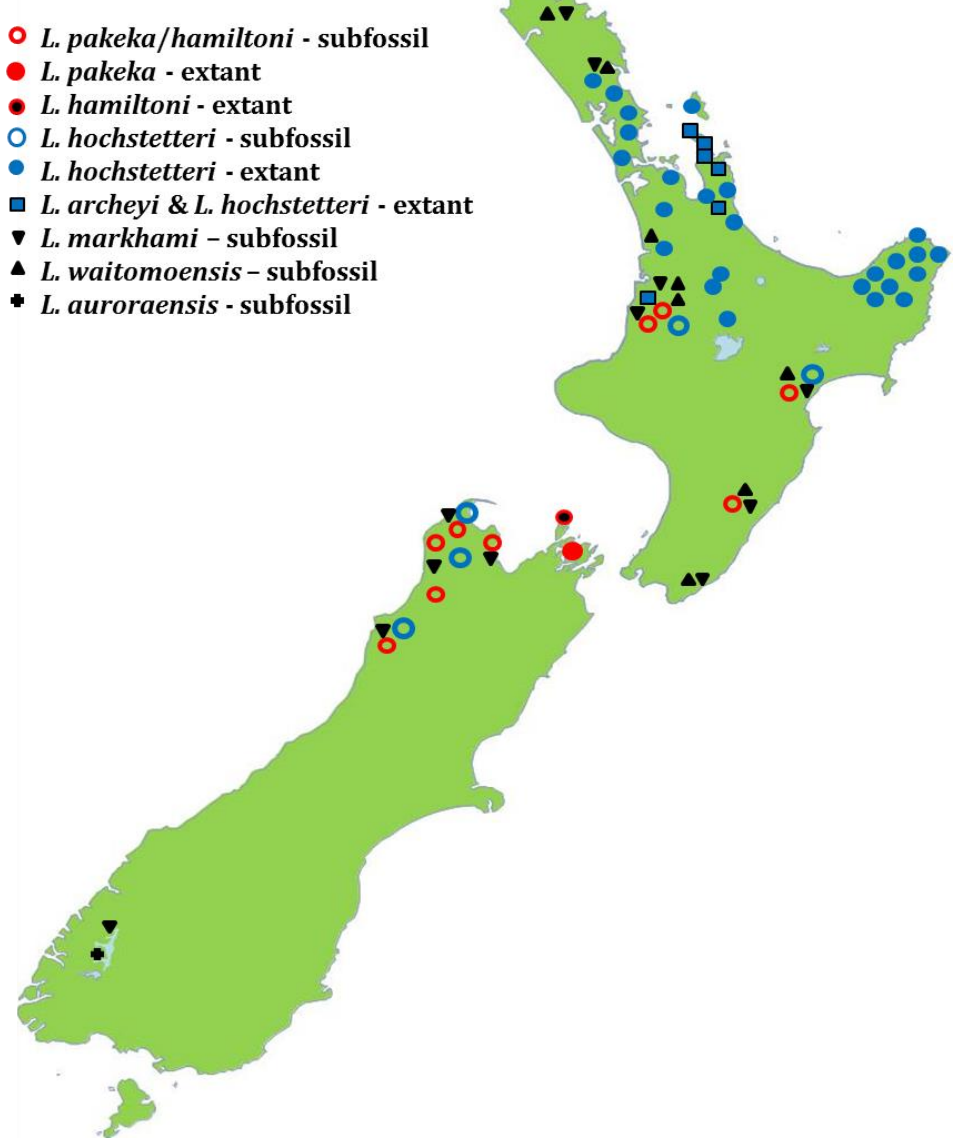

Figure 1: Past and present distribution, excluding recent translocation sites, of New Zealand native Leiopelma frogs. Used with permission (after Bell et al. 1998).

\subsection{Leiopelma archeyi and Leiopelma pakeka: two contrasting terrestrial frogs}

\subsubsection{Leiopelma archeyi, Archey's frog}

Leiopelma archeyi (Fig. 2) is the smallest of the New Zealand frogs. The snout-vent lengths of adult females exceed $31 \mathrm{~mm}$, males or young females are between $25-31 \mathrm{~mm}$ and sub-adults $<25 \mathrm{~mm}$ (Bell 1978). This is the least nocturnal species of the genus with frogs active on the surface until a few hours after daybreak (Bell 1978, Cree 1989). Its predominant body colour is green, although various shades of brown with green or pink patches can also be found (Bell 1978, Thurley and Bell 1994). L. archeyi naturally occurs as scattered populations in the Coromandel Peninsula and in a 600 ha area within Whareorino Forest, New Zealand's North Island (Bell 1978, Thurley and 
Bell 1994, Bishop et al. 2013; Fig. 3). In both locations this species exists in sympatry with $L$. hochstetteri and co-occurs with introduced mammal predators, such as rats, mice and stoats, and introduced frogs (Litoria aurea; Worthy 1987, Bell 1978, Bell 1994, Thurley and Bell 1994). The total population size estimate is 5,000 to 20,000 individuals (Bishop et al. 2013). Direct evidence of rat predation was found in Whareorino Forest where eight L. archeyi adults were found dead with rat tooth puncture marks (Thurley 1996, Fitzgerald and Campbell 2003). Long-term population monitoring revealed a major decline on the Coromandel Peninsula between 1996 and 2001, and chytridiomycosis was thought to be the most likely explanation for this decline (Bell et al. 2004b). The amphibian chytrid fungus (Batrachochytrium dendrobatidis) has been detected in both locations where populations of L. archeyi are found, and has only been detected in this species (Shaw et al. 2008, 2013). In order to mitigate these predation and disease threats, management actions for this species have included a translocation of chytrid-free frogs to Pureroa Forest, New Zealand's North Island, in 2006, disease surveillance and hygiene protocols, and establishment of captive breeding and mammal control programmes (Thurley 2003, Haigh et al. 2007, Bishop et al. 2013). In particular, a rat control programme carried out in Whareorino Forest has shown to be effective in maintaining, and increasing, L. archeyi population numbers (Pledger 2013, Bridgman 2015). Globally, L. archeyi is seen as the most endangered Leiopelma species being classified as Critically Endangered according to the IUCN Red List Criteria (IUCN 2017) and as number one in the world's top 100 Evolutionarily Distinct and Globally Endangered Amphibians (EDGE) list (EDGE 2016). Under the New Zealand Threat Classification System its status is considered as Nationally Vulnerable (Newman et al. 2013). 


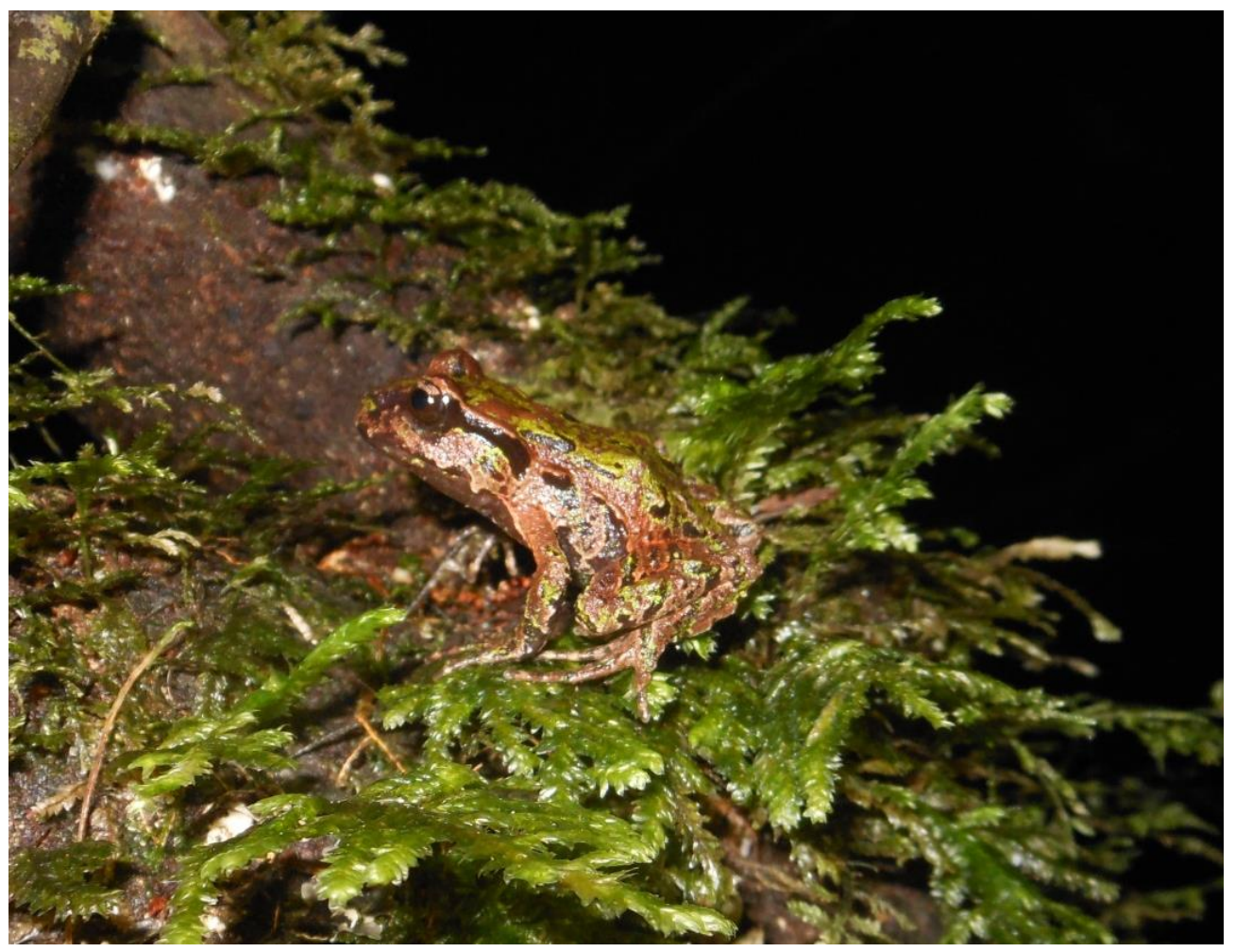

Figure 2: Leiopelma archeyi on a moss-covered tree at Whareorino Forest. Photo: P.A. Ramírez

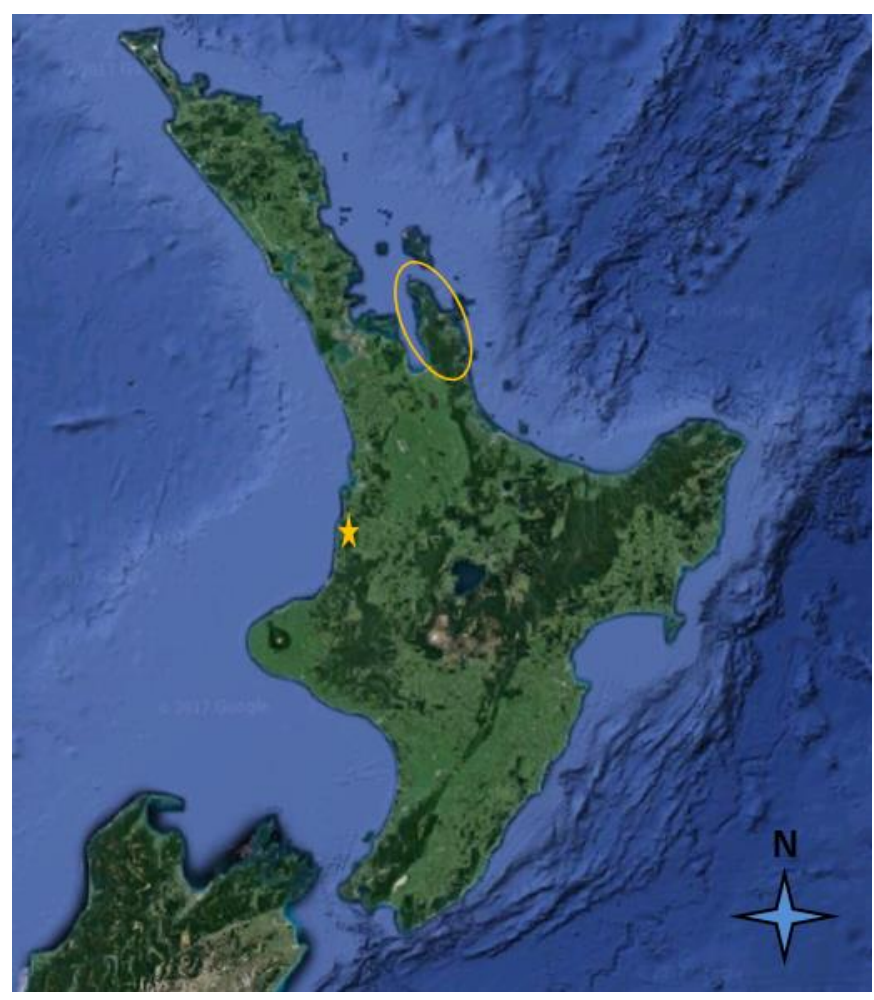

Figure 3: Satellite image showing the locations of L. archeyi natural populations within New Zealand's North Island: the various populations in the Coromandel Peninsula (yellow oval) and in Whareorino Forest (yellow star). 


\subsubsection{Leiopelma pakeka, Maud Island frog}

Leiopelma pakeka (Fig. 4) is the largest of the extant New Zealand frogs. Adult females attain snout-vent lengths greater than $40 \mathrm{~mm}$, males or younger females between 34 - $40 \mathrm{~mm}$ and subadults < 34 mm (Bell 1978, Bell et al. 2004a). Unlike L. archeyi, its body colour is mostly brown going from light to dark brown (Bell 1978). Controversy exists around this species' designation, as it was formerly regarded as L. hamiltoni but later distinguished from it based on multivariate analyses of 19 external measurements and fixed allozyme differences (Bell et al. 1998). However, this species distinction was not supported by DNA analysis (Holyoake et al. 2001) and debate about this species' status remains ongoing. The only natural population of L. pakeka is located in Maud Island, New Zealand's South Island, where it is confined to a 16 ha of forest remnant (Bell and Bell 1994; Fig. 5). Maud Island is considered to be a mammalian predator-free island, although occasional incursions of mustelids occur. A house mouse incursion was first reported in 2013 (Frog Recovery Group 2013), but mice have since been eradicated (Department of Conservation 2016). Long-term demographic studies have shown that this species is expanding beyond the 16 ha forest remnant and its population size has been variously estimated at between 25,000 and 30,000 individuals (Le Roux and Bell 2007, Bell and Pledger 2010). Translocations have been the principal management action, mainly focused on the extension of its range. The first translocation took place over 1984 - 1985 to a nearby area of habitat on Maud Island (Boat Bay; Bell et al. 2004a). After this successful translocation, three island-to-island translocations have been carried out to Motuara Island (1997 and 2014) and Long Island (2005), along with two mainland translocations to ZEALANDIA ${ }^{\mathrm{TM}}$ (Karori Sanctuary) in Wellington, New Zealand's North Island (2007 and 2012; Lukis 2009, Bell et al. 2010, Karst 2013, Bishop et al. 2013). A small $L$. pakeka population is currently being held at the University of Otago to develop indoor captive breeding techniques (Bishop et al. 2013). This species is considered as Vulnerable according to the IUCN Red List Criteria (IUCN 2017) and as Nationally Vulnerable under the New Zealand Threat Classification System (Newman et al. 2013). 


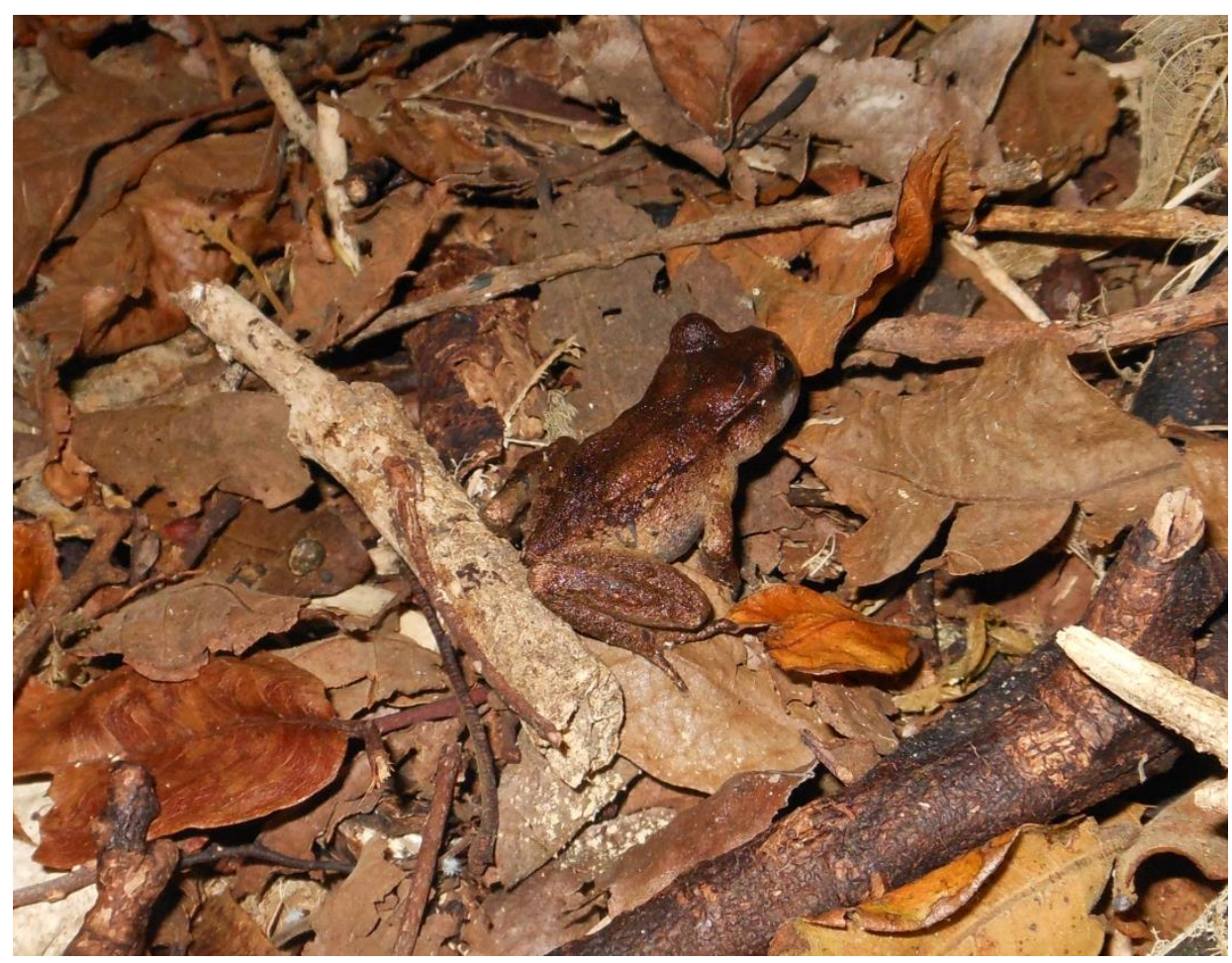

Figure 4: Leiopelma pakeka among leaf litter on Maud Island. Photo: P.A. Ramírez

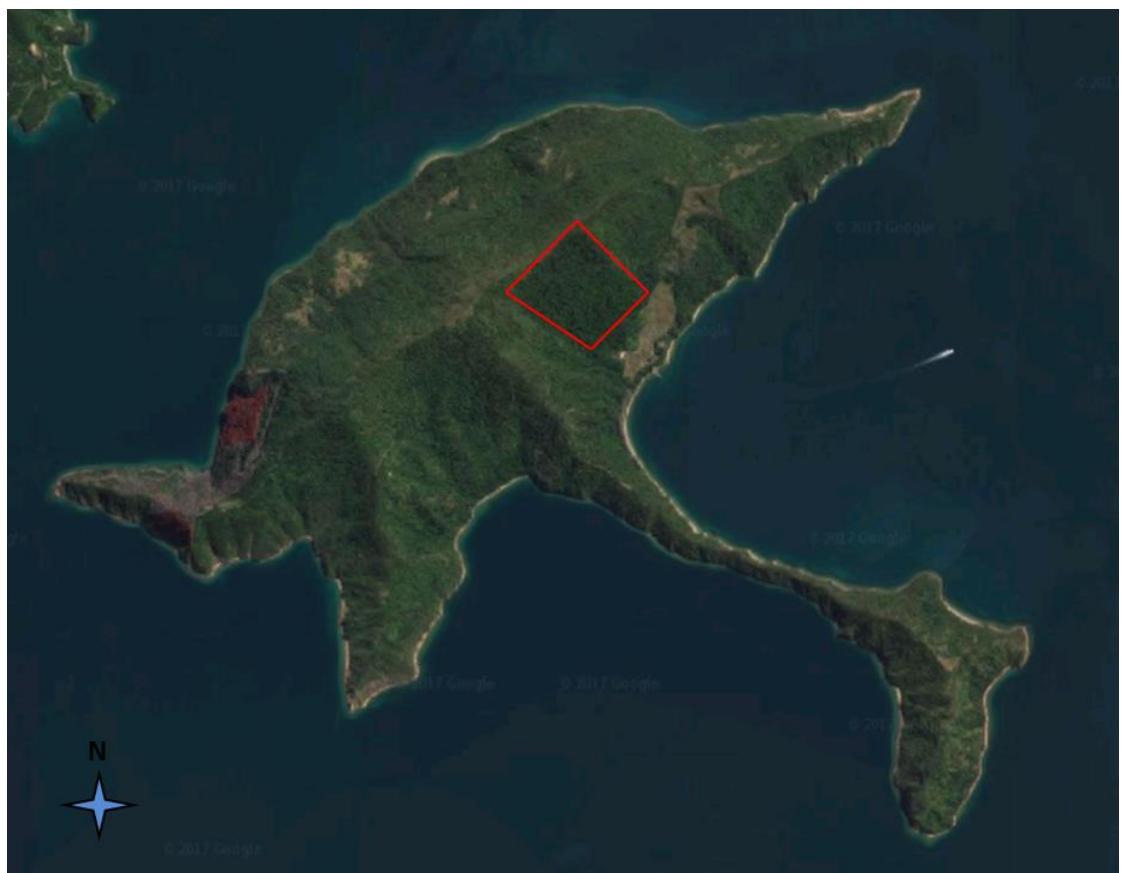

Figure 5: Satellite image of Maud Island, Marlborough Sounds, New Zealand. Red area shows location of the extant L. pakeka population in the 16 ha forest remnant. 


\subsection{Behavioural studies for the conservation of L. archeyi and L. pakeka}

To date, studies describing the movement patterns and microhabitat use (the habitat an organism experiences; Huey 1991) of these species have taken place inside small study areas (e.g. 12 x 12 m plots) or have relied on techniques such as mark-recapture and frog surveys (e.g. Bell 1978, Cree 1986, Newman 1990, Bell 1995, Bell at el. 2004a, b, Webster 2004, Germano 2006, Bell and Pledger 2010, Bell and Moore 2015). These techniques, although important for the understanding of species ecology, provide only a coarse representation of the behaviour of individuals within a

population. Because data include only single nightly records of capture locations within a limited area as a representation of microhabitat use and movement, these behaviours could have been underestimated (Smith and Green 2005, Roe and Grayson 2008). The factors affecting emergence of frogs, such as abiotic factors, have been investigated (e.g. Cree 1989, Newman 1990, Bell 1995, Le Roux 2008, Karst 2013, Pledger 2013), but currently there is little information regarding the effect of these factors on movement and microhabitat use (but see Cree 1986 for L. archeyi retreat sites use). Because of their current conservation status, such knowledge is of direct value for the conservation and management of these species. The recommended management tools to maintain self-sustaining populations of and provide insurance populations for Leiopelma species, proposed in the Native Frog Recovery Plan 2013-2018, include translocations and captive management (Bishop et al. 2013). By studying the behavioural patterns of frogs, in the movement and microhabitat use context, valuable information will be obtained regarding the requirements and the habitat features that are essential for these species which can be directly used to improve these proposed conservation tools.

The study of frogs' behavioural patterns will not only improve the baseline for management and conservation programmes, but it can also help us evaluate the population viability of these two Leiopelma species in the long term. These studies can indicate behaviours that could be linked to the survival of L. archeyi in the presence of introduced mammalian predators, such as rats, and how these frog species could be affected by climate change. 


\subsection{Thesis aim and organization}

The main aim of this study is to advance the knowledge of the fine-scale movement behaviour and microhabitat use of L. archeyi and L. pakeka in their natural habitats, incorporating the factors that may be affecting their behaviours, and to establish how these behavioural observations might affect their population viability in the long term.

\subsubsection{Main questions}

1. Do activity periods, movement patterns, microhabitat selection (including retreat sites) differ between L. archeyi and L. pakeka?

2. Do extrinsic (temperature, relative humidity or season) or intrinsic (body size) factors affect $L$. archeyi and L. pakeka movement behaviour and microhabitat selection?

3. What are the thermal and structural attributes of L. pakeka retreat sites?

4. Is there evidence of activity inside L. pakeka retreat sites?

5. Is the presence of rats imposing changes in the movements and microhabitat use of L.archeyi that could be associated with their survival?

\subsubsection{Thesis outline and style}

This thesis includes one technical chapter that has been published in a peer reviewed journal and four research chapters that are formatted for journal submission. Therefore, there is repetition of necessary information in order to produce independent publishable studies while maintaining the coherence of the thesis, particularly in the introductory sections and some parts of the methods sections. Chapter 2 is a modified version of a short communication published in the New Zealand Journal of Ecology (Ramírez et al. 2017), which focuses on the usefulness of non-toxic fluorescent powders as a fine-scale tracking technique for studying the behaviour of Leiopelma. 
It has been modified to fit the structure of this thesis and to highlight my contribution to the publication. This Chapter is pivotal for this thesis as Chapters 3 to 5 rely on this technique to obtain information on the frogs' behaviour. In Chapter 3, I investigated the activity periods and fine-scale movement patterns of L. archeyi and L. pakeka, including the factors that could be affecting these observed patterns, in order to obtain valuable information for captive breeding and appropriateness of translocation sites. In Chapter 4 I studied the microhabitat use of $L$. archeyi and L. pakeka, the factors affecting this use, and whether the use of those microhabitat types they have in common differed between species, in order to obtain more information on the habitat requirements of these species. In Chapter 5, I investigated retreat site selection, and further investigated L. pakeka retreat sites in order to gain information about their thermal and physical attributes, and the activity that occurs inside retreats. In Chapter 6, I assessed whether rats are imposing indirect effects on $L$. archeyi in terms of their movement (home range) and microhabitat use. For this chapter, I used a long-term frog capture data-set provided by the Department of Conservation spanning 2005 - 2013 from an area with and without rat control within Whareorino Forest. Finally, in Chapter 7, I provide a summary of the findings of each chapter, discuss implications for the conservation of Leiopelma species and propose future areas of research. 


\section{Chapter $2^{1}$}

\section{Tracking a small cryptic amphibian with fluorescent powders}

\subsection{Introduction}

Information on amphibian spatial behaviour is crucial for a better understanding of species ecology (Duellman and Trueb 1994, Pittman et al. 2014) and for conservation purposes where key habitat features aid in management (Eggert 2002, Lemckert 2004). Various techniques are available to track amphibians; however, their use is often limited by the size of the focal species and the method of tracking device attachment. Small $(<7$ g; Rowley and Alford 2007) and burrowing species represent a challenge as commonly used techniques, such as radio-telemetry, are too heavy, may injure the animal when burrowing (Eggert 2002, Graeter and Rothermel 2007, Rowley and Alford 2007), or are not appropriate for detecting fine-resolution habitat use (Lövei et al. 1997, Birchfield and Deters 2005). Non-toxic fluorescent powders have been used to track small animals including insects (e.g. Johansson 1959, Vardeman et al. 2007), mammals (e.g. Lemen and Freeman 1985, Mullican 1988), and amphibians (e.g. Woolbright 1985, Birchfield and Deters 2005, Ramirez et al. 2012). This tracking method has proven harmless for amphibians (Rittenhouse et al. 2006, Orlofske et al. 2009) while providing detailed data on small-scale movements and habitat use (Eggert 2002, Graeter and Rothermel 2007).

Leiopelma pakeka is a small, terrestrial, cryptically-coloured and nocturnal species with the only naturally occurring population found on Maud Island, Marlborough Sounds (Bell 1978, Bell and Pledger 2010, Bishop et al. 2013). It is one of the largest extant Leiopelma species, with snoutvent length of females greater than $40 \mathrm{~mm}$ and 34 - $40 \mathrm{~mm}$ in males or young females (Bell 1978, Newman 1990, Bell et al. 2004b). Adults are highly sedentary with individuals occupying discrete home ranges of $26.7 \pm 2.2 \mathrm{~m}^{2}$ (Bell 1994, Bell et al. 2004b, Webster 2004) over a period of decades

\footnotetext{
${ }^{1}$ This chapter has been reproduced in its published form, but with some modifications to the formatting and with added content to better integrate with this thesis.
} 
(Bell and Moore 2015). The species is considered to be 'vulnerable' both at a national and international level (Newman et al. 2013, IUCN 2017). To date, studies of L. pakeka have focused on describing patterns of spatial distribution within small long-term study plots $(12 \times 12 \mathrm{~m}$ plots studied since 1983), relying heavily on mark-recapture techniques (e.g. Newman 1990, Bell 1994, Bell et al. 2004b, Webster 2004, Germano 2006, Bell and Pledger 2010). However, the information obtained at an individual level is often limited by a single nightly record of capture locations over a limited capture period. Moreover, it depends on the recapture rate and survey area so the space and time accuracy is usually quite coarse (Lövei et al. 1997, Eggert 2002). To improve the conservation status of L. pakeka, several translocations have been carried out since 1984 (Bell 1994, 2010). Homing tendencies are one of the biggest problems affecting translocations (Matthews 2003, Sullivan et al. 2004, Tocher and Brown 2004, Germano 2006). Therefore, being able to track post-translocation movements can help us to understand the behaviour that impacts translocation successes.

Fluorescent powders are recognized as a temporary identification method for New Zealand species (Beausoleil et al. 2004), and were first used to track Leiopelma species by Germano (2006) who studied the immediate post-translocation movements of the native New Zealand frog $L$. pakeka following an inter-island translocation. However, there has been no evaluation of this technique for Leiopelma species so far. Here I assessed the effectiveness of non-toxic fluorescent powders to track the fine-scale movements of L. pakeka. I evaluated the effect of the powder on the frogs' movement behaviour and the effect of weather on the detectability of the path length. Additionally, I collaborated with Dr Jennifer Germano in order to show the usefulness of this technique for monitoring translocated individuals for conservation purposes. 


\subsection{Methods}

\subsubsection{Powder application and path marking}

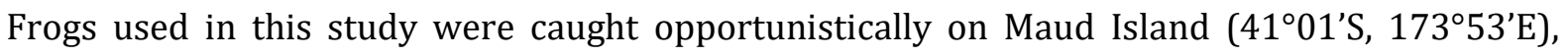
Marlborough Sounds, within a 16 ha remnant of broad-leaved forest (described in Bell and Bell 1994). Once a frog was detected on the ground, it was captured by hand, measured (snout-vent length) and photographed. Frogs had non-toxic fluorescent powders (ECO-Series, Dayglo Color Corp, Cleveland, USA, colours: green, yellow and magenta; or R-105 Series, Radiant Color Ltd., Houthalen, Belgium, colours: green, yellow, blue and magenta) applied to their bodies in the field by placing the frog on top of the powder to cover the ventral surface and legs, ensuring it would stick to their feet. After measurements and powder application (handling time $<1$ minute), frogs were immediately released at their capture location (or release site) and researchers departed to ensure minimal disturbance. After every 30 minutes, the pigmented trail left behind by the frogs as they moved was checked using a portable UV light (MTE UV301, Urban Outback Gear, Wallsend, Australia). At each time interval (i.e. every 30 minutes) the location and the change of direction (turn) relative to the previous mark was marked with either wooden pegs the size of a toothpick or cloth tape (Fig. 1). 


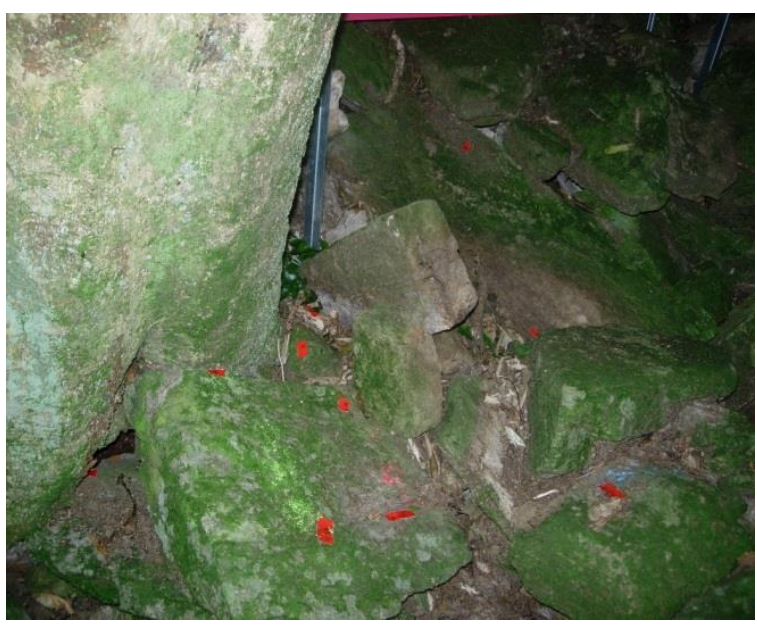

A

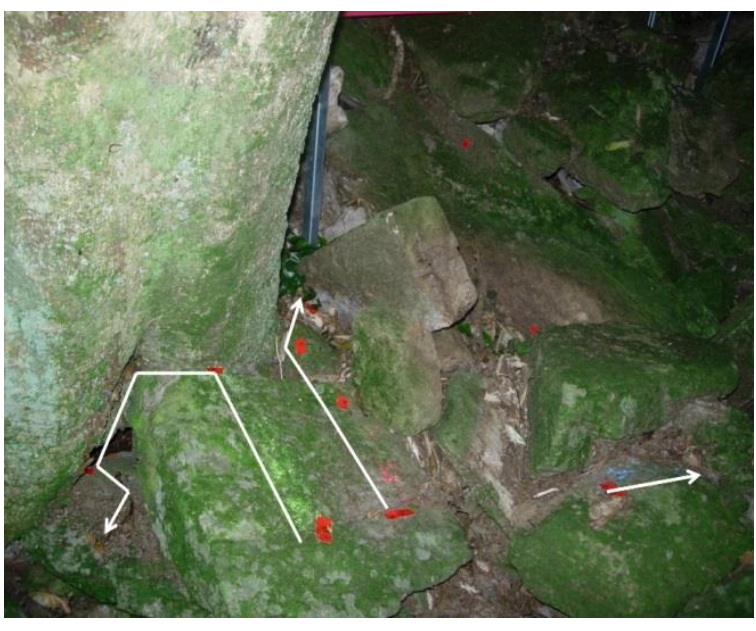

B

Figure 1: Frogs' post-translocation movements shown as (A) three fluorescent trails marked with red cloth tapes after 30 minutes of observation/turn and (B) with white lines highlighting the pathways (photos by JM Germano).

\subsubsection{Effect of handling and powder application on frogs' movement}

To investigate the effects of the powder application and handling of frogs on their movements, in March 2014 five randomly selected frogs were tracked using a night vision scope (Yukon NVMT 3 (4x50) Prowler Night Vision Monocular, Vilnius, Lithuania), without any type of handling or powder. Frogs were tracked for two continuous hours each and after every 30 minutes observation a mark was placed on the frogs' pathways as described above. To establish the impact on the frogs' movement behaviour, I compared the total distances moved (measured the following day as a straight-line between successive marks) and movement rate (distance moved per 30 minutes) during the first 2 hours among 30 powdered and these five non-powdered frogs.

\subsubsection{Effect of weather on path detectability}

To investigate the effect of weather on the detectability of frogs' pathways, 30 randomly selected adult frogs were tracked using fluorescent powders for one night each during a dry period 
(December 2014, no rain during the five tracking nights) and another 30 during a wet period (April 2015, rain during all three tracking nights). Frogs were tracked throughout the night to ensure their wellbeing and to obtain information of their entire activity period. Of the 60 tracked frogs, $82 \%$ were females and $18 \%$ males (or younger females). The mean precipitation during the tracking nights in the wet period was $27.4 \mathrm{~mm}$. To establish the effect on path detectability, I compared the path length (i.e. total distance moved), tracking period (total time (hours) spent tracking frogs during a night until all frogs sought a final retreat site) and movement rate among frogs tracked during the wet and dry periods. I considered a retreat site as 'final' when a frog went inside after dawn, or during the night but stayed inside until after dawn.

\subsubsection{Use of powder for monitoring translocated frogs}

Germano (2006) used fluorescent powders to investigate frogs' pathways and dispersal following a translocation. Frogs $(n=101)$ were translocated in July 2005 from Maud Island to Long Island ( $41^{\circ} 07^{\prime} \mathrm{S}, 174^{\circ} 17^{\prime} \mathrm{E}$ ), Queen Charlotte Sound, in a release site of $10 \times 12 \mathrm{~m}$ dominated by broadleaf tree species. Twenty-five of the released frogs were tracked using fluorescent powders during the first night following release. After the release, frogs were tracked every 30 minutes until they found initial retreats. Total distances moved were recorded the following day as described above, as was the compass bearing from the release point to the path end (Germano 2006).

\subsubsection{Data analyses}

Because assumptions of parametric tests were not met due to the small sample sizes and unbalanced design (non-powdered vs powdered frogs), linear data were analysed using nonparametric Kruskal-Wallis tests. Rayleigh's test for uniformity was used to determine if bearings were uniformly distributed (Germano 2006). Analyses were performed in R version 3.2.0 (R core 
Team 2015) and Oriana (version 2.0, Kovach Computing Services; Germano 2006). Summary statistics presented are the means \pm one standard error (SE).

\subsection{Results}

\subsubsection{Effect of fluorescent powders on frogs' movement}

All frogs remained alive throughout the study periods and were not obviously disturbed by the handling or powder application. The powder remained on the frogs and left a noticeable trail during the entire night so there was no need for re-handling or re-application, and the different powder colours did not affect the detectability of the paths. All five non-powdered frogs fell within the distribution of the powdered frogs when plotted against the total distance moved (Fig. 2). The mean total distance moved by the five non-powdered frogs did not differ significantly from the mean total distance moved by the 30 frogs tracked with powders $(1.12 \pm 0.26 \mathrm{~m}$ vs $1.56 \pm 0.23 \mathrm{~m}$, respectively; $\mathrm{H}=0.18, P=0.67)$. Similarly, there were no significant differences in the mean movement rate between non-powdered and powdered frogs $(0.28 \pm 0.06 \mathrm{~m} / 30 \mathrm{~min}$ vs $0.39 \pm 0.06$ $\mathrm{m} / 30 \mathrm{~min}$, respectively; $\mathrm{H}=0.18, P=0.67$ ). 


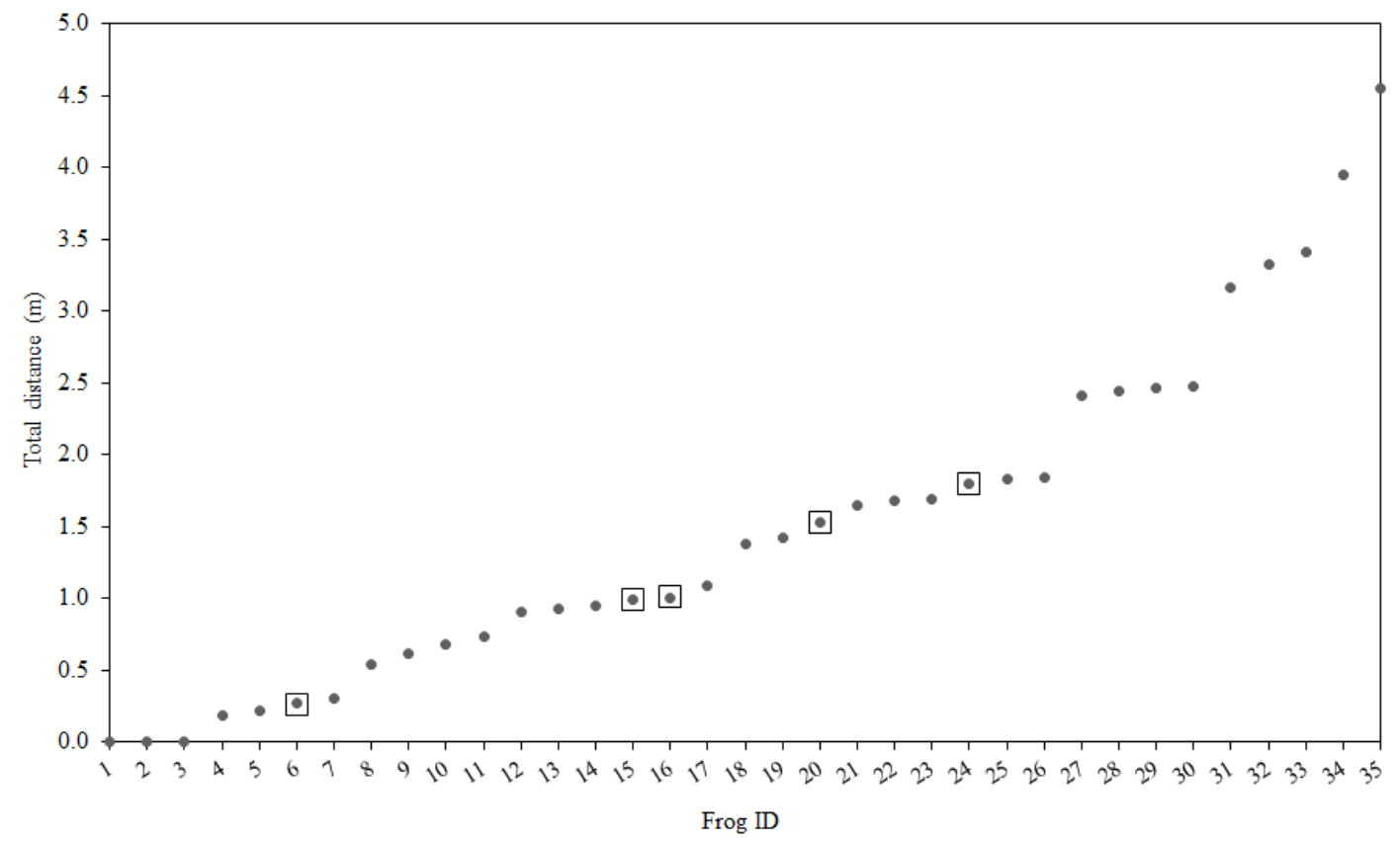

Figure 2: Total distances moved during the first two hours of tracking frogs with fluorescent powders $(n=30)$ and with night vision scope $(n=5$; marked with squares).

\subsubsection{Effect of weather on path detectability}

During rainy nights, trails were less noticeable and faded faster than during dry nights but it was still possible to detect frogs' pathways until they reached a final retreat site. The mean tracking period was significantly longer during the wet period compared to the dry period $(8.68 \pm 0.12 \mathrm{~h}$ vs $6.92 \pm 0.15$ h per night; $\mathrm{H}=37.52, P<0.001$ ) due to the longer nights at that time of year. All frogs were tracked systematically until after dawn, even if they had reached their final retreat sites prior to dawn. The mean path length and mean movement rate did not significantly differ between the dry and wet periods $(\mathrm{H}=0.34, P=0.56 ; \mathrm{H}=0.27, P=0.60$, respectively; Table 1$)$. 
Table 1: Measured path lengths (i.e. total distance) and movement rates for frogs tracked with fluorescent powders during a dry (December 2014) and a wet (April 2015) period.

\begin{tabular}{|c|c|c|c|c|c|c|c|}
\hline \multirow[b]{2}{*}{ Season } & \multirow[b]{2}{*}{$\begin{array}{c}\text { Mean precipitation } \\
\text { during tracking nights } \\
(\mathrm{mm})\end{array}$} & \multicolumn{3}{|c|}{ Path length (m) } & \multicolumn{3}{|c|}{ Movement rate $(\mathrm{m} / 30 \mathrm{~min})$} \\
\hline & & Min & $\operatorname{Max}$ & Mean \pm SE & Min & Max & Mean \pm SE \\
\hline Dry & 0 & 0.34 & 12.93 & $5.13 \pm 0.57$ & 0.08 & 5.26 & $0.87 \pm 0.18$ \\
\hline Wet & 27.4 & 0.75 & 12.44 & $4.72 \pm 0.56$ & 0.04 & 2.58 & $0.71 \pm 0.12$ \\
\hline
\end{tabular}

\subsubsection{Use of powder for monitoring translocated frogs}

Of the 25 frogs Germano (2006) tracked, 21 left tracks to retreats. Four trails ended when the powder became too faint to follow. The mean path length was $1.31 \pm 0.25 \mathrm{~m}$. The mean bearing for these paths was $309.3^{\circ} \pm 16.3^{\circ}$ and bearings were not randomly distributed $(Z=5.45, P=$ 0.003; Germano 2006).

\subsection{Discussion}

Due to the relatively small size of L. pakeka and the fact that a large proportion of its life is spent under large rock piles, obtaining detailed information on individuals' movements and habitat use can be difficult as fine-scale tracking methods (e.g. harmonic radar tracking) are quite limited for small species. Germano (2006) assessed the homing abilities of L. pakeka individuals displaced from their home range using harmonic radar tracking. However, as with traditional radio telemetry studies, its precision relies on the number of relocation points and it does not give a detailed description of movement or habitat use. Furthermore, while harmonic radar tracking can be used for small species (Langkilde and Alford 2002), it does not allow for individual identification without extra manipulation. Despite testing on captive frogs, a small proportion (2 of 11 frogs) of the wild L. pakeka tracked using harmonic radar died due to prolonged excessive muscular activity, with necropsy reports attributing this to capture myopathy or exertional 
rhabdomyolysis (Germano 2006). This mortality rate suggests that other less intrusive techniques, such as fluorescent powder tracking, may be more appropriate and safer to use with threatened Leiopelmatid frogs.

This is the first evaluation of the use of fluorescent powders as a tracking technique for Leiopelma. The use of these powders for tracking frogs was quite efficient. Detailed information on the finescale movements of frogs was obtained without much disturbance. Powders were quickly and easily applied involving minimal handling of frogs, with a handling time that is less compared to other tracking techniques as no tracking device is either attached or inserted. I detected no evidence of negative effects on frogs, such as death or unusual behaviour (e.g. attempts to remove powder) and there was no need for re-handling or for re-application of powders, even during rainy nights. Where fluorescent powders have been used previously, they were still visible on frogs two days after first application in the absence of rain (Rittenhouse et al. 2006). In our study, some frogs could be seen with residues of powder on their bodies the following night but considerably less than when first applied, and the majority of them no longer left a trail. Rain speeded up the removal of powders from the frogs' bodies and habitat; subsequently, from December 2014 to April 2015 only very few areas had visible remnants of powder.

Some studies have tested the detectability of different powder colours (Birchfield and Deters 2005, Graeter and Rothermel 2007), which helped in the selection of colours for this study. The colours used (yellow, green, blue, and magenta) allowed to track the movement of frogs until they reached their final retreat sites, even during wet periods. Yellow and green can be difficult to differentiate under UV light, nonetheless, using both or either of these along with magenta and blue allowed tracking of adjacent animals and differentiation between individuals. Additionally, although it was not tested here, powders were detectable in all the different microhabitat types present in the area, including on wet vegetation and on trees. 
Handling and releasing marked individuals can be problematic as it can affect their behaviour, therefore attempts should be made to measure any negative effects of the marking technique (Turchin 1998). As measured by total distances moved and movement rate, I found no major influences of the use of fluorescent powders for tracking frogs' movements. Mean total distances travelled by powdered frogs were not significantly different from the distances travelled by frogs tracked with night-vision equipment, and the same pattern was observed for the mean movement rates. While both groups (powdered and tracked) were potentially influenced by researcher intervention, I conclude that powders can give accurate information on frogs' movements despite the initial manipulation needed to apply the powders, the release method and the 30 minute checking intervals.

Rain did not affect the detectability of the frogs' pathways. During the dry and wet periods, frogs were tracked during the entire night and the detected mean path lengths did not differ significantly. By allowing enough powder to cover the legs and ventral skin of the frogs tracked during the wet period, it was possible to detect the frogs' pathways during rainy nights. Furthermore, because nights are longer during the wet season, tracking period was longer and yet the powder remained on the frogs long enough to track their entire movement. Most amphibian studies check the trails left by individuals after a few hours or even after 24 hours (e.g. Graeter and Rothermel 2007, Ramirez et al. 2012, Pittman and Semlitsch 2013), but this time interval can present disadvantages as paths can be confused by trails crossing, heavy downpours erasing trails, old and new trails being confused as the powders can remain visible for 1-2 days in absence of rain (Graeter and Rothermel 2007, P. Ramírez, pers. obs.) and paths becoming faint as distance from release site increases not allowing clear identification. By tracking frogs every 30 minutes throughout the night I was able to detect a clear fluorescent trail allowing a more accurate description of frog movements during their activity period and during two different weather conditions. 
Translocations are increasingly common in wildlife management but their effectiveness can be reduced by the homing instinct of many species, so it is important to examine how species respond to translocations. Germano (2006) showed that fluorescent powders were useful as they rendered a very detailed description of the paths taken by frogs immediately upon release. Paths had a mean bearing NW $\left(309.3^{\circ}\right)$ which is close to the NW $\left(320^{\circ}\right)$ bearing from Maud Island (the capture site). Germano (2006) states that this pattern could reflect a homing inclination towards their capture site, but since the ability to home is negatively correlated with the displacement distance (Sinsch 1991, Gonser and Woolbright 1995), it is unlikely that an immediate homing instinct would be present as this translocation took place roughly $25 \mathrm{~km}$ from Maud Island. A more plausible explanation for this directional movement upon release is the availability of better habitat quality uphill in a W-NW direction (Germano 2006).

Given that L. pakeka is a threatened species, future studies could further evaluate the effect of the powders on its physiology, reproduction and health. Additionally, because individual frogs were tracked for one night only, we cannot establish the effect powders may have on subsequent nights, therefore, the possible effects of prolonged exposure (i.e. more than one night) on frogs still needs to be assessed. Due to the fluorescent powders, marked individuals could be more conspicuous and more susceptible to predation by avian predators; therefore, the use of this technique should carefully consider presence of such predators in the area. This technique could also be useful for tracking other species from different taxa which are too small or cryptic to be tracked with conventional methods. 


\section{Chapter 3 \\ Fine-scale movements of two Leiopelmatid frogs: Leiopelma archeyi and L. pakeka}

\subsection{Introduction}

Movement patterns are an essential component of the ecology of organisms (Daugherty and Sheldon 1982, Benhamou 2004, Nathan 2008, Nathan et al. 2008, Kays et al. 2015). Movement can be defined as a change in the spatial location of an individual over time, which is driven by processes that act across multiple spatial and temporal scales (Nathan et al. 2008). The movement of organisms has an individual component that reflects the behaviour of individuals (Sinsch 2014), directly impacting their individual fitness (Nathan et al. 2008, Pittman et al. 2014, Kays et al. 2015), but it also has an ecological component that reflects the spatial organization of a species (Turchin 1998, Revilla et al. 2004, Sinsch 2014). Therefore, the study of the movement patterns of individuals is fundamental for species conservation as it provides information that allows for scaling up from the individual to the population level (Wiens et al. 1993, Lima and Zollner 1996, Revilla et al. 2004, Nathan et al. 2008, Osbourn et al. 2014, Pittman et al. 2014). For example, Haddad (1999) was able to predict the effect of corridors on inter-patch movements, and therefore their conservation potential, by studying the movement paths of three butterfly species instead of detailed dispersal studies. Graeter (2005) studied the movement patterns of three amphibian species in the context of forest management and found that clear-cuts acted as ecological traps for the marbled salamander (Ambystoma opacum). This observed behaviour explained the reduced abundance of this species in forest clearings, and recommendations were made to leave buffers of intact forest around wetlands to facilitate movements and therefore survival of this species.

Many population processes, such as population distribution, are largely mediated by the behaviour of individuals within a population (Laskowski et al. 2015). Fine-scale movement 
patterns, movement patterns at an individual level, can have important consequences for the fitness of individuals, and therefore for the entire population (Wiens et al. 1993, Lima and Zollner 1996). Thus, the study of fine-scale movement patterns and the factors affecting them are crucial for the protection and management of species. Due to their permeable skin, frogs are susceptible to desiccation and must regulate their activities in order to maintain a positive water balance to survive (Tracy 1976, Duellman and Trueb 1994, Wells 2007). In this sense, abiotic factors, such as air temperature and relative humidity, can influence frogs' movement patterns by either facilitating or constraining them (Price-Rees et al. 2014). Additionally, as smaller frogs can experience higher rates of desiccation due to the greater surface-area-to-volume ratio compared to larger frogs (Spotila 1972, Tracy 1976, Duellman and Trueb 1994), the size of frogs can also be a factor affecting their movement patterns.

Even though movement studies have been shown to be important in amphibians, most research has focused on pond-breeding species (e.g. Dole 1965, Eggert 2002, Lemckert 2004, Birchfield and Deters 2005, Patrick et al. 2008, Osbourn et al. 2014, Pittman et al. 2014), leaving terrestrial species comparatively neglected (but see Woolbright 1985, Bulger et al. 2003, Tozettti and Toledo 2005, Yetman and Ferguson 2011). The commonly cryptic nature and small size of the latter can complicate the study of their movement (Roe and Grayson 2008, Price-Rees et al. 2014). To accurately characterise the spatial behaviour of a species it is necessary to collect information throughout its activity period (Bulger et al. 2003, Lemckert 2004, Smith and Green 2006), with the least amount of disturbance to the study species (Duellman and Trueb 1994, Eggert 2002, Birchfield and Deters 2005). Although this study approach can be difficult and time-consuming, it is one of the most powerful approaches for quantifying movement (Turchin 1998). Other study techniques, such as mark-recapture, may underestimate the magnitude of movements and may not be able to detect fine-scale patterns, such as changes in location at the microhabitat scale (Graeter 2005, Sinsch 2014). 
Leiopelma archeyi and L. pakeka are terrestrial and cryptically-coloured species that retreat under rocks and vegetation during daytime (Bell 1978, Newman 1990, Chapter 5). They are nocturnal species, with L. archeyi presenting activity until a few hours after daybreak (Bell 1978, Cree 1989). There is no consistently observable sexual dimorphism in either of these species, but females grow larger (Bell 1978). L. pakeka adult females attain snout-vent lengths (SVL) greater than $40 \mathrm{~mm}$, compared with $34-40 \mathrm{~mm}$ in males or younger females and $<34 \mathrm{~mm}$ in sub-adults (Bell 1978, Newman 1990, Bell et al. 2004b). In L. archeyi snout-vent lengths of adult females exceed $31 \mathrm{~mm}$, with 25 - $31 \mathrm{~mm}$ in males or young females and < $25 \mathrm{~mm}$ in sub-adults (Bell 1978). Both species are classified as threatened nationally and internationally (Newman et al. 2010, 2013, Bishop et al. 2013, IUCN 2017). While L. archeyi has been found to co-occur with introduced mammalian predators, such as rats and mice, in Whareorino Forest and the Coromandel Ranges (Bell 1978, Worthy 1987, Thurley and Bell 1994), the only natural population of L. pakeka is confined to a 16 ha of forest remnant on Maud Island, a mammalian predator-free island (occasional incursions of mustelids occur and a house mouse incursion was first reported in 2013, though apparently the mice have since been eradicated; Department of Conservation 2016) in the Marlborough Sounds (Bell 1978, Bell and Pledger 2010, Bishop et al. 2013). To date, field studies of these species have focused on describing patterns of spatial distribution mainly within small long-term study plots, relying on mark-recapture techniques (e.g. Newman 1990, Bell 1994, Bell et al. 2004a, b, Webster 2004, Germano 2006, Haigh et al 2007, Pledger 2011, Bell and Moore 2015). However, mark-recapture data include single-nightly records of capture locations over a limited capture period (e.g. 4 to 6 successive nights), and therefore may underestimate the movement behaviour of frogs over the short-term. Additional information I have about the activity patterns of these species has relied on spot-sightings and frog counts (Bell 1978, Bell and Bell 1994, Bell 1995, Cree 1989, Bell 2016) with a lack of detailed information about their activity over time. As there is significant variation among the behaviour of anuran species, it is not possible to make generalizations about their movement patterns or habitat requirements (Lemckert 2004, Yetman and Ferguson 2011). Hence, it is necessary to obtain species-specific 
biological information for the establishment of general guidelines for the conservation of these threatened species.

\subsubsection{Study aim and research questions}

I aimed to compare the fine-scale movement patterns of two terrestrial Leiopelma species, $L$. archeyi and L. pakeka, in their natural environments in order to gain more information on their movement behaviour during their entire activity period when on the surface. I asked: 1) Do activity patterns differ between species? 2) Do small-scale movements differ between species or seasons? and 3) Are movement patterns associated with extrinsic (air temperature and relative humidity) or intrinsic (SVL) factors in these species?

\subsection{Methods}

\subsubsection{Study sites and visits}

Fine-scale movements of $L$. archeyi were investigated in Whareorino Forest ( $\left.38^{\circ} 22^{\prime} \mathrm{S}, 174^{\circ} 47^{\prime} \mathrm{E}\right)$, Northern King Country, New Zealand, inside an area of 45 x 28 m (tracking area) located within a 300-ha area where an on-going rat control programme has been carried out since 2003 (Haigh et al. 2007). The forest is comprised of mixed broadleaf and podocarp cloud forest, such as tawa (Beilschmieda tawa) and rimu (Dacrydium cupressinum; Thurley and Bell 1994, Haigh et al. 2007). Fine-scale movements of L. pakeka were investigated on Maud Island ( $41^{\circ} 01^{\prime} \mathrm{S}, 173^{\circ} 53^{\prime} \mathrm{E}$ ), Marlborough Sounds, New Zealand, considered to be a predator-free island (but see introduction) inside an area of $45 \times 28 \mathrm{~m}$ (tracking area) located in the lower slopes of a 16 ha remnant of broadleaved forest growth. The forest is composed mainly of broadleaf species dominated by kohekohe

(Dysoxylum spectabile), mahoe (Melicytus ramiflorus), tawa (B. tawa), pigeonwood (Hedycarya arborea), and pukatea (Laurelia novae-zelandiae), with an understorey composed of seedlings 
and saplings of those tree species as well as kawakawa (Macropiper excelsum) and ferns (Bell and Bell 1994, Newman 1990).

Over November 2014 - November 2015 there were a total of three field trips to Whareorino Forest covering the breeding (November $[\mathrm{n}=2]$ ) and non-breeding (March $[\mathrm{n}=1]$ ) seasons of $L$. archeyi, and over December 2013 - December 2015, a total of five field trips to Maud Island covering the breeding (November/December [n=3]) and non-breeding (March/April [n=2]) seasons of L. pakeka. Each filed trip lasted between seven to 10 days. Germano et al. (2012) found a high concentration of reproductive hormones in L. pakeka frogs during the winter season suggesting a winter or early spring breeding period for L. pakeka on Maud Island. However, no evidence of mating or oviposition in the field or in captivity during the winter months is available. Bell (1978, 1985b, 2011), on the other hand, reported oviposition of L. archeyi eggs during October-November and of L. pakeka eggs (in outdoor enclosures) during December. For this study, the breeding season for both species has been considered as the time when oviposition has been observed, that is; Austral spring-early summer.

\subsubsection{Tracking of frogs}

Thirty frogs were tracked in each field visit, except in the breeding season of 2014 where only 17 L. archeyi were tracked due to logistical constraints. Between four to 10 frogs were tracked per night. All frogs used in this study were caught opportunistically on or near the ground surface at night in the field. Frogs were captured by hand, quickly measured (snout-vent length) and dorsally photographed for later identification (only one photograph was taken to minimize disturbance to frogs). Non-toxic fluorescent powders (ECO-Series, Dayglo Color Corporation, Cleveland, USA) were applied to the frogs' body in the field by placing the frog on top of the powder to cover the ventral surface and legs, ensuring it would stick to their feet. A small amount was also applied on the dorsal skin by shaking a small vial a few centimetres above the frog, avoiding contact with its eyes and face. Three powder colours, yellow, green and magenta, were 
used to allow for simultaneous tracking of three or more frogs on a given night by a researcher. These powders have proven to be safe for amphibians (Rittenhouse et al. 2006, Orlofske et al. 2009) and a suitable tracking method for Leiopelma (Germano 2006, Chapter 2). After measurements and powder application (handling time $<1$ minute), frogs were immediately released at their capture location and researchers departed to ensure minimal disturbance. Every 30 minutes, the pigmented trail left behind by the frogs as they moved was checked using a portable UV light (MTE UV301, Urban Outback Gear, Wallsend, Australia). The new location of the frog was marked with wooden pegs the size of a toothpick ( 4 x $65 \mathrm{~mm}$ ). To avoid disturbing the frogs, toothpicks were placed close to the frogs' location and moved to the exact location once the frog left the area. Frogs were tracked throughout the night to ensure their well-being and to obtain information on their entire activity period when on the surface. Tracking ended when frogs sought a final retreat site. I considered retreat sites as the sites where frogs disappeared from the surface, and a retreat site was considered as 'final' when a frog went inside the retreat after dawn, or if a frog entered a retreat during the night and remained inside for the remainder of the night. Each frog was tracked for one night only at each site so there was no repeated sampling of individuals within each trip.

\subsubsection{Fine-scale movements}

For each pigmented trail, I recorded the total distance moved by the frog (distance between marks measured as a straight line), net distance (distance from the capture location to the final retreat site measured as a straight line), and compass bearings (measured as the bearing from the capture site to the path end). I also obtained a path linearity index as the ratio between net distance and total distance moved (Batschelet 1981, Bell 1991). To obtain a representation of the activity of frogs in relation to the sunset, the frequency of movements during the activity period was used, with the frequency calculated as the ratio between the number of movements observed and the total number of observations during each hour. Since I obtained information on the movement of each frog every 30 minutes, a given frog could move up to two times in one hour, 
translating into two movements/hr for that frog. I chose frequency of movements as a representation of the frogs' activity as not all the frogs were tracked at the beginning of the night. This is because captures of frogs started shortly after sunset and lasted up to midnight. Sunset data relevant to each study site were obtained from the US Naval Meteorology and Oceanography Command website (http://aa.usno.navy.mil/data/docs/RS_OneYear.php).

\subsubsection{Abiotic measurements}

Air temperature and relative humidity were measured every 30 minutes during the duration of each site visit using a Digitech hygrometer (model QM7312) placed in a predetermined location at each study site. Data were individually summarized for each tracking night and six parameters were obtained: average, minimum and maximum night-time temperature (AVETN, MINTN and MAXTN, respectively) and average, minimum and maximum night-time relative humidity (AVERHN, MINRHN and MAXRHN, respectively). Precipitation data were obtained from the in situ station on Maud Island and the Te Kuiti Electronic Weather Station (61 km from Whareorino Forest; CliFlo database: http://cliflo.niwa.co.nz).

\subsubsection{Data analyses}

To assess whether the total and net distances moved, and the path linearity differed between species or seasons, I used generalized linear mixed models (GLMMs) with Gaussian distribution for the distances moved and a linear model with Gaussian distribution for path linearity. Individual frogs were included as a random effect to account for repeated measurements, and species and season as fixed effects with an interaction term. Years were not included as a factor as a priori analyses showed no significant differences in the total and net distances moved, and

path linearity for either species (Kruskal-Wallis tests, all $P>0.05$ ). I used separate nonparametric Kruskal-Wallis tests to compare the net and total distances moved between L. archeyi 
and small L. pakeka of similar SVL. Rayleigh's tests for uniformity were used to determine if bearings were uniformly distributed (Zar 1999).

I carried out separate non-parametric Kruskal-Wallis tests to assess whether air temperature and relative humidity differed between the breeding and non-breeding season of each species at each site. To establish whether extrinsic (temperature and relative humidity) or intrinsic (SVL) variables were associated with the total and net distances moved, a linear model was used with individual frogs included as a random effect and the explanatory variables as fixed effects. As there are still uncertainties associated with the sexing of frogs using their size (Tocher et al. 2006, Germano et al. 2011), sex was not included as an intrinsic variable. Movement data (total and net distances) were log transformed for normality (Sokal and Rohlf 1995). I used a variance inflation factor (VIF) to identify multicollinearity between extrinsic explanatory variables. Explanatory variables with a VIF above 2.5 are considered to be correlated (Allison 1999) and were eliminated from the models, starting from the variables with the highest values. A set of models was then created using the remaining explanatory variables and SVL. Models included the individual effect of the explanatory variables (MINTN, MAXTN, MINRHN, MAXRHN, and SVL), as well as additive models including intrinsic and extrinsic variables and only extrinsic variables. A model including all the main effects and a null model including only the intercept were also analysed. I used an information-theoretic approach for model selection using second-order Akaike's Information Criterion $\left(\mathrm{AIC}_{\mathrm{c}}\right)$ for small sample sizes (Burnham and Anderson 2002). For model performance assessment, $\Delta \mathrm{AIC}_{\mathrm{c}}$ and Akaike weights $\left(w_{\mathrm{i}}\right)$ were computed. Models with Akaike weights $>10 \%$ were considered for analyses (Burnham and Anderson 2002). Finally, to evaluate the importance of a given predictor variable, the sum of the Akaike model weights across all interpretable models where that variable occurred was used (Burnham and Anderson 2002). Confidence intervals of 85\% were used for parameter estimates as suggested by Arnold (2010). If confidence intervals included zero, then the predictor variable is considered as having no effect on the response variable (Yeiser and Richter 2015). 
Precipitation, although known to affect amphibians' emergence (Duellman and Trueb 1994), was not included as an extrinsic variable in the analysis as there were only three nights of rain during the entire sampling of L. pakeka and only two days for L. archeyi. Accordingly, to determine whether precipitation had an effect on frogs' movements, the presence or absence of rain during the tracking night and the amount on rain during the previous $24 \mathrm{~h}(0,<10 \mathrm{~mm}$ or $\geq 10 \mathrm{~mm})$ were analysed independently with regression analyses. Analyses were performed in R version 3.2.0 (R core Team 2015) and STATISTICA 7.0 (StatSoft Inc., USA). Summary statistics presented are the means \pm one standard error (SE).

\subsection{Results}

A total of 76 L. archeyi were tracked from 2014 to 2015 with five recaptures, while 123 L. pakeka were tracked from 2013 to 2015 with 26 recaptures. The paths of two L. pakeka and two L.archeyi became too faint to follow to their respective retreat sites. Based on their SVL, L. archeyi adult females comprised $40.3 \%$, males (or younger females) $38.9 \%$ and sub-adults $20.8 \%$ (15 frogs) of individuals across all trips. The mean size of adult female frogs was $34.0 \pm 0.3 \mathrm{~mm}$ (range 31.4 $38.1 \mathrm{~mm}$ ), of males (or younger females) was $28.2 \pm 0.3 \mathrm{~mm}$ (range $25.0-30.7 \mathrm{~mm}$ ) and of subadults $20.6 \pm 1.2 \mathrm{~mm}$ (range $10.9-24.8 \mathrm{~mm}$ ). For L. pakeka, I estimated that adult females comprised 77.2\%, males (or younger females) $21.1 \%$ and sub-adults $1.7 \%$ ( 2 frogs) of individuals across all trips. The mean size of adult female frogs was $43.5 \pm 0.2 \mathrm{~mm}$ (range $40.0-48.4 \mathrm{~mm}$ ), of males (or younger females) was $37.8 \pm 0.3 \mathrm{~mm}$ (range $34.7-39.9 \mathrm{~mm}$ ) and of sub-adults $29.2 \pm$ $3.0 \mathrm{~mm}$ (range $26.2-32.3 \mathrm{~mm}$ ). All frogs remained alive throughout the study periods and were not obviously disturbed by the handling or powder application (Chapter 2). The powder usually remained on the frogs and left a noticeable trail during the entire night so there was no need for re-handling or re-application, and the different powder colours did not affect the detectability of the paths (Chapter 2). 


\subsubsection{Abiotic conditions in Whareorino Forest and Maud Island}

In Whareorino Forest, the mean nightly temperature and relative humidity recorded during the breeding season were $8.84 \pm 0.06{ }^{\circ} \mathrm{C}$ and $95.35 \pm 1.01 \%$, respectively, and during the nonbreeding season, $13.80 \pm 0.13{ }^{\circ} \mathrm{C}$ and $74.48 \pm 0.55 \%$, respectively. Mean nightly temperature and relative humidity differed significantly between seasons $(H=164.57, P<0.0001, H=99.10, P<$ 0.0001, respectively). On Maud Island, the mean nightly temperature and relative humidity recorded during the breeding season were $13.48 \pm 0.09^{\circ} \mathrm{C}$ and $75.57 \pm 0.64 \%$, respectively, while during the non-breeding season were $12.90 \pm 0.13{ }^{\circ} \mathrm{C}$ and $92.44 \pm 0.48 \%$, respectively. Mean nightly temperature and relative humidity also differed significantly between seasons $(H=11.60$, $P<0.001, \mathrm{H}=243.66, P<0.0001$, respectively).

\subsubsection{Activity periods}

Both species had bimodal activity patterns, with peaks of movement during the early night, between the first three hours after sunset and close to the sunrise (Fig. 1). The time of sunrise for each location differs within each season because visits took place in different months. Regarding the time of movement, L. pakeka ceased movement at sunrise and up to one hour after, whilst $L$. archeyi continued moving after sunrise, ceasing movement after one or two hours after sunrise (Fig 1). During the non-breeding season, both species had a longer activity period due to the later time of sunrise. L pakeka showed activity up to $13 \mathrm{~h}$ after sunset during this season and up to 10 $\mathrm{h}$ after sunset during the breeding season (Fig. 1). L archeyi showed activity up to $15 \mathrm{~h}$ after sunset during the non-breeding season and up to $11 \mathrm{~h}$ during the breeding season (Fig. 1). L. archeyi had a longer activity period compared to $L$. pakeka, showing two more hours of activity than L. pakeka on each season (Fig. 1). Additionally, both species showed a relatively sedentary pattern of movement as usually less than $50 \%$ of the frogs moved per hour during the non-peak times (e.g. 
between 5 and $8 \mathrm{~h}$ after sunset). The exceptions were the breeding season of 2014 for L. archeyi and the breeding season of 2015 for L. pakeka where $\geq 50 \%$ of the frogs moved per hour (Fig. 1).

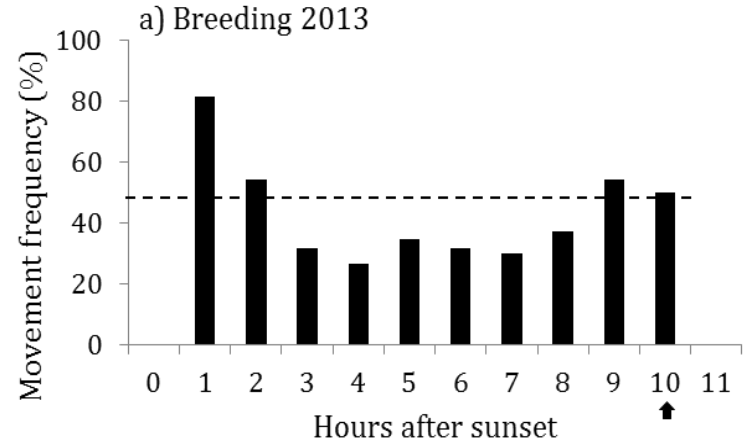

c) Breeding 2014

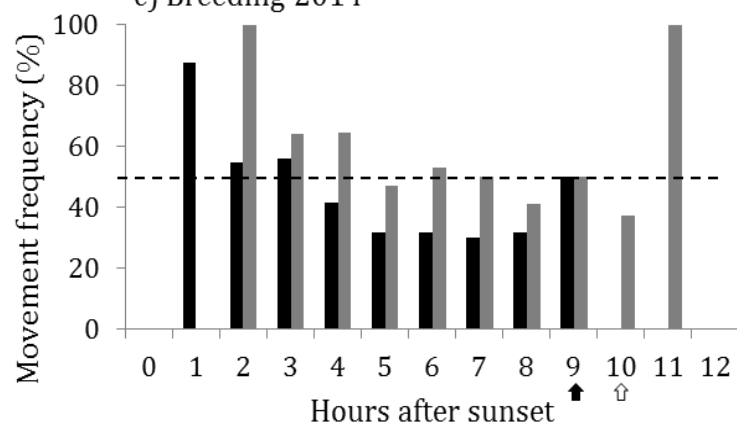

e) Breeding 2015

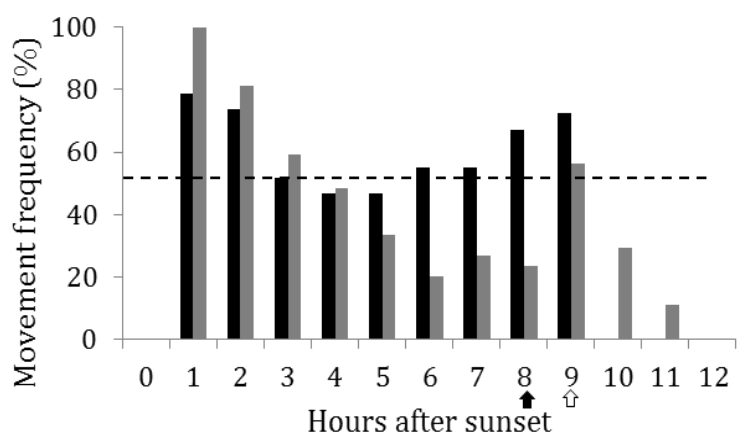

b) Non-breeding 2014

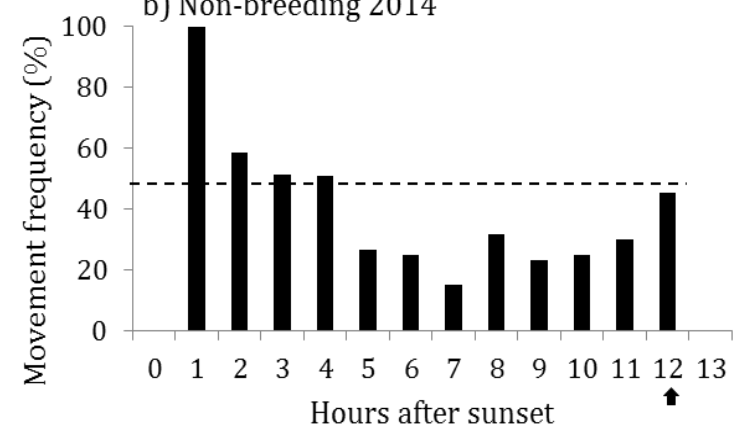

d) Non-breeding 2015

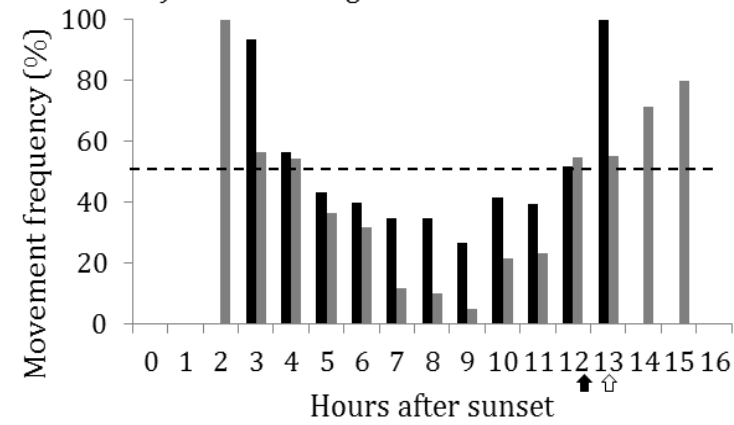

Figure 1. Movement frequencies for L. archeyi in Whareorino Forest (grey bars) and L. pakeka on Maud Island (black bars) during successive breeding and non-breeding seasons from 2013 to 2015. Arrows are used to denote sunrise in Whareorino Forest (white) and Maud Island (black). At every hour after sunset at least one frog was being tracked so a movement frequency of $0 \%$ means that none of the tracked frogs moved. Dashed lines represent a 50\% movement frequency. 


\subsubsection{Movement patterns}

Net distances moved varied among individuals of each species, with most $L$. archeyi moving between 0.5 and $1.5 \mathrm{~m}$ while most L. pakeka moved between 1.0 and $3.0 \mathrm{~m}$, with one frog moving $11.8 \mathrm{~m}$ (Fig. 2). The total distance moved by most L. archeyi was between 1.0 and $3.0 \mathrm{~m}$, with one frog moving a maximum of $10.56 \mathrm{~m}$ and for most L. pakeka was between 1.5 and $7.5 \mathrm{~m}$ with a maximum of $14.31 \mathrm{~m}$ (Fig. 2). The frog that moved the most (total distance: $14.31 \mathrm{~m}$ ) and the furthest (net distance: $11.80 \mathrm{~m}$ ) from all the tracked frogs was an individual of L. pakeka (frog 56; Fig. 3).

a) L. archeyi

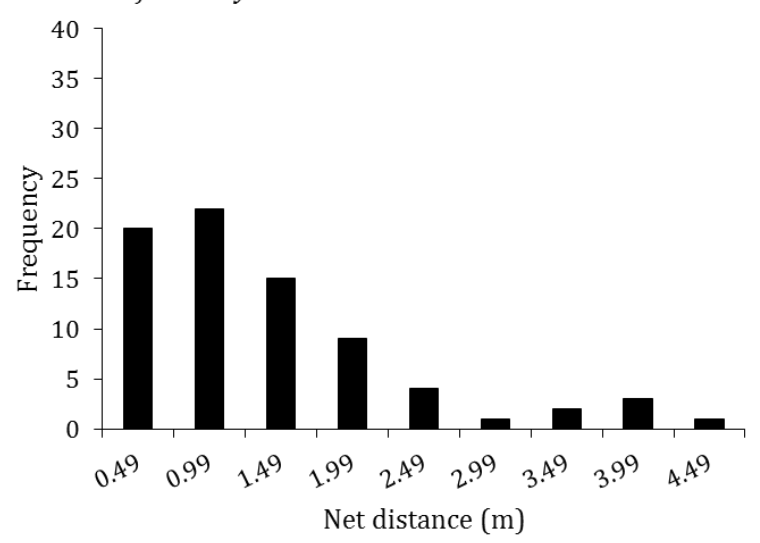

c) L. pakeka

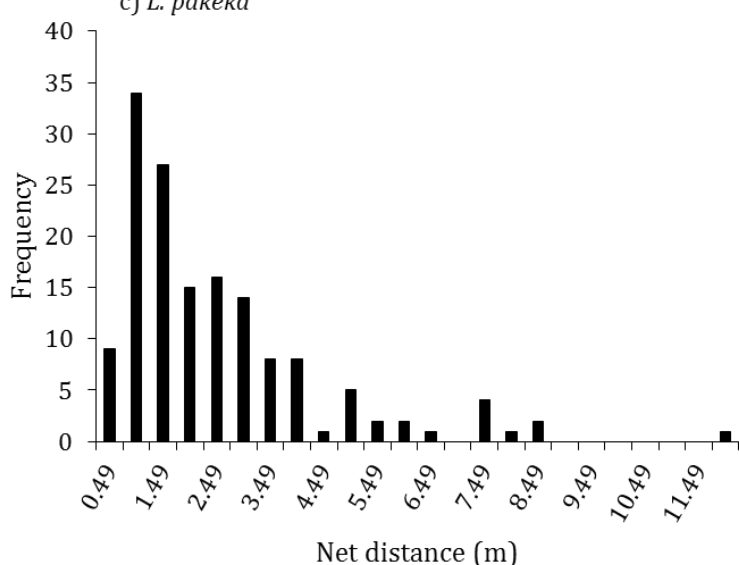

b) L. archeyi

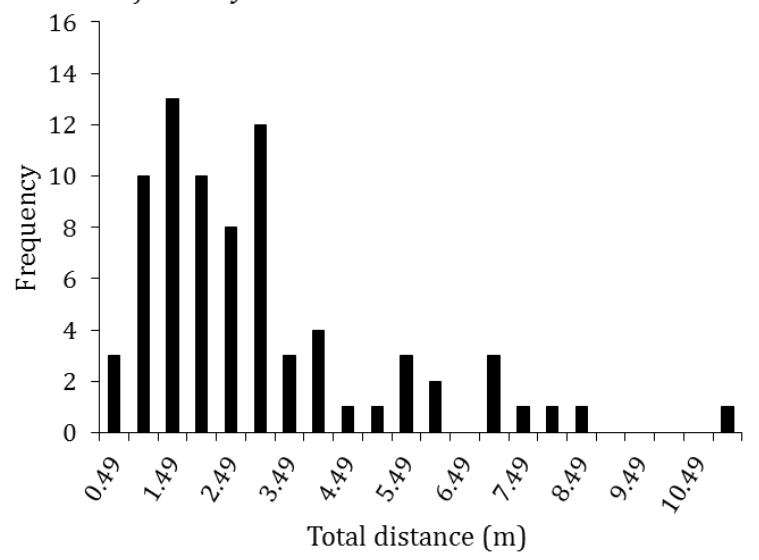

d) L. pakeka

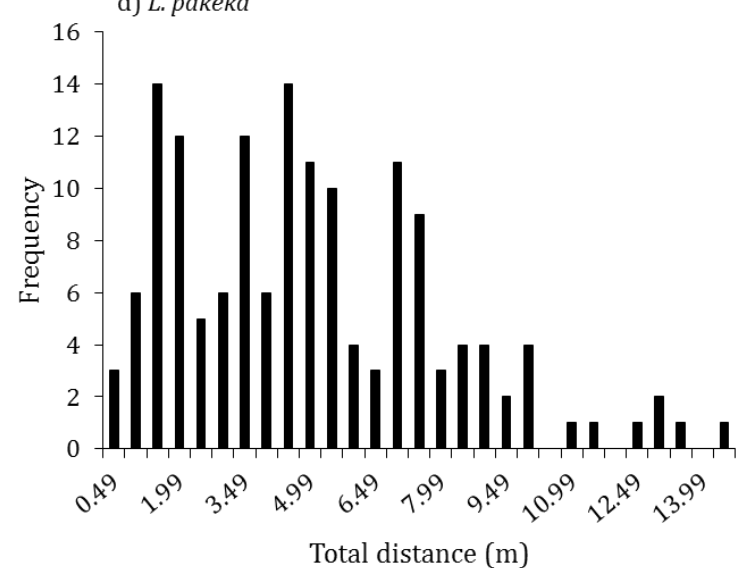

Figure 2: Frequency distribution of the net and total distances moved by L. archeyi and L. pakeka. 


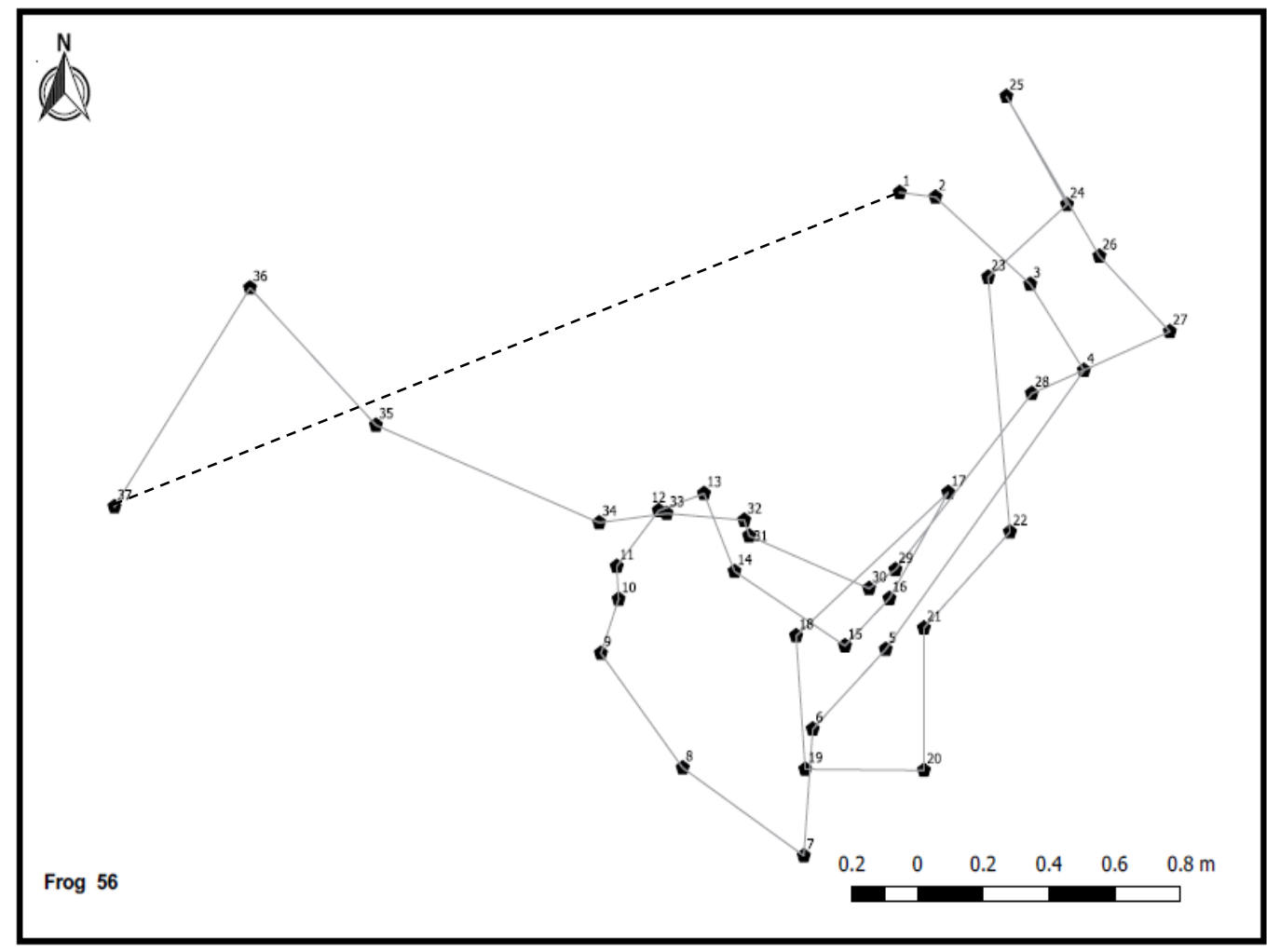

Figure 3: Movement path of a L. pakeka (no. 56) tracked on 18 November 2013 which moved the most (total distance) and the furthest (net distance) of all the tracked frogs from the two species. Dashed line shows the net distance moved. Figure was obtained using the ArcGIS Desktop 10.4.1 software.

The mean total and net distances moved varied significantly between species, with L. pakeka moving more (total distance) and further (net distance) than L. archeyi during their activity period (net distance: $\mathrm{t}=4.61, P=<0.001$; total distance: $\mathrm{t}=4.77, P=<0.001$; Table 1). Comparing those L. archeyi and L. pakeka of similar size, however, the mean net and total distances moved did not significantly differ between the two species $(\mathrm{H}=3.24, P=0.08 ; \mathrm{H}=0.57, P=0.45$, respectively). Season did not have an effect on distances moved for either species (net distance: $t$ $=0.20, P=0.84$ and total distance: $\mathrm{t}=-0.41, P=0.68$ ). Path linearity (ratio between net and total distance) did not differ between species or seasons (between species: $\mathrm{z}=0.13, P=0.89$; between seasons: $\mathrm{z}=0.48, P=0.63$; species $\mathrm{x}$ season: $\mathrm{z}=-0.20, P=0.84$ ). The compass bearings of the paths of L. pakeka and L. archeyi were randomly distributed both in the breeding and nonbreeding seasons (L. pakeka: breeding season $Z=0.15, P=0.14$; non-breeding season $Z=0.19, P$ 
$=0.11 ;$ L. archeyi: breeding season $Z=0.16, P=0.28$; non-breeding season $Z=0.31, P=0.10 ;$ Fig 4). Similarly, no directionality in movements was observed for L. pakeka with two and three recaptures ( $n=22, n=4$, respectively; Rayleigh's tests, all $P>0.05)$, or L. archeyi recaptured twice (n = 5; Rayleigh's tests, all $P>0.05$ ).

Table 1: Summary of movement patterns of Leiopelma archeyi and L. pakeka during their activity period; including mean, minimum ( $\mathrm{min}$ ) and maximum ( $\max$ ) total and net distances moved, and path linearity.

\begin{tabular}{|c|c|c|c|c|c|c|c|}
\hline \multirow[b]{2}{*}{ Species } & \multicolumn{3}{|c|}{ Net distance $(\mathrm{m})$} & \multicolumn{3}{|c|}{ Total distance $(\mathrm{m})$} & \multirow{2}{*}{$\begin{array}{l}\text { Path linearity } \\
\text { Mean } \pm \text { SE }\end{array}$} \\
\hline & Mean \pm SE & Min & Max & Mean \pm SE & Min & Max & \\
\hline L. archeyi & $1.34 \pm 0.10$ & 0.05 & 4.44 & $2.88 \pm 0.24$ & 0.21 & 10.56 & $0.50 \pm 0.03$ \\
\hline L. pakeka & $2.91 \pm 0.16$ & 0.05 & 11.80 & $4.75 \pm 0.25$ & 0.22 & 14.31 & $0.53 \pm 0.02$ \\
\hline
\end{tabular}


a) L archeyi breeding season

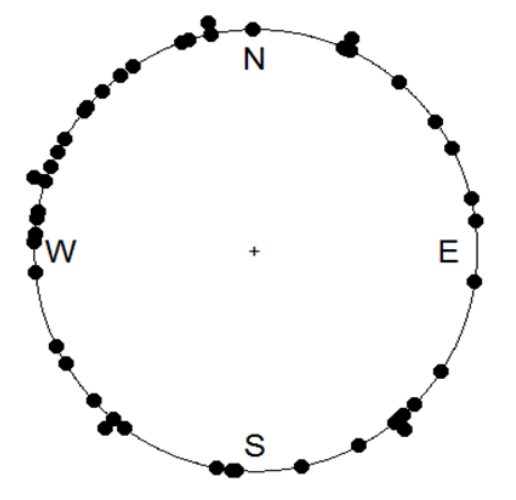

a) L. pakeka breeding season

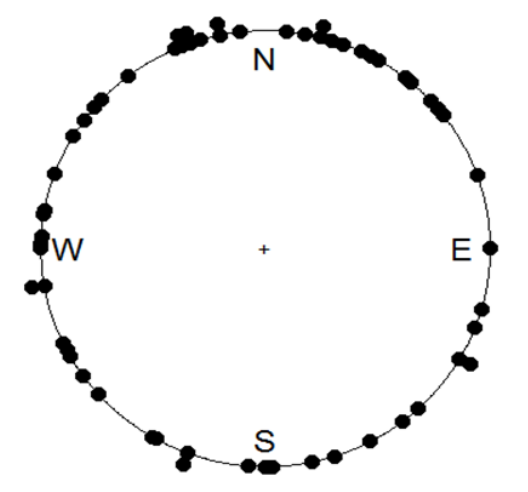

d) L. archeyi non-breeding season

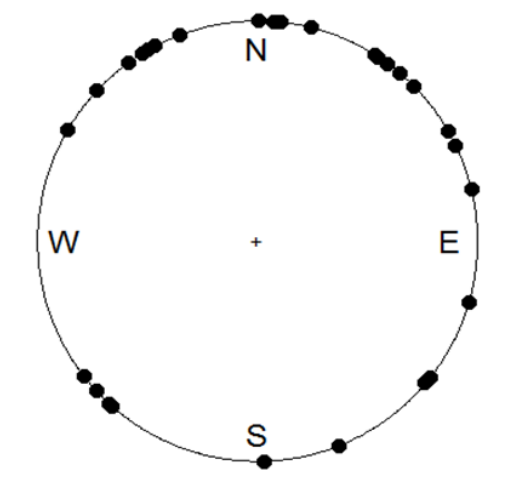

b) L. pakeka non-breeding season

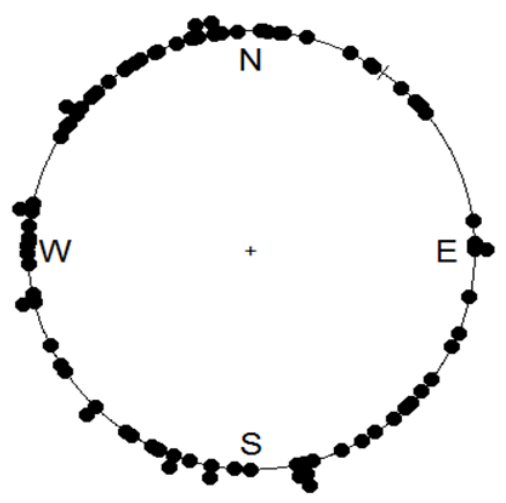

Figure 4: Compass bearings for the paths of L. archeyi and L. pakeka during the breeding and nonbreeding seasons.

\subsubsection{Factors affecting movement}

The best models affecting the net and total distances moved by L. archeyi had weights of 0.42 and 0.54 , respectively, and included SVL and minimum temperature and relative humidity during the night (Table 2). For L. pakeka, the best model for the net distance moved had a weight of 0.18 and for the total distance a weight of 0.33 , and included SVL and minimum temperature during the night (Table 3). 
Table 2: Candidate models for the relationship between intrinsic and extrinsic factors and the distance moved by L. archeyi in Whareorino Forest. Interpretable models have Akaike weights $>10 \%$ relative to the model with best fit.

\begin{tabular}{lllllll}
\hline Distance & Model & $\mathrm{K}^{\mathrm{a}}$ & $\mathrm{AIC}_{\mathrm{c}}$ & $\Delta \mathrm{AIC}_{\mathrm{c}}$ & Likelihood & $w_{i}$ \\
\hline Net & SVL + MINTN + MINRHN & 6 & 198.79 & 0.00 & 1.00 & 0.42 \\
SVL + MINTN & 5 & 199.43 & 0.64 & 0.73 & 0.31 \\
SVL & 4 & 200.42 & 1.63 & 0.44 & 0.19 \\
SVL + MINRHN & 5 & 202.09 & 3.30 & 0.19 & 0.08 \\
MINTN & 4 & 208.85 & 10.06 & 0.01 & 0.00 \\
MINRHN + MINTN & 5 & 209.74 & 10.95 & 0.00 & 0.00 \\
Intercept & 3 & 210.40 & 11.61 & 0.00 & 0.00 \\
MINRHN & 4 & 212.55 & 13.76 & 0.00 & 0.00
\end{tabular}

Total

$\begin{array}{lccccc}\text { SVL } & 4 & 173.19 & 0.00 & 1.00 & 0.54 \\ \text { SVL + MINRHN } & 5 & 175.22 & 2.04 & 0.36 & 0.19 \\ \text { SVL + MINTN } & 5 & 175.26 & 2.07 & 0.35 & 0.19 \\ \text { SVL + MINTN + MINRHN } & 6 & 177.02 & 3.83 & 0.15 & 0.08 \\ \text { Intercept } & 3 & 185.74 & 12.55 & 0.00 & 0.00 \\ \text { MINTN } & 4 & 187.31 & 14.12 & 0.00 & 0.00 \\ \text { MINRHN } & 4 & 187.94 & 14.75 & 0.00 & 0.00 \\ \text { MINRHN + MINTN } & 5 & 189.53 & 16.34 & 0.00 & 0.00\end{array}$

a Indicates number of parameters (including error term and intercept)

SVL=snout-vent length, MINTN=minimum temperature during night and MINRHN=minimum relative humidity during night 
Table 3: Candidate models for the relationship between intrinsic and extrinsic factors and distances moved by L. pakeka on Maud Island. Interpretable models have Akaike weights $>10 \%$ relative to the model with best fit.

\begin{tabular}{|c|c|c|c|c|c|c|}
\hline Distance & Model & $\mathrm{K}^{\mathrm{a}}$ & $\mathrm{AIC}_{\mathrm{c}}$ & $\Delta \mathrm{AIC}_{\mathrm{c}}$ & Likelihood & $w_{i}$ \\
\hline \multirow[t]{16}{*}{ Net } & SVL + MINTN & 5 & 398.54 & 0.00 & 1.00 & 0.18 \\
\hline & MINTN & 4 & 398.74 & 0.20 & 0.90 & 0.17 \\
\hline & SVL & 4 & 399.92 & 1.38 & 0.50 & 0.09 \\
\hline & SVL + MAXTN & 5 & 400.26 & 1.72 & 0.42 & 0.08 \\
\hline & SVL + MINTN + MAXTN & 6 & 400.65 & 2.11 & 0.35 & 0.06 \\
\hline & SVL + MINTN + MAXRHN & 6 & 400.67 & 2.13 & 0.34 & 0.06 \\
\hline & MINTN + MAXTN & 5 & 400.80 & 2.25 & 0.32 & 0.06 \\
\hline & MINTN + MAXRHN & 5 & 400.80 & 2.26 & 0.32 & 0.06 \\
\hline & MAXTN & 4 & 401.01 & 2.46 & 0.29 & 0.05 \\
\hline & Intercept & 3 & 401.41 & 2.87 & 0.24 & 0.04 \\
\hline & SVL + MAXRHN & 5 & 402.03 & 3.48 & 0.18 & 0.03 \\
\hline & SVL + MAXTN + MAXRHN & 6 & 402.21 & 3.67 & 0.16 & 0.03 \\
\hline & MAXTN + MAXRHN & 5 & 402.77 & 4.22 & 0.12 & 0.02 \\
\hline & SVL + MINTN + MAXTN + MAXRHN & 7 & 402.78 & 4.24 & 0.12 & 0.02 \\
\hline & MINTN + MAXTN + MAXRHN & 6 & 402.82 & 4.28 & 0.12 & 0.02 \\
\hline & MAXRHN & 4 & 403.44 & 4.90 & 0.09 & 0.02 \\
\hline \multicolumn{7}{|l|}{ Total } \\
\hline & MINTN & 4 & 357.13 & 0.00 & 1.00 & 0.33 \\
\hline & MINTN + MAXRHN & 5 & 358.70 & 1.57 & 0.46 & 0.15 \\
\hline & SVL + MINTN & 5 & 359.03 & 1.90 & 0.39 & 0.13 \\
\hline & MINTN + MAXTN & 5 & 359.21 & 2.08 & 0.35 & 0.12 \\
\hline & SVL + MINTN + MAXRHN & 6 & 360.58 & 3.46 & 0.18 & 0.06 \\
\hline & MINTN + MAXTN + MAXRHN & 6 & 360.86 & 3.73 & 0.15 & 0.05 \\
\hline & SVL + MINTN + MAXTN & 6 & 361.14 & 4.02 & 0.13 & 0.04 \\
\hline & MAXTN & 4 & 361.73 & 4.60 & 0.10 & 0.03 \\
\hline & SVL + MINTN + MAXTN + MAXRHN & 7 & 362.78 & 5.65 & 0.06 & 0.02 \\
\hline & SVL + MAXTN & 5 & 363.25 & 6.12 & 0.05 & 0.02 \\
\hline & Intercept & 3 & 363.61 & 6.48 & 0.04 & 0.01 \\
\hline & MAXTN + MAXRHN & 5 & 363.76 & 6.63 & 0.04 & 0.01 \\
\hline & SVL & 4 & 364.63 & 7.50 & 0.02 & 0.01 \\
\hline & SVL + MAXTN + MAXRHN & 6 & 365.25 & 8.12 & 0.02 & 0.01 \\
\hline & MAXRHN & 4 & 365.31 & 8.18 & 0.02 & 0.01 \\
\hline & SVL + MAXRHN & 5 & 366.26 & 9.13 & 0.01 & 0.00 \\
\hline
\end{tabular}

a Indicates number of parameters (including error term and intercept)

SVL=snout-vent length, MINTN=minimum temperature during night, MINRHN=minimum relative humidity during night, MAXTN=maximum temperature during night, and MAXRHN = maximum relative humidity during the night 
For L. archeyi, model averaging showed that the net and total distances moved were affected by SVL $\left(w_{i}=0.91, w_{i}=0.92\right.$, respectively; Table 4$)$, with larger frogs moving further (net distance) and more (total distance) during their activity period than smaller frogs (Fig. 5). For L. pakeka, total distances moved were affected by the minimum temperature during the night (MINTN: $w_{i}=$ 0.73; Table3), with frogs moving more as the minimum temperature during the night increased (Fig. 5). The net distances moved by this species were not affected by either of the highest weighted factors (Table 4).

Table 4: Cumulative Akaike weights $\left(w_{i}\right)$, averaged parameter estimates and $85 \%$ confidence intervals (CI) for the top predictive parameters of net and total distances moved by L. archeyi in Whareorino Forest and L. pakeka on Maud Island.

\begin{tabular}{|c|c|c|c|c|c|c|}
\hline \multirow[b]{2}{*}{ Species } & \multirow[b]{2}{*}{ Distance } & \multirow[b]{2}{*}{ Parameter } & \multirow[b]{2}{*}{ Estimate } & \multicolumn{2}{|c|}{$85 \% \mathrm{CI}$} & \multirow[b]{2}{*}{$w_{i}$} \\
\hline & & & & Lower & Upper & \\
\hline \multicolumn{7}{|c|}{ L. archeyi } \\
\hline & Net & SVL & 0.06 & 0.04 & 0.09 & 0.91 \\
\hline & & MINTN & $0.08^{a}$ & 0.00 & 0.13 & 0.73 \\
\hline & & MINRHN & $0.01^{\mathrm{a}}$ & 0.00 & 0.01 & 0.42 \\
\hline & Total & SVL & 0.06 & 0.04 & 0.08 & 0.92 \\
\hline & & MINTN & $0.02^{\mathrm{a}}$ & -0.03 & 0.07 & 0.19 \\
\hline & & MINRHN & $0.0^{\mathrm{a}}$ & 0.00 & 0.01 & 0.19 \\
\hline \multicolumn{7}{|c|}{ L. pakeka } \\
\hline & Net & MINTN & $0.08^{a}$ & 0.00 & 0.14 & 0.35 \\
\hline & & SVL & $0.03^{a}$ & 0.00 & 0.07 & 0.18 \\
\hline & Total & MINTN & 0.1 & 0.05 & 0.15 & 0.73 \\
\hline & & SVL & $0.01^{\mathrm{a}}$ & -0.02 & 0.04 & 0.13 \\
\hline & & MAXRHN & $0.0^{\mathrm{a}}$ & 0.00 & 0.01 & 0.15 \\
\hline & & MAXTN & $0.01^{\mathrm{a}}$ & -0.05 & 0.08 & 0.12 \\
\hline
\end{tabular}

a Parameter estimates with $85 \% \mathrm{CI}$ including zero

SVL=snout-vent length, MINTN=minimum temperature during night, MINRHN=minimum relative humidity during night, MAXTN=maximum temperature during night, and MAXRHN = maximum relative humidity during the night 

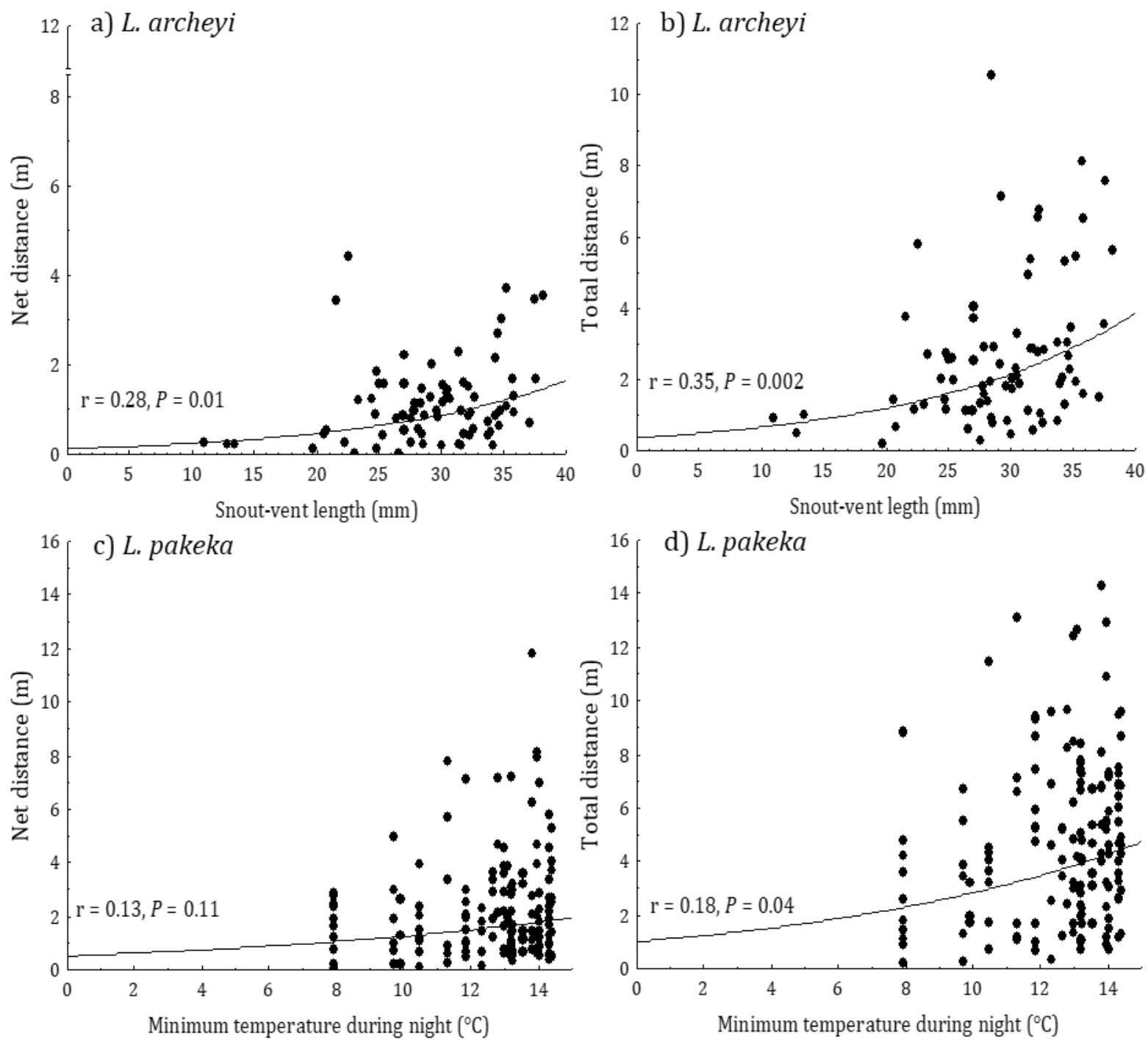

Figure 5: Relationship between net and total distances moved by L. archeyi and frogs' SVL, and net and total distance moved by L. pakeka and the minimum temperature during the night.

Rain during the tracking night (presence/absence) did not have a significant effect on the total or net distances moved by either species (L. pakeka: net distance: $\mathrm{R}^{2}=0.003, P=0.52$; total distance $\mathrm{R}^{2}=0.017, P=0.83 ;$ L. archeyi: net distance: $\mathrm{R}^{2}=0.039, P=0.11 ;$ total distance: $\mathrm{R}^{2}=0.0002, P=$ 0.92). Similarly, rain during the previous $24 \mathrm{~h}$ did not have a significant effect on the movement patterns of either species (L. pakeka: net distance: $\mathrm{R}^{2}=0.005, P=0.39$; total distance $\mathrm{R}^{2}=0.0008$, $P=0.72 ;$ L. archeyi: net distance: $\mathrm{R}^{2}=0.001, P=0.99$; total distance: $\mathrm{R}^{2}=0.015, P=0.29$ ). 


\subsection{Discussion}

Both species showed bimodal activity patterns with peaks of movement during the first hours of the night and approaching dawn. Throughout their activity period, frogs of each species showed relatively sedentary movement behaviour as during the non-peak movement times (e.g. between 5 and $8 \mathrm{~h}$ after sunset) usually less than $50 \%$ of frogs moved per hour. L. pakeka moved more (total distance) and further (net distance) than L. archeyi during their activity periods, but there were no differences in the distances moved between frogs of the two species with similar body length. Season had no effect on distances moved for either species. The association of L.archeyi SVL and the net and total distances moved suggests that larger frogs tend to be more active, moving more and further than smaller frogs. The total distance moved by L. pakeka was correlated with the minimum temperature during the night; that is, increased movement was associated with increased temperature. The net bearing of the movement paths of both species were randomly distributed suggesting that frogs did not have a particular orientation during movement. The same pattern was found for frogs with two and three recaptures reflecting a random movement pattern at an individual level.

Leiopelma archeyi showed a more pronounced bimodal pattern of activity than L. pakeka and a longer activity period, with L. archeyi being active for up to two hours after sunrise. L. pakeka ceased activity soon after sunrise and on the breeding and non-breeding seasons of 2015, one hour after sunrise. The presence of L. archeyi on the surface of the forest or in higher vegetation after daybreak is similar to previously reported (Cree 1989, Bell 1996). The longer activity hours of L. archeyi could be partially explained by the structure of their retinal ultrastructure which facilitates nocturnal vision but it is less pronounced in this species compared to the other extant Leiopelma species (Meyer-Rochow and Pehlemann 1990). During the non-breeding season both species showed longer activity periods which could be due to the longer nights compared to the breeding season. L. archeyi was active up to $15 \mathrm{~h}$ after sunset, four hours more than during the breeding season, and L. pakeka up to $13 \mathrm{~h}$ after sunset, between three and four hours more than 
during the breeding season. These results support previous studies that have shown Leiopelma species to be highly sedentary (Bell 1994, Bell et al. 2004b, Bell and Moore 2015, Bell and Pledger 2010, Reilly et al. 2015). Results may also reflect the sit-and-wait predatory strategy for obtaining food (Bell 1985a, Reilly et al. 2015).

The mean net and total distances moved were greater for L. pakeka than for L. archeyi with individuals of the former moving twice as far and almost twice more often, indicating L. pakeka are more mobile than L. archeyi. Individuals of similar size of the two species showed no significant differences in the total or net distances moved, which suggests that species-specific size differences could be responsible for this observed movement behaviour: L. archeyi seems to moves less than L. pakeka because of its smaller size. Newman (1990) recorded median distances moved between successive captures by L. pakeka of $0.9 \mathrm{~m}$ to $2.2 \mathrm{~m}$, with maxima of $5.1 \mathrm{~m}$ to 7.2 m. Cree (1989) found that a population of L. archeyi in the Coromandel Peninsula, New Zealand, moved a maximum of $3 \mathrm{~m}$ between the retreat site and perch. The greater distances reported here may reflect the different methodologies among studies; Newman (1990) and Cree (1989) relied on mark-recapture frog surveys within a limited search area $(10 \times 10 \mathrm{~m}$ and $10 \times 8 \mathrm{~m}$, respectively) rather than following individuals throughout the night.

I started tracking frogs once they were out on the surface. Therefore, I cannot confirm whether frogs went back to the same retreat sites as they emerged from at the start of the night, a behaviour that might be assumed from the earlier studies indicating extremely small home ranges. The estimated home range size of L. pakeka adults was $26.7 \pm 2.2 \mathrm{~m}^{2}$ (mean minimum convex polygon area \pm SE) over a period of decades, and settled adult frogs only shifted their range centroids by 1.3 m every 10 years (Bell and Moore 2015). However, the net distances moved by frogs could provide an indication of how far frogs are moving in relation to their emergence place and whether they reuse retreats. L. archeyi are more likely to be choosing retreat sites closer to their place of emergence than L. pakeka as most L. archeyi stayed within of 0.5 to $1.5 \mathrm{~m}$ of the place of capture with a maximum of $4.5 \mathrm{~m}$, whereas most L. pakeka extended their 
range to $3 \mathrm{~m}$ reaching up to $11.8 \mathrm{~m}$. Additionally, I hypothesise that the home range of $L$. archeyi, to date unquantified, could be smaller than that of L. pakeka.

Path linearity is a measure of the efficiency of a species' orientation mechanism. A value of 1 suggests a very efficient orientation with a species having the ability to move in a straight line from the origin to end point, whereas a value of 0 (zero) suggests a less efficient orientation with a species spending more time moving around before arriving to the end point (Batschelet 1981). Both species in this study had a path linearity of 0.5 suggesting an intermediate orientation efficiency, which could reflect species searching for resources during movement. However, it could also be a result of the physical structure of the environment or conspecifics or predator presence as these can weaken the path linearity value by forcing individuals to take detours before reaching the end point (Benhamou 2004). Similarly, there was no directionality of movement in either species or over repeated captures of individuals suggesting frogs move in a random fashion, perhaps in search of food, shelter or mates. Directionality in the movement of $L$. pakeka has been observed in translocated frogs, showing a tendency to move either uphill or downhill towards areas of better habitat quality (Dewhurst 2003, Germano 2006).

Larger L. archeyi moved more often and further during their activity period than smaller frogs, which is to be expected considering that L. pakeka moves more and further and is larger than $L$. archeyi. The relationship between distances moved and frogs' SVL was not evident in L. pakeka, but this may be due to the lower number of small frogs sampled in this species compared with $L$. archeyi ( 2 vs 15, respectively). Juveniles may not have prior knowledge of resource distribution or optimal movement patterns (Osbourn et al. 2014), so they may be restricting their movements to known areas. This hypothesis is supported by evidence of most small tracked frogs (L. archeyi sub-adults up to $24 \mathrm{~mm}$ snout vent length) which restricted their movements to an area close to their capture location (pers. obs.). This may seem to be counter intuitive as usually juveniles are thought to be the main dispersers in amphibian populations (Duellman and Trueb 1994). However, I only assessed the fine-scale movements of frogs (i.e. tracking of frogs for one night per 
individual), which is not an appropriate methodology to measure dispersal. By increasing the time frame per individual and over more seasonal time frames, this expected pattern of juveniles as the main dispersers could be investigated.

Amphibians are more susceptible to desiccation because of their permeable skin, and therefore prefer moist and cooler environments (Sinsch 1990, Duellman and Trueb 1994). Humidity and precipitation have been shown to have positive effects on the distances moved by different amphibian species (Woolbright 1985, Sinsch 1990, Seebacher and Alford 2002, Greenberg and Tanner 2005, Roe and Grayson 2008). In this study, only the total distances moved by L. pakeka were influenced by temperature (minimum temperature during the night), and no effects of relative humidity or precipitation were observed on the movements of either species. In previous studies, emergence of L. pakeka and L. archeyi was significantly correlated with relative humidity, temperature and/or precipitation (e.g. Bell 1978, Cree 1989, Newman 1990, Bell 1995). The lack of significance of factors like humidity and precipitation on movement behaviour in this study may be because tolerance limits of individuals were not reached (Sinsch 1990), particularly regarding humidity, and the lack of power to evaluate effects of precipitation due to the low rainfall occurrence.

To my knowledge this is the first study quantifying fine-scale movement patterns of both $L$. pakeka and L. archeyi during their activity period in their natural habitats. I provide information regarding the nightly movements of these species showing that they move more and further than previously expected based on earlier mark-recapture studies. An understanding of movement behaviour in Leiopelma, along with information on their microhabitat use, will inform husbandry requirements for captive breeding or rearing and selection of translocation sites with the appropriate size and suitable habitat. 


\section{Chapter 4 \\ Microhabitat use of Leiopelma archeyi and L. pakeka in their natural habitats}

\subsection{Introduction}

By selecting microhabitats (the habitat an organism experiences; Huey 1991) that favour their physiological performance, individuals can perform vital activities, such as feeding, locomotion and predator avoidance, that directly influence their fitness, allowing their growth, reproduction and survival (Huey 1991, Morris 2003, Wells 2007). These effects on individual fitness can ultimately influence the spatial and temporal dynamics of populations and their long-term persistence (Huey 1991, Lima and Zollner 1996, Morris 2003). Microhabitat selection is the process by which individuals preferentially use a non-random set of available habitats (Morris 2003). A species microhabitat provides resources that are necessary for its survival, such as food, breeding sites and shelter (Jaeger 1978, Graeter 2005, Baldwin et al. 2006, Garner 2006, Indermaur et al. 2008, Browne and Paszkowski 2014, Garnham et al. 2015).

For all aspects of their ecology, ectotherms are influenced by the environmental conditions (e.g. temperature) and therefore, they rely on thermoregulation to regulate their body temperature and to maintain their vital bodily processes (Huey 1991, Wells 2007). Microhabitat selection is an important form of behavioural thermoregulation and a key component of their performance (Huey 1991, Domingos et al. 2015). Due to their permeable skin, amphibians are susceptible to desiccation, and many species rely on changes in behaviour to alter rates of heat loss and to regulate evaporative water loss as they lack morphological or physiological adaptations to offset these effects (Duellman and Trueb 1994, Wells 2007). Hence, amphibians must select microhabitats that provide suitable thermal conditions along with a reduction of evaporation rates to be able to regulate their physiological performance (Tracy 1976, Duellman and Trueb 1994, Wells 2007). In this sense, humid or cooler environments are preferred by amphibians (e.g. 
Seebacher and Alford 2002, Baldwin et al. 2006, Baczynski 2013, Domingos et al. 2015, Garnham et al. 2105, Farallo and Miles 2016). For nocturnal species, in particular, microhabitat selection is very relevant as the absence of solar radiation during the night offers limited opportunities for other types of behavioural thermoregulation (e.g. postural changes; Kearney and Predavec 2000, Farallo and Miles 2016).

In addition to the importance for physiological requirements of amphibians, several studies have investigated the consequences of microhabitat selection on the individual's fitness, showing its effects on important behaviours, such as predation avoidance, reproduction and movement (e.g. Morey 1990, Birchfield and Deters 2005, Graeter 2005, Skidds et al. 2007, Garner 2012). For example, Morey (1990) found that the polymorphic Pacific treefrog, Pseudacris regilla, selected matching microhabitat background colours to their dorsal body colours when in the presence of a visual predator, likely enhancing camouflage and reducing the risk of predation, Garner (2006) observed that the preference by the Great Basin spadefoot toad, Spea intermontata, for areas cleared of vegetation within the forest may be due to a higher ease of movement, and Resetarits and Wilbur (1989) found that female tree frog, Hyla chrysoscelis, selected oviposition sites that favoured offspring survival, maximizing its reproductive success.

Leiopelma archeyi and L. pakeka are terrestrial, cryptically-coloured and burrowing species that retreat under rocks and vegetation during daytime (Bell 1978, Newman 1990, Chapter 5). They are nocturnal species, with L. archeyi showing activity until a few hours after daybreak (Bell 1978, Cree 1989, Chapter 3). There is no consistently observable sexual dimorphism in either of these species, apart from body size; females grow larger (Bell 1978). L. pakeka adult females attain snout-vent lengths (SVL) greater than $40 \mathrm{~mm}$, while L. archeyi adults exceed $24 \mathrm{~mm}$ compared with $34-40 \mathrm{~mm}$ in males or younger females and $<34 \mathrm{~mm}$ in sub-adults (Bell 1978, Newman 1990, Bell et al. 2004b). In L. archeyi, snout-vent lengths of adult females exceed $31 \mathrm{~mm}$, with 25 - $31 \mathrm{~mm}$ in males or young females and $<25 \mathrm{~mm}$ in sub-adults (Bell 1978). Both species are classified as threatened nationally and internationally (Newman et al. 2010, 2013, Bishop et al. 
2013, IUCN 2016). L. archeyi has been found to co-occur with introduced mammalian predators, such as rats and mice in Whareorino Forest and in the Coromandel Ranges (Bell 1978, Worthy 1987, Thurley and Bell 1994), the only natural population of L. pakeka is confined to a 16 ha forest remnant on Maud Island, a mammalian predator-free island (occasional incursions of mustelids occur and a house mouse incursion was first reported in 2013, though apparently the mice have since been eradicated), in the Marlborough Sounds (Bell 1978, Bell and Pledger 2010, Bishop et al. 2013). Habitat associations have been described for these species through mark-recapture studies and surveys (Bell 1978, Cree 1986, Thurley and Bell 1994, Bell 1995). However, this is a coarse representation of their microhabitat use as only one record of a capture location is collected per night. The study of species microhabitat use is important for the conservation of declining species as it gives insights into the habitat features that are essential for species persistence (Eggert 2002, Green 2003, Lemckert 2004, Birchfield and Deters 2005, Browne and Paszkowski 2014). Therefore, it is necessary to investigate microhabitat selection by both Leiopelma species at a finer scale, including the factors that may be affecting this selection. This information will provide a more detailed description of the species-specific habitat requirements, allowing improvement in the conservation management of these two species.

\subsubsection{Study aim and research questions}

I aimed to investigate the microhabitat selection of two terrestrial Leiopelma species, L. archeyi and L. pakeka in their natural environments during their entire activity period when on the surface. I asked: 1) Does microhabitat use by each species differ from microhabitat availability? 2) For those microhabitats they have in common, does microhabitat use differ between species? and 3) Is microhabitat selection associated with intrinsic (SVL) or extrinsic factors (temperature or season) in each species? 


\subsection{Methods}

\subsubsection{Study sites and visits}

Microhabitat use by L. archeyi was investigated in Whareorino Forest (38 $22^{\prime} \mathrm{S}, 174^{\circ} 47^{\prime} \mathrm{E}$ ), Northern King Country, New Zealand, inside an area of 45 x 28 m (tracking area) located within a 300-ha area where an on-going rat control programme has been carried out since 2003 (Haigh et al. 2007, for more details see Chapter 3). Mean nightly temperatures sampled during the study period ranged from $8.8-13.8{ }^{\circ} \mathrm{C}$ and mean nightly relative humidity ranged from $74.5-95.3 \%$

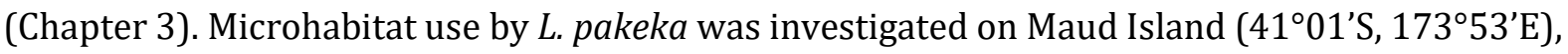
Marlborough Sounds, New Zealand, considered to be a predator-free island (but see introduction), inside an area of $45 \times 28 \mathrm{~m}$ (tracking area) located in the lower slopes of a 16 ha remnant of broad-leaved forest growth (for more details see Chapter 3). Mean nightly temperatures sampled during the study period ranged from $12.9-13.5{ }^{\circ} \mathrm{C}$ and mean nightly relative humidity ranged from $75.6-92.4 \%$ (Chapter 3 ).

Over November 2014 - November 2015 there were three field trips to Whareorino Forest covering the breeding (November [n=2]) and non-breeding (March [n=1]) seasons of L.archeyi there, and over December 2013 - December 2015 five field trips to Maud Island covering the breeding (November/December [n=3]) and non-breeding (March/April [n=2]) seasons of $L$. pakeka. For this study, the breeding season for both species has been considered as the time when oviposition has been observed; that is, Austral spring-early summer (for more details see Chapter $3)$. 


\subsubsection{Tracking of frogs}

All frogs used in this study were caught opportunistically at night in the field. Frogs were captured by hand, quickly measured (snout-vent length) and dorsally photographed for later identification. Non-toxic fluorescent powders were applied to the frogs' bodies in the field. After measurements and powder application, frogs were immediately released at their capture location. After every 30 minutes, the pigmented trail left behind by the frogs as they moved was checked using a portable UV light. The new location of the frog was marked with wooden pegs. Frogs were tracked throughout the night and tracking ended when frogs sought a final retreat site (for more details see Chapter 3).

\subsubsection{Observed microhabitat use}

For each pigmented trail, I recorded as the microhabitat type the substrate that was in direct contact with the frog at each new location, including the final retreat site. Six microhabitat types were categorized for both L. archeyi and L. pakeka (Table 1). Trees in Whareorino Forest were covered by Sphagnum moss whereas on Maud Island there was no such cover. At each new location, I also recorded whether that location provided cover to the frog (i.e. frog not easily visible) either by the microhabitat the frog was in contact with (e.g. a frog inside a pile of rocks) or by other microhabitats in the vicinity (e.g. a frog on top of soil covered by a plant). When frogs were found on top of trees or ferns I recorded the height from ground level to the nearest centimetre. 
Table 1: Microhabitat types used during movement by L. archeyi in Whareorino Forest (WF) and L. pakeka on Maud Island (MI).

\begin{tabular}{lll}
\hline Microhabitat type & Location & Description \\
\hline Leaf litter & WF $/$ MI & Dead plant material (e.g. leaves, twigs) \\
Soil & WF/MI & Exposed soil \\
Rock & WF/MI & Rocks of all sizes \\
Woody debris & WF/MI & Fallen woody material not attached to a tree (e.g. branches, \\
Tree & WF/MI & All parts of the tree (i.e. roots, trunk), including tree ferns \\
Fern & WF & Ferns of all sizes (e.g. crown fern Blechnum discolor) \\
Plant & MI & Any small plant or seedlings \\
\hline
\end{tabular}

\subsubsection{Microhabitat availability}

To assess microhabitat availability at each site I used the method of Smith et al. (2003). Inside each tracking area I set up a $45 \mathrm{~m}$ transect every $2 \mathrm{~m}$ obtaining a total of 15 parallel transects. I walked along each transect and every 10 paces a $30 \mathrm{~cm}$ ruler was dropped and the microhabitat type at both ends of the ruler was recorded.

\subsubsection{Abiotic measurements}

As microclimates influence the physiological capacities of organisms (Huey 1991), I measured abiotic conditions at the microhabitat level. I established four main microhabitat types used by $L$. pakeka using information gathered after the first field visit to Maud Island (2013): leaf litter, soil, rocks, and woody debris. In the case of L. archeyi, due to the lower number of field visits available in Whareorino Forest, the main microhabitat types were established according to their abundance: trees, soil, woody debris, rocks, and leaf litter. After the first field visit (March 2014) I confirmed that those microhabitat types were in fact the most used ones so I maintained this selection. I measured the temperature during the entire tracking period of each main microhabitat type every 30 minutes using a data logger (HOBO Pro v2) with the sensor placed in 
direct contact with the microhabitat itself (i.e. surface of microhabitat). Attempts were made to measure relative humidity, but the data loggers failed to record it consistently. Due to the increased use of ferns by L. archeyi and trees by L. pakeka, I also recorded temperature and humidity for these microhabitats from November 2015 and December 2014, respectively.

\subsubsection{Data analyses}

To assess whether microhabitat use differed from microhabitat availability I obtained the observed frequencies of microhabitat use per season by adding the number of times a frog was located in a given microhabitat at each new location. I compared the observed frequencies of microhabitat use with the microhabitat availability (i.e. expected frequencies) using $G$ tests of goodness-of-fit with William's correction (Sokal and Rohlf 1995). I carried out single-degree-offreedom G tests with Bonferroni corrections to determine which microhabitat type use differed from availability (Sokal and Rohlf 1995). I compared the use of shared microhabitat types between both species (i.e. microhabitats used by L. archeyi and L. pakeka) to assess whether microhabitat use differed between species. I qualitatively compared the proportion of use of each of these microhabitats between both species against the microhabitat availability (expected proportions) in their respective locations.

I carried out separate non-parametric Kruskal-Wallis tests per species to assess whether the temperatures of a given microhabitat differed between seasons. To assess whether microhabitat types differed among each other within a given season I also carried out separate non-parametric Kruskal-Wallis tests with post-hoc multiple comparison of mean ranks per species and per season.

To establish whether extrinsic (temperature and season) or intrinsic (SVL) variables were associated with microhabitat use, I used generalized linear mixed models (GLMMs) with binomial distribution for each microhabitat type, applying a one-vs-rest classification scoring the use of a 
given microhabitat as 1 and the use of the rest as 0 (Arppe 2008). Individual frogs were included as a random effect to account for repeated measurements and the explanatory variables as fixed effects. The temperature considered here is the temperature of a given microhabitat at the moment an individual frog was found in contact with it. As there are uncertainties associated with the sexing of frogs using their size (Tocher et al. 2006, Germano et al. 2011), sex was not included as an intrinsic variable. From the main microhabitat types described for both species (Table 1), rocks (for L. archeyi) and plants (for L. pakeka) were not included in these analyses as insufficient use was observed for rocks and no temperature data were recorded for plants. For each species, I constructed eight candidate models for each microhabitat type including the individual effect of each explanatory variable, as well as additive models including intrinsic and extrinsic variables and only extrinsic variables. A model including all the main effects and a null model including only the intercept were also analysed. I used an information-theoretic approach for model selection using second-order Akaike's Information Criterion (AICc) for small sample sizes (Burnham and Anderson 2002). For model performance assessment, $\triangle \mathrm{AICc}$ and Akaike weights $\left(w_{i}\right)$ were computed. Models with Akaike weights $>10 \%$ were considered for analyses (Burnham and Anderson 2002). Because all models had weights $<0.90$, the sum of the Akaike model weights across all interpretable models where that variable occurred was used to evaluate the importance of a given predictor variable (i.e. model averaging; Burnham and Anderson 2002). Confidence intervals (CI) of $85 \%$ were used for parameter estimates as suggested by Arnold (2010). If confidence intervals included zero, then the predictor variable is considered as having no effect on the response variable (Yeiser and Richter 2015). Years were not included as a factor as a priori analyses showed no significant differences in the proportion of microhabitats used between years (GLMMs, all $\mathrm{P}>0.05$ except for plants $(\mathrm{z}=2.68, P=0.007)$ ). Finally, to assess whether the proportion of frogs found under cover differed between species and/or seasons I used GLMMs with binomial distribution, including species and season as fixed effects, and individual frogs as random effects. A frog was scored as 1 if it was covered or 0 if it was not covered. Analyses were performed in R version 3.2.0 (R core Team 2015) and STATISTICA 7.0 (StatSoft Inc., USA). Summary statistics presented are the means \pm one standard error (SE). 


\subsection{Results}

A total of 76 L. archeyi were tracked from 2014 to 2015 with five recaptures while 123 L. pakeka were tracked from 2013 to 2015 with 26 recaptures. Apparent female L. archeyi comprised 40.3\% (mean SVL: $34.0 \pm 0.3 \mathrm{~mm}$ ), apparent males (or younger females) 38.9\% (mean SVL: $28.2 \pm 0.3$ mm), and sub-adults 20.8\% (mean SVL: $20.6 \pm 1.2 \mathrm{~mm}$ ). Apparent female L. pakeka comprised $77.2 \%$ of the tracked frogs (mean SVL: $43.5 \pm 0.2 \mathrm{~mm}$ ), apparent males (or younger females) 21.1\% (mean SVL: $37.8 \pm 0.3 \mathrm{~mm}$ ), and sub-adults 1.7\% (mean SVL: $29.2 \pm 3.0 \mathrm{~mm}$; for more details see Chapter 3). A total of 594 locations were recorded for L. archeyi and 1144 for L. pakeka, including final retreat sites.

\subsubsection{Microhabitat use}

Both species tended to use more than one microhabitat during their activity period, using between one to five microhabitats (Fig. 1). Most L. archeyi individuals used two different types of microhabitats during the entire time (41\%) whereas a high proportion of L. pakeka used three different microhabitats (42\%). Pooling the breeding and non-breeding seasons, L. archeyi used a high proportion of leaf litter during movement (39\%) followed by trees (36\%). L. pakeka also used mainly leaf litter (42\%) followed by soil (22\%) and rocks (15\%). 


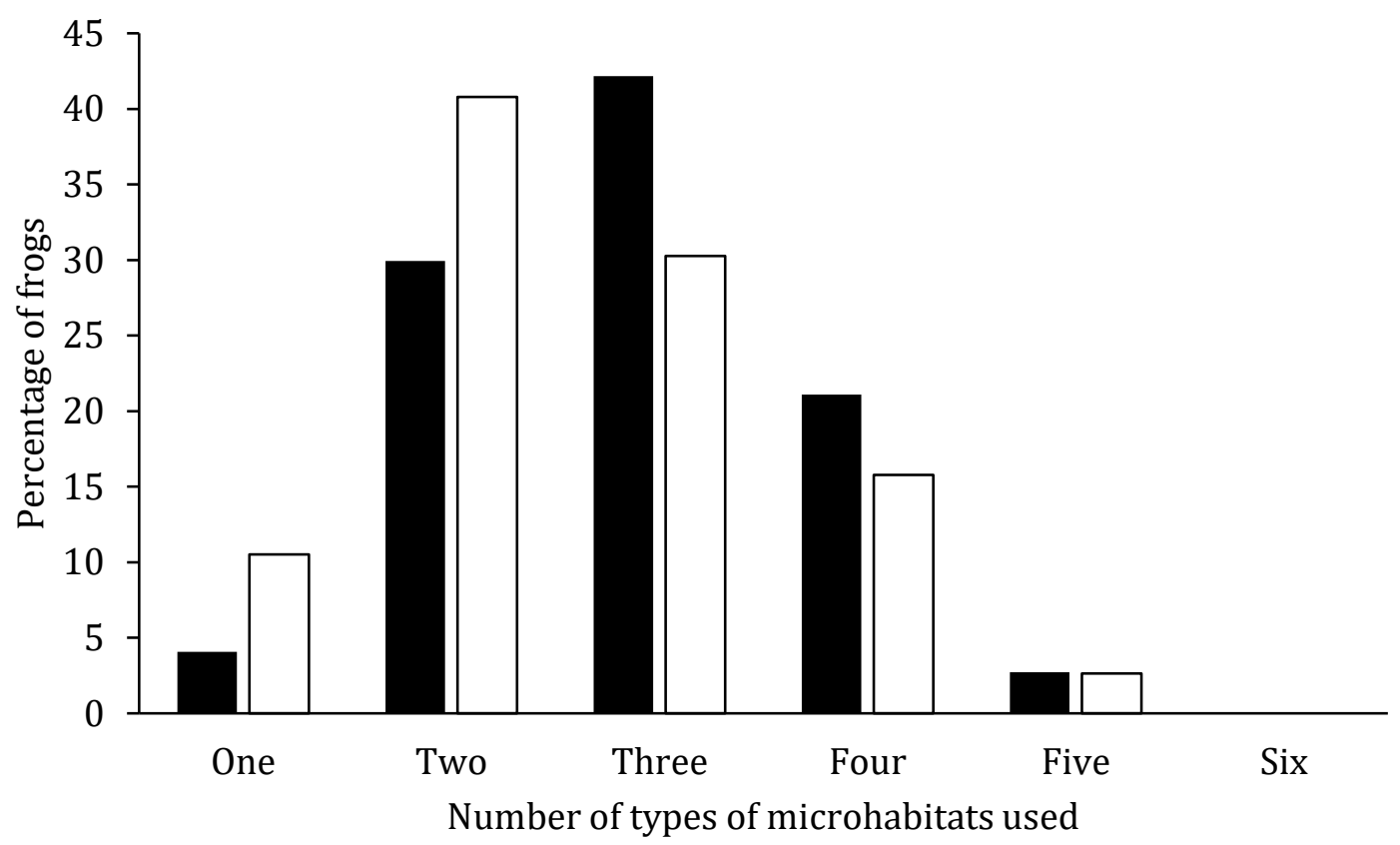

Figure 1: Percentage of L. archeyi (white bars) and L. pakeka (black bars) individuals and the number of different types of microhabitat they used during movement.

The microhabitat available in Whareorino Forest consisted mainly of leaf litter $(80.4 \%)$ and trees (12.5\%; Table 2). On Maud Island leaf litter was also the main microhabitat (64.2\%) followed by woody debris (14.1\%) and rocks (13.3\%; Table 2). During both the breeding and non-breeding seasons of L. archeyi there were significant differences in the proportion of microhabitats used compared to availability $\left(\mathrm{G}_{\mathrm{adj}}=1025.64, \mathrm{df}=5, P<0.0001 ; \mathrm{G}_{\mathrm{adj}}=294.77, \mathrm{df}=5, P<0.0001\right.$, respectively; Table 2). During the breeding season ferns, trees, soil, rocks, and woody debris were used in higher proportion compared to availability (ferns: $\mathrm{G}_{\text {adj }}=81.50, \mathrm{df}=1, P<0.0001$; trees: $\mathrm{G}_{\text {adj }}=62.45, \mathrm{df}=1, P<0.0001 ;$ soil: $\mathrm{G}_{\text {adj }}=22.23, \mathrm{df}=1, P<0.0001 ;$ rocks: $\mathrm{G}_{\text {adj }}=4.71, \mathrm{df}=1, P=$ 0.03; woody debris: $\mathrm{G}_{\text {adj }}=107.93, \mathrm{df}=1, P<0.0001$ ) while leaf litter was used in less proportion $\left(\mathrm{G}_{\text {adj }}=257.12, \mathrm{df}=1, P<0.0001\right)$. During the non-breeding season ferns, trees and woody debris were also used in higher proportion compared to availability $\left(\mathrm{G}_{\mathrm{adj}}=21.01, \mathrm{df}=1, P<0.0001 ; \mathrm{G}_{\text {adj }}\right.$ $=195.17, \mathrm{df}=1, P<0.0001 ; \mathrm{G}_{\mathrm{adj}}=60.00, \mathrm{df}=1, P<0.0001$, respectively), whereas soil and leaf litter were used in less proportion $\left(G_{\text {adj }}=11.12, \mathrm{df}=1, P<0.0001 ; G_{\text {adj }}=18.21\right.$, $\mathrm{df}=1, P<0.0001$, respectively). No significant differences from availability were found in the use of rocks $\left(G_{\text {adj }}=\right.$ 
$5.79, \mathrm{df}=1, P=0.02)$. L. archeyi climbed trees often, either in the presence or absence of rain, being found above ground level $66 \%$ of the times trees were used. The average height climbed per individual $(\mathrm{n}=32)$ was $0.72 \mathrm{~m}$ with a range of $0.24-1.62 \mathrm{~m}$ (Fig. 2). When found on ferns, the average height climbed per individual $(\mathrm{n}=5)$ was $0.53 \mathrm{~m}$ with a range of $0.34-1.00 \mathrm{~m}$.

In the case of L. pakeka, significant differences in the proportion of microhabitats used compared to availability were also found for the breeding and non-breeding seasons $\left(\mathrm{G}_{\text {adj }}=428.59, \mathrm{df}=5, P\right.$ $<0.0001 ; \mathrm{G}_{\mathrm{adj}}=310.80, \mathrm{df}=5, P<0.0001$, respectively; Table 2). During the breeding season trees, soil and rocks were used in higher proportion compared to availability $\left(\mathrm{G}_{\mathrm{adj}}=78.37, \mathrm{df}=1, P<\right.$ $0.0001 ; \mathrm{G}_{\text {adj }}=303.71, \mathrm{df}=1, P<0.0001 ; \mathrm{G}_{\mathrm{adj}}=9.66, \mathrm{df}=1, P=0.002$, respectively), whereas leaf litter and woody debris were used in less proportion $\left(\mathrm{G}_{\text {adj }}=126.09, \mathrm{df}=1, P<0.0001 ; \mathrm{G}_{\text {adj }}=18.21\right.$, $\mathrm{df}=1, P<0.0001$, respectively). No significant differences from availability were found in the use of plants $\left(\mathrm{G}_{\mathrm{adj}}=0.02, \mathrm{df}=1, P=0.89\right)$. During the non-breeding season trees and soil were also used in higher proportion compared to availability $\left(\mathrm{G}_{\mathrm{adj}}=132.23, \mathrm{df}=1, P<0.0001 ; \mathrm{G}_{\text {adj }}=156.24\right.$, $\mathrm{df}=1, P<0.0001$, respectively), whereas leaf litter and plants were used in less proportion $\left(\mathrm{G}_{\text {adj }}\right.$ $=61.01, \mathrm{df}=1, P<0.0001 ; \mathrm{G}_{\mathrm{adj}}=9.08, \mathrm{df}=1, P=0.003$, respectively). No significant differences from availability were found in the use of rocks and woody debris $\left(\mathrm{G}_{\text {adj }}=0.78, \mathrm{df}=1, P=0.37 ; \mathrm{G}_{\text {adj }}\right.$ $=5.70, \mathrm{df}=1, P=0.017$, respectively). Contrary to L. archeyi, L. pakeka used the roots of trees during movement (ground level) and climbed tree trunks only $9.4 \%$ of the times trees were used, either during rainy or dry nights. The average height climbed per individual $(\mathrm{n}=6)$ was $0.58 \mathrm{~m}$ with a range of $0.20-1.50 \mathrm{~m}$. 
Table 2: Microhabitat availability (frequency of occurrence at sample points) and use (observed proportions) by L. archeyi in Whareorino Forest and $L$. pakeka on Maud Island.

\begin{tabular}{|c|c|c|c|c|c|c|c|}
\hline \multirow[b]{2}{*}{ Species } & \multirow[b]{2}{*}{$\begin{array}{l}\text { Microhabitat } \\
\text { type }\end{array}$} & \multirow[b]{2}{*}{$\begin{array}{l}\text { Availability } \\
\text { (frequency) }\end{array}$} & \multirow[b]{2}{*}{$\begin{array}{l}\text { Expected } \\
\text { proportion }\end{array}$} & \multicolumn{2}{|c|}{ Breeding season } & \multicolumn{2}{|c|}{ Non-breeding season } \\
\hline & & & & $\begin{array}{l}\text { Observed } \\
\text { proportion }\end{array}$ & Difference $^{\mathrm{a}}$ & $\begin{array}{l}\text { Observed } \\
\text { proportion }\end{array}$ & Difference $^{\mathrm{a}}$ \\
\hline \multicolumn{8}{|l|}{ L. archeyi } \\
\hline & Leaf litter & 193 & 0.80 & 0.41 & $<$ & 0.31 & $<$ \\
\hline & Tree & 30 & 0.13 & 0.28 & $>$ & 0.52 & $>$ \\
\hline & Soil & 12 & 0.05 & 0.11 & $>$ & 0.01 & $<$ \\
\hline & Woody debris & 3 & 0.01 & 0.11 & $>$ & 0.11 & $>$ \\
\hline & Fern & 1 & 0.004 & 0.06 & $>$ & 0.04 & $>$ \\
\hline & Rock & 1 & 0.004 & 0.01 & $>$ & 0.02 & ns \\
\hline \multicolumn{8}{|l|}{ L. pakeka } \\
\hline & Leaf litter & 154 & 0.64 & 0.43 & $<$ & 0.44 & $<$ \\
\hline & Woody debris & 34 & 0.14 & 0.09 & $<$ & 0.10 & ns \\
\hline & Rock & 32 & 0.13 & 0.17 & $>$ & 0.12 & ns \\
\hline & Soil & 11 & 0.05 & 0.23 & $>$ & 0.21 & $>$ \\
\hline & Tree & 5 & 0.02 & 0.08 & $>$ & 0.13 & $>$ \\
\hline & Plant & 4 & 0.02 & 0.02 & ns & 0.002 & $<$ \\
\hline
\end{tabular}

a Indicates significant differences in the observed proportions against expected proportions based on availability: less than expected ( $<$ ), more than expected (>) and no significant differences between expected and observed proportions (ns). 


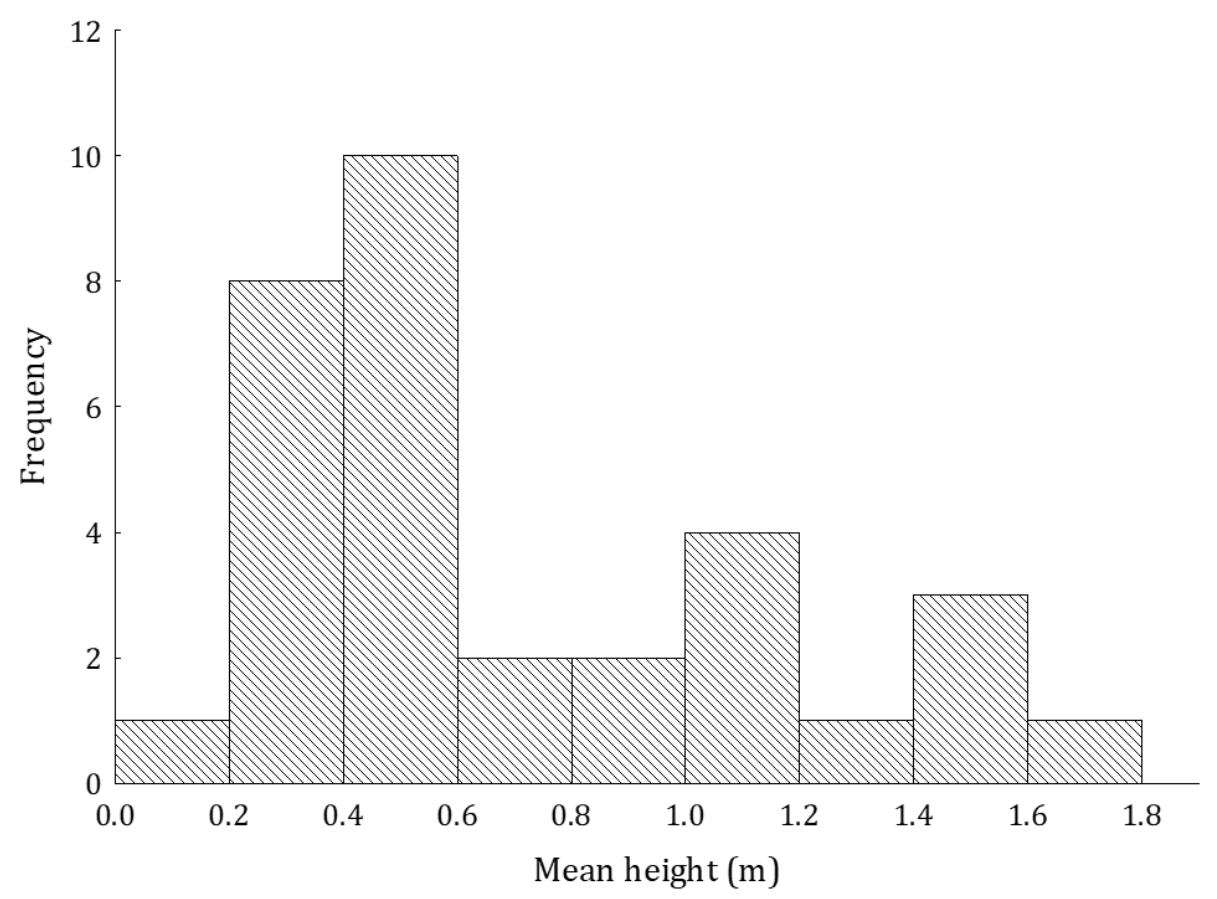

Figure 2: Frequency distribution of mean heights (m) climbed for L. archeyi individuals on trees.

Five microhabitat types were shared by L. archeyi and L. pakeka: leaf litter, soil, rocks, trees, and woody debris (Table 1). L. archeyi were found $57.1 \%$ of the times in these microhabitats whereas L. pakeka were found $88.6 \%$ of the times (Table 2). There was a high variability in the use of these microhabitats by both species. Leaf litter, although used by both species in a lower proportion compared to availability, was highly used by both L. archeyi and L. pakeka (0.39 and 0.42, respectively; Fig. 3). Rocks and soil were used considerably more often by L. pakeka than by $L$. archeyi (rocks: 0.15 vs 0.01 , respectively; soil: 0.22 vs 0.07 , respectively; Fig. 3). In contrast, trees were more often used by L. archeyi than by L. pakeka (0.36 vs 0.10 , respectively; Fig. 3). Woody debris was used in a similar proportion by both species (L. archeyi: 0.11 and L. pakeka: 0.09), but L. pakeka used this microhabitat type in a lower proportion compared to availability (Fig. 3). 


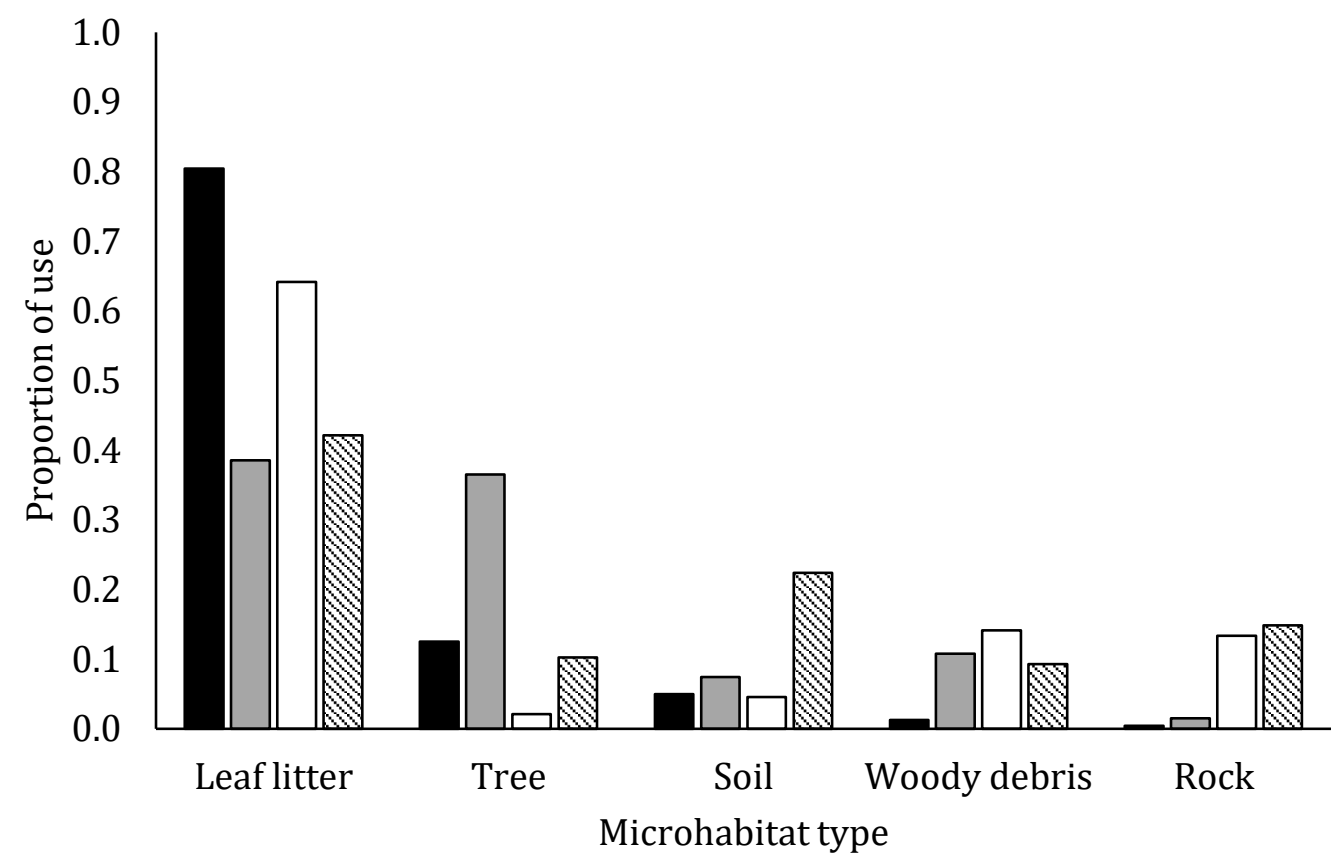

Figure 3: Proportion of use of the microhabitats shared by both species (i.e. microhabitats used by both species) compared to availability. Black and grey bars represent expected and observed proportions of use, respectively, by L. archeyi. White and dashed bars represent expected and observed proportions of use, respectively, by L. pakeka.

Considering the cover provided at frog locations, L. pakeka was more often found in locations that did not provide cover compared to L. archeyi, excluding microhabitats used as final retreat sites $(\mathrm{z}=-2.80, P=0.005)$. From the total of recorded locations for L. pakeka, 23\% were under cover whereas for L. archeyi 67\% were under cover. The proportion of L. archeyi and L. pakeka found under cover did not differ between seasons $(\mathrm{z}=-1.03, P=0.30 ; \mathrm{z}=1.20, P=0.21$, respectively $)$.

\subsubsection{Microhabitat temperatures}

For both species, all temperatures of the different microhabitat types differed between seasons (Table 3), except for soil (breeding: $13.22 \pm 0.12^{\circ} \mathrm{C}$, non-breeding: $12.85 \pm 0.15^{\circ} \mathrm{C}, P=0.08$; Table 3) and woody debris (breeding: $13.40 \pm 0.12{ }^{\circ} \mathrm{C}$, non-breeding: $12.74 \pm 0.15^{\circ} \mathrm{C}, P=0.07$; Table 3 ) in L. pakeka habitat. For L. archeyi, temperatures among microhabitat types did not differ during 
the non-breeding season $(\mathrm{H}=1.28, \mathrm{df}=4, P=0.86)$, whereas during the breeding season there were significant differences among microhabitats $(\mathrm{H}=14.00, \mathrm{df}=5, P=0.01)$ with ferns having a significantly lower mean temperature than rocks $\left(8.56 \pm 0.08^{\circ} \mathrm{C}\right.$ vs $8.87 \pm 0.05^{\circ} \mathrm{C}$, respectively; $\mathrm{z}$ $=2.94, P=0.05$; Table 3). For L. pakeka, there were no significant differences in the temperatures among microhabitat types during the non-breeding season either $(\mathrm{H}=3.06 \mathrm{df}=4, P=0.71)$, whereas during the breeding season rocks had a significantly higher mean temperature $(13.93 \pm$ $0.10^{\circ} \mathrm{C}$ ) than the other microhabitat types (rocks vs woody debris $\mathrm{z}=3.39, P=0.007$; rocks vs soil $\mathrm{z}=5.04, P<0.0001$; rocks vs leaf litter $\mathrm{z}=4.19, P<0.001$; rocks vs trees $\mathrm{z}=3.40, P=0.007$; Table 3).

Table 3: Mean temperatures $( \pm \mathrm{SE})$ of microhabitat types found in Whareorino Forest (L.archeyi) and on Maud Island (L. pakeka). P-values from Kruskal-Wallis test comparing microhabitat temperatures between both seasons are shown.

\begin{tabular}{lllll}
\hline & & \multicolumn{2}{c}{ Mean temperature $\left({ }^{\circ} \mathrm{C} \pm \mathrm{SE}\right)$} & \\
\cline { 3 - 4 } Species & Microhabitat type & Breeding season & Non-breeding season & $P$-value \\
\hline L. archeyi & & & & \\
& Leaf litter & $8.80 \pm 0.06$ & $13.80 \pm 0.13$ & $<0.0001$ \\
& Tree & $8.65 \pm 0.07$ & $13.78 \pm 0.14$ & $<0.0001$ \\
& Soil & $8.80 \pm 0.07$ & $13.78 \pm 0.13$ & $<0.0001$ \\
& Woody debris & $8.82 \pm 0.07$ & $13.84 \pm 0.13$ & $<0.0001$ \\
& Fern & $8.56 \pm 0.08$ & $\mathrm{n} / \mathrm{a}$ & $\mathrm{n} / \mathrm{a}$ \\
& Rock & $8.87 \pm 0.05$ & $13.91 \pm 0.14$ & $<0.0001$ \\
& & & & \\
& Leaf litter & $13.36 \pm 0.10$ & $12.88 \pm 0.14$ & 0.03 \\
& Woody debris & $13.40 \pm 0.12$ & $12.74 \pm 0.15$ & 0.07 \\
& Rock & $13.93 \pm 0.10$ & $12.92 \pm 0.14$ & $<0.0001$ \\
& Soil & $13.22 \pm 0.12$ & $12.85 \pm 0.15$ & 0.08 \\
& Tree & $13.41 \pm 0.12$ & $12.86 \pm 0.14$ & $<0.001$ \\
\hline
\end{tabular}

$\mathrm{n} / \mathrm{a}=$ temperature not measured 


\subsubsection{Factors affecting microhabitat use}

Microhabitat selection was affected by different factors in each species (Tables 4 and 5). Few models held similar weights for all types of microhabitats, with the null model being the highest supported model for woody debris (L.archeyi; Table 4) and the second highest for leaf litter and woody debris (L. pakeka; Table 5). The highest weighted model for L. archeyi had a weight of 0.60 (trees) whereas for L. pakeka a weight of 0.42 (soil).

Table 4: Candidate models for the relationship between intrinsic (SVL) and extrinsic (temperature) factors and microhabitat use by L. archeyi in Whareorino Forest. Interpretable models have Akaike weights $>10 \%$ relative to the model with best fit.

\begin{tabular}{lllllll}
\hline Microhabitat & Model & $\mathrm{K}^{\mathrm{a}}$ & $\mathrm{AIC}_{\mathrm{c}}$ & $\Delta \mathrm{AIC}_{\mathrm{c}}$ & Likelihood & $w_{i}$ \\
\hline Leaf litter & & & & & & \\
& Season + SVL + temp & 5 & 750.35 & 0.00 & 1.00 & 0.52 \\
& Season + temp & 4 & 752.33 & 1.98 & 0.37 & 0.19 \\
& Season + SVL & 4 & 753.01 & 2.66 & 0.26 & 0.14 \\
& SVL & 3 & 754.96 & 4.61 & 0.10 & 0.05 \\
& SVL + temp & 4 & 755.40 & 5.06 & 0.08 & 0.04 \\
& Season & 3 & 755.84 & 5.49 & 0.06 & 0.03 \\
Woody debris & 2 & 757.31 & 6.96 & 0.03 & 0.02 \\
& Intercept & 3 & 758.16 & 7.81 & 0.02 & 0.01 \\
& Temp & & & & & \\
& Intercept & 2 & 364.15 & 0.00 & 1.00 & 0.30 \\
& SVL & 3 & 364.78 & 0.63 & 0.73 & 0.22 \\
& Season & 3 & 366.11 & 1.96 & 0.37 & 0.11 \\
& Temp & 3 & 366.17 & 2.02 & 0.36 & 0.11 \\
& Season + SVL & 4 & 366.73 & 2.59 & 0.27 & 0.08 \\
& SVL + temp & 4 & 366.80 & 2.66 & 0.26 & 0.08 \\
& Season + temp & 4 & 367.39 & 3.24 & 0.20 & 0.06 \\
Season + SVL + temp & 5 & 368.24 & 4.09 & 0.13 & 0.04 \\
& & & & & \\
Soil & 3 & 266.52 & 0.00 & 1.00 & 0.31 \\
& Season & 4 & 266.83 & 0.31 & 0.86 & 0.27 \\
Season + SVL & 4 & 267.87 & 1.35 & 0.51 & 0.16 \\
Season + temp & 5 & 267.89 & 1.36 & 0.51 & 0.16 \\
& Season + SVL + temp & 3 & 269.98 & 3.46 & 0.18 & 0.06 \\
& Temp & 4 & 270.57 & 4.05 & 0.13 & 0.04 \\
SVL + temp & 2 & 278.77 & 12.25 & 0.00 & 0.00 \\
& Intercept & 278.80 & 12.28 & 0.00 & 0.00 \\
& SVL & 64 & & & & \\
& & & & & &
\end{tabular}


Table 4: Continuation

\begin{tabular}{lllllll}
\hline Microhabitat & Model & $\mathrm{K}^{\mathrm{a}}$ & $\mathrm{AIC}_{\mathrm{c}}$ & $\Delta \mathrm{AIC}_{\mathrm{c}}$ & Likelihood & $w_{i}$ \\
\hline Trees & & & & & & \\
& Season + SVL + temp & 5 & 665.52 & 0.00 & 1.00 & 0.60 \\
& Season + temp & 4 & 667.78 & 2.26 & 0.32 & 0.19 \\
& Season + SVL & 4 & 668.58 & 3.06 & 0.22 & 0.13 \\
& Season & 3 & 669.85 & 4.32 & 0.12 & 0.07 \\
& SVL + temp & 4 & 676.05 & 10.52 & 0.01 & 0.00 \\
& Temp & 3 & 676.92 & 11.40 & 0.00 & 0.00 \\
& SVL & 3 & 683.41 & 17.89 & 0.00 & 0.00 \\
& Intercept & 2 & 684.70 & 19.18 & 0.00 & 0.00
\end{tabular}

Fern

$\begin{array}{llllll}\text { SVL + temp } & 4 & 106.10 & 0.00 & 1.00 & 0.57 \\ \text { Season + SVL } & 4 & 107.16 & 1.06 & 0.59 & 0.34 \\ \text { SVL } & 3 & 111.51 & 5.42 & 0.07 & 0.04 \\ \text { Temp } & 3 & 112.09 & 6.00 & 0.05 & 0.03 \\ \text { Season + temp } & 4 & 114.12 & 8.02 & 0.02 & 0.01 \\ \text { Season } & 3 & 114.50 & 8.40 & 0.01 & 0.01 \\ \text { Intercept } & 2 & 114.69 & 8.59 & 0.01 & 0.01\end{array}$

a Indicates number of parameters included in the model (including error term and intercept) Temp $=$ temperature 
Table 5: Candidate models for the relationship between intrinsic (SVL) and extrinsic (temperature) factors and microhabitat use by L. pakeka on Maud Island. Interpretable models have Akaike weights $>10 \%$ relative to the model with best fit.

\begin{tabular}{|c|c|c|c|c|c|c|}
\hline Microhabitat & Model & $\mathrm{K}^{\mathrm{a}}$ & $\mathrm{AIC}_{\mathrm{c}}$ & $\Delta \mathrm{AIC}_{\mathrm{c}}$ & Likelihood & $w_{i}$ \\
\hline \multicolumn{7}{|l|}{ Leaf litter } \\
\hline & Season & 3 & 1242.93 & 0.00 & 1.00 & 0.28 \\
\hline & Intercept & 2 & 1243.70 & 0.77 & 0.68 & 0.19 \\
\hline & Season + SVL & 4 & 1244.03 & 1.11 & 0.57 & 0.16 \\
\hline & Season + temp & 4 & 1244.92 & 1.99 & 0.37 & 0.10 \\
\hline & SVL & 3 & 1245.13 & 2.20 & 0.33 & 0.09 \\
\hline & Temp & 3 & 1245.65 & 2.73 & 0.26 & 0.07 \\
\hline & Season + SVL + temp & 5 & 1246.05 & 3.12 & 0.21 & 0.06 \\
\hline & SVL + temp & 4 & 1246.94 & 4.01 & 0.13 & 0.04 \\
\hline \multicolumn{7}{|l|}{ Woody debris } \\
\hline & Temp & 3 & 603.44 & 0.00 & 1.00 & 0.21 \\
\hline & Intercept & 2 & 603.71 & 0.27 & 0.87 & 0.19 \\
\hline & SVL + temp & 4 & 603.73 & 0.29 & 0.87 & 0.18 \\
\hline & Season + temp & 4 & 604.69 & 1.24 & 0.54 & 0.11 \\
\hline & SVL & 3 & 604.98 & 1.54 & 0.46 & 0.10 \\
\hline & Season + SVL + temp & 5 & 605.11 & 1.67 & 0.43 & 0.09 \\
\hline & Season & 3 & 605.62 & 2.17 & 0.34 & 0.07 \\
\hline & Season + SVL & 4 & 606.95 & 3.51 & 0.17 & 0.04 \\
\hline \multicolumn{7}{|l|}{ Rock } \\
\hline & SVL + temp & 4 & 690.42 & 0.00 & 1.00 & 0.41 \\
\hline & Season + SVL + temp & 5 & 691.90 & 1.48 & 0.48 & 0.20 \\
\hline & SVL & 3 & 692.60 & 2.18 & 0.34 & 0.14 \\
\hline & Season + SVL & 4 & 692.71 & 2.29 & 0.32 & 0.13 \\
\hline & Temp & 3 & 695.07 & 4.65 & 0.10 & 0.04 \\
\hline & Intercept & 2 & 695.37 & 4.95 & 0.08 & 0.03 \\
\hline & Season & 3 & 696.08 & 5.66 & 0.06 & 0.02 \\
\hline & Season + temp & 4 & 696.69 & 6.27 & 0.04 & 0.02 \\
\hline \multicolumn{7}{|l|}{ Soil } \\
\hline & Season & 3 & 958.11 & 0.00 & 1.00 & 0.42 \\
\hline & Season + temp & 4 & 959.42 & 1.31 & 0.52 & 0.22 \\
\hline & Season + SVL & 4 & 960.12 & 2.01 & 0.37 & 0.15 \\
\hline & Season + SVL + temp & 5 & 961.40 & 3.29 & 0.19 & 0.08 \\
\hline & Temp & 3 & 962.52 & 4.41 & 0.11 & 0.05 \\
\hline & Intercept & 2 & 962.57 & 4.46 & 0.11 & 0.05 \\
\hline & SVL & 3 & 964.45 & 6.34 & 0.04 & 0.02 \\
\hline & SVL + temp & 4 & 964.53 & 6.42 & 0.04 & 0.02 \\
\hline \multicolumn{7}{|l|}{ Tree } \\
\hline & Season & 3 & 586.96 & 0.00 & 1.00 & 0.38 \\
\hline & Season + temp & 4 & 587.70 & 0.73 & 0.69 & 0.26 \\
\hline & Season + SVL & 4 & 588.52 & 1.55 & 0.46 & 0.17 \\
\hline
\end{tabular}




\begin{tabular}{lccccc}
\hline Model & $\mathrm{K}^{\mathrm{a}}$ & $\mathrm{AIC}_{\mathrm{c}}$ & $\Delta \mathrm{AIC}_{\mathrm{c}}$ & Likelihood & $w_{i}$ \\
\hline Season + SVL + temp & 5 & 589.03 & 2.07 & 0.36 & 0.13 \\
Temp & 3 & 592.45 & 5.48 & 0.06 & 0.02 \\
Intercept & 2 & 593.66 & 6.70 & 0.04 & 0.01 \\
SVL & 3 & 594.18 & 7.22 & 0.03 & 0.01 \\
SVL + temp & 4 & 595.60 & 8.64 & 0.01 & 0.01 \\
\hline
\end{tabular}

a Indicates number of parameters included in the model (including error term and intercept) Temp = temperature

For L. archeyi, model averaging showed that leaf litter and soil were more often used during the breeding season whereas trees were more often used in the non-breeding season (Table 6). The use of leaf litter was also affected by SVL $\left(w_{i}=0.65\right)$ and temperature $\left(w_{i}=0.71\right)$, with an increase in frogs' size and in the microhabitat temperature resulting in a higher use of this microhabitat. The use of trees was also affected by SVL ( $\left.w_{i}=0.73\right)$, with larger frogs using them more often, and temperature $\left(w_{i}=0.80\right)$, with lower temperatures on trees resulting in a higher use of this microhabitat. The use of ferns was negatively affected by SVL $\left(w_{i}=0.91\right)$ and temperature $\left(w_{i}=\right.$ 0.57), with smaller frogs and decreases in the microhabitat temperatures resulting in an increased use of this microhabitat type. The use of woody debris was not affected by either of the studied factors (Table 6). 
Table 6: Cumulative Akaike weights $\left(w_{i}\right)$, averaged parameter estimates and $85 \%$ confidence intervals (CI) for the top predictive parameters of microhabitat selection by L. archeyi in Whareorino Forest.

\begin{tabular}{llllll}
\hline & & & & \multicolumn{2}{c}{$85 \%$ CI } \\
\cline { 5 - 6 } Microhabitat & Parameter & $w_{i}$ & Estimate & Lower & Upper \\
\hline Leaf litter & & & & & \\
& Season & 0.85 & -2.01 & -3.45 & -0.57 \\
& Temp & 0.71 & 0.36 & 0.13 & 0.50 \\
Woody debris & SVL & 0.65 & 0.05 & 0.01 & 0.08 \\
& & & & & \\
& SVL & 0.22 & $-0.05^{\mathrm{a}}$ & -0.12 & 0.01 \\
\multirow{5}{*}{ Soil } & Season & 0.11 & $0.12^{\mathrm{a}}$ & -0.59 & 0.82 \\
& Temp & 0.11 & $0.00^{\mathrm{a}}$ & -0.14 & 0.13 \\
& & & & & \\
\multirow{5}{*}{ Trees } & Season & 0.90 & -3.34 & -5.86 & -0.82 \\
& SVL & 0.43 & $-0.07^{\mathrm{a}}$ & -0.14 & 0.00 \\
& Temp & 0.32 & $0.36^{\mathrm{a}}$ & -0.22 & 0.95 \\
& & & & & \\
Fern & Season & 0.92 & 3.46 & 1.76 & 5.16 \\
& Temp & 0.80 & -0.44 & -0.70 & -0.49 \\
& SVL & 0.73 & 0.07 & 0.02 & 0.12 \\
& & & & & \\
& SVL & 0.91 & -0.23 & -0.32 & -0.13 \\
& Temp & 0.57 & -1.01 & -1.92 & -0.10 \\
& Season & 0.34 & $-0.30^{\mathrm{a}}$ & -0.20 & 0.75 \\
\hline
\end{tabular}

a Parameter estimates with $85 \% \mathrm{CI}$ including zero

Temp = temperature

For L. pakeka, model averaging indicated that trees were more often used during the nonbreeding season whereas soil was more often used during the breeding season (Table 7). The use of rocks was influenced by both SVL and temperature ( $w_{i}=0.88, w_{i}=0.61$, respectively) with rocks more often used by larger frogs and with increases in this microhabitat temperature. Woody debris and leaf litter were not affected by either of the studied factors (Table 7). 
Table 7: Cumulative Akaike weights $\left(w_{i}\right)$, averaged parameter estimates and $85 \%$ confidence intervals (CI) for the predictive parameters of microhabitat selection by L. pakeka on Maud Island.

\begin{tabular}{|c|c|c|c|c|c|}
\hline \multirow[b]{2}{*}{ Microhabitat } & \multirow[b]{2}{*}{ Parameter } & \multirow[b]{2}{*}{$w_{i}$} & \multirow[b]{2}{*}{ Estimate } & \multicolumn{2}{|c|}{$85 \% \mathrm{CI}$} \\
\hline & & & & Lower & Upper \\
\hline \multicolumn{6}{|l|}{ Leaf litter } \\
\hline & Season & 0.55 & $0.28^{a}$ & -0.04 & 0.48 \\
\hline & SVL & 0.16 & $0.02^{\mathrm{a}}$ & -0.01 & 0.06 \\
\hline & Temp & 0.10 & $0.01^{\mathrm{a}}$ & -0.07 & 0.09 \\
\hline \multicolumn{6}{|l|}{ Woody debris } \\
\hline & Temp & 0.51 & $-0.15^{a}$ & -0.20 & 0.02 \\
\hline & SVL & 0.18 & $0.07^{a}$ & -0.01 & 0.14 \\
\hline & Season & 0.11 & $-0.28 \mathrm{a}$ & -0.74 & 0.18 \\
\hline \multicolumn{6}{|l|}{ Rock } \\
\hline & SVL & 0.88 & 0.12 & 0.05 & 0.19 \\
\hline & Temp & 0.61 & 0.17 & 0.04 & 0.31 \\
\hline & Season & 0.33 & $-0.30^{a}$ & -0.76 & 0.16 \\
\hline \multicolumn{6}{|l|}{ Soil } \\
\hline & Season & 0.79 & -0.68 & -1.09 & -0.27 \\
\hline & Temp & 0.22 & $0.08^{a}$ & -0.06 & 0.21 \\
\hline & SVL & 0.15 & $0.00^{\mathrm{a}}$ & -0.07 & 0.06 \\
\hline \multicolumn{6}{|l|}{ Tree } \\
\hline & Season & 0.95 & 0.99 & 0.46 & 1.52 \\
\hline & Temp & 0.40 & $-0.12^{\mathrm{a}}$ & -0.26 & 0.03 \\
\hline & SVL & 0.31 & $0.04 \mathrm{a}$ & -0.04 & 0.13 \\
\hline
\end{tabular}

a Parameter estimates with $85 \% \mathrm{CI}$ including zero

Temp = temperature

\subsection{Discussion}

I found significant differences in the use of microhabitats by each species. L. pakeka and L. archeyi were observed using more than one microhabitat type during movement with a high percentage of both species using between two to four types. Differences in the number of microhabitats used by both species could be a reflection of the higher movement magnitude showed by L. pakeka (Chapter 3) or unmeasured site-specific conditions, such as differences in habitat diversity. Each species selected microhabitats differently from those available suggesting that frogs sought out specific microhabitats during movement. Considering both seasons together, L. archeyi used more trees, woody debris and ferns than were available and selected against leaf litter, while L. pakeka used more soil and trees during movement than were available, also selecting against leaf litter. 
Both extrinsic (microhabitat temperature and season) and intrinsic (frogs' size) factors differentially affected the microhabitats use by each species, which suggests that thermoregulation and water balance could be important drivers in their behaviour. Although each species used less leaf litter than what was available, this microhabitat type comprised a high proportion of all the microhabitat types used during their movement. Despite differences in the habitats of each species, such as slope and altitude, I attempted to compare their microhabitat use by comparing the use of microhabitats they had available in common. From microhabitats used by both species, L. pakeka used more soil and rocks than L. archeyi, whereas L. archeyi used more trees and woody debris than L. pakeka. L. archeyi tended to use microhabitats that provided more cover (e.g. under small ferns), and were more often observed higher up on vegetation in contrast to L. pakeka. Those that climbed onto vegetation tended to be larger frogs (i.e. adults).

These patterns of microhabitat use are in general accordance with previous studies reporting the microhabitat types where frogs were found during single or multiple sessions of nightly surveys. However, because those studies rely on sightings of frogs (depending on the ability of each viewer), by continuously tracking frogs I was able to obtain detailed and more precise information on their microhabitat use. The use of leaf litter and soil by L. pakeka has previously been observed during night-time surveys (Bell 1978, Bell 1995, Reilly et al. 2015), but the high use of leaf litter by L. archeyi contrasts with other studies that found few frogs on the forest floor (Haigh et al. 2007, Reilly et al. 2015). The preference of rocks by L. pakeka may, in part, be due to the use of this microhabitat type as a transitory or final retreat site (Bell 1978, Bell 1995, Chapter 5), whereas L. archeyi is more likely to select trees for this purpose (Chapter 5). Climbing by $L$. archeyi has been previously noted with studies reporting individuals climbing a few metres above ground level on trees and ferns (Bell 1978, Bell 1982, Cree 1989, Thurley and Bell 1994, Reilly et al. 2015), with adults more often found above ground level than juveniles (Cree 1989). In this study, I provide quantitative data on the climbing patterns of both species, showing that L. archeyi is indeed a more avid climber than L. pakeka, spending most of its activity period above ground level. 
The differential microhabitat use by each species and factors affecting this selection suggest that different processes may be influencing frogs' behaviour at each site, which I hypothesise is partially explained by physiology maintenance and predation avoidance, although these patterns of microhabitat use could also be influenced by the different ambient temperatures at each location. Because amphibians have a highly permeable skin they are susceptible to desiccation and must avoid water loss (Duellman and Trueb 1994, Wells 2007). As terrestrial species generally rely on behavioural changes to thermoregulate and maintain water balance (Wells 2007), microhabitat selection is likely to be aiding in the physiology of these two Leiopelma species. Leaf litter has a moister microclimate than the ambient air (Baldwin et al. 2006), which could explain why this microhabitat type was so highly used by both species during their movement. Leaf litter could aid in the maintenance or restoration of water balance (Tracy et al. 1993, Wells 2007). Cree (1986) found that frogs from a L. archeyi population in the Coromandel Peninsula, New Zealand, were able to rapidly rehydrate from wet foliage (kiekie fronds; Freycinetia baueriana banksii), increasing in weight from $92-99 \%$ of their original bladderempty body weight. Leaf litter and soil were more often used by L. archeyi during the breeding season which could be associated with the thermoregulation process as the mean temperatures of these microhabitat types were significantly lower compared to the non-breeding season. The canopy within the forest remnant on Maud Island is composed of trees with bare trunks (i.e. no vegetation cover), providing no protection from the wind and potentially increasing evaporation rates. This could partially explain why climbing may not be a frequently observed behaviour in $L$. pakeka.

Another important factor in the water balance and thermoregulation processes is the size of the organisms. Smaller organisms have a greater surface area-to-volume ratio which makes them more susceptible to desiccation (Spotila 1972, Duellman and Trueb 1994, Bartelt et al. 2004), and therefore they have lower physiological tolerances than larger frogs (Rittenhouse et al. 2004). This may explain why rocks and trees were used more often by larger frogs. Rocks on Maud Island had a significantly higher mean temperature than the other microhabitat types during the 
breeding season and a slightly higher mean temperature during the non-breeding season. Similarly, although trees in Whareorino Forest are covered by Sphagnum moss, which are moisture-retaining forms and provide a suitable environment for frogs to manage desiccation rates (Baldwin et al. 2006), air flow is presumably higher above ground level which can increase evaporation rates (Tracy 1976, Cree 1986, Seebacher and Alford 1999). For these reasons, smaller frogs could be more susceptible to desiccation than larger frogs when using these microhabitat types and thus, may limit their use (Duellman and Trueb 1994, Bartelt et al. 2004). Lastly, L. archeyi selected microhabitats that provided cover, either by the microhabitat itself or by surrounding elements, more often than L. pakeka, which could be aiding in the prevention of desiccation to compensate for their smaller body size.

Predator avoidance could also play an important role in directing microhabitat selection. Although there has been an on-going ship rat (Rattus rattus) control programme in Whareorino Forest since 2003 (Thurley 2003, Haigh et al. 2007), L. archeyi could still encounter rats as rat capture rates ranged between $2.5 \%$ - 55\% during the study period (Department of Conservation unpub. data). Ship rats spend $91 \%$ of their time active on the forest floor (Dowding and Murphy 1994) and therefore, the use of trees could increase L. archeyi probabilities of survival by decreasing the number of encounters with these introduced predators. Additionally, due to the green coloration of most L. archeyi (Bell 1978, Thurley and Bell 1994, pers. obs.), trees could provide camouflage for this species, which could also facilitate its extended diurnal activity (Chapter 3). Similarly, the use of leaves and soil by L. pakeka could allow for camouflage due to this species' darker dorsal coloration (Bell 1978, pers. obs.).

I only investigated the effect of three factors on the behaviour of these two species: SVL, air temperature and season, but it is very likely that other factors are also playing a major role in microhabitat selection. For example, abiotic factors such as relative humidity and soil moisture have been shown to affect microhabitat selection by amphibian species (Cree 1986, Tracy et al. 1993, Seebacher and Alford 1999, Graeter 2005, Farallo and Miles 2016). Food resources can also 
act as cues for microhabitat selection (Rittenhouse et al. 2004). In this study, prey abundance could have driven the use of woody debris, leaf litter and trees as these microhabitat types have a high diversity and abundance of invertebrates (Jaeger 1978, Evans et al. 2003, Roe and Grayson 2008), and bryophytes (as the mosses covering trees in Whareorino Forest) also provide shelter to a wide variety of invertebrates (Božanić et al. 2013).

To my knowledge, this is the first study showing the extent of microhabitat selection by L. pakeka and $L$. archeyi during their activity periods when on the surface. Both species use a variety of microhabitats types, potentially facilitating their growth and survival by providing suitable conditions for thermoregulation/water balance and predator avoidance. The studied factors affected their microhabitat selection differently which could reflect differences in their physiological requirements, ecology and habitats, but affirm basic similarities between the species in their need for microhabitats that limit desiccation and allow for camouflage. More research on the ecophysiological factors that affect microhabitat selection, such as, substrate moisture and prey availability, would help clarify further the drivers that influence microhabitat selection in both species. Microhabitat use studies are essential in understanding species ecology as they can render information on the habitat features that are preferred by organisms. The incorporation of retreat sites as another important component of microhabitat selection will help identify habitat requirements of species and will aid in the conservation of suitable habitats for threatened species and the maintenance of populations. 


\section{Chapter 5 \\ Retreat site selection by Leiopelma archeyi and L. pakeka in their natural habitats}

\subsection{Introduction}

Retreat sites have an important role in the life of animals as they provide favourable microclimate conditions against climate extremes, protection against predators, and food and reproduction resources (Schwarkopf and Alford 1996, Langkilde and Shine 2004, Roznik and Johnson 2009, Milne and Bull 2000). Thus, the selection of suitable retreat sites can directly affect individual fitness and, ultimately, population viability (Huey et al. 1989, Long and Prepas 2012). The selection of retreat sites varies greatly between and within species, with a different array of retreats being used in a given population, such as, rocks, leaf litter, coarse woody debris, and vegetation (Seebacher and Alford 1999, Long and Prepas 2012). Factors affecting retreat site selection include biotic factors, such as the presence of one species affecting the habitat selection of another. For example, obligate use of crayfish burrows by crawfish frogs (Lithobates areolatus; Heemeyer et al. 2012). Abiotic factors affecting retreat site selection include the environmental conditions (e.g. temperature, humidity), or structural features of retreats (e.g. colour, crevice width; Heemeyer et al. 2012, Bleach et al. 2014, Domingos et al. 2015). Understanding factors affecting retreat site selection is particularly important for endangered species, as more knowledge is gained about their habitat requirements, providing useful information for the improvement of conservation strategies (Heemeyer et al. 2012, Domingos et al. 2015).

The skin of amphibians does not prevent evaporative water loss (Jørgensen 1997, Duellman and Trueb 1994). As such, amphibians are susceptible to desiccation, and therefore rely on retreat sites that provide them with the necessary conditions to retain water to survive, while achieving suitable temperatures for their vital activities, such as prey capture and digestion (Duellman and Trueb 1994, Schwarzkopf and Alford 1996, Long and Prepas 2012, Bleach et al 2014). Retreat sites can be of even greater importance for nocturnal species, as the thermal environment offers 
limited opportunities for behavioural thermoregulation during their activity period (Kearney and Predavec 2000), and retreat sites provide amphibians with abiotic conditions that are important for their physiology maintenance and performance. For example, boreal toads (Anaxyrus boreas) have been shown to select microhabitats with elevated relative humidity as refugia (Long and Prepas 2012), cane toads (Bufo marinus) favoured shelters with higher soil temperatures when soil moistures were above zero (Cohen and Alford 1996), and the bromelicolous tree frog (Scinax cuspidatus) selected shelters with high water pH (Domingos et al. 2015).

The structural features of retreat sites that can affect retreat site selection include burrow depth, entrance diameter and width. For example, endangered pygmy blue tongue lizards (Tiliqua adelaidensis) select burrows to fit in based on their size, including burrow depth and entrance diameter (Milne and Bull 2000), therefore a variety of burrows differing in depth and entrance diameter are needed to maintain a viable population. Female fiddler crabs (Uca mjoebergi) were shown to select different burrow widths according to the stage of the mating cycle, which may be a selection to optimise incubation rates (Reaney and Backwell 2007).

Leiopelma archeyi and L. pakeka are terrestrial and cryptically-coloured species that retreat under rocks and vegetation during daytime (Bell 1978, Newman 1990). They are nocturnal, with L. archeyi showing additional activity until a few hours after daybreak (Bell 1978, Cree 1989, Chapter 3). Both species are classified as threatened nationally and internationally (Newman et al. 2010, 2013, Bishop et al. 2013, IUCN 2017). There is no consistently observable sexual dimorphism in either of these species, apart from body size; females grow larger (Bell 1978). In L. archeyi, snout-vent length (SVL) of adult females exceeds $31 \mathrm{~mm}$, with $25-31 \mathrm{~mm}$ in males or young females (Bell 1978). In L. pakeka, adult females attain snout-vent lengths greater than 40 mm, compared with 34 - 40 mm in males or younger females (Bell 1978, Newman 1990, Bell et al. 2004b). While L. archeyi has been found to co-occur with introduced mammalian predators, such as rats and mice in Whareorino Forest and in the Coromandel Ranges (Worthy 1987, Bell 1978, Thurley and Bell 1994), the only natural population of L. pakeka is confined to 16 ha of 
forest remnant on Maud Island, a mammalian predator-free island (occasional incursions of mustelids occur and a house mouse incursion was first reported in 2013, though apparently the mice have since been eradicated; Department of Conservation 2016), in the Marlborough Sounds (Bell 1978, Bell and Pledger 2010, Bishop et al. 2013). The retreat sites used by L. archeyi have been described through daytime searches by lifting rocks or logs where frogs are likely to be found (e.g. Bell 1978, Cree 1986, Thurley and Bell 1994), and for L. pakeka, through night-time searches with frogs found inside or close to a crevice considered to be possible retreats, or by daytime sightings (e.g. Newman 1990, Bell 1994, Bell 1995). However, limited research on the retreat sites used by these species has been carried out. Cree (1986) studied the abiotic conditions inside and outside L. archeyi retreat sites finding that the temperature was lower and the humidity higher inside compared to the ambient. Nevertheless, no information is available on the abiotic conditions inside L. pakeka retreat sites, and no studies have investigated whether these frogs remain inactive or active inside retreat sites. A better understanding of the habitat requirements and the factors influencing retreat site selection by these two Leiopelma species will provide useful information on their ecology for their management and conservation.

\subsubsection{Study aim and research questions}

I aimed to investigate the retreat site selection by L. archeyi and L. pakeka, and, in particular, the factors affecting retreat site selection of L. pakeka. I asked: 1) Does retreat site use by each species differ from retreat sites availability? 2) Does retreat site selection differ between species? 3) What are the physical (height, width and diameter) and thermal attributes of the retreat sites selected by L. pakeka? and 4) Is there evidence of frog activity inside L. pakeka retreat sites? 


\subsection{Methods}

\subsubsection{Study sites and visits}

Retreat site use by L. archeyi was investigated in Whareorino Forest $\left(38^{\circ} 22^{\prime} \mathrm{S}, 174^{\circ} 47^{\prime} \mathrm{E}\right.$ ), Northern King Country, New Zealand, inside an area of 45 x 28 m (tracking area) located within a 300-ha area where an on-going rat control programme has been carried out since 2003 (Haigh et al. 2007, for more details see Chapter 3). Mean nightly temperatures sampled during the study period ranged from $8.8-13.8{ }^{\circ} \mathrm{C}$ and mean nightly relative humidity ranged from $74.5-95.3 \%$ (Chapter 3). Retreat site use by L. pakeka was investigated on Maud Island ( $\left.41^{\circ} 01^{\prime} \mathrm{S}, 173^{\circ} 53^{\prime} \mathrm{E}\right)$, Marlborough Sounds, New Zealand, considered to be a predator-free island (but see introduction), inside an area of $45 \times 28 \mathrm{~m}$ (tracking area) located in the lower slopes of a 16 ha remnant of broad-leaved forest growth (for more details see Chapter 3). Mean nightly temperatures sampled during the study period ranged from $12.9-13.5{ }^{\circ} \mathrm{C}$ and mean nightly relative humidity ranged from $75.6-92.4 \%$ (Chapter 3 ).

Over November 2014 - November 2015 there were a total of three field trips to Whareorino Forest covering the breeding (November $[\mathrm{n}=2]$ ) and non-breeding (March $[\mathrm{n}=1]$ ) seasons of $L$. archeyi, and over December 2013 - December 2015, a total of five field trips to Maud Island covering the breeding (November/December [n=3]) and non-breeding (March/April [n=2]) seasons of L. pakeka. For this study, the breeding season for both species is regarded as the time when oviposition has been observed, that; is Austral spring-early summer (for more details see Chapter 3).

\subsubsection{Tracking of frogs}

All frogs used in this study were caught opportunistically at night in the field. Frogs were captured by hand, quickly measured (snout-vent length) and dorsally photographed for later identification. 
Non-toxic fluorescent powders were applied to the frogs' bodies in the field. After measurements and powder application, frogs were immediately released at their capture location. After every 30 minutes, the pigmented trail left behind by the frogs as they moved was checked using a portable UV light. The new location of the frog was marked with wooden pegs. Frogs were tracked throughout the night and tracking ended when frogs sought a final retreat site (for more details see Chapter 3).

\subsubsection{Observed and available L. archeyi and L. pakeka retreat sites}

Once a final retreat site (henceforth retreat site) was identified, it was marked with a plastic numbered peg and characterized according to the microhabitat type that constituted the retreat site entrance (site where frog disappeared from the surface), that is, crevices among leaf litter (leaves and twigs), soil, rocks, woody debris (branches and logs), trees (roots, branches or trunk, including tree ferns), ferns or plants. Additionally, the height above ground level where the retreat site was located was measured.

To obtain an indicative measurement of retreat site availability at each site, I set up a $45 \mathrm{~m}$ transect every $2 \mathrm{~m}$ inside each tracking area obtaining a total of 15 parallel transects (Smith et al. 2003). I walked along each transect and every 10 paces a $30 \mathrm{~cm}$ ruler was dropped and the microhabitat type at both ends of the ruler was recorded. I chose this methodology to estimate the availability of retreat sites that frogs had access to, as frogs use a variety of microhabitats as retreat sites (Table 1) and I did not want to make assumptions over what frogs might select as a retreat.

\subsubsection{Structural characteristics of $\underline{\mathrm{L} . \text { pakeka }}$ retreat sites' entrance}

Measurements of the dimensions of the retreat sites entrance of L. pakeka started in December 2014. Using digital callipers I measured the height (measured at the highest point from the 
bottom to the ceiling of the entrance), width (measured as the maximum width of the entrance) and diameter (average of height and width; Milne and Bull 2000) of the retreat site entrances. Retreats were not destroyed during this process and the most fragile ones (e.g. among leaf litter) were carefully measured by removing adjacent leaves/twigs, and placing them back in their original position after measurements were taken. When a retreat site was used by more than one frog on the same day, the measurements of that retreat were only included once in subsequent analyses.

\subsubsection{Thermal conditions inside and outside L. pakeka retreat sites}

The thermal conditions of retreats were measured during the same period as the structural characteristics. Temperatures inside the retreat sites were recorded every 30 minutes from the moment a retreat site was confirmed as final to one hour after dusk the following night (i.e. until 6 to 8 pm depending on the season), using data loggers (HOBO Pro v2) with the probe inserted into the retreat site. Attempts were made to measure relative humidity, but the data loggers failed to record it consistently. To obtain a paired measure of the temperatures inside and outside retreat sites, I first randomly selected two sites per microhabitat type (leaf litter, soil, rocks, woody debris, and trees) separated by at least $5 \mathrm{~m}$ within the tracking area to evaluate spatial heterogeneity in temperature. I recorded temperatures (30 minute time intervals, HOBO Pro v2) at the surface of each microhabitat type for the length of the field trip (April 2014, 11 days). Analyses supported reduction of temperature sampling to one site per microhabitat type in future field trips (sites within microhabitat types did not significantly differ from each other; KruskalWallis tests, all $P>0.05$ ). I paired each temperature measurement inside each retreat site with its equivalent microhabitat surface temperature measurement at the same time point. I calculated the mean temperatures inside and outside retreat sites, as well as the temperature ranges considered as the difference between the maximum and minimum temperatures recorded. 


\subsubsection{Activity inside L. pakeka retreat sites}

Activity inside retreat sites was recorded from the moment a retreat site was confirmed as final, with three burrow-scopes using infrared lighting ( $850 \mathrm{~nm}$; which is not known to be visible to frogs; Jaeger and Hailman 1973) and a recording screen (Faunatech Austbat, Mount Taylor, Australia). When retreats were identified, the burrow-scope probe (13.8 $\mathrm{mm}$ diameter and 1000 mm length) was introduced into those sites where the entrance was big enough for insertion of the probe, and set to record if a frog was visible. Recording time varied from 0.5 to $6.1 \mathrm{~h}$ (average: $5.3 \mathrm{~h}$ ), depending on battery charge. I watched the recordings later in the lab and collected data on activity, number of frogs inside the retreat and their dispersion inside the retreat (i.e. frogs spread or clustered). Activities were classified into three different categories: movements without displacement (i.e. without moving from its position), movements with displacement (i.e. frogs moving from their original location), and not moving (i.e. frogs staying still). For all three categories I calculated the time spent by frogs performing each activity and the frequency of movements with and without displacement during the length of the recording. I calculated the total time spent by frogs moving inside the retreat by adding the duration of movements with and without displacement.

\subsubsection{Internal dimensions of $\underline{\mathrm{L}}$. pakeka retreat sites}

I measured the width and height of the inside of the retreat site, and the width and height of the frog's head, as a proxy for the frog's body size, in a standardized way considering the screen size, distance of the frog from the camera and the frog position inside the retreat (Fig. 1). For each retreat site, I selected a frame that showed the frog at a mid-distance from the camera (i.e. not too close to, or too far from, the camera) and with the frog's head facing the burrow-scope to allow measurements to be taken. I aimed to measure all the frogs inside a retreat site with more than one frog. Not all recordings allowed for these data to be collected; three retreat sites were left out 
of this analysis. All measurements were taken with a $30 \mathrm{~cm}$ ruler and with the same screen size for all recordings.

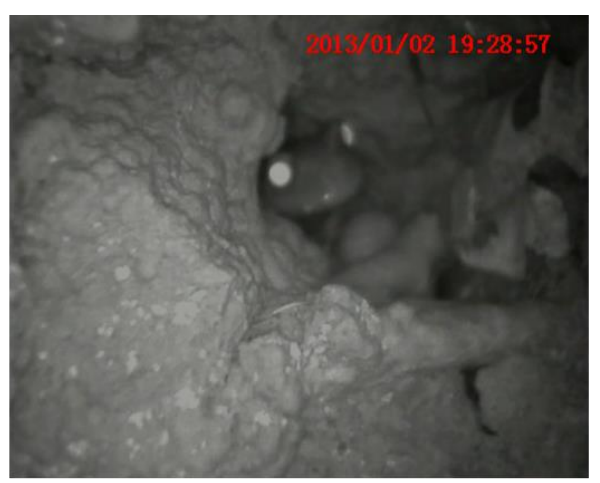

A

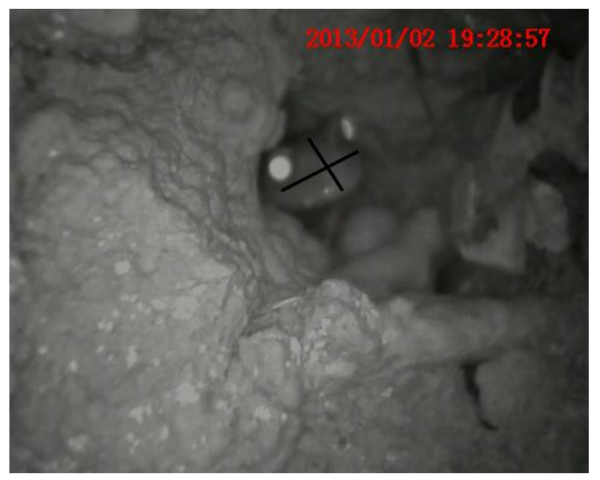

$\mathrm{C}$

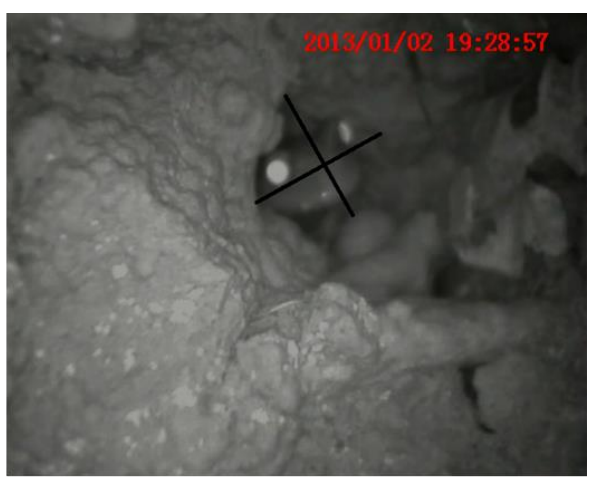

B

Figure 1: Measurements of the retreat site width and height. Figure (A) shows the original image of a frog inside its retreat. Figures (B) and (C) show how the heights (vertical line) and widths (horizontal line) of the retreat sites and frogs, respectively, were measured.

\subsubsection{Data analyses}

To assess whether retreat site use differed from retreat site availability I obtained the observed frequencies of retreat site use per season by adding the number of times a frog chose a given microhabitat type as a retreat site. I compared the observed frequencies of retreat site use with the retreat site availability (i.e. expected frequencies) using G tests of goodness-of-fit with William's correction (Sokal and Rohlf 1995). I carried out single-degree-of-freedom G tests with Bonferroni corrections to determine which retreat site use differed from availability (Sokal and Rohlf 1995). 
I qualitatively assessed whether the retreat site use differed between species by comparing the proportion of retreat sites used between both species, against the retreat site availability (expected proportions) in their respective locations. To establish whether retreat site type selection differed between seasons, I constructed individual dichotomous generalized linear mixed models (GLMMs) with binomial distribution for each retreat type, applying a one-vs-rest classification scoring the use of a given retreat as 1 and the use of the rest as 0 (Arppe 2008). Season was included as a fixed effect and individual frogs included as a random effect to account for repeated measurements. I ran separate dichotomous GLMMs to assess whether frogs' size (SVL) affected retreat site type selection with SVL as a fixed effect and individual frogs as a random effect. Years were not included as a factor as a priori analyses showed no significant differences in the retreat sites used between years (Fisher's exact test, $\mathrm{P}>0.05$ for the breeding and non-breeding seasons of L. pakeka and the breeding season of L. archeyi).

I analysed whether the dimensions of the retreat sites' entrance, height, width and diameter were correlated with SVL of frogs by carrying out separate linear regressions. To obtain an estimate of the size of the inside of the retreat site and the number of frogs that could fit inside, I calculated the ratio between the width/height of the retreat site and the width/height of the frog found inside. This ratio gave me an estimate of the number of frog-widths and frog-heights that could fit inside the retreat. To establish if the inside size of the retreat sites, measured in terms of the frogs' size, varied according to the number of frogs found inside, I graphed this ratio vs the number of frogs inside the retreat. Lastly, the mean temperatures and ranges inside and outside retreat sites were compared using paired Wilcoxon matched-pairs test per each season.

I used non-parametric Mann-Whitney U tests to analyse whether the duration of movements with and without displacement differed, and whether the proportion of total time moving (total time moving/recording time) differed among retreats by the number of frogs inhabiting retreats. I also analysed whether the frequency of movements with and without displacement differed using a Fisher's exact test for count data with simulated p-value (based on $1 \mathrm{e}+07$ replicates). Analyses 
were performed in R version 3.2.0 (R core Team 2015) and STATISTICA 7.0 (StatSoft Inc., USA). Summary statistics presented are the means \pm one standard error (SE).

\subsection{Results}

A total of 72 L. archeyi were tracked from 2014 to 2015 with five recaptures, while 123 L. pakeka were tracked from 2013 to 2015 with 26 recaptures. Apparent female L. archeyi comprised a 40.3\% (mean SVL: $34.0 \pm 0.3 \mathrm{~mm}$ ), apparent males (or younger females) 38.9\% (mean SVL: 28.2 $\pm 0.3 \mathrm{~mm}$ ), and sub-adults 20.8\% (mean SVL: $20.6 \pm 1.2 \mathrm{~mm}$ ) (for more details see Chapter 3). Apparent female L. pakeka comprised 77.2\% of the tracked frogs (mean SVL: $43.5 \pm 0.2 \mathrm{~mm}$ ), males (or younger females) 21.1\% (mean SVL: $37.8 \pm 0.3 \mathrm{~mm}$ ), and sub-adults 1.7\% (mean SVL: $29.2 \pm 3.0 \mathrm{~mm})$. The retreat sites of two frogs for each species were not identified as the fluorescent powder became too faint to follow, and therefore a total of 75 retreat sites were identified for L. archeyi and 148 for L. pakeka. All retreats used by each species were natural retreats, that is, natural cavities found in the environment.

\subsubsection{Retreat site use}

The retreat sites available in Whareorino Forest consisted mainly of leaf litter (80.4\%) and trees (12.5\%; Table 1). On Maud Island leaf litter was also the main retreat site type (64.2\%) followed by woody debris $(14.1 \%)$ and rocks (13.3\%; Table 1$)$. During the breeding and non-breeding seasons of $L$. archeyi there were significant differences in the proportion of retreat sites used compared to availability $\left(\mathrm{G}_{\mathrm{adj}}=80.09, \mathrm{df}=5, P<0.0001 ; \mathrm{G}_{\mathrm{adj}}=51.91\right.$, df $=5, P<0.0001$, respectively; Table 1). During the breeding season, trees, soil, rocks, and woody debris were used as retreat sites in higher proportion compared to availability (trees: $\mathrm{G}_{\text {adj }}=10.22, \mathrm{df}=1, P<0.01$; soil: $\mathrm{G}_{\text {adj }}=11.89, \mathrm{df}=1, P<0.001 ;$ rocks: $\mathrm{G}_{\text {adj }}=10.92, \mathrm{df}=1, P<0.001 ;$ woody debris: $\mathrm{G}_{\text {adj }}=28.17$, $\mathrm{df}=1, P<0.0001)$ while leaf litter was used in less proportion $\left(\mathrm{G}_{\mathrm{adj}}=65.88, \mathrm{df}=1, P<0.0001\right)$. No significant differences from availability were found in the use of ferns $\left(G_{\text {adj }}=1.66, \mathrm{df}=1, P=\right.$ 
0.20). During the non-breeding season, ferns, trees and woody debris were used in higher proportion compared to availability $\left(\mathrm{G}_{\text {adj }}=7.71, \mathrm{df}=1, P=0.005 ; \mathrm{G}_{\text {adj }}=27.12, \mathrm{df}=1, P<0.0001\right.$; $\mathrm{G}_{\mathrm{adj}}=18.08, \mathrm{df}=1, P<0.0001$, respectively), whereas leaf litter was used in less proportion $\left(\mathrm{G}_{\text {adj }}\right.$ $=45.16, \mathrm{df}=1, P<0.0001)$. No significant differences from availability were found in the use of soil and rocks $\left(\mathrm{G}_{\text {adj }}=2.87, \mathrm{df}=1, P=0.10 ; \mathrm{G}_{\text {adj }}=0.23, \mathrm{df}=1, P=0.63\right.$, respectively $)$.

In the case of L. pakeka, significant differences were also found in the proportion of retreat sites used compared to availability during both seasons (breeding: $\mathrm{G}_{\text {adj }}=202.18$, $\mathrm{df}=5, P<0.0001$; non-breeding: $\mathrm{G}_{\mathrm{adj}}=214.02, \mathrm{df}=5, P<0.0001$; Table 1). During the breeding season, trees, soil and rocks were used as retreat sites in higher proportion compared to availability $\left(G_{a d j}=62.42\right.$, $\mathrm{df}=1, P<0.0001 ; \mathrm{G}_{\mathrm{adj}}=27.75, \mathrm{df}=1, P<0.0001 ; \mathrm{G}_{\mathrm{adj}}=49.14, \mathrm{df}=1, P=0.002$, respectively; Table 1), whereas leaf litter and woody debris were used in less proportion $\left(G_{\text {adj }}=124.56, \mathrm{df}=1, P<\right.$ $0.0001 ; \mathrm{G}_{\mathrm{adj}}=9.00, \mathrm{df}=1, P=0.003$, respectively). During the non-breeding season, trees and rocks were used in higher proportion compared to availability $\left(\mathrm{G}_{\text {adj }}=171.56, \mathrm{df}=1, P<0.0001\right.$; $\mathrm{G}_{\text {adj }}=7.15, \mathrm{df}=1, P=0.008$, respectively $)$, whereas leaf litter was used in less proportion $\left(\mathrm{G}_{\mathrm{adj}}=\right.$ 89.52, $\left.\mathrm{df}=1, P<0.0001 ; \mathrm{G}_{\mathrm{adj}}=5.46\right)$. No significant differences from availability were found in the use of soil and woody debris $\left(\mathrm{G}_{\mathrm{adj}}=0.48, \mathrm{df}=1, P=0.49 ; \mathrm{G}_{\text {adj }}=5.46, \mathrm{df}=1, P=0.02\right.$, respectively). Plants were not used as retreat sites in either of the seasons. 
Table 1: Retreat sites availability (frequency of occurrence at sample points) and use (observed proportions) by L. archeyi in Whareorino Forest and L. pakeka on Maud Island.

\begin{tabular}{|c|c|c|c|c|c|c|c|}
\hline \multirow[b]{2}{*}{ Species } & \multirow[b]{2}{*}{$\begin{array}{l}\text { Microhabitat } \\
\text { type }\end{array}$} & \multirow[b]{2}{*}{$\begin{array}{l}\text { Availability } \\
\text { (frequency) }\end{array}$} & \multirow[b]{2}{*}{$\begin{array}{l}\text { Expected } \\
\text { proportion }\end{array}$} & \multicolumn{2}{|c|}{ Breeding season } & \multicolumn{2}{|c|}{ Non-breeding season } \\
\hline & & & & $\begin{array}{l}\text { Observed } \\
\text { proportion }\end{array}$ & Difference $^{a}$ & $\begin{array}{l}\text { Observed } \\
\text { proportion }\end{array}$ & Difference ${ }^{a}$ \\
\hline \multicolumn{8}{|l|}{ L. archeyi } \\
\hline & Leaf litter & 193 & 0.8 & 0.25 & $<$ & 0.21 & $<$ \\
\hline & Tree & 30 & 0.13 & 0.3 & $>$ & 0.53 & $>$ \\
\hline & Soil & 12 & 0.05 & 0.19 & $>$ & 0 & ns \\
\hline & Woody debris & 3 & 0.01 & 0.17 & $>$ & 0.18 & $>$ \\
\hline & Fern & 1 & 0.004 & 0.02 & ns & 0.07 & $>$ \\
\hline & Rock & 1 & 0.004 & 0.06 & $>$ & 0 & ns \\
\hline \multicolumn{8}{|l|}{ L. pakeka } \\
\hline & Leaf litter & 154 & 0.64 & 0.23 & $<$ & 0.07 & $<$ \\
\hline & Woody debris & 34 & 0.14 & 0.04 & $<$ & 0.05 & $<$ \\
\hline & Rock & 32 & 0.13 & 0.44 & $>$ & 0.27 & $>$ \\
\hline & Soil & 11 & 0.05 & 0.20 & $>$ & 0.07 & ns \\
\hline & Tree & 5 & 0.02 & 0.23 & $>$ & 0.55 & $>$ \\
\hline & Plant & 4 & 0.02 & 0 & 0 & 0 & 0 \\
\hline
\end{tabular}

a Indicates differences in the observed proportions against expected proportions: less than expected $(<)$, more than expected (>) and no significant differences between expected and observed proportions (ns). 
Trees were the preferred retreat site for L. archeyi with these retreats comprising $40 \%$ of retreat sites used (Fig. 2). Fifty-two percent of these retreats were located high above the ground (0.8 \pm $0.1 \mathrm{~m}$ ) inside crevices in branches or trunks. Although L. archeyi selected leaf litter in a lower proportion than available, this microhabitat type was the second most selected type of retreat site (Fig. 2). Ferns were selected as retreats only by three individuals. Leiopelma pakeka used trees in a similar proportion to L. archeyi ( 0.36 vs 0.39 ), but L. pakeka also used rocks in a similar proportion as trees (Fig. 2). When using trees, all the retreat sites used by L. pakeka were found at ground level (i.e. among roots).

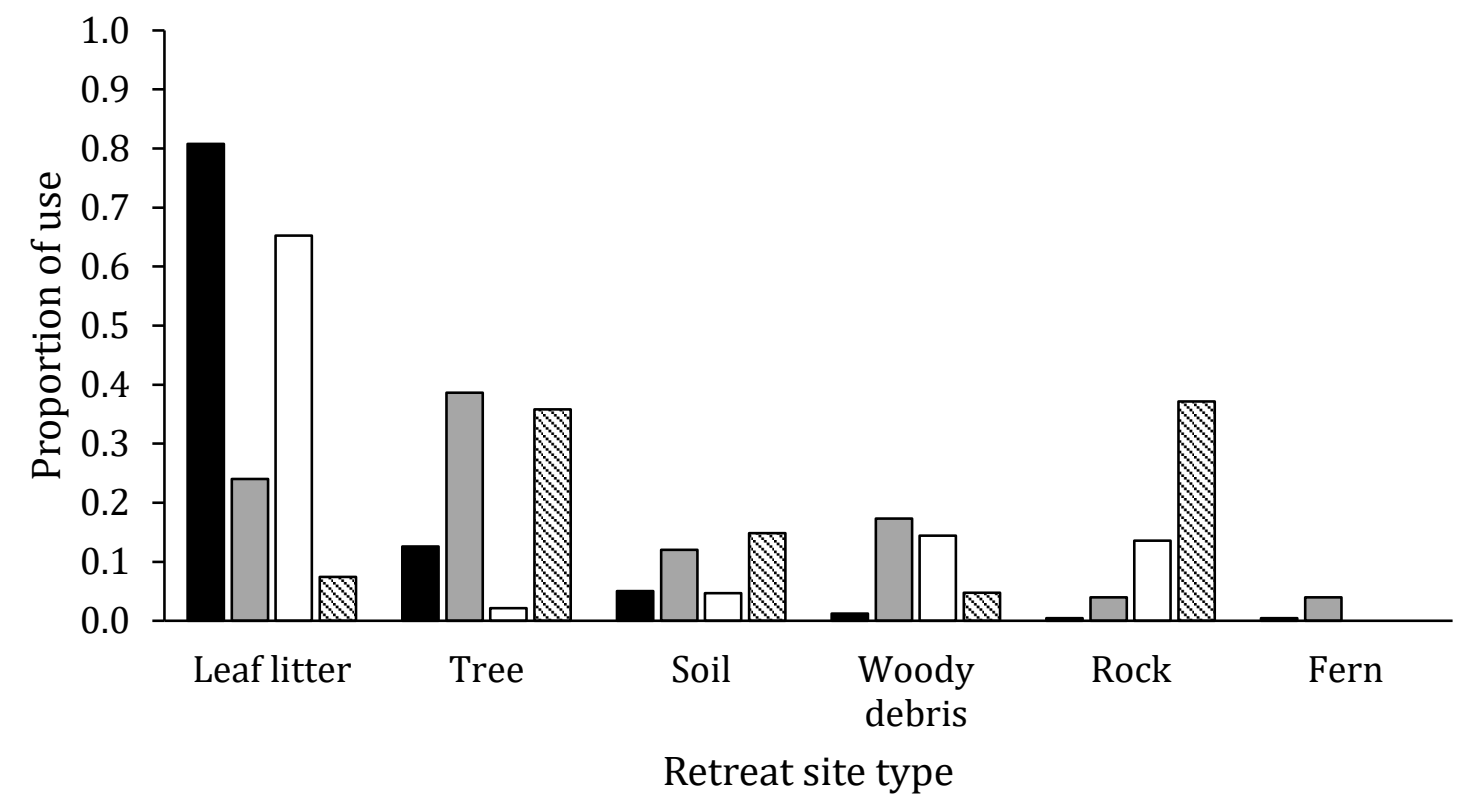

Figure 2: Proportion of retreat sites use compared to availability. Black and grey bars represent expected and observed proportions of use, respectively, by L. archeyi. White and dashed bars represent expected and observed proportions of use, respectively, by L. pakeka.

\subsubsection{Factors affecting retreat site use}

For L. archeyi, there were no significant seasonal differences in the use of leaf litter, soil, rocks, and woody debris as retreat sites $(\mathrm{z}=0.23, P=0.82 ; \mathrm{z}=0.86, P=0.39 ; \mathrm{z}=-1.40, P=0.17 ; \mathrm{z}=-$ $0.05, P=0.96$, respectively), whereas trees were more often used as retreats during the nonbreeding season $(\mathrm{z}=2.30, P=0.02)$. For L. pakeka, there were no significant seasonal differences 
in microhabitats used as retreat sites (leaf litter: $\mathrm{z}=-0.30, P=0.77$; soil: $\mathrm{z}=-0.02, P=0.98$; rocks: $\mathrm{z}=-0.02, P=0.98$; woody debris: $\mathrm{z}=0.09, P=0.93$; trees: $\mathrm{z}=1.74, P=0.10$ ).

The size of L. archeyi had no effect on the selection of leaf litter, soil, rocks, woody debris or ferns as retreat sites $(\mathrm{z}=-0.66, P=0.51 ; \mathrm{z}=-0.24, P=0.81 ; \mathrm{z}=0.1, P=0.92 ; \mathrm{z}=-0.25, P=0.80 ; \mathrm{z}=0.04$, $P=0.97$, respectively), but it did have an effect of the selection of trees with larger frogs using them as retreat sites $(\mathrm{z}=2.20, P=0.03)$. In the case of $L$. pakeka, frog size had no effect on the selection of microhabitat types as retreat sites (leaf litter: $\mathrm{z}=0.11, P=0.92$; soil: $\mathrm{z}=-1.06, P=$ 0.29 ; rocks: $\mathrm{z}=-0.44, P=0.66$; woody debris: $\mathrm{z}=0.58, P=0.56$; trees: $\mathrm{z}=-0.23, P=0.82$ ).

\subsubsection{L. pakeka retreat sites' dimensions}

The entrances of $L$. pakeka retreat sites $(n=86)$ had a mean height of $48.1 \pm 2.8 \mathrm{~mm}$, with $36 \%$ of the frogs using retreats with a height between 21-40 mm (Fig. 3). The mean width of retreats was $75.8 \pm 6.0 \mathrm{~mm}$, with $28 \%$ of frogs using retreats with a width between $21-40 \mathrm{~mm}$ (Fig. 3 ). The mean diameter of retreats was $62.0 \pm 3.6 \mathrm{~mm}$, with $30 \%$ of the frogs using retreats with a diameter between 41-60 mm (Fig. 3). There were no significant relationships between retreat height, width or diameter and the SVL of frogs there $\left(\mathrm{F}_{1,86}=0.0001, P=0.99 ; \mathrm{F}_{1,86}=0.02, P=0.89\right.$; $\mathrm{F}_{1,86}=0.01, P=0.90$, respectively).

The size of the inside of retreat sites, measured in terms of estimated frog size, varied among retreat sites. There was a tendency for retreat sites with two or three frogs inside to be larger (minimum of 2.6-frog-widths) than retreats with one frog (Fig. 4). For retreats with only one frog, sizes could be smaller, with one retreat measuring just 1-frog-width (Fig. 4). In terms of height, there was a less clear tendency for retreats with two or three frogs to have greater frog-heights (Fig. 4). However, retreat sites with more than one frog had at least 2.7-frog-heights. Three retreat sites measured just 1 -frog-height, that is, there was no discernible space above the frogs. No retreats were found to have both 1-frog-height and 1-frog-width. 
Retreat's entrance height

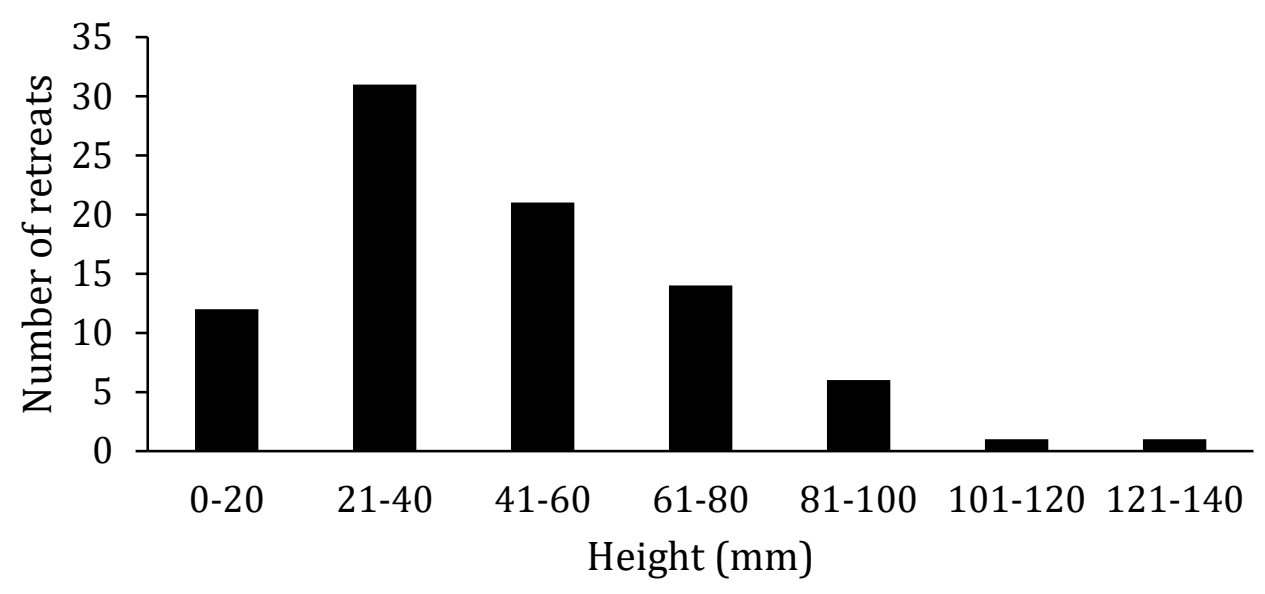

Retreat's entrance width

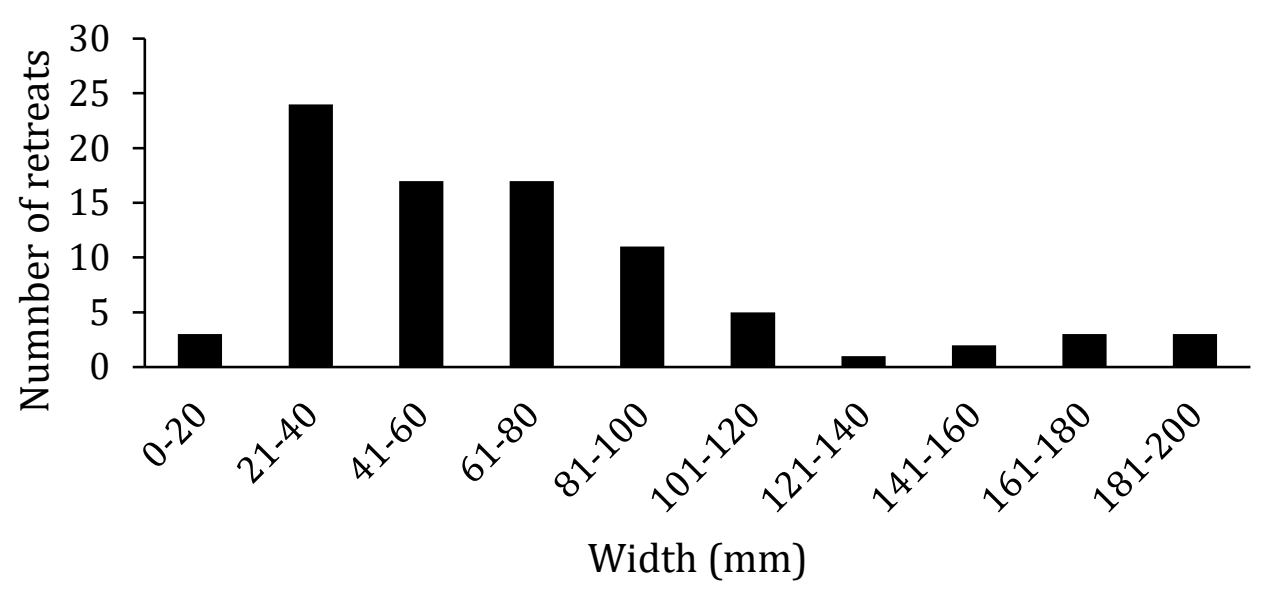

Retreat's entrance diameter

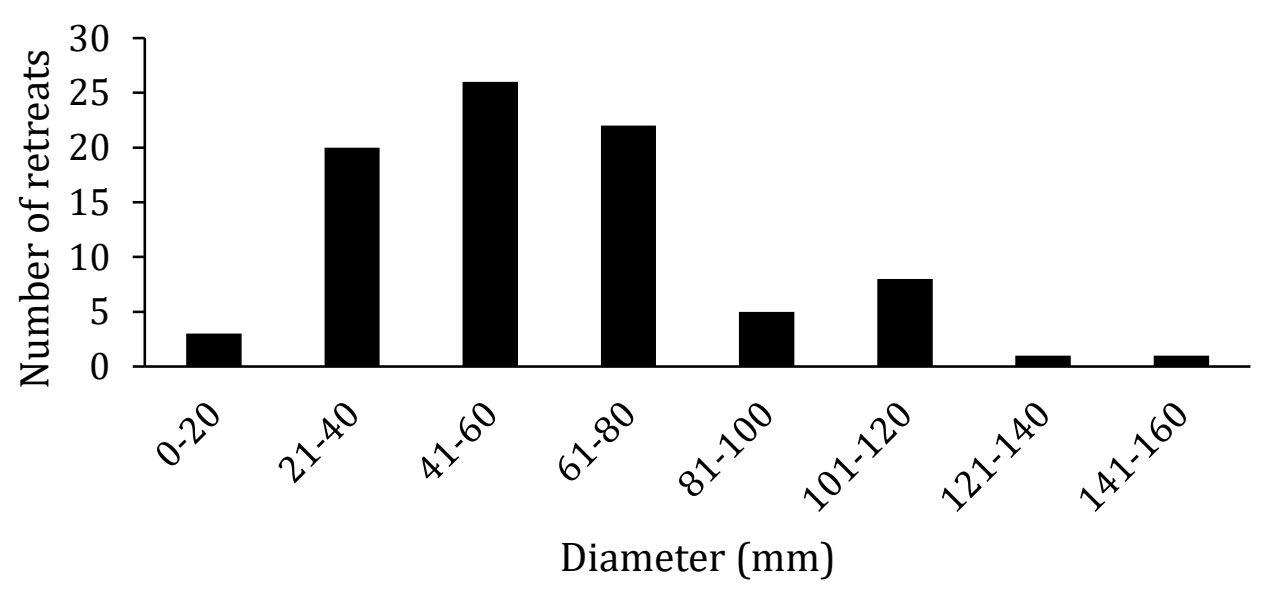

Figure 3: Frequency of L. pakeka retreat site use in relation to the dimensions (height, width and diameter) of the retreat sites' entrance. 

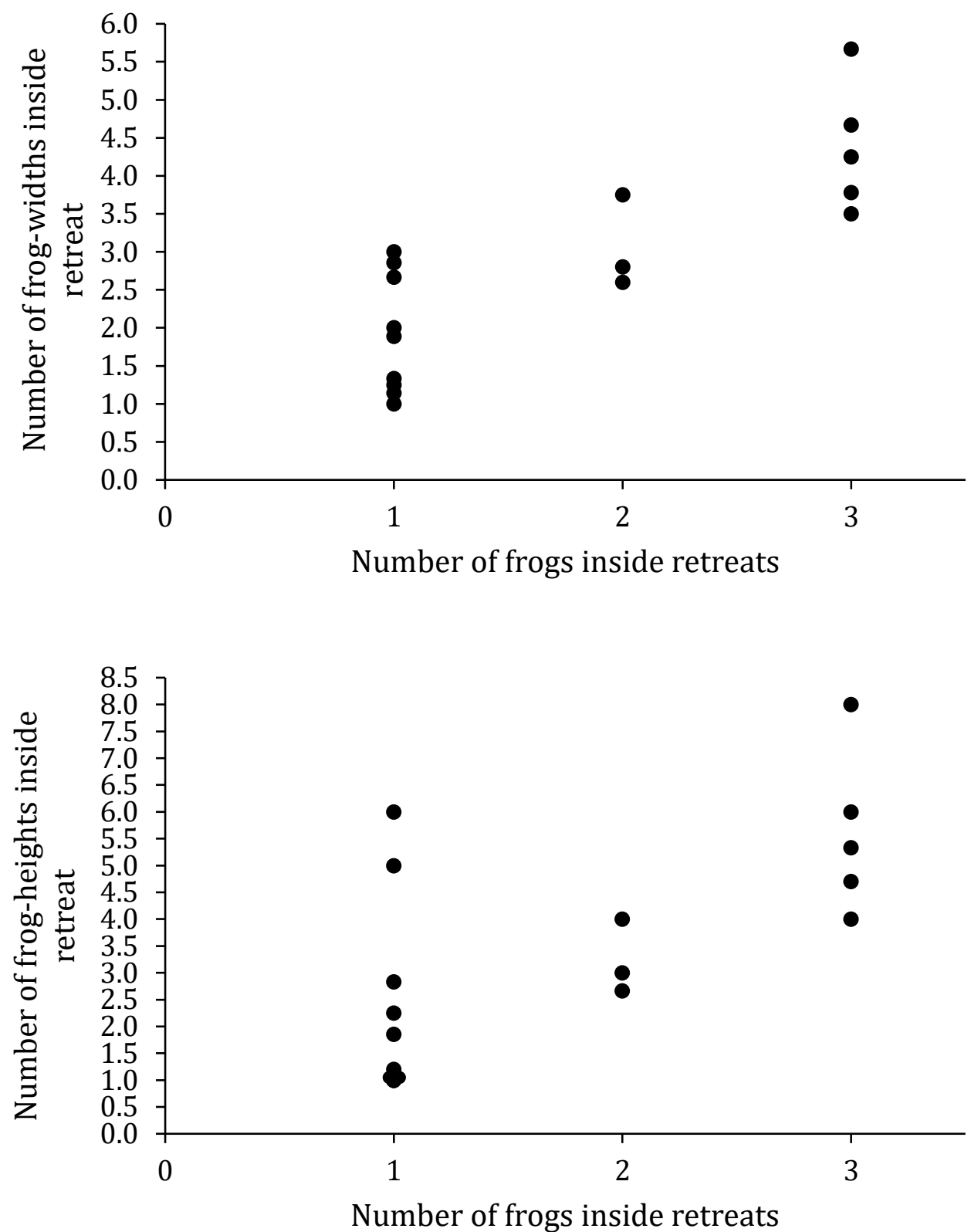

Figure 4: Number of L. pakeka frog-widths and frog-heights that could fit inside a retreat according to the number of frogs found inside based on measurements obtained from the burrowscope recordings.

\subsubsection{L. pakeka retreat sites' thermal conditions}

During the breeding season the mean temperature and range differed significantly inside versus outside L. pakeka retreat sites $(\mathrm{n}=52 ; \mathrm{z}=3.82, P<0.001 ; \mathrm{z}=5.54, P<0.0001$, respectively) with both variables being higher outside retreat sites (Fig. 5). The mean temperature and range inside 
retreat sites were $13.44 \pm 0.11^{\circ} \mathrm{C}$ and $2.04 \pm 0.13^{\circ} \mathrm{C}$, respectively, whereas the mean temperature and range outside retreat sites were $14.25 \pm 0.18{ }^{\circ} \mathrm{C}$ and $4.00 \pm 0.22^{\circ} \mathrm{C}$, respectively. During the non-breeding season the same pattern was observed with the mean temperature and range being higher outside retreat sites $(\mathrm{n}=23 ; \mathrm{z}=2.58, P=0.01 ; \mathrm{z}=4.00, P<0.0001$, respectively; Fig. 5). The mean temperature and range inside retreat sites were $12.50 \pm 0.47{ }^{\circ} \mathrm{C}$ and $2.40 \pm 0.19{ }^{\circ} \mathrm{C}$, respectively, whereas the mean temperature and range outside retreat sites were $13.71 \pm 0.20^{\circ} \mathrm{C}$ and $5.23 \pm 0.83{ }^{\circ} \mathrm{C}$, respectively.
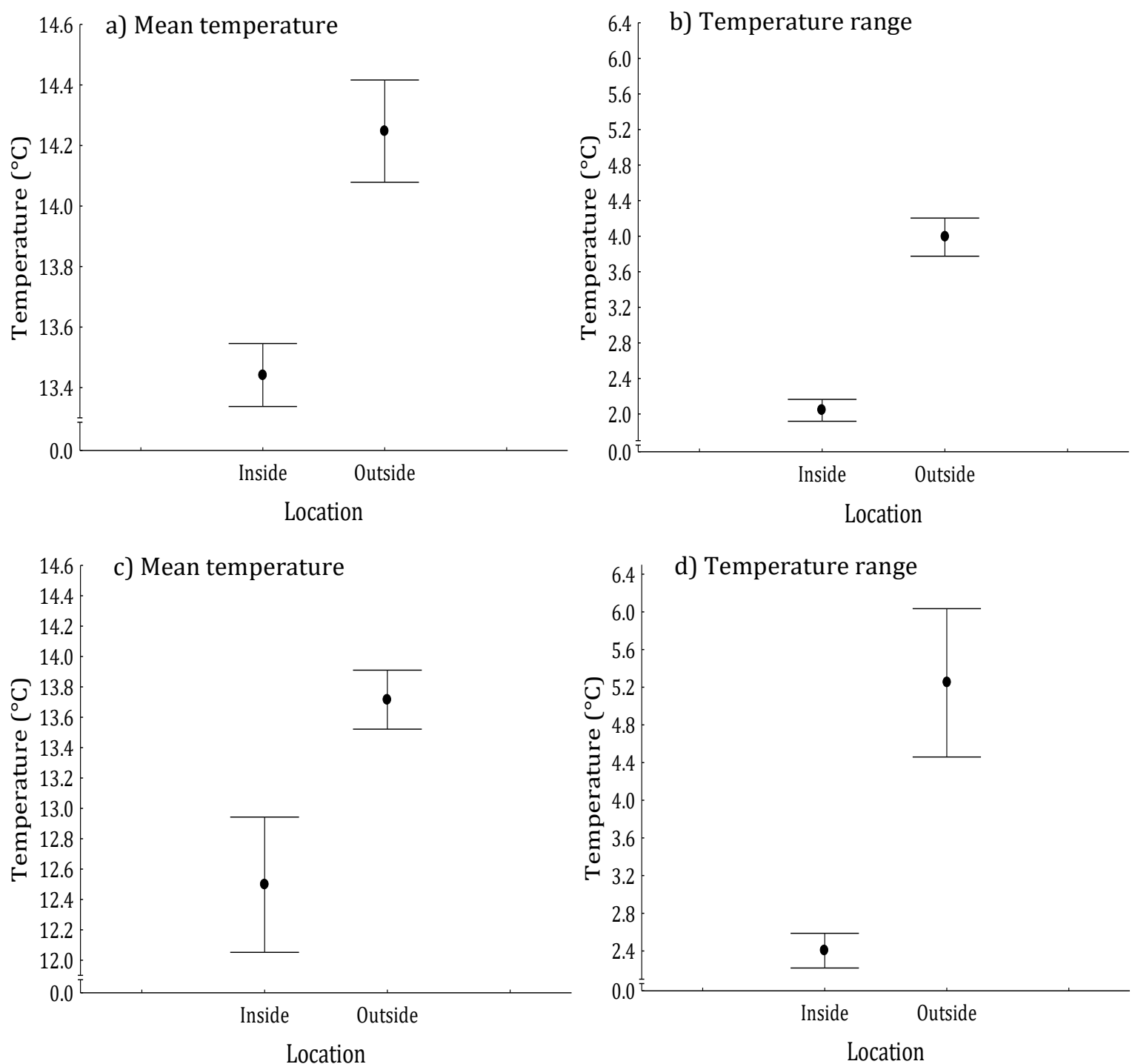

Figure 5: Mean temperature and range inside and outside L. pakeka retreat sites during the breeding (a-b) and non-breeding (c-d) seasons. Both measurements were higher outside retreat sites during both seasons. 


\subsubsection{Activity inside L. pakeka retreat sites}

I was able to record activity inside 14 different retreat sites ( $71 \mathrm{~h}$ of recording). One burrowscope malfunctioned; only 30 minutes of recording were retrieved for retreat site \# 7083 compared to the average of 306 minutes of recording per retreat site (Table 2), so this retreat site was not included in the movement and frequency analyses. By using the burrow-scope, I observed variation in the shape of the retreat sites. For example, some retreat sites had the entrance connected to a wider area deep inside through a narrow tunnel, whereas others opened up directly to the wider inside area. Some also had several crevices inside that led to different chambers, with one retreat site showing a very clear bifurcated shape. In 10 retreat sites $(71 \%$ of the total) only one frog was seen during the recording period, whereas in four retreat sites two or three frogs were seen inside (Table 2). Due to the intricate configuration of the retreat sites (i.e. with several tunnels and chambers) and the presence of more than one frog inside, the frog that was originally being tracked may or may not be the one that was recorded and for this reason the SVL of frogs could not be included as a factor affecting activity. On average, frogs spent $99.8 \%$ of the time not moving inside retreats, moving only $0.2 \%$ of the time (Table 2). Movements without displacement involved head movements, such as turning their heads to one side or the other without moving their limbs, repositioning of limbs, and body reorientation without moving from their position. Movements with displacement included feeding attempts (see below) and displacements around the retreat site, or towards the exterior. These movements were slow and short, except for the feeding attempts. Four frogs displaced towards the exterior of the retreat site, disappearing from the frame before the recording time ended. Movements without displacement were more frequent than movements with displacement (Fischer's exact test, $P<$ $0.0001)$ but had a similar duration $(27.90 \pm 8.7 \mathrm{~s}$ vs $14.60 \pm 4.04 \mathrm{~s}$, respectively; $\mathrm{U}=151.50, P=$ 0.20; Table 2). The proportion of time spent moving by frogs inside retreat sites with one frog did not differ from the retreat sites with more than one frog $(0.003 \pm 0.0008,0.002 \pm 0.0007$, respectively; $U=38.00, P=0.57$; Table 2). All frogs were observed with their eyes open throughout the recording period, closing their eyes at other times for less than a second. When 
not moving, all recorded frogs adopted a flat body posture with their ventral skin touching or very close to the retreat's lower surface. Frogs sharing a retreat site tended to be closer together in one corner of the retreat site, sometimes in direct contact with each other. Two frogs (frogs 8 and 17) were seen slowly moving on top of the other frogs (Fig. 6). Four frogs performed movements that differed from the other frogs. Frog 8, while being away from the other two frogs, made slow movements opening its mouth for a few seconds and then closing it for a total of 8 times (57 s). Frog 13, which was alone inside the retreat site, also performed this movement, but only once and for a total of $4 \mathrm{~s}$. Frog 18, which also was alone, moved its head from side to side on five different occasions, each time moving it from 19 to 30 times for a total of $93 \mathrm{~s}$, while frog 12 , sharing its retreat site with another frog, made this movement once for $6 \mathrm{~s}$. Additionally, frogs 8 and 18 performed cleaning-like movements rubbing a front leg over the top of their heads (Fig. 7). Frog 8 did this once and frog 18 twice. Although I could see live invertebrates (e.g. spiders, millipedes) moving inside the retreats, only two frogs attempted to eat. They did this by performing several short movements moving towards the prey, finishing with a fast jump trying to catch the prey with their mouths (frogs 3 and 17). Frogs did not seem to be interested in the burrow-scope as none of the frogs came close to it or avoided it during the entire recording period. 
Table 2: Quantitative summary of the recordings of 14 L. pakeka retreat sites showing frequency and duration of movements during the recording period.

\begin{tabular}{|c|c|c|c|c|c|c|c|c|c|}
\hline \multirow[b]{3}{*}{ Retreat } & \multirow[b]{3}{*}{ Recording time (s) } & \multirow[b]{3}{*}{ No. of frogs inside } & \multirow[b]{3}{*}{ Frog ID } & \multicolumn{4}{|c|}{ Movements } & \multirow[b]{3}{*}{$\begin{array}{l}\text { Total time } \\
\text { moving (s) }\end{array}$} & \multirow[b]{3}{*}{$\begin{array}{l}\text { Total time } \\
\text { not moving (s) }\end{array}$} \\
\hline & & & & \multicolumn{2}{|c|}{ Without displacement } & \multicolumn{2}{|c|}{ With displacement } & & \\
\hline & & & & Frequency & Duration (s) & Frequency & Duration (s) & & \\
\hline & & & 1 & 2 & 4 & 8 & 34 & 38 & 18963 \\
\hline 7042 & 19001 & 2 & 2 & 4 & 12 & 2 & 10 & 22 & 18979 \\
\hline 7062 & 21867 & 1 & 3 & 25 & 36 & 7 & 15 & 51 & 21816 \\
\hline 7070 & 12731 & 1 & 4 & 9 & 16 & 4 & 15 & 31 & 12700 \\
\hline 7032 & 22075 & 1 & 5 & 7 & 11 & 0 & 0 & 11 & 22064 \\
\hline 7135 & 21832 & 1 & 6 & 3 & 13 & 12 & 42 & 55 & 21777 \\
\hline \multirow[t]{3}{*}{7082} & 13948 & 1 & 7 & 10 & 14 & 0 & 0 & 14 & 13934 \\
\hline & & & 8 & 48 & 134 & 7 & 31 & 165 & 20400 \\
\hline & & & 9 & 2 & 5 & 0 & 0 & 5 & 20560 \\
\hline \multirow[t]{2}{*}{7099} & 20565 & 3 & 10 & 1 & 1 & 0 & 0 & 1 & 20564 \\
\hline & & & 11 & 8 & 12 & 4 & 32 & 44 & 21271 \\
\hline 7036 & 21315 & 2 & 12 & 10 & 23 & 0 & 0 & 23 & 21292 \\
\hline 7098 & 21835 & 1 & 13 & 6 & 6 & 4 & 13 & 19 & 21816 \\
\hline \multirow[t]{3}{*}{7112} & 20673 & 1 & 14 & 3 & 3 & 0 & 0 & 3 & 20670 \\
\hline & & & 15 & 18 & 37 & 0 & 0 & 37 & 20217 \\
\hline & & & 16 & 7 & 11 & 3 & 17 & 28 & 20226 \\
\hline 7068 & 20254 & 3 & 17 & 8 & 17 & 4 & 18 & 35 & 20219 \\
\hline 7046 & 17710 & 1 & 18 & 33 & 125 & 0 & 0 & 125 & 17585 \\
\hline $7083^{*}$ & 1801 & 1 & 19 & 0 & 0 & 0 & 0 & 0 & 1801 \\
\hline 7114 & 21491 & 1 & 20 & 23 & 78 & 19 & 65 & 143 & 21348 \\
\hline
\end{tabular}

* Burrow-scope malfunctioned after 30 minutes of recording. Retreat not included in movement and frequency analyses. 


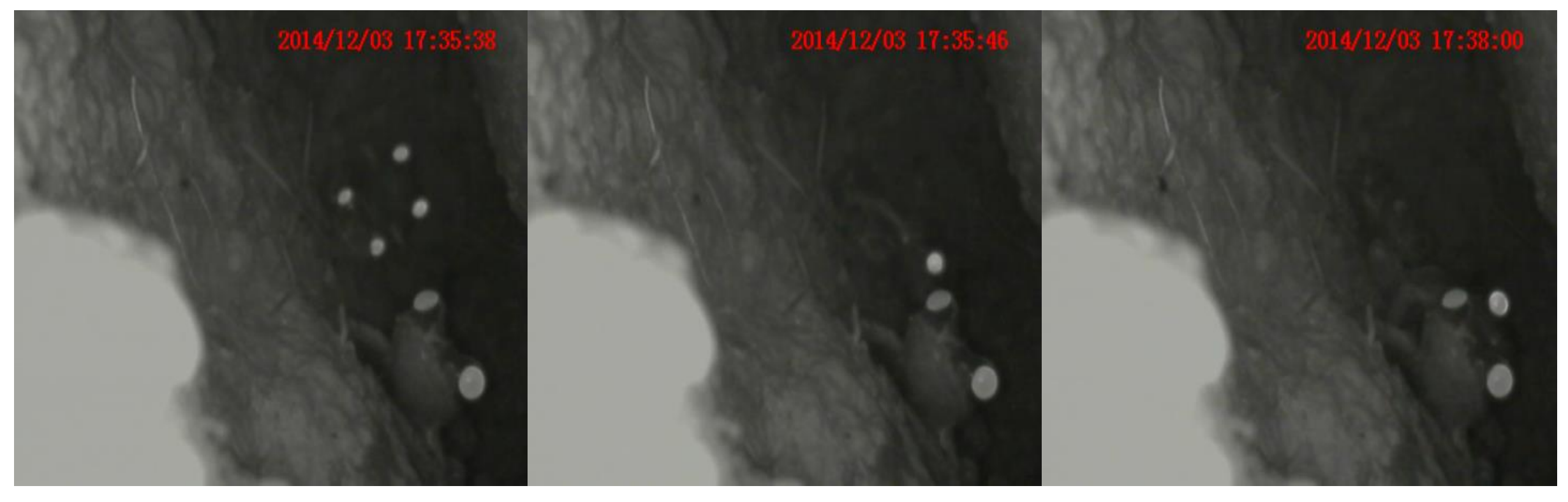

Figure 6: Movement sequence of frog 8 inside its retreat site. Sequence shows frog 8 walking on top of the other two frogs found inside the retreat site. 

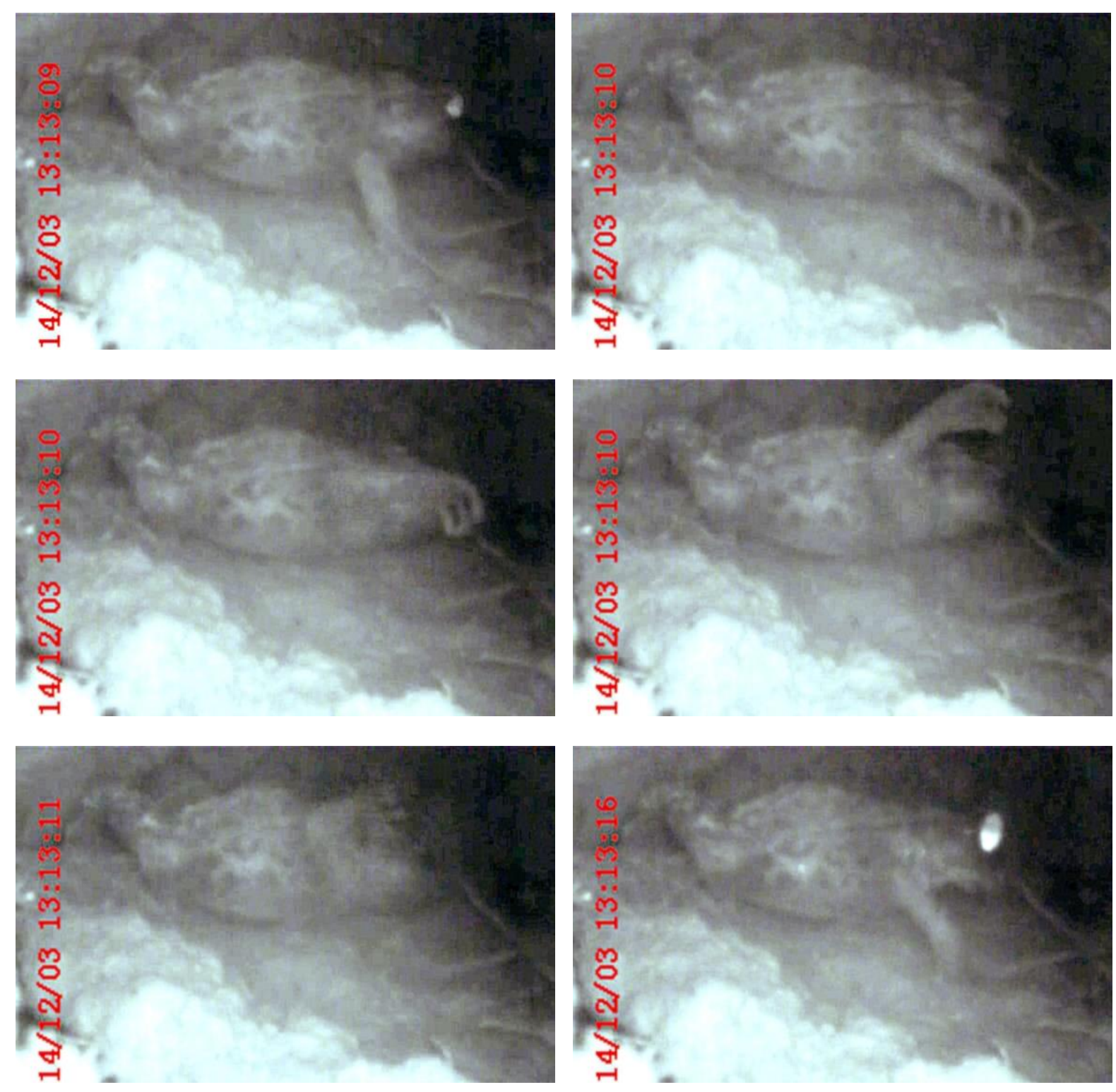

Figure 7: Movement sequence of frog 18 inside its retreat site performing cleaning-like movements inside the retreat site by rubbing a front leg over the top of its head. Sequence starts from top left corner following a left-right direction to the bottom right corner.

\subsection{Discussion}

Leiopelma archeyi and L. pakeka selected retreat sites differently from those available, indicating that frogs were not just retreating into the habitat they find themselves in at the end of the night, but actively selecting retreat sites. L. archeyi used more trees than were available. Either the roots 
or crevices above the ground in trunks and branches of trees were preferred retreat sites during the breeding and non-breeding seasons, with a considerably higher use during the former. Although frogs used less leaf litter than what was available, this microhabitat type was the second most preferred retreat site. Similar to L. archeyi, L. pakeka also used trees as retreat sites, but only the base (i.e. root), and it also used rocks in a similar proportion. Frogs' SVL only had an effect in the selection of trees by L. archeyi, with larger frogs using them as retreat sites.

Retreat site characteristics of L. pakeka were investigated in more detail. Retreat sites often had one frog inside, but there were also retreat sites with two or three frogs. The dimensions of entrances varied among retreats, but were not related to frog size (snout-vent length). For the retreat sites I was able to measure, there was a tendency for those with more than one frog inside to be wider (at least 2-frog-widths) and higher (at least 2-frog-heights). The sizes of the retreat sites with one frog inside varied more and included the smallest retreats (both in width and height). In situations with more than one frog, frogs were observed clustered in one corner of the retreat site in contact with one another. Frogs were always seen with their eyes open inside the retreat sites and spent most of the time without moving. When they did move, it was mostly without displacement. The presence of other frogs inside a retreat site did not affect the proportion of time spent by frogs moving inside the retreat and there were no behaviours seen only when frogs were alone or with others. During both seasons, the mean and range of temperature inside L. pakeka retreat sites were significantly lower than in the environment.

Previous studies of L. archeyi based on night and daytime surveys have also reported the use of woody debris (logs), vegetation (e.g. crown fern) and rocks as retreat sites (Bell 1978, Bell et al. 1985, Cree 1986, Thurley and Bell 1994), and rocks and logs for L. pakeka (Bell 1978, Newman 1990, Bell 1995). However, by tracking the frogs throughout their activity period, I found that both species also used leaf litter and soil, which had not been described before. Climbing in $L$. archeyi has been previously described with individuals climbing a few metres above the ground 
(Bell 1978, Cree 1989, Reilly et al. 2015, Chapter 4), but to my knowledge, this is the first study reporting quantitative information of selection of retreat sites high above the ground. Only larger L. archeyi used trees as retreat sites, perhaps to avoid predation, or due to reduced vulnerability to water loss compared to smaller frogs. Up trees air flow is presumably higher than at ground level, and frogs experience increased evaporation rates with increased air flow. Smaller frogs would be more vulnerable to water loss up trees as they experience higher rates of desiccation due to the greater surface area-to-volume-ratio than larger frogs (Spotila 1972, Tracy 1976, Cree 1986, Duellman and Trueb 1994, Seebacher and Alford 1999, Bartelt et al. 2004).

Amphibians have very limited abilities to alter rates of heat loss (Wells 2007), and can experience rapid water loss at high temperatures and low humidity due to their permeable skin (Duellman and Trueb 1994, Vitt and Caldwell 2009). Nocturnal species that remain sheltered during the day have the option to avoid adverse conditions imposed by the environment through retreat site selection (Kearney and Predavec 2000). This is because retreat sites minimize drying of the substrate and protect frogs from the desiccating effects of wind and direct solar radiation (Cree 1986, Cohen and Alford 1996). I show that retreat sites used by L. pakeka provided lower mean temperatures compared with the ambient, and a more stable microclimate as the temperature range was also lower inside than outside the retreats. Other studies have also found that retreat sites have the potential to buffer climate by providing lower mean temperatures compared to the ambient (Scheffers et al. 2014, Butts and McComb 2000, Seebacher and Alford 2002, Kluber et al. 2009, Fritts et al. 2015) and by maintaining a more stable environment inside retreats (Huey et al. 1989). For example, microrefuges used by 15 frog species in Southeast Asia reduced mean temperatures by $1-2{ }^{\circ} \mathrm{C}$ compared to the ambient and reduced the duration of extreme temperature exposure by 14-31 times (Scheffers et al. 2014). Similarly, the southern toad (Anaxyrus terrestris) used diurnal refuges made of coarse woody debris which were $2.1{ }^{\circ} \mathrm{C}$ cooler than open areas (Fritts et al. 2015). Cree (1986) found that the retreat sites of a population of $L$. archeyi in the Coromandel Peninsula, New Zealand, were cooler and relative humidity was higher 
than the ambient, aiding in the frogs' water balance. Although I could not measure relative humidity inside L. pakeka retreat sites, the lower mean temperatures found inside, compared to the environment, could also be indicative of higher humidity inside their retreat sites. Moisture is important for amphibians as they need to maintain a positive water balance in order to avoid desiccation, and therefore retreats can provide the means to restore the water lost during nightly activities (Duellman and Trueb 1994). Several studies have shown that amphibians select moist retreat sites that can allow for water balance (e.g. Schwarzkopf and Alford 1996, Oromí et al. 2010, Long and Prepas 2012). For example, the tropical cane toad (Bufo marinus) selected sheltered sites that provided the most protection from desiccation, thus reducing rates of water loss (Schwarzkopf and Alford 1996), and boreal toads (Anaxyrus boreas boreas) selected their refugia for favourable microclimatic conditions with elevated relative humidity compared to the surrounding habitat (Long and Prepas 2012).

In this study, all frogs were seen awake inside their retreat sites. Even though they spent most of their time staying still, they were all seen with their eyes open throughout the recording period and their limbs were not tucked in toward the body, behaviours that are indicative of sleep in amphibians (Hobson et al. 1968, Hoffman et al. 2010). Sleeping behaviour has been observed in other nocturnal species, such as tree frogs (Hyla squirella and H. cinerea; Hobson et al. 1968) and the western toad (Bufo Boreas; Huntley et al. 1978). However, just like in the case of L. pakeka, other amphibian species have been reported to lack this behaviour and be either quiescent at night (Rana (Lithobates) catesbeiana; Hobson et al. 1968), or to have circumdiel activity patterns (Lithobates areolatus; Hoffman et al. 2010). The behaviours of L. pakeka detected inside retreat sites could be indicative of behavioural thermoregulation and water balance, as well as a reflection of their sit-and-wait predatory behaviour. All frogs were recorded in a flat posture with the ventral skin touching or very close to the ground, which could allow frogs to regulate their water balance as less air is in contact with the skin, experiencing less water evaporation. Frogs were also seen displacing within their retreat sites and changing their posture with relative 
frequency. For nocturnal species, changes in posture within retreat sites are another form of thermoregulation (Huey 1982). Kearney and Predavec (2000) found that the marbled geckos (Christinus marmoratus) were able to thermoregulate by adjusting their position or posture inside their retreat sites in order to exploit thermal gradients beneath the rocks. In this case, I cannot be certain if the movements of frogs inside their retreat sites were related to thermoregulation as I did not measure temperatures at different locations beneath retreat sites, or the body temperatures of frogs.

I found more than one frog occupying the same retreat site on four occasions, and no aggressive behaviours towards conspecifics were observed. Waldman and Bishop (2004) found that $L$. pakeka showed no preference between substrates marked by themselves or by neighbours (i.e. frogs collected close to them), but did show preference for substrates marked by themselves compared to ones marked by frogs collected further away. The behaviours observed inside retreat sites suggest that perhaps L. pakeka are not territorial, or are socially territorial with the frogs they share retreat sites with being familiar to them. Alternatively, there can be compelling reasons for sharing retreats that aid fitness. Frogs sharing a retreat site were seen close to one another, and sometimes even touching, even though the retreat sites had enough space for frogs to be spread without direct contact. This behaviour suggests that being closer together brings benefits for the frogs while being sheltered inside retreat sites during the day. Aggregation of conspecifics has been reported for other amphibian species, such as tree frogs (Litoria spp; Bleach et al. 2014), the Great Plains toad (Bufo cognatus; Graves et al. 1993), and the Luschan's salamander (Mertensiella luschani; Gautier et al. 2006), with the benefits associated with this behaviour including thermoregulation and water balance. Because the surface area available for heat loss and water evaporation is reduced in aggregated individuals, the dehydration rates are lower in frogs that aggregate compared to single frogs (Johnson 1969). Additionally, the presence of conspecifics could be aiding in the selection of retreat sites as it can be a good indication of the habitat quality of that site (Stamps 1988, Woody and Mathis 1997). 
Leiopelma species have been reported to be sit-and-wait predators (Bell 1978, Eggers 1998, Reilly et al. 2015). L. pakeka nightly activity patterns show that they spend most of their time staying still on the surface (Reilly et al. 2015, Chapter 3). Reilly et al. (2015) found that when L. pakeka did move, their most common movements involved head-moves and rearrangements without change in location, which are also common movements in sit-and-wait ranid frogs (Heatwole 1961, Hoffman et al. 2010). I observed these same patterns in frogs inside their retreat sites. Frogs spent between 99.2 - 100\% of their time completely still, but when they moved, $77 \%$ of those movements were without displacement, moving their heads, limbs or reorienting. Additionally, two feeding attempts were observed with frogs slowly approaching the prey and performing a quick final jump towards it. These observations are another indication that frogs are still active inside their retreats, at least during the first hours of the day (i.e. up to $11 \mathrm{am}$ ).

There was a high variation in the structural dimensions of L. pakeka retreat site entrances, width, height, and diameter, with no relationship between those dimensions and the size of frogs. Although I did not find evidence of retreat site selection based on frog size, it may be that another property of the frog influences site selection. For example, dorsal coloration of L. archeyi is related to the microhabitat type where frogs are found, with greener frogs selecting retreat sites among vegetation more often than brown frogs (Thurley 1996). It is possible that the dorsal colour of frogs may be related to retreat site selection, but I did not investigate this factor here.

Overall, this study shows that the microclimate conditions inside the retreat sites used by $L$. pakeka are likely to facilitate their thermoregulation and water balance, aiding in their physiological performance (Huey 1991). Evidence also shows that L. pakeka are still active inside their retreat sites, performing movements with and without displacement, with no evidence of sleep behaviour for at least the first hours of the day. It would be interesting to investigate whether temperature or relative humidity vary spatially within retreat sites, and if this could be related to displacements of frogs inside retreat sites. Here I describe microhabitats selected as 
retreat sites, their characteristics and the behaviour of frogs inside these retreat sites, which will inform the creation of retreats in enclosures to maintain appropriate abiotic conditions for holding frogs in captivity and for improved captive husbandry. Additionally, this behavioural information, along with microhabitat selection in general (Chapter 4) and movement patterns (Chapter 3), can shed light into the behavioural aspects that are involved in the survival of species in the face of novel threats, such as introduced predators (Chapter 6). 


\section{Chapter 6}

\section{Indirect effects of an introduced predator on a population of the native frog Leiopelma archeyi}

\subsection{Introduction}

It has been widely recognized that introduced predators have a detrimental effect on biodiversity (Vitousek et al. 1997), including on amphibian species (Kats and Ferrer 2003, Kiesecker 2003, Wells 2007). Introduced predators have been linked to amphibian populations declines and even extinctions (e.g. Bradford 1991, Bradford et al. 1994, Hecnar and M'Closkey 1997, Knapp and Matthews 2000, Gillespie 2001), and in some cases, impose a greater risk than native predators (Salo et al. 2007). The lack of evolutionary history between introduced predators and native prey makes the latter naïve to the predators' tactics increasing the native species' susceptibility to predation (Kats and Ferrer 2003, Salo et al. 2007, Sih et al. 2010, Bucciarelli et al. 2014).

In addition to predation, introduced predators can have indirect impacts on native populations, that is, non-lethal effects which impose changes in food supplies, feeding behaviour, communication systems, activity levels, habitat use, and timing of life-history events (Lima and Dill 1990, Kiesecker and Blaustein 1997, 1998, Lima 1998, Paoletti et al. 2011, Bleach et al. 2015). These indirect effects can mitigate or increase impacts of direct predation (Lima 1998, Kats and Ferrer 2003, Preisser et al. 2005, D'Amore et al. 2009). For example, California red-legged frogs (Rana draytonii) have been found to use bare shores more frequently in the absence of an introduced adult frog while using more shoreline vegetation as cover in the presence of the introduced predator (D'amore et al. 2009), Duvaucel's geckos use a greater proportion of habitat preferred by rats after rat eradication (Hoare 2006) and Mallorcan midwife toad tadpoles decrease the time they spent actively swimming in the presence of introduced viperine snakes (Griffiths et al. 1998), in all cases minimizing the risk of predation. 
Amphibians in New Zealand are represented by nine endemic frog species: Leiopelma acricarina, L. miocaenale, L. auroraensis, L. markhami, L. waitomoensis, L. archeyi, L. hamiltoni, L. hochstetteri, and L. pakeka. The first two species are only known from Miocene deposits (Worthy et al. 2013) and the next three species became extinct during the Holocene period (Worthy 1987). The arrival of Polynesians in the thirteenth century AD (Wilmshurst and Higham 2004) and the subsequent introduction of mammals, especially rats, have been documented as the major cause for these recent Holocene extinctions and for the dramatic range reductions of the four extant species (Bell 1985a, Worthy 1987, Bell 1994, Towns and Daugherty 1994). New Zealand's biota evolved in the absence of predaceous mammals (Gibbs 2006), and therefore lack appropriate anti-predator responses (Worthy and Holdaway 2002). Currently, the only natural populations of L. pakeka and L. hamiltoni survive on two mammalian predator-free islands, although L. pakeka on Maud Island receive occasional incursions of mustelids, and a house mouse incursion was reported in 2013 but subsequently eradicated (Department of Conservation 2016). L. archeyi and L. hochstetteri have been able to co-occur with introduced predators but in fragmented populations across the North Island (Bell 1978, Thurley and Bell 1994, Bell et al. 2004b, Bishop et al. 2013).

Leiopelma archeyi is a terrestrial, cryptically-coloured and nocturnal species that retreats under rocks and vegetation during daytime (Bell 1978, Newman 1990, Chapter 5). Although nocturnal, this species can be found active on the surface until a few hours after daybreak (Bell 1978, Cree 1989, Chapter 3). There is no consistently observable sexual dimorphism apart from body size; females grow larger (Bell 1978). The snout-vent lengths of adult females exceed $31 \mathrm{~mm}$, with 25 - $31 \mathrm{~mm}$ in males or young females, and $<25 \mathrm{~mm}$ in sub-adults (Bell 1978). This makes it the smallest of the Leiopelma species. L. archeyi is currently classified as Critically Endangered by the World Conservation Union (IUCN 2017) and is listed as number one in the world's top 100 Evolutionarily Distinct and Globally Endangered Amphibians (EDGE) list (EDGE 2016). It is found on New Zealand's North Island within the Coromandel Peninsula and over a 600-ha area in Whareorino Forest (Northern King Country; Bell 1994, Thurley and Bell 1994). Whareorino 
Forest $\left(38^{\circ} 22^{\prime} \mathrm{S}, 174^{\circ} 47^{\prime} \mathrm{E}\right)$ is comprised of mixed broadleaf and podocarp cloud forest, such as tawa (Beilschmieda tawa) and rimu (Dacrydium cupressinum; Thurley and Bell 1994, Haigh et al. 2007). Here, L. archeyi co-occurs with a range of introduced predators including ship rats (Rattus rattus), house mice (Mus musculus) and brushtail possums (Trichosurus vulpecula; Thurley 1996, Thurley 2003, Haigh et al. 2007), along with the introduced frog Litoria aurea (Bell 1993, Thurley 1996). After clear evidence of rat predation on this species, most likely ship rat (Thurley and Bell 1994, Fitzgerald and Campbell 2003), a rat control programme was established on the northern 300-ha of the frogs' range in August 2003. The rat control consisted of ground-based bait stations with anticoagulant rodenticides (i.e. Coumatetralyl and Diphacinone; Department of Conservation unpub. data, Thurley 2003, Haigh et al. 2007) and five yearly aerial 1080 operations (Bridgman 2015). The southern 300-ha received no treatment (non-treatment area).

A frog monitoring programme established in 2005 demonstrated direct predation effects of rats with a higher frog abundance and recruitment found in the rat control area (Pledger 2011, 2013, Bridgman 2015). However, the indirect impacts these predators may have on this species have not been investigated. In Whareorino Forest, L. archeyi use a wide range of microhabitat types during their activity period, such as leaf litter, rocks and trees (Thurley 1996, Reilly et al. 2015, Chapter 4), and can climb up trees to an average height of 0.7-0.8 m (Chapters 4 and 5). Potentially, rats could indirectly affect L. archeyi microhabitat use and/or observed activity, and explain, in part, their co-occurrence. This key ecological information could aid in the design of effective conservation management programmes.

\subsubsection{Study aim and research questions}

I aimed to investigate whether non-native mammal predators (i.e. rats) impose indirect effects on the L. archeyi population in Whareorino Forest by influencing frog behaviour. I asked: Do microhabitat use and activity (represented by home range) of L. archeyi differ between the non- 
treatment and rat control areas? Here, home range is defined as the area in which an individual travels in search for resources, including food and mates (Brown 1975).

\subsection{Methods}

\subsubsection{Study sites}

The data used in this chapter were obtained from the New Zealand Department of Conservation (DOC) Te Kuiti office, and consisted of frog monitoring data in Whareorino Forest from 2005 to 2013 inside four $10 \times 10$ m grids, two of them established in the non-treatment area (grids A and B) and two in the rat control area (grids C and D). Each pair of grids was approximately $70-80 \mathrm{~m}$ apart to ensure independence of data (A. Haigh pers. comm.). These grids were established in similar habitat types with a high frog density, with at least 10 frogs captured in each grid on a given night (Haigh et al. 2007, A. Haigh pers. comm.). Nonetheless, grids A and D presented a more flat, open habitat compared to grids B and C which were on a slight slope. Additionally, grid B had more dense vegetation with several hanging vines and patches of ferns and saplings (Fig. 1). Each grid was separated into $1 \mathrm{~m}$ wide transects represented by a letter (A to J) along the width of the grid and by a number along its length ( 1 to 10 ) to mark a frog's location to the nearest $\mathrm{m}^{2}$. Rat monitoring started in 2008 and showed that during the period 2008 - 2013 rat capture rates ranged between $0 \%-38 \%$ in the rat control area and between $25 \%-90 \%$ in the non-treatment area (Department of Conservation unpub. data). 


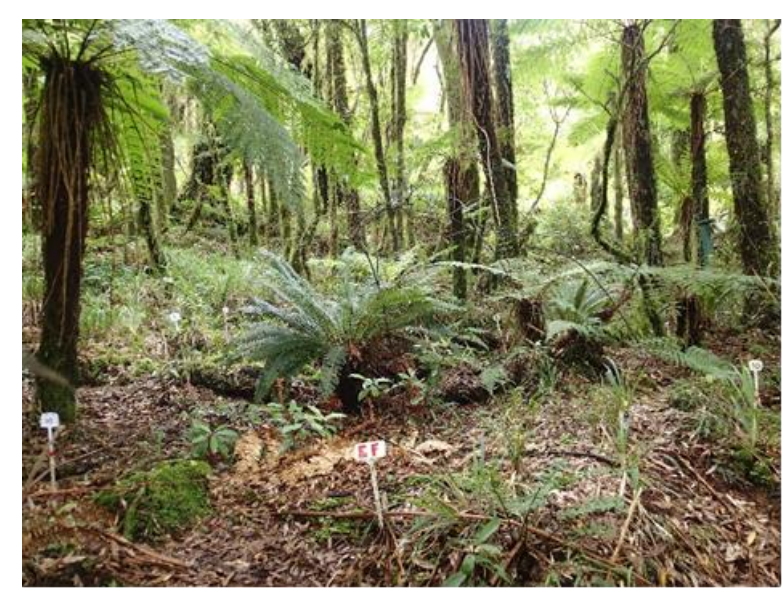

A

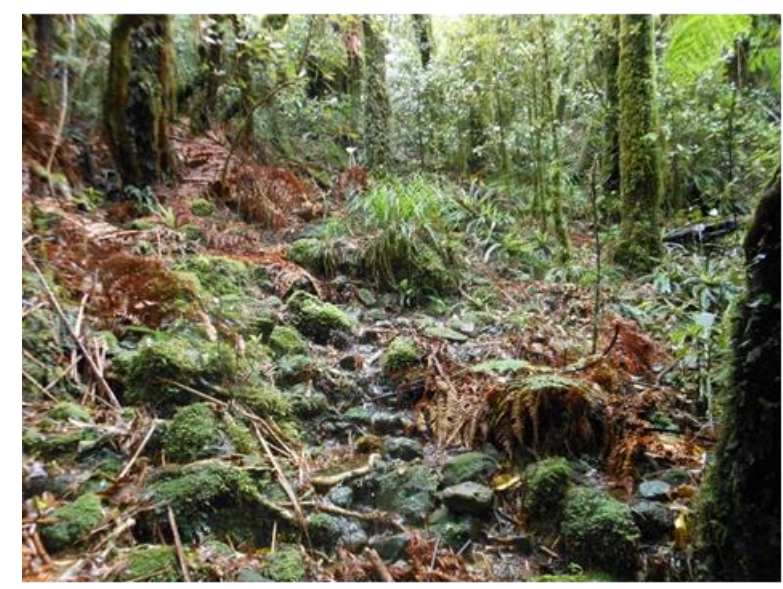

C

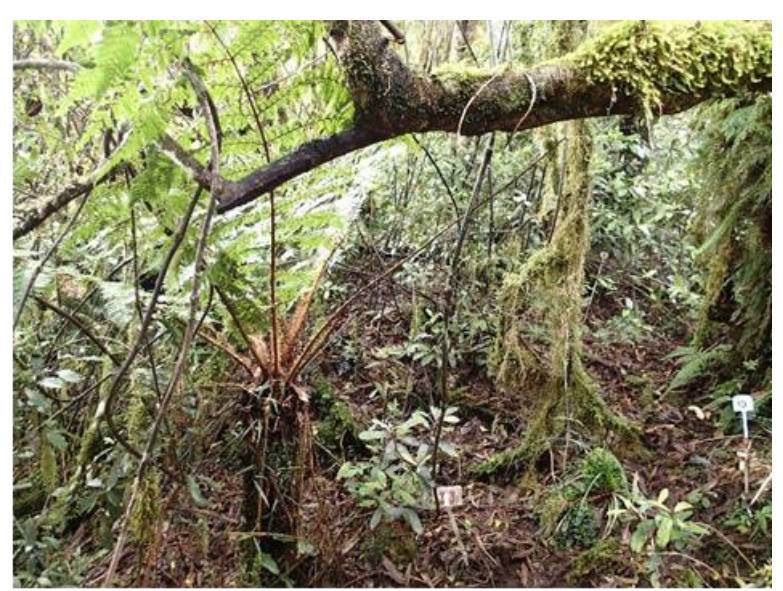

B

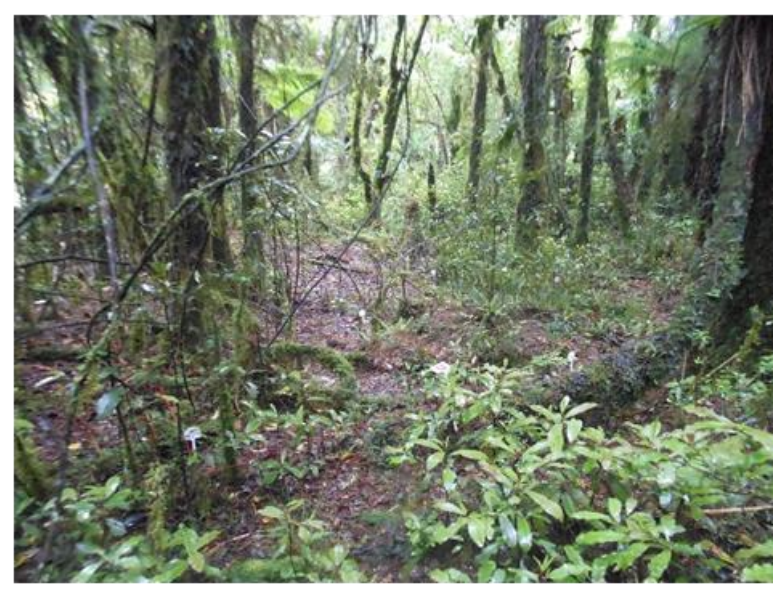

D

Figure 1: View of the four $10 \times 10 \mathrm{~m}$ grids established in Whareorino Forest. Letters below the bottom left corner identify each grid (grids A to D). Grids A and B are non-treatment grids and grids $\mathrm{C}$ and $\mathrm{D}$ are rat control grids.

\subsubsection{Frog monitoring}

Searches for frogs, carried out by DOC personnel, started one hour after sunset and ended once a grid was completely searched (mean duration 3.8 hours). Each grid was searched twice in a year (February/March and November/December), except in 2011 where sampling was conducted only once (February/March), for four consecutive nights each, except for February 2008 (n = 3) and November 2013 ( $n=8$, due to a very low capture rate) in grid A and February $2007(n=3)$ and December $2012(n=3)$ in grid D. To search for frogs, grids were divided into $2 \mathrm{~m}$ wide lanes 
and each lane was systematically searched for any emerged frogs, including under overhanging vegetation and up to two metres high. Once a frog was found, it was placed inside a zip-lock plastic bag and the location was marked with a plastic gardening stake bearing the same number as the bag. The microhabitat type and height where the frog was found were recorded and the point of capture was measured to the nearest centimetre in relation to the transect line. When all transects were searched, frogs were individually processed for identification by measuring their snoutvent length (SVL, $\mathrm{mm}$ ) and weight $(\mathrm{g})$, then photographed using a photographic mirror stage that enabled four views (lateral left, lateral right, frontal and dorsal) to be in the same photograph (Haigh et al. 2007). After processing, all frogs were returned to their capture location. Air temperature $\left({ }^{\circ} \mathrm{C}\right)$ and relative humidity $(\%)$ were recorded at the beginning of each search with a kestrel weather meter.

\subsubsection{Microhabitat availability}

To assess microhabitat availability inside the grids, 11 transects of $10 \mathrm{~m}$ each were established inside each grid, two of them corresponding to the borders of the grids. Along each transect a sampling point was set up at every metre starting from $0 \mathrm{~m}$. In each of the sampling points the microhabitat type that fell right under the metre mark was recorded. A total of 10 microhabitat types were characterized among the four grids (Table 1). 
Table 1: Microhabitat types found inside the grids

\begin{tabular}{ll}
\hline Microhabitat type & Description \\
\hline Leaf litter & Dead plant material (e.g. leaves, twigs) \\
Soil & Exposed soil \\
Rock & Rocks of all sizes \\
Woody debris & Fallen woody material not attached to a tree (e.g. branches, logs) \\
Tree/vine & Trees (e.g. Pseudowintera colorata) and vines (e.g. Ripogonum scandens) \\
Other plants & Any small plant, seedlings or shrub \\
Fern & Ferns of all sizes (e.g. Blechnum discolor) \\
Tree fern & Tree fern (e.g. Cyathea dealbata) \\
Grass/sedge & Grasses (e.g. Microlaena stipoides) and sedges (e.g. Uncinia uncinata) \\
Moss & Moss covered structures (e.g. bark) \\
\hline
\end{tabular}

\subsubsection{Home range}

To assess home range, the position of the captured frogs was transformed into Cartesian coordinates (X, Y coordinates). The 95\% minimum convex polygons (MCP; Row and BlouinDemers 2006) were calculated for frogs with eight or more recaptures following protocols from another study on L. pakeka (Karst 2013). Analyses were conducted in ArcGIS Desktop 10.4.1 and QGIS 2.14.3 'Essen'.

\subsubsection{Data analyses}

To assess whether the distribution of sizes (SVL) of frogs differed between grids, I carried out non-parametric Kruskal-Wallis tests with multiple comparison post-hoc tests. To assess whether microhabitat use differed from microhabitat availability, I first assessed whether grid replicates $\mathrm{A}$ and $\mathrm{B}$, and $\mathrm{C}$ and $\mathrm{D}$ differed from each other in microhabitat availability by using a Chi-square test with Yates correction to account for low expected frequencies in some microhabitat types. Because there were no significant differences in either of the two comparisons (A vs B: $\chi^{2}=7.49$, $P=0.38 ; \mathrm{C}$ vs $\mathrm{D}: \chi^{2}=2.87, P=0.97$ ), I grouped the data from each set of grids (A-B and C-D) for this analysis to increase sample size for investigation of the effect of predator control. I also 
assessed whether both set of grids differed in microhabitat availability by using a Chi-square test with Yates correction followed by single-degree-of-freedom Chi-square test with Bonferroni corrections to determine which microhabitat types differed between both set of grids (Sokal and Rohlf 1995). Lastly, I obtained the observed frequencies of microhabitat use per grid set by adding the number of times frogs were captured in a given microhabitat. I compared the observed frequencies of microhabitat use with the expected frequencies according to each microhabitat availability, using G tests of goodness-of-fit with William's correction (Sokal and Rohlf 1995). I carried out single-degree-of-freedom G tests with Bonferroni corrections to determine which microhabitat types differed from expectation (Sokal and Rohlf 1995).

I assessed whether microhabitat use was affected by treatment (non-treatment and rat control) or SVL (as frog size affect microhabitat use; Chapter 4). I constructed individual dichotomous generalized linear mixed models (GLMMs) with binomial distribution for each microhabitat type, applying a one-vs-rest classification scoring the use of a given microhabitat as 1 and the use of the rest as 0 (Arppe 2008). Treatment and SVL were included as fixed effects, while years, individual frogs and grids were included as random effects to account for differences among survey years, repeated measurements and differences among grids, respectively, with individuals nested within each grid as frogs were not observed moving between grids. As there are still uncertainties associated with the sexing of frogs using their size (Tocher et al. 2006, Germano et al. 2011), sex was not included as an intrinsic variable. Per microhabitat type, I constructed five candidate models including the individual effect of each explanatory variable, the additive and interaction models, and the null model including only the intercept. Because of the low use frequency, rocks were not included in this analysis and for the trees/vines and soil only three models were constructed as the use frequency of these microhabitats did not allow for the incorporation of additive or interaction terms. I used an information-theoretic approach for model selection using second-order Akaike's Information Criterion (AICc) for small sample sizes (Burnham and Anderson 2002). For model performance assessment, $\Delta$ AICc and Akaike weights $\left(w_{i}\right)$ were 
calculated. Models with Akaike weights $>10 \%$ were considered for analyses (Burnham and Anderson 2002). For models with weights $<0.90$, the sum of the Akaike model weights across all interpretable models where that variable occurred was used to evaluate the importance of a given predictor variable (Burnham and Anderson 2002). Confidence intervals (CI) of 85\% were used for parameter estimates (Arnold 2010). If confidence intervals included zero, then the predictor variable was considered as having no effect on the response (Yeiser and Richter 2015).

The heights where frogs were found were considered as the vertical component of the microhabitat use. I assessed whether the probability of a frog being found above the ground was affected by the treatment or the relative humidity, as ambient moisture can be a factor controlling climbing behaviour due to the frogs' permeable skin (Jaeger 1978, Duellman and Trueb 1994). I used GLMMs with binomial distribution $(0=$ frog found at ground level, $1=$ frog found above ground level), individual frogs nested within grids as a random effect, and relative humidity and treatment as fixed effects. Air temperature was not included in the models as multicollinearity analysis with relative humidity showed that temperature had a variance inflation factor (VIF) above 2.5 (Allison 1999). I used Akaike weights for model selection as described above.

To assess whether the home range differed between treatments, I used a non-parametric KruskalWallis test comparing frogs' home range from the non-treatment and rat control grids. Additionally, I assessed whether the home range of sub-adults $(<25 \mathrm{~mm} \mathrm{SVL})$ or adults $(>25 \mathrm{~mm}$ SVL) differed between treatments. To do this, I assigned an age class to each frog according to the age class that consecutively comprised $\geq 80 \%$ of the most recent recaptures. Analyses were also done using non-parametric Kruskal-Wallis tests. Statistical analyses were performed in R version 3.2.0 (R core Team 2015) and STATISTICA 7.0 (StatSoft Inc., USA). Summary statistics presented are the means \pm one standard error (SE). 


\subsection{Results}

A total of 5689 captures were obtained during 2005-2013 inside the four grids (Table 2). The highest number of captures was found in grid D ( $\mathrm{n}=2094)$, as well as the highest number of individuals $(\mathrm{n}=817)$. Although sampling effort was higher in grid A (see methods) the total number of individuals and captures were the lowest out of all the grids (Table 2). Overall, there were more frogs in the rat control grids than in the non-treatment grids by a factor of 2.3 (Table 2). Most captures inside each grid were sub-adults, comprising $68.7 \%$ of the overall total of captures (Table 2).

Table 2: Summary of frogs captures inside each of the four grids

\begin{tabular}{llcccc}
\hline & & & \multicolumn{3}{c}{ Captures } \\
\cline { 3 - 5 } Grids & Treatment & Individuals & Total & Sub-adults & Adults \\
\hline A & No treatment & 188 & 644 & 278 & 366 \\
B & No treatment & 398 & 1066 & 837 & 229 \\
C & Rat control & 810 & 1885 & 1370 & 515 \\
D & Rat control & 817 & 2094 & 1421 & 673 \\
Total & & 2213 & 5689 & 3906 & 1783 \\
\hline
\end{tabular}

The distribution of frogs' sizes varied significantly among grids $(H=243.9823, \mathrm{df}=3, P<0.0001)$, with sizes ranging from 6.3 to $41.1 \mathrm{~mm}$ (Fig. 2). Both the smallest and largest frogs were found on grid D. The highest mean SVL occurred on grid A $(25.5 \pm 0.3 \mathrm{~mm})$ followed by grid D $(22.2 \pm$ $0.2 \mathrm{~mm})$. Frogs on grids B and C had the lowest mean SVL $(20.5 \pm 0.2 \mathrm{~mm}$ and $20.8 \pm 0.2 \mathrm{~mm}$, respectively). A post-hoc test showed that mean SVL on grids B and C did not differ significantly from each other (multiple comparisons of means: $P=0.66$ ). 

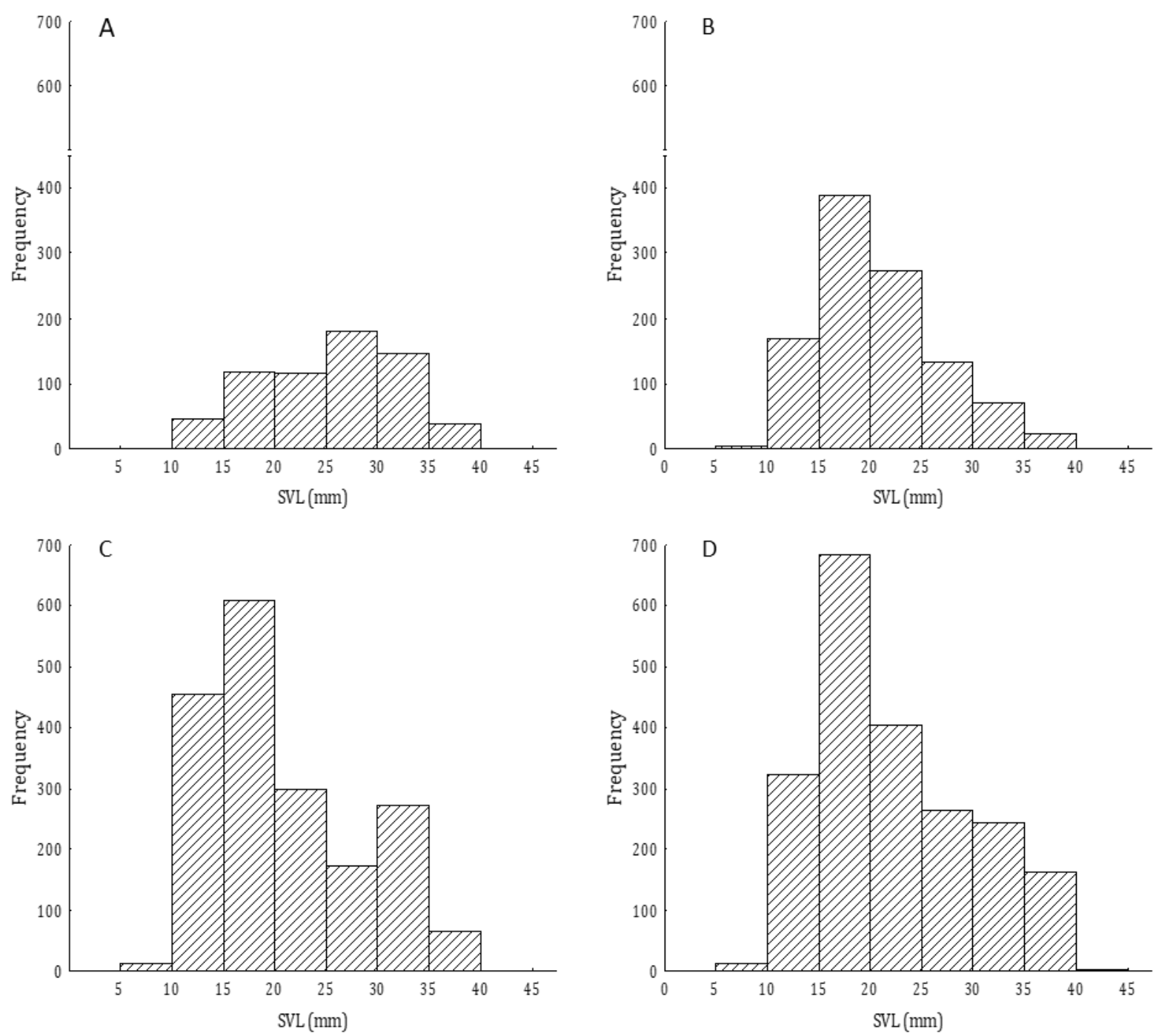

Figure 2: Size distribution (SVL) of frogs captured inside each of the four grids. Letters at the top corner identify each grid (grids $\mathrm{A}$ and $\mathrm{B}=$ non-treatment grids, $\mathrm{C}$ and $\mathrm{D}=$ rat control grids).

\subsubsection{Microhabitat use}

The main microhabitat types available on the non-treatment grids (A-B) and on the rat control grids (C-D) were leaf litter $(72.3 \%$ and $57.0 \%$, respectively) and ferns $(10 \%$ and $12.8 \%$, respectively; Table 3). Soil and rocks were only found on the rat control grids but in a very low proportion $(2.5 \%$ and $0.8 \%$, respectively). The microhabitat availability differed significantly between the two set of grids $\left(\chi^{2}=21.39, P=0.01\right)$, with this difference due only to the higher 
proportion of leaf litter found in the non-treatment grids $\left(\chi^{2}=12.38, P<0.001\right)$. None of the other microhabitat types differed between grids (all $P>0.005$ )

On both set of grids there were significant differences in the proportion of microhabitats used compared to availability (non-treatment grids: $\mathrm{G}_{\text {adj }}=2612.07, \mathrm{df}=8, P<0.0001$; rat control grids: $\left.G_{\text {adj }}=2763.05, \mathrm{df}=9, P<0.0001\right)$. On the non-treatment grids, leaf litter was used in less proportion compared to availability $\left(\mathrm{G}_{\mathrm{adj}}=2190.07, \mathrm{df}=1, P<0.0001\right)$ whereas ferns, moss, grasses/sedges, tree fern, and other plants were used in higher proportion $\left(G_{\text {adj }}=376.94, \mathrm{df}=1\right.$, $P<0.0001 ; \mathrm{G}_{\text {adj }}=100.31, \mathrm{df}=1, P<0.0001 ; \mathrm{G}_{\text {adj }}=848.79, \mathrm{df}=1, P<0.0001 ; \mathrm{G}_{\text {adj }}=443.26, \mathrm{df}=1$, $P<0.0001 ; \mathrm{G}_{\text {adj }}=11.87, \mathrm{df}=1, P<0.001$, respectively). No significant differences from availability were found in the use of trees/vines and woody debris $\left(\mathrm{G}_{\text {adj }}=3.53, \mathrm{df}=1, P=0.06 ; \mathrm{G}_{\mathrm{adj}}=0.164\right.$, $\mathrm{df}=1, P=0.69$, respectively). The use of soil and rocks were not incorporated in this analysis as these microhabitat types were not detected as available in the non-treatment grids and their use was only observed on four occasions (soil: $n=2$, rocks: $n=2$ ). In the rat control grids, leaf litter was also used in less proportion compared to availability $\left(\mathrm{G}_{\mathrm{adj}}=1439.63, \mathrm{df}=1, P<0.0001\right)$, along with tree fern, other plants, woody debris, and rocks $\left(\mathrm{G}_{\text {adj }}=9.86, \mathrm{df}=1, P=0.002 ; \mathrm{G}_{\text {adj }}=105.82\right.$, $\mathrm{df}=1, P<0.0001 ; \mathrm{G}_{\text {adj }}=19.054, \mathrm{df}=1, P<0.0001 ; \mathrm{G}_{\text {adj }}=30.25, \mathrm{df}=1, \mathrm{P}<0.0001$, respectively). As in the non-treatment grids, ferns and grasses/sedges were also selected in higher proportion compared to availability $\left(\mathrm{G}_{\mathrm{adj}}=1888.13, \mathrm{df}=1, P<0.0001 ; \mathrm{G}_{\text {adj }}=62.75, \mathrm{df}=1, P<0.0001\right.$, respectively), as well as trees/vines $\left(G_{a d j}=254.56, \mathrm{df}=1, P<0.0001\right)$. No significant differences from availability were found in the use of moss and soil $\left(G_{\text {adj }}=6.60, \mathrm{df}=1, P=0.01 ; \mathrm{G}_{\text {adj }}=1.21\right.$, $\mathrm{df}$ $=1, P=0.27$, respectively). 
Table 3: Microhabitat availability (frequency of occurrence at sample points) and use (observed proportion) by L. archeyi in the two sets of grids (non-treatment and rat control).

\begin{tabular}{|c|c|c|c|c|c|}
\hline Grids & $\begin{array}{l}\text { Microhabitat } \\
\text { type }\end{array}$ & $\begin{array}{l}\text { Availability } \\
\text { (frequency) }\end{array}$ & $\begin{array}{l}\text { Expected } \\
\text { proportion }\end{array}$ & $\begin{array}{l}\text { Observed } \\
\text { proportion }\end{array}$ & Difference $^{a}$ \\
\hline \multicolumn{6}{|l|}{ Non-treatment } \\
\hline \multirow[t]{8}{*}{$(A-B)$} & Leaf litter & 175 & 0.723 & 0.180 & $<$ \\
\hline & Fern & 24 & 0.099 & 0.265 & $>$ \\
\hline & Moss & 14 & 0.058 & 0.123 & $>$ \\
\hline & Grass/sedge & 13 & 0.054 & 0.271 & $>$ \\
\hline & Tree/vine & 7 & 0.029 & 0.037 & ns \\
\hline & Woody debris & 6 & 0.025 & 0.026 & ns \\
\hline & Tree fern & 2 & 0.008 & 0.087 & $>$ \\
\hline & Other plants & 1 & 0.004 & 0.011 & $>$ \\
\hline \multicolumn{6}{|l|}{ Rat control } \\
\hline \multirow[t]{10}{*}{ (C-D) } & Leaf litter & 138 & 0.570 & 0.273 & $<$ \\
\hline & Fern & 31 & 0.128 & 0.404 & $>$ \\
\hline & Moss & 22 & 0.091 & 0.103 & ns \\
\hline & Woody debris & 15 & 0.062 & 0.046 & $<$ \\
\hline & Tree fern & 9 & 0.037 & 0.028 & $<$ \\
\hline & Grass/sedge & 8 & 0.033 & 0.058 & $>$ \\
\hline & Other plants & 7 & 0.029 & 0.006 & $<$ \\
\hline & Soil & 6 & 0.025 & 0.022 & ns \\
\hline & Tree/vine & 4 & 0.017 & 0.058 & $>$ \\
\hline & Rock & 2 & 0.008 & 0.002 & $<$ \\
\hline
\end{tabular}

a Indicates significant differences in the observed proportions against expected proportions based on availability: less than expected $(<)$, more than expected $(>)$ and no significant difference between expected and observed proportions (ns).

\subsubsection{Factors affecting microhabitat use}

The selection of the different microhabitat types was influenced by different factors (Table 4). The highest weighted models had a weight of 1.00 while the lowest had a weight of 0.47 . The selection of soil was influenced by the treatment, with a higher use of soil found in the grids with rat control (estimate $=2.85, P=0.002$; Table 4 ). The selection of leaf litter, fern and tree fern was influenced by the interaction between SVL and treatment (Table 4). 
Table 4: Candidate models for the relationship between microhabitat selection and treatment (non-treatment and rat control grids) and SVL (snoutvent length) of L. archeyi. Interpretable models have Akaike weights > 10\% relative to the model with best fit.

\begin{tabular}{|c|c|c|c|c|c|c|}
\hline Microhabitat & Model & $\mathrm{K}^{\mathrm{a}}$ & $\mathrm{AIC}_{\mathrm{c}}$ & $\Delta \mathrm{AIC}_{\mathrm{c}}$ & Likelihood & $w_{i}$ \\
\hline \multicolumn{7}{|l|}{ Soil } \\
\hline & Treatment & 4 & 812.83 & 0.00 & 1.00 & 0.92 \\
\hline & Intercept & 3 & 818.75 & 5.92 & 0.05 & 0.05 \\
\hline & SVL & 4 & 819.75 & 6.92 & 0.03 & 0.03 \\
\hline \multicolumn{7}{|l|}{ Leaf litter } \\
\hline & Treatment + SVL + Treatment $*$ SVL & 6 & 5036.61 & 0.00 & 1.00 & 1.00 \\
\hline & Treatment & 4 & 5079.76 & 43.15 & 0.00 & 0.00 \\
\hline & Treatment + SVL & 5 & 5081.76 & 45.15 & 0.00 & 0.00 \\
\hline & Intercept & 3 & 5083.50 & 46.89 & 0.00 & 0.00 \\
\hline & SVL & 4 & 5085.46 & 48.84 & 0.00 & 0.00 \\
\hline \multicolumn{7}{|l|}{ Fern } \\
\hline & Treatment + SVL + Treatment $*$ SVL & 6 & 4170.90 & 0.00 & 1.00 & 1.00 \\
\hline & Treatment + SVL & 5 & 4189.42 & 18.51 & 0.00 & 0.00 \\
\hline & SVL & 4 & 4192.81 & 21.91 & 0.00 & 0.00 \\
\hline & Treatment & 4 & 4277.29 & 106.39 & 0.00 & 0.00 \\
\hline & Intercept & 3 & 4280.14 & 109.23 & 0.00 & 0.00 \\
\hline \multirow[t]{5}{*}{ Tree fern } & Treatment + SVL + Treatment $*$ SVL & 6 & 1636.89 & 0.00 & 1.00 & 1.00 \\
\hline & Treatment + SVL & 5 & 1654.58 & 17.70 & 0.00 & 0.00 \\
\hline & SVL & 4 & 1655.74 & 18.85 & 0.00 & 0.00 \\
\hline & Treatment & 4 & 1744.02 & 107.13 & 0.00 & 0.00 \\
\hline & Intercept & 3 & 1744.59 & 107.70 & 0.00 & 0.00 \\
\hline \multicolumn{7}{|l|}{ Other plants } \\
\hline & Intercept & 3 & 282.30 & 0.00 & 1.00 & 0.58 \\
\hline & Treatment & 4 & 284.30 & 2.00 & 0.37 & 0.21 \\
\hline
\end{tabular}




\begin{tabular}{|c|c|c|c|c|c|c|}
\hline Microhabitat & Model & $\mathrm{K}^{\mathrm{a}}$ & $\mathrm{AIC}_{\mathrm{c}}$ & $\Delta \mathrm{AIC}_{\mathrm{c}}$ & Likelihood & $w_{i}$ \\
\hline & SVL & 4 & 284.35 & 2.05 & 0.36 & 0.21 \\
\hline \multicolumn{7}{|l|}{ Grass/sedge } \\
\hline & Treatment + SVL & 5 & 3251.52 & 0.00 & 1.00 & 0.65 \\
\hline & Treatment + SVL+ Treatment $*$ SVL & 6 & 3252.78 & 1.26 & 0.53 & 0.35 \\
\hline & Treatment & 4 & 3261.00 & 9.48 & 0.01 & 0.01 \\
\hline & SVL & 4 & 3351.02 & 99.50 & 0.00 & 0.00 \\
\hline & Intercept & 3 & 3377.21 & 125.70 & 0.00 & 0.00 \\
\hline \multicolumn{7}{|l|}{ Moss } \\
\hline & Treatment + SVL+ Treatment $*$ SVL & 6 & 2740.23 & 0.00 & 1.00 & 0.60 \\
\hline & SVL & 4 & 2741.84 & 1.61 & 0.45 & 0.27 \\
\hline & Treatment + SVL & 5 & 2743.32 & 3.09 & 0.21 & 0.13 \\
\hline & Intercept & 3 & 2802.60 & 62.37 & 0.00 & 0.00 \\
\hline & Treatment & 4 & 2803.82 & 63.59 & 0.00 & 0.00 \\
\hline \multicolumn{7}{|l|}{ Tree/vine } \\
\hline & Treatment & 4 & 1722.16 & 0.00 & 1.00 & 0.47 \\
\hline & Treatment + SVL+ Treatment $*$ SVL & 6 & 1722.98 & 0.82 & 0.66 & 0.31 \\
\hline & Treatment + SVL & 5 & 1723.73 & 1.57 & 0.46 & 0.22 \\
\hline & Intercept & 3 & 1821.93 & 99.77 & 0.00 & 0.00 \\
\hline & SVL & 4 & 1823.84 & 101.68 & 0.00 & 0.00 \\
\hline \multicolumn{7}{|l|}{ Woody debris } \\
\hline & SVL & 4 & 1736.10 & 0.00 & 1.00 & 0.60 \\
\hline & Treatment + SVL & 5 & 1737.89 & 1.78 & 0.41 & 0.25 \\
\hline & Treatment + SVL+ Treatment $*$ SVL & 6 & 1739.01 & 2.90 & 0.23 & 0.14 \\
\hline & Intercept & 3 & 1745.59 & 9.48 & 0.01 & 0.01 \\
\hline & Treatment & 4 & 1747.46 & 11.36 & 0.00 & 0.00 \\
\hline
\end{tabular}

a Indicates number of parameters included in the model (including error term and intercept) 
There was a higher use of leaf litter by larger frogs in the rat control grids and by smaller frogs in the non-treatment grids (Fig. 3). The use of ferns was higher among smaller frogs in both sets of grids, but this effect was stronger in the rat control grids (Fig. 3), whereas the use of tree fern was higher among larger frogs in both sets of grids, but with a stronger effect in the nontreatment grids (Fig. 3).
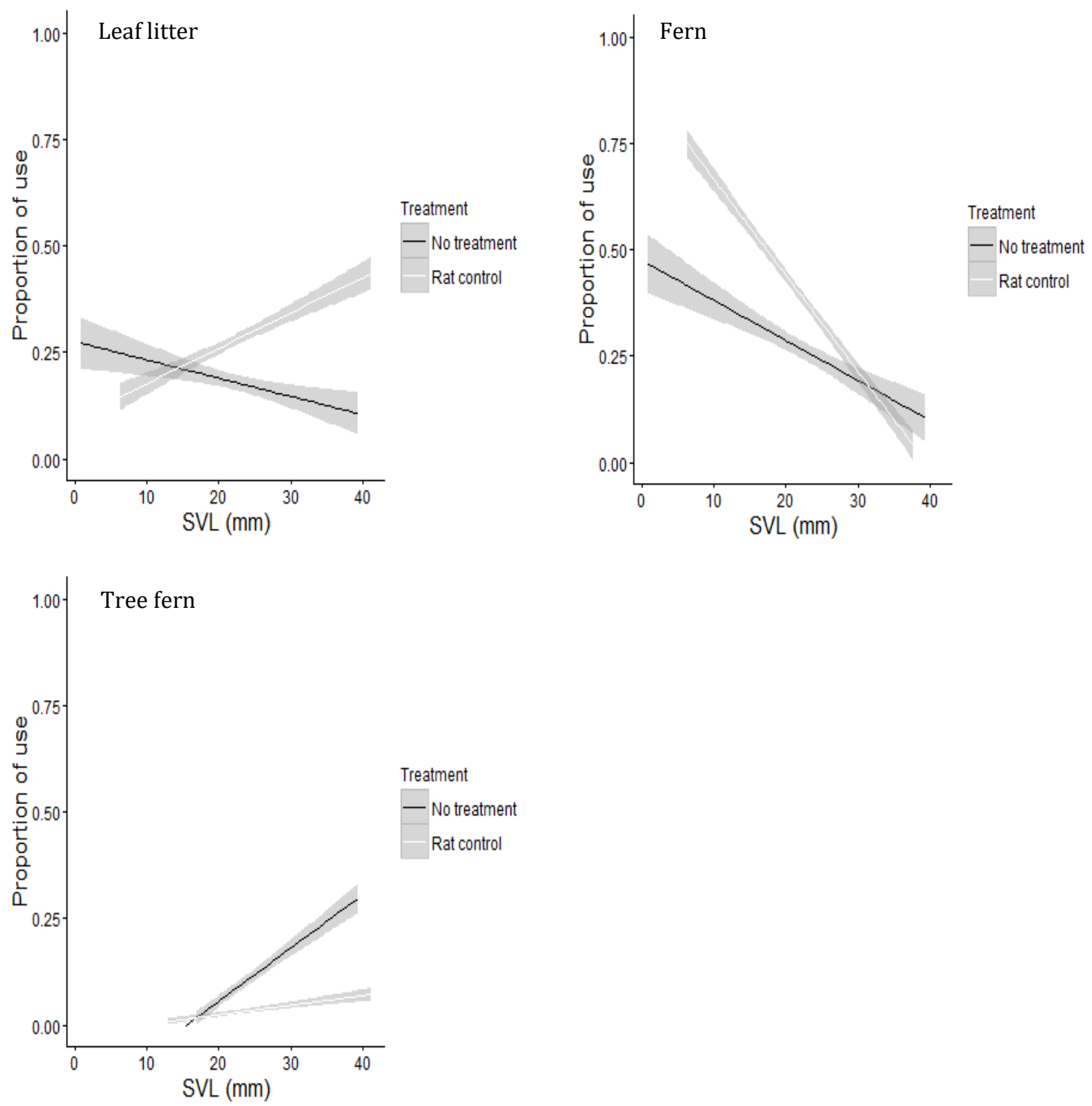

Figure 3: Interaction plots between treatment and size (SVL) of L. archeyi, and the proportion of use of leaf litter, ferns and tree fern. Grey areas represent 95\% confidence intervals. 
The models explaining the use of the other microhabitat types did not have a weight $>0.90$, and therefore model averaging was applied (Table 5). Grasses/sedges were more often used by smaller frogs and by frogs in the non-treatment grids. The use of moss, trees/vines and woody debris were influenced by SVL, with larger frogs using these microhabitats more often. Additionally, the use of trees/vines was also influenced by the treatment, with a higher use in the non-treatment grids. The use of other plants was not influenced by any of the studied factors (Table 5).

Table 5: Cumulative Akaike weights $\left(w_{i}\right)$, averaged parameters estimates and $85 \%$ confidence intervals (CI) for the predictive parameters, treatment (non-treatment and rat control grids) and SVL (snout-vent length) of microhabitat selection by L. archeyi.

\begin{tabular}{lllllll}
\hline & & & & \multicolumn{2}{c}{$85 \%$ CI } \\
\cline { 5 - 7 } Microhabitat & Parameter & $w_{i}$ & Estimate & Lower & Upper \\
\hline Other plants & & & & & \\
& Treatment & 0.21 & $-0.08^{\mathrm{a}}$ & -1.84 & 1.68 \\
& SVL & 0.21 & $-0.01^{\mathrm{a}}$ & -0.02 & 0.00 \\
Grass/sedge & & & & & \\
& Treatment & 0.99 & -2.75 & -3.24 & -2.27 \\
& SVL & 0.99 & -0.11 & -0.12 & -0.09 \\
Moss & & & & & \\
SVL & 1.00 & 0.06 & 0.05 & 0.08 \\
& Treatment & 0.40 & -0.49 a & -1.44 & 0.45 \\
& & & & & \\
SVL & 1.00 & 0.11 & 0.09 & 0.13 \\
& Treatment & 0.78 & -0.29 & -0.61 & -0.33 \\
& & & & & \\
& SVL & 0.99 & 0.03 & 0.02 & 0.05 \\
& Treatment & 0.39 & $0.32^{\mathrm{a}}$ & -0.66 & 1.31 \\
\hline
\end{tabular}

a Parameter estimates with 85\% CI including zero

\subsubsection{Vertical component of microhabitat use}

The mean night-time air temperature during which frogs were found was $13.3 \pm 0.03{ }^{\circ} \mathrm{C}$ (range: $5.9-19.2^{\circ} \mathrm{C}$ ), whereas the mean relative humidity was $96.2 \pm 0.07 \%$ (range: $73.9-100 \%$ ). In the 
non-treatment grids, $74.0 \%$ of the frogs were found above ground level at an average height of $0.20 \pm 0.009 \mathrm{~m}$ (range: $0.0-2.1 \mathrm{~m}$ ), while in the rat control grids $61.5 \%$ of the frogs were found above ground level at an average height of $0.13 \pm 0.005 \mathrm{~m}$ (range: $0.0-2.9 \mathrm{~m}$ ). The probability of a frog being found above ground level was affected by the treatment and relative humidity (Table 6). Model averaging indicated that frogs were more likely to be above ground level in the nontreatment grids (averaged parameter estimate $=-0.56,85 \% \mathrm{CI}=-0.73--0.39$ ) and when relative humidity was higher (model-averaged estimate $=0.05,85 \% \mathrm{CI}=0.04-0.06$ ).

Table 6: Candidate models for the relationship between the probabilities of frogs being found above ground level and treatment (non-treatment and rat control grids) and relative humidity (RH). Interpretable models have Akaike weights $>10 \%$ relative to the model with best fit.

\begin{tabular}{lcllll}
\hline Model & $\mathrm{K}^{\mathrm{a}}$ & $\mathrm{AIC}_{\mathrm{c}}$ & $\Delta \mathrm{AIC}_{\mathrm{c}}$ & Likelihood & $w_{i}$ \\
\hline Treatment + RH + Treatment ${ }^{*} \mathrm{RH}$ & 6 & 5755.78 & 0.00 & 1.00 & 0.66 \\
Treatment + RH & 5 & 5757.32 & 1.54 & 0.46 & 0.31 \\
$\mathrm{RH}$ & 4 & 5761.83 & 6.05 & 0.04 & 0.03 \\
Treatment & 4 & 5815.57 & 59.79 & 0.00 & 0.00 \\
Intercept & 3 & 5820.54 & 64.76 & 0.00 & 0.00 \\
Indicates number of parameters included in the model (including error term and intercept)
\end{tabular}

\subsubsection{Home range}

There was a high variation in the frogs' home ranges determined using the minimum convex polygon (MCP) method, with values ranging from $0.61 \mathrm{~m}^{2}$ to $18.56 \mathrm{~m}^{2}$ (Appendices 1 and 2). Mean home range estimates did not significantly differ between treatments (non-treatment grids $=4.98$ $\pm 0.77 \mathrm{~m}^{2}$, rat control grids $=4.32 \pm 0.49 \mathrm{~m}^{2} ; \mathrm{H}=0.09, \mathrm{df}=1, P=0.76$ ). Similarly, mean home range of sub-adults and adults did not significantly differ between treatments either $(\mathrm{H}=0.11, \mathrm{df}=1, P$ $=0.73 ; \mathrm{H}=0.67, \mathrm{df}=1, P=0.98$, respectively; Fig. 4, Table 7). 


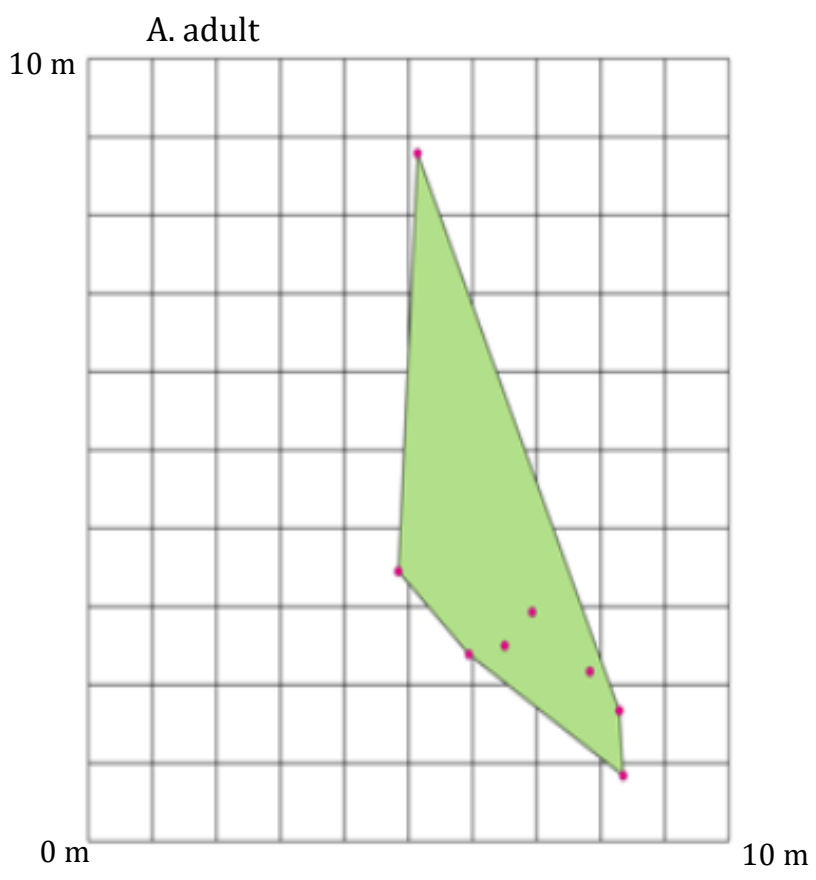

B. sub-adult

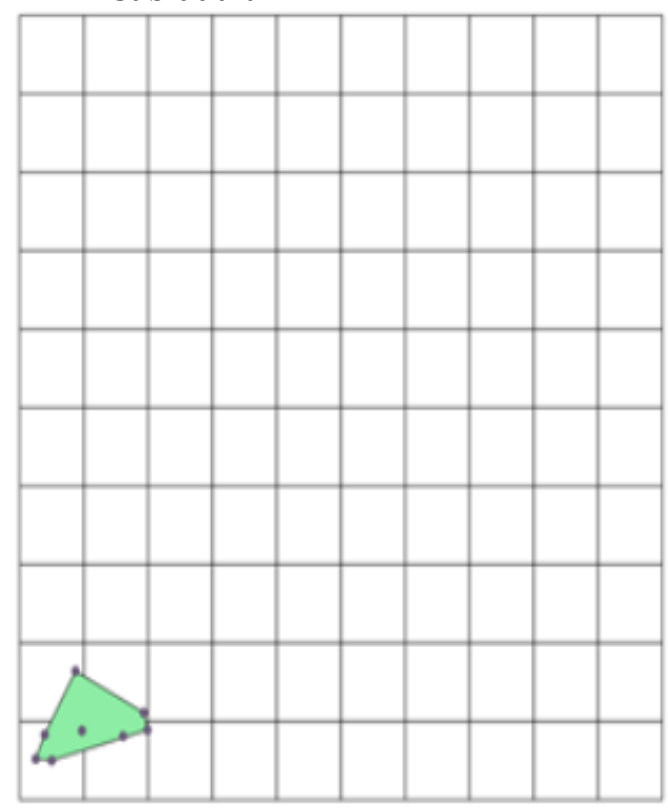

D. sub-adult

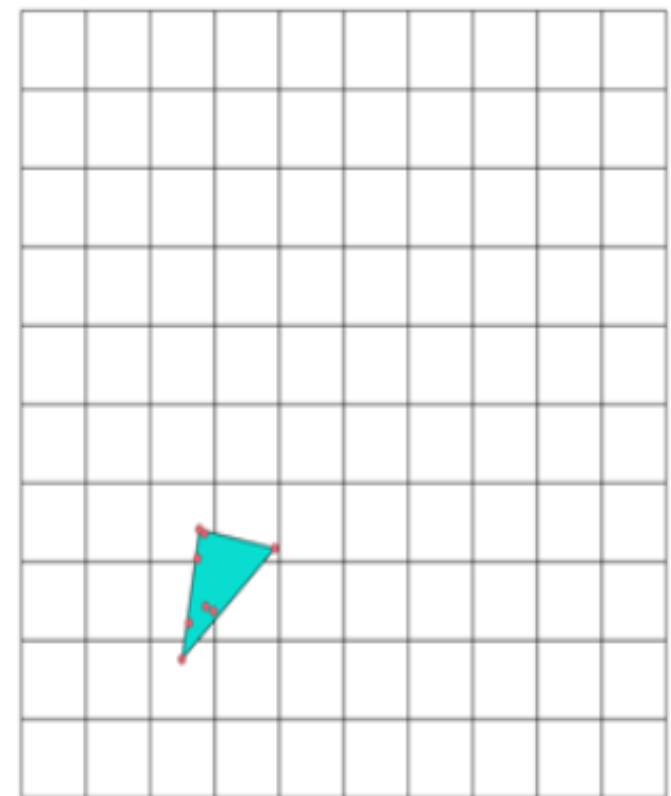

Figure 4: Randomly chosen examples of minimum convex polygons of adult and sub-adult $L$. archeyi from the non-treatment (A-B) and rat control grids (C-D). Grids dimensions are $10 \times 10$ m. 
Table 7: Range and mean $( \pm$ SE) minimum convex polygon (MCP) estimates for sub-adults and adult $L$. archeyi with $\geq 8$ recaptures.

\begin{tabular}{llcll}
\hline & & & \multicolumn{2}{c}{$\mathrm{MCP}\left(\mathrm{m}^{2}\right)$} \\
\cline { 4 - 5 } Grids & Age class & Number of frogs & Range & Mean \pm SE \\
\hline Non-treatment & & & & \\
& Sub-adult & 10 & $0.61-6.81$ & $2.29 \pm 0.67$ \\
\multirow{3}{*}{ Rat control } & Adult & 10 & $1.10-11.28$ & $4.91 \pm 1.06$ \\
& & & & \\
& Sub-adult & 3 & $1.00-2.22$ & $1.47 \pm 0.38$ \\
& Adult & 37 & $1.00-17.63$ & $5.27 \pm 0.69$ \\
\hline
\end{tabular}

\subsection{Discussion}

Leiopelma archeyi in both the rat control and non-treatment grids selected microhabitats differently from those available which suggests that frogs sought out specific microhabitats when on the surface. Frogs in the rat control grids used more soil, leaf litter and ferns (excluding tree ferns) than frogs in the non-treatment grids, even though there was a significantly higher proportion of leaf litter in the non-treatment grids, with an effect of the frogs' size mediating the use of leaf litter and ferns. Heights off the ground at which frogs were found were affected by the treatment, with frogs in the non-treatment grids more likely to be above ground level than frogs in the grids with rat control. Additionally, increases in air relative humidity also increased the likelihood of finding frogs above ground level. Finally, home range estimates were similar between grids and no effect of rat control was identified. These results suggest that although rats have direct negative effects on frog abundance and recruitment (Pledger 2011, 2013, Bridgman 2015), the indirect effects on frogs resulting in a non-random selection of microhabitats in the presence of higher rat abundance, may allow the species to co-occur with rats by increasing opportunities for cover or avoidance of microhabitat overlap.

The high number of sub-adult frogs captured in the non-treatment and rat control grids indicates recruitment occurs in both areas, although population studies carried out within the same area 
have found a significantly higher frog recruitment in the rat control grids (Pledger 2011, 2013). Additionally, all the different frog size classes, and therefore both sexes, were present in both areas. Lower frog capture rates in the non-treatment grids likely reflect higher mortality of frogs due to rat abundance. However, considering my results demonstrating changes in behaviour of frogs in the presence of higher rat densities, I cannot rule out lower detectability in some habitats or differences in the use of the microhabitat types that are also used by rats. Furthermore, because the density of frogs before the rat control programme was established is unknown, I cannot rule out either that the non-treatment grids could have had an intrinsically lower frog density compared to the rat control grids.

Larger L. archeyi tended to use a wider selection of microhabitats than smaller frogs, such as trees (i.e. trees/vines), tree fern, moss, and woody debris, whereas smaller frogs preferred the use of grasses/sedges (e.g. rice grass) and ferns. This higher variety of microhabitats used by larger frogs is unlikely to be due to size distribution as there were more sub-adult frogs captured in all four grids. In non-treatment grids, smaller frogs preferred the use of grasses/sedges while larger frogs favoured the used of tree ferns. Additionally, frogs in general were more likely to be found above ground level than at ground level. Once the predator pressure was reduced, as it was in the rat control grids, larger frogs made more use of the leaf litter while smaller frogs increased the use of ferns, with frogs in general found more often at ground level. This could indicate that in the presence of higher numbers of rats, frogs spatially avoid rats to minimise the chance of encounters in a size-specific manner, including the selection of microhabitats above ground level. Field and experimental studies have shown that introduced species can alter behaviour of amphibians by altering their use of space. For example, tadpoles and larvae of the western United States native Rana aurora have been found to alter their microhabitat use in the presence of larval and adult introduced bullfrogs (Rana catesbeiana; Kiesecker and Blaustein 1998) and increase the use of refuges in response to cues from introduced crayfish (Procambarus clarkii) and bluegill sunfish (Lepomis macrochirus; Pearl et al. 2003). Similarly, Nunes et al. (2013) found that tadpoles 
of five native southwestern Portugal anuran species also reduced their activity and showed a strong spatial avoidance to introduced crayfish. In all these cases, native prey effectively reduced encounters with introduced predators and therefore, lowered their predation risk.

However, the variability in microhabitat types used by frogs of different sizes in my study could also be related to factors other than, or in addition to, introduced predators, for example, sizespecific food availability (Jaeger 1978, Evans et al. 2003, Roe and Grayson 2008) or physiological requirements. Smaller organisms have a greater surface-area-to-volume ratio which makes them more susceptible to desiccation (Spotila 1972, Duellman and Trueb 1994, Bartelt et al. 2004), and so size-based habitat selection by frogs may help maintain water balance during active periods. Additionally, frogs in my study were more likely to be found above ground level when the relative humidity was higher, which suggests that desiccation avoidance could restrict climbing to wetter nights to overcome the potential increase of evaporation rates due to a higher exposure to the wind (Jaeger 1978). Other factors may also contribute to these behavioural patterns; for example, size-specific behavioural responses to potential, but unmeasured, increases in house mouse (Mus musculus) abundance resulting from mesopredator release.

The notion that frog co-occurrence with rats is possible by frogs selecting more elevated microhabitats is supported by evidence from behavioural studies of rats. Although I did not investigate the microhabitats used by rats, evidence shows that ship rats spend an average of $91 \%$ of their time moving on the forest floor (Dowding and Murphy 1994). This indicates that ship rats are primarily ground-dwelling predators, although they are also considered good climbers. This predominant ground use by rats may also apply to my study site where frogs were more often found above ground level when rat numbers were greater, indeed those higher microhabitats used by frogs may not support the rats' weight. A similar behaviour has been observed in other native species in the presence of other introduced Rattus species. For example, common geckos (Hoplodactylus maculatus) were more frequently found in habitats closer to the 
ground in the absence of the Norway and Pacific rats (R. norvegicus and $R$. exulans, respectively) than in their presence (Gorman 1996). Tree weta (Hemideina crassidens) occupied refuges lower to the ground after the removal of the Pacific rat (Rufaut 1995), similar to the behaviour observed in Duvaucel's geckos (Hoplodactylus duvaucelii) under the same circumstances (Hoare 2006).

Home range estimates did not differ between the rat control and non-treatment grids regardless of whether all frogs were analysed together or separated into sub-adults and adults. Many studies have shown a decrease in amphibians' activity in the presence of introduced predators (e.g. Griffiths et al. 1998, Bosch et al. 2006, Paoletti et al. 2011, Alcaraz et al. 2015, Berec et al. 2016). However, it may be that in this situation the effects of introduced predators are more related to changes in L. archeyi microhabitat use rather than activity (measured by home range) or that an alternative measure, like distances moved, could better reflect effects of rats on frogs' activity. Alcaraz et al. (2015) measured the activity of axolotls (Ambystoma mexicanum), Central Mexico native amphibians, as the total distance moved during a $3 \mathrm{~h}$ experiment, and found a decrease in their activity in the presence of combined chemical and visual cues from an introduced predatory fish. Similarly, Berec et al. (2016) showed that the activity of European brown frog tadpoles (Rana temporaria), measured as the total path length of their swimming trajectories, decreased in the presence of an invasive predatory turtle.

Direct effects of rat predation on L. archeyi (i.e. effects on frogs' abundance and recruitment) have been thoroughly studied at Whareorino Forest (Pledger 2011, 2013, Bridgman 2015). However, indirect effects had not been investigated until now, and their effects on fitness can be equal to, or even stronger than, the effects of direct predation (Preisser et al. 2005). Although rats were not completely eradicated from the rat control area, which is the preferred approach when studying indirect effects of introduced predators (Zavaleta et al. 2001, D’amore et al. 2009), my results indicate that these introduced predators may be imposing indirect effects on frogs by modifying their behaviour in relation to their microhabitat use, and that these responses may 
help frogs avoid rats. Even though L. archeyi have been able to survive in the presence of rats, the lower frog abundance found in the non-treatment grids suggests that the absence of rat control, and therefore an increased number of rats, could be affecting other frogs' fitness components, such as their reproductive output, body condition or their survival by different age classes. However, is important to consider other factors that could also be impacting frogs' health and survival such as the low infection rate with the amphibian Chytrid fungus (Batrachochytrium dendrobatidis) found in this population (Shaw et al. 2008, 2013). Because the effects of invasions on native species can be a slow process, it is possible that what we are now observing is a 'snapshot' of a longer process that may lead this frog population to extinction (Kats and Ferrer 2003, Hoare 2006). My research provides some evidence for the benefits of rodent control (even if it does not result in complete eradication), but further research is needed to understand the indirect effects of rat control on L. archeyi to evaluate the mechanism between behavioural changes and survival, and other ecological effects of only partial rodent control such as mesopredator release of other frog predators. Evidence of behaviour in the complete absence of rats would provide better context for understanding effects of rats on long term population viability, especially considering that Leiopelma frogs are long-lived species and that the effects of rats could be insidious. 


\section{Chapter 7 \\ General discussion}

\subsection{Introduction}

Currently, 31.8\% of the known amphibian species are globally threatened (IUCN 2017). It is crucial to understand the mechanism underlying amphibian declines in order to implement effective conservation management strategies. In this sense, the study of amphibians' spatial behaviour, including fine-scale movements and microhabitat selection, could better our understanding of how their behaviour and environmental structure might influence their sensitivity to the global amphibian decline phenomenon, and enable the identification of habitat features that are essential for their persistence. New Zealand native frogs, Leiopelma species, are classified as threatened both nationally and internationally (Newman et al. 2010, 2013, Bishop et al. 2013, IUCN 2017). Given the conservation status of these frogs, their restricted distributions and their ancient lineage, protection and conservation is a matter of national concern. The study of their spatial behaviour is of direct value for the conservation of these species and will provide valuable information for the management actions proposed in the in the Native Frog Recovery Plan 2013-2018 (Bishop et al. 2013).

The main aim of this study was to advance the knowledge of the fine-scale movement behaviour and microhabitat use of L. archeyi in Whareorino Forest and L. pakeka on Maud Island, establishing the factors that may affect the observed behaviours. Using a fine-scale tracking technique (i.e. non-toxic fluorescent powders), I obtained detailed information on these two species' activity periods, microhabitat and retreat sites use, movement patterns, and factors affecting their behaviour. I also obtained a more detailed description of the physical and thermal characteristics, and activity inside L. pakeka retreat sites. Lastly, I assessed how $L$. archeyi microhabitat use and activity could be affected by the presence of an introduced predator. By studying two different species at two different sites I was able to broaden my findings across 
more than one site/species to establish how the observed behavioural patterns might affect their population viability in the long term. This chapter summarizes the major findings of this research, limitations, conservation implications, and future research.

\subsection{Chapter overviews}

\section{Chapter 2: Tracking a small cryptic amphibian with fluorescent powders}

The study of amphibian spatial behaviour is crucial for a better understanding of species ecology and provides key information for species conservation. Most commonly used techniques to track amphibians are either unsuitable for small species or fail to give sufficiently fine-resolution data of habitat use. In this chapter I evaluated the usefulness of non-toxic fluorescent powders to track the fine-scale movements of Leiopelma pakeka. This technique has proven to be safe to use with amphibians (Rittenhouse et al. 2006, Orlofske et al. 2009). I assessed the effect of powder application on frog movements, detection of frog pathways during a dry and a wet period, and collaborated with Dr Jennifer Germano to show the use of this marking technique after a translocation for conservation purposes.

I found that fluorescent powders can be successfully used to obtain detailed information of finescale movements and habitat use of frogs, even during rainy periods. All frogs remained alive throughout the study period and no ill effects were noticeable. Fluorescent powders have been widely used to track the movements and microhabitat use of other amphibians (e.g. Woolbright 1985, Birchfield and Deters 2005, Ramirez et al. 2012) and has been used previously to track translocated L. pakeka by Germano (2006). However, this is the first evaluation of this technique for Leiopelma species. This technique proved to be safe to use with L. pakeka and has potential use for tracking other species that are too small or cryptic to be tracked using more conventional methods. 


\section{Chapter 3: Fine-scale movements of two Leiopelmatid frogs: Leiopelma archeyi and $L$.}

pakeka

The movement of organisms has an individual component that reflects the behaviour of individuals, directly impacting their individual fitness, and an ecological component that reflects the spatial organization of a species (Turchin 1998, Nathan et al. 2008, Sinsch 2014). Therefore, the study of the movement patterns of individuals is fundamental for species conservation. Using fluorescent powders for tracking individuals, I investigated the fine-scale movement patterns of L. archeyi and L. pakeka throughout their activity periods by measuring the net and total distances moved, orientation during movement and the factors affecting their movement (temperature and size of frogs).

I found bimodal patterns of activity with peaks of movements during the first hours of the night and approaching dawn, and high intra- and inter-species variability in movement behaviour. $L$. archeyi had a longer activity period than L. pakeka with the former being active up to two hours after sunrise, but L. pakeka moved more and further than L. archeyi during their activity periods. I found an effect of size on L. archeyi movements, with larger frogs moving more and further than smaller frogs. Increases in the minimum temperature during the night were related to increases in the total distances moved by L. pakeka. Overall, frogs moved more and further than previously expected based on earlier mark-recapture studies.

\section{Chapter 4: Microhabitat use of Leiopelma archeyi and L. pakeka in their natural habitats}

A species habitat provides resources that are necessary for its survival, such as food, breeding sites and shelter. The study of microhabitat use is essential for the conservation of declining species as it gives insights into the habitat features that are essential for species persistence (Green 2003, Lemckert 2004, Browne and Paszkowski 2014). I used a fine-scale tracking 
technique (i.e. fluorescent powders) to investigate microhabitat use by L. archeyi and L. pakeka and the factors (temperature, season and size of frogs) affecting selection of microhabitats in their natural environments.

Leiopelma archeyi and L. pakeka selected microhabitat types differently from those available in their habitats, suggesting that frogs sought out specific microhabitats during their movement. $L$. archeyi tended to use microhabitat types that provided cover, including vegetation (i.e. trees), and were more often found high up vegetation compared to L. pakeka. Both species used a variety of microhabitat types, potentially facilitating their growth and survival by providing suitable conditions for thermoregulation/water balance and predator avoidance. Microhabitat temperature, season and size of frogs affected microhabitat selection, but effects were speciesspecific, which could reflect differences in their physiological requirements, habitat and ecology.

\section{Chapter 5: Retreat site selection by Leiopelma archeyi and L. pakeka in their natural habitats}

Retreat sites are essential for amphibians' persistence as they not only provide protection against predators, food and reproduction resources, but they also provide them with the necessary conditions to retain water to survive, including thermoregulation opportunities (Long and Prepas 2012, Bleach et al. 2014, Schwarkopf and Alford 1996, Duellman and Trueb 1994). Thus, the selection of suitable retreat sites can directly affect individual fitness, and ultimately, population viability (Huey et al. 1989, Long and Prepas 2012). Using fluorescent powders for tracking individuals, I investigated retreat site selection by L. archeyi and L. pakeka. I further investigated L. pakeka retreat sites by measuring their structural characteristics (entrance height, width and diameter) and internal temperature, and recorded activity inside retreat sites using a burrowscope. 
Both species actively selected retreat sites, rather than hiding out in the habitat they found themselves in at the end of the night. L. archeyi preferred the use of trees as retreat sites (roots, branches or trunk), whereas L. pakeka used trees (roots) and rocks in a similar proportion. $L$. pakeka retreat sites had a lower mean and more stable (lower range) temperature compared to the ambient outside retreats, likely facilitating their thermoregulation and water balance, and aiding in their physiological performance. Additionally, L. pakeka were still active inside their retreat sites, with no evidence of sleep behaviour for at least the first hours of the day.

\section{Chapter 6: Indirect effects of an introduced predator on a population of the native frog Leiopelma archeyi}

Introduced predators have detrimental effects on biodiversity as the lack of shared evolutionary history leaves native prey naïve to predatory tactics of introduced predators, and can result in population declines of native species (Bucciarelli et al. 2014, Kats and Ferrer 2003, Sih et al. 2010). Besides predation itself, introduced predators can also have indirect impacts (i.e. nonlethal effects; Lima 1998) on native populations, such as, changes in their feeding behaviour, habitat use and activity levels (e.g. Lima and Dill 1990, Kiesecker and Blaustein 1997, 1998). Using frog capture data spanning 2005-2013, I examined the indirect impacts of ship rats (Rattus rattus) on L. archeyi, by studying the microhabitat use and activity (home range) of this species in an area with and without rat control within Whareorino Forest.

I found a lower number of frogs and more frogs above ground level in the area without rat control compared to the area with rat control. Frogs modified their behaviour according to rat abundance, using more soil, leaf litter and ferns in the rat control area, with an effect of the frogs' snout-vent length mediating the use of leaf litter and ferns. Frogs' home range area did not differ between rat control and non-treatment areas. Differences in the lower number of frogs may be due to 1) higher mortality by rats, 2) changes in behaviour by lowering detectability by humans, 
or 3) changes in microhabitat use by frogs to avoid rats. Since indirect effects of introduced predators on native species' fitness can be equal or even stronger than the effects of direct predation (Preisser et al. 2005), it is necessary to incorporate the study of the indirect effects of rats on the long-term population viability of L. archeyi, especially considering that Leiopelma frogs are long-lived species and that the effects of rats could be insidious.

\subsection{Discussion}

Observed behavioural differences could relate to species-specific physiological requirements, predation avoidance or site-specific ecology. The behaviour of frogs related to microhabitat and retreat site selection along with the effect of the studied factors (size of frogs, temperature and season), suggest that water balance and thermoregulation may be important drivers in their behaviour. For example, temperature affected distances moved by L. pakeka, indicating that frogs moved more with increases in the minimum temperature observed during the night (Chapter 3). The selection of some microhabitat types by L. archeyi and L. pakeka were also affected by the temperature of the microhabitat itself (Chapter 4). L. pakeka retreat sites had lower mean temperatures and range than the environment, making them cooler and more thermally stable than outside retreats (Chapter 5), and when more than one L. pakeka were found inside a retreat site, frogs were always close to each other even when there was enough space for frogs to be spread out, suggesting some physiological benefit of this aggregation pattern (Chapter 5). Additionally, L. archeyi movements and the selection of certain microhabitat types by each species were affected by the size of frogs (Chapters 3 and 4), which is known to influence desiccation rates in amphibians. Together these behaviours could help frogs regulate their physiological requirements, aiding in their performance, but other factors could also be driving these behaviours. 
Predation avoidance could also be facilitated by the observed behavioural traits. Evidence from my research on the behavioural attributes of L. archeyi (i.e. extended activity period, activity above ground level and small home ranges and movement) suggest that maybe frogs are spatially avoiding rats, which could explain why $L$. archeyi has been able to survive in their presence. $L$. archeyi were more often found up in trees in the presence of rats, compared to those in the presence of lower levels of rats (Chapter 6) and L. pakeka without introduced mammalian predators (Chapter 4). Ship rats have been found to spend most of the time active on the ground than up trees (Dowding and Murphy 1994), and may not be able to access some of the vertical aspects of habitat in the same way that frogs can due to size differences (e.g. small limp branches of fern fronds). Additionally, or alternatively, behaviours in the presence of rats may facilitate camouflage opportunities, with frogs selecting habitats according to the colouration of their bodies allowing for effective crypsis against visually oriented predators, such as avian predators with which they evolved. L. archeyi are usually green or have some green on their skin and can easily camouflage among the vegetation and trees (which are covered with Sphagnum moss, Chapter 4) in Whareorino Forest. Additionally, L. archeyi had a longer activity period than $L$. pakeka, at least when on the surface, being active until a few hours after daybreak, and moved less than L. pakeka (Chapter 3). The estimated home range of L. pakeka adults is $26.7 \pm 2.2 \mathrm{~m}^{2}$ (mean minimum convex polygon area $(\mathrm{MCP}) \pm \mathrm{SE}$ ) over a period of decades, and settled adult frogs only shift their range centroids by 1.3 m every 10 years (Bell and Moore 2015). I found that the estimated home range for L. archeyi adults was $4.91 \pm 1.06 \mathrm{~m}^{2}$ (MCP $\pm \mathrm{SE}$, Chapter 6), which could indicate even more prominent site fidelity and more sedentary behaviour in this species. Because L. archeyi do not seem to be very active when on the surface, the longer activity periods could allow them to obtain food in a relatively safer habitat as rats are less likely to be active during the daytime.

Behavioural changes attributed as responses to introduced mammalian predators allowing cooccurrence have also been observed in other species. From a study of 20 weta species $(7$ species 
of tree weta, Hemideina; 11 species of giant weta, Deinacrida; and 2 tusked weta, Motuweta), Gibbs (1998) found that the species that spent less time on the ground (more arboreal), had a strong refuge fidelity (less nomadic), a narrower refuge entrance (rat-proof refuge), and smaller body sizes, were less vulnerable to rats. Similarly, adult tree weta (H. crassidens) from rodentinfested sites spent less time outside their refuges and moved less often than populations from rodent-free islands (Rufaut 1995). Duvaucel's geckos (Hoplodactylus duvaucelii) used a greater proportion of habitats preferred by rats and used diurnal retreat sites that were lower to the ground after rat eradication (Hoare 2006).

Alternatively, the behaviours observed in my study may be unrelated to predator presence and better explained by site- or species-specific traits. For example, due to their retinal ultrastructure L. archeyi have a better adapted vision for increased ambient light compared to the other extant Leiopelma species (Meyer-Rochow and Pehlemann 1990). Additionally, L. archeyi body size could be another species-specific trait facilitating its survival as this species is the smallest of the extant Leiopelma (Bell 1978) and all the largest Leiopelma species are extinct (Worthy 1987).

Whether inter-specific differences between L. archeyi and L. pakeka relate to innate or sitespecific ecological factors, the differences in behavioural attributes, along with its larger body size, could be detrimental for L. pakeka if rats were to reach Maud Island.

\subsection{Limitations of this study}

My study is limited by several factors that are important to discuss.

Sample size of L. archeyi: I intended to start studying L. archeyi one field season after the first field season of L. pakeka on Maud Island (i.e. after December 2013), which was the trial visit for my study. Therefore, in March 2014 I went to the Coromandel Peninsula, which was my intended 
study site for this species, but I could not carry on with the study as there were hunters very close to our tracking area and someone tampered with my equipment. For this reason, I had to delay tracking L. archeyi until the following field season but this time in Whareorino Forest (November 2014). Additionally, even though I aimed to track 30 frogs per site visit and species, in the first visit to Whareorino Forest I could only track 17 L. archeyi due to harsh weather and unfamiliarity with the field site. Overall, these two situations reduced the total sample size of L.archeyi in my study, but I was still able to obtain adequate numbers for analysis.

Biased sample offrogs: Most of the frogs I tracked, in both species, were large frogs indicating that my sample could be biased towards apparent females. This may be due to the comparatively easier sighting of larger frogs in the field. Therefore, behavioural observations may be largely influenced by the behaviour of females.

Tracking technique: I used non-toxic fluorescent powders and obtained a detailed description of the short-term behaviour of frogs, with data gathered until the end of their activity periods when on the surface. However, this tracking technique does not allow for individual identification of frogs in the field unless the number of powder colours matches the number of frogs tracked. I used three different colours throughout this study to be able to track more than one frog on a given night, but I had to make sure frogs marked with the same colour were separated enough from each other so as not confuse their tracks. I was only able to track individuals for one continuous night on each site visit as powders were not reliably detectable and individuals were not marked to allow identification of recaptures.

Weather conditions: The time period of this study (December 2013 - December 2015) coincided with relatively dry weather conditions, with only two nights of rain during the entire sampling period of L. archeyi and three for L. pakeka. Observed behaviours may be influenced by the weather frogs experienced, and wetter conditions might have allowed frogs to move more and 
use more or different microhabitats. Additionally, because of their permeable skin and susceptibility to desiccation, moisture is an important factor helping frogs maintain their water balance (Jørgensen 1997, Duellman and Trueb 1994). Although I aimed to obtain relative humidity (RH) measurements of the different microhabitat types used by L. archeyi and L. pakeka, and of L. pakeka retreat sites, data loggers malfunctioned and did not provide reliable data. Some data loggers either did not measure relative humidity at all or remained at $100 \% \mathrm{RH}$ for the entire time they were deployed in the field, but most of them gave readings that were not likely to be accurate (i.e. relative humidity values constantly increasing or decreasing). Therefore, I could only rely on temperature measurements for microhabitat and retreat sites use.

Internal dimensions of retreat sites: To obtain an indication of the dimensions of the inside of $L$. pakeka retreat sites (width and height), I used the recordings obtained with the burrow-scopes. I standardized the measuring process (e.g. by using the same screen size for all recordings and using frames with the frogs facing the camera), but acknowledge these are only relative measurements of the dimensions of retreats (and of the frogs inside the retreats), not exact dimensions that would have enabled more thorough analyses. However, more intrusive retreat measurements would have disturbed frog behaviour.

Rat control programme: To asses if rats were imposing indirect effects on L. archeyi, I used frog survey data from 2005-2013 from areas with and without rat control kindly supplied to me by the Department of Conservation, Te Kuiti Office. I did not have control over the study design, however, nor the effectiveness of rat control. Rats still occurred in low numbers $(0 \%-38 \%)$ in the area receiving Coumatetralyl and Diphacinone poisons, therefore I was not able to compare the behaviour of frogs in areas with and without rats. In addition, no pre-control data were available so I could not assess the effect of the rat control programme on the frogs' behaviour preand post-control. I expect evidence of indirect effects of predation on frog behaviour to be more marked than I found if better control of rats can be attained. 
Chytrid fungus: The presence of the amphibian chytrid fungus (Batrachochytrium dendrobatidis) has been detected in L. archeyi populations in the Coromandel Ranges and in Whareorino Forest, but not in L. pakeka (Bell et al. 2004a, Shaw et al. 2008, 2013). Besides causing death, $B$. dendrobatidis can also affect frogs' behaviour by making them less active, more lethargic, unable to jump, adopt abnormal postures, lack the righting reflex, or by modifying their call effort (Berger et al. 2005, Voyles et al. 2009, An and Waldman 2016). I did not test whether tracked frogs were infected with this fungus as it was beyond the scope of this study.

\subsection{Conservation implications}

The research I conducted broadens our understanding of Leiopelma microhabitat use and movement behaviour. I directly contributed towards achieving the following goals in the Native Frog Recovery Plan 2013-2018 (Bishop et al. 2013): determine impact of rats on L. archeyi population in Whareorino Forest, identify appropriate microhabitats for captive breeding environments and increase our understanding of suitable habitats for the establishment and maintenance of frog populations.

Translocations have been one of the main management tools used to protect $L$. pakeka and to a lesser extent for L. archeyi and L. hamiltoni (Bell et al. 2004b, Bell et al. 2010, Bishop et al. 2013). To minimise the risk of extinctions, the recovery plan states the necessity of establishing new wild populations of all Leiopelma species, but in particular for L. archeyi due to its recent declines observed on the Coromandel population (Bell et al. 2004a, Bishop et al. 2013). One of the requirements for successfully establishing new populations in the wild is to assess the suitability of new sites for translocation. My research indicates both species relied heavily on leaf litter during movement and on trees for retreat sites, so these habitat features should be considered when selecting translocation sites. Additionally, bare ground (i.e. soil) and rocks should be available for L. pakeka and some amount of woody debris for L. archeyi, as these were not only 
used during movement but also as retreat sites. Both species moved considerably more than expected on the ground surface, and therefore, the size of translocation sites should account for frogs moving a total distance of at least $10.56 \mathrm{~m}$ to $14.31 \mathrm{~m}$ during their activity period.

Ex-situ conservation techniques, such as captive rearing and breeding, have been used to protect all Leiopelma species (Bell 2010, Bishop et al. 2013). Captive breeding can provide insurance populations in case of catastrophic declines, and stocks for re-introductions and translocations, and therefore is important in the long-term conservation of frogs (Bishop et al. 2013). Currently, there is a need to improve captive husbandry techniques for successful maintenance of populations, and an increased knowledge of the frogs' ecology can beneficially inform husbandry requirements. Frogs of both species used a variety of retreats, particularly rocks, leaf litter and trees. Trees should be incorporated in frog enclosures, and when not possible, woody debris could be adopted instead. For L. archeyi, it would be advantageous to offer retreat sites above ground level as this species was seen using retreat sites high up trees very often. This could be achieved using coarse woody debris with cavities for frogs. Because L. pakeka only retreated inside tree roots, woody debris could be placed at ground level to mimic this microhabitat. The investigation of L. pakeka retreat sites suggests that frogs do not select retreat sites by the dimension of their entrances and that they can share retreat sites with more than one frog. Retreat sites should aim to provide space for more than one frog by having an internal size of more than 2-frog-widths and 2-frog-lengths.

Overall, L. archeyi and L. pakeka show a higher site fidelity and sedentary behaviour in comparison to other anuran species. For example, L. archeyi moves half the mean total distance moved by the similarly-sized common coquí (Eleutherodactylus coqui; Woolbright 1985) while for both Leiopelma species the maximum net and total distances moved are half the magnitude of the distances moved by the similarly-sized northern cricket frogs (Acris crepitans; Ramirez et al. 2012). Their home ranges are also small compared to the home ranges of Bufonidae, Hylidae and 
Leptodactilydae, and most Ranidae (Wells 2007), and more similar to some Dendrobatidae species (Wells 2007) and, L. archeyi in particular, to Rhinodermatidae (Valenzuela-Sánchez et al. 2014). Because of their small home ranges and movement patterns, these Leiopelma species could be properly managed in captivity, provided their habitat allows them to maintain a positive water-balance, with appropriate retreat sites that allow for sociability between frogs and a 3D habitat incorporating microhabitats above ground level. The net distances moved in the field could be related to food search, and therefore, by supplying food captive frogs may not need to move as much during their activity periods.

Predator management has been shown to be beneficial for L. archeyi in Whareorino Forest as its population size and recruitment are greater in areas with rat control than in areas without (Pledger 2011, 2013, Bridgman 2015). However, the effects of predator control on frog populations still need to be better understood (Bishop et al. 2013). My research suggests that rats impose changes in the behaviour of L. archeyi as frogs were found more often at ground level using leaf litter and soil in the rat control area, potentially spatially avoiding rats where they are in greater abundance. Although mechanisms driving these behaviours and their direct relationship to population viability are not known, it is important to note that a high abundance of rats has effects on frogs that go beyond population numbers, which could include aspects not studied here such as resource competition between frogs and rats. Therefore, it is crucial to continue to manage rat numbers in Whareorino Forest and maintain strict quarantine procedures to ensure L. pakeka habitat remains rat free, especially considering that the effects of rats on frog populations could be insidious.

Lastly, climate change is likely to affect both populations as temperature was important for movement and for microhabitat and retreat site selection for both species. For instance, mean air temperatures in New Zealand are predicted to increase by about $3^{\circ} \mathrm{C}$ by 2090 under a high emission scenario (Ministry for the Environment 2016). Native frogs seek out cooler retreats than 
ambient temperatures, facilitating their maintenance of water balance and avoidance of dehydration. Frogs would be at risk if appropriate habitats that can buffer against increased temperatures and allow for moist conditions are not available.

\subsection{Future research}

I have identified several areas of future research to strengthen my findings as well as new opportunities that arise out of my research.

Movement behaviour: Study the movement behaviour of frogs for more than one night and consolidate my work with long term mark recapture studies as that could give more detailed information on their activity patterns and retreat site fidelity. It would be optimal to include a variety of frogs' sizes in order to track sub-adults and adults alike.

Microhabitat use: Investigate additional extrinsic factors that could be affecting microhabitat selection, including retreat sites, such as relative humidity, soil moisture and prey availability. This would help further inform on effects of climate warming and changes in water availability with climate change.

Retreat site use: Expand L. pakeka retreat site investigation to L. archeyi retreat sites by studying the internal and external dimensions of their retreat sites, as well as frogs' activity inside. Additionally, increase recording time to obtain a clear picture of the diel activity patterns of frogs.

Indirect effects of introduced predators: Study the movement patterns and microhabitat selection of rats in Whareorino Forest as that would reveal important information regarding the observed L. archeyi behaviour. Additionally, it is necessary to further the study of the indirect effects of rats on frog populations. For example, whether frogs' behaviours could be associated with resource 
competition with rats, if frogs are detecting rats and behaving accordingly or if this is the result of selection pressure. This will increase our understanding of the effect of introduced predators on frogs' long-term population viability.

Physiological studies: To complement the findings of this study, the incorporation of physiological studies of L. pakeka should be considered. These studies will help better understand how the behaviour of frogs, such as microhabitat selection, can be influencing their physiological performance.

Seasonal studies: It would be ideal to incorporate winter and summer in the sampling regime, allowing information of year-round movements and microhabitat requirements of frogs. This would give important information on their seasonal habitat requirements which is one of the goals stated in the Native Frog Recovery Plan 2013-2018 (Bishop et al. 2013).

Other species: Investigate the behavioural patterns of the two other Leiopelma species, $L$. hamiltoni and L. hochstetteri, as in order to protect all species, it is necessary to have speciesspecific data to develop effective conservation and management programmes. By including these two species we will be able to establish which behaviours are specific to a species and which are general to all Leiopelma, which will inform conservation management. 


\section{References}

Alcaraz G, López-Portela X, Robels-Mendoza C 2015. Response of a native endangered axolotl, Ambystoma mexicanum (Amphibia), to exotic fish predator. Hydrobiologia 753: 73-80.

Alford RA, Richards SJ 1999. Global amphibian declines: A problem in applied ecology. Annual Review of Ecology and Systematics 30: 133-165.

Allison PD 1999. Multiple regression: A primer. Pine Forge Press, California.

AmphibiaWeb 2017. Species by the numbers. University of California, Berkeley. $<$ http://www.amphibiaweb.org>.

An D, Waldman B 2016. Enhanced call effort in Japanese tree frogs infected by amphibian chytrid fungus. Biology Letters 12: 20160018.

Arnold TW 2010. Uninformative parameters and model selection using Akaike's Information Criterion. The Journal of Wildlife Management 74: 1175-1178.

Arppe A 2008. Univariate, bivariate, and multivariate methods in corpus-based lexicography - a study of synonymy. Unpublished PhD thesis, University of Helsinki, Helsinki.

Baczynski K 2013. Evaluating anuran relative abundance and assessing salamander movements in protected areas. Unpublished PhD thesis, Bowling Green State University, Ohio. 
Baldwin RF, Calhoun AJK, deMaynadier PG 2006. Conservation planning for amphibian species with complex habitat requirements: A case study using movements and habitat selection of the Wood Frog Rana sylvatica. Journal of Herpetology 40: 442-453.

Barinaga M 1990. Where have all the froggies gone? Science 247: 1033-1034.

Bartelt PE, Peterson CR, Klaver RW 2004. Sexual differences in the post-breeding movements and habitats selected by Western toads (Bufo boreas) in southeastern Idaho. Herpetologica 60: 455467.

Batschelet E 1981. Circular statistics in biology. Academic Press, London.

Beausoleil NJ, Mellor DJ, Stafford KJ 2004. Methods for marking New Zealand wildlife: Amphibians, reptiles and marine mammals. Department of Conservation, Wellington.

Beebee TJC, Griffiths RA 2005. The amphibian decline crisis: A watershed for conservation biology? Biological Conservation 125: 271-285.

Bell BD 1978. Observations on the ecology and reproduction of the New Zealand Leiopelmid frogs. Herpetologica 34: 340-354.

Bell BD 1982. New Zealand frogs. Herpetofauna 14: 1-21.

Bell BD 1985a. Conservation status of the endemic New Zealand frogs. In: Grigg G, Shine R, Ehmann H (Eds.): Biology of Australasian Frogs and Reptiles. Surrey Beatty \& Sons Pty Limited, Chipping Norton, New South Wales. 
Bell BD 1985b. Development and parental care in the endemic New Zealand frogs. In: Grigg, G, Shine R and Ehmann H (Eds.): Biology of Australasian Frogs and Reptiles. Surrey Beatty \& Sons Pty Limited, Chipping Norton, New South Wales.

Bell BD 1993. The status of endemic Leiopelma frogs recently discovered in the western Maniapoto Ranges, near Te Kuiti. New Zealand Journal of Zoology 20: 130.

Bell BD 1994. A review of the status of New Zealand Leiopelma species (Anura: Leiopelmatidae), including a summary of demographic studies in Coromandel and on Maud Island. New Zealand Journal of Zoology 21: 341-349.

Bell BD 1996. Aspects of the ecological management of New Zealand frogs: Conservation status, location, identification, examination and survey techniques. Ecological Management 4: 91-111.

Bell BD 2010. The threatened Leiopelmatid frogs of New Zealand: Natural history integrates with conservation. Herpetological Conservation and Biology 5: 515-528.

Bell BD 2011. Breeding phenology of Leiopelma pakeka: A threatened frog never found breeding in the wild. Journal of Herpetology 42: 29-32.

Bell BD, Bishop PJ, Germano JM 2010. Lessons learned from a series of translocations of the archaic Hamilton's frog and Maud Island frog in central New Zealand. In: Soorae PS (Ed.): Global Re-introduction Perspectives: Additional case-studies from around the globe. IUCN/SSC Reintroduction Specialist Group, Abu Dhabi. 
Bell BD, Carver S, Mitchell NJ, Pledger S 2004a. The recent decline of a New Zealand endemic: How and why did populations of Archey's frog Leiopelma archeyi crash over 1996-2001? Biological Conservation 120: 189-199.

Bell BD, Daugherty CH, Hay JM 1998. Leiopelma pakeka, n. sp. (Anura: Leiopelmatidae), a cryptic species of frog from Maud Island, New Zealand, and a reassessment of the conservation status of L. hamiltoni from Stephens Island. Journal of The Royal Society of New Zealand 28: 39-54.

Bell BD, Moore JA 2015. Extreme site fidelity in adult Maud Island frogs over successive decades. In: Nelson NJ and Keall SN (Eds.): Recent developments in New Zealand herpetofauna research; Abstracts of papers presented at the 15th and 16th biennial conferences of the Society for Research on Amphibians and Reptiles in New Zealand; 2013 Conference abstracts. Department of Conservation Research \& Development Series 347: 4.

Bell BD, Newman DG, Daugherty CH 1985. The ecological biogeography of the archaic New Zealand herpetofauna (Leiopelmatidea, Sphenodontiadea). In: Grigg G, Shine R and Ehmann H (Eds.): Biology of Australasian Frogs and Reptiles. Surrey Beatty \& Sons Pty Limited, Chipping Norton, New South Wales.

Bell BD, Pledger S 2010. How has the remnant population of the threatened frog Leiopelma pakeka (Anura: Leiopelmatidae) fared on Maud Island, New Zealand, over the past 25 years? Austral Ecology 35: 241-256.

Bell BD, Pledger S, Dewhurst PL 2004b. The fate of a population of the endemic frog Leiopelma pakeka (Anura: Leiopelmatidae) translocated to restored habitat on Maud Island, New Zealand. New Zealand Journal of Zoology 31: 123-131. 
Bell BD, Wassersug RJ 2003. Anatomical features of Leiopelma embryos and larvae: Implications for anuran evolution. Journal of Morphology 256:160-170.

Bell EA 1995. Habitat use, distribution and population dynamics of the Maud Island frog, Leiopelma hamiltoni. Unpublished MSc thesis, Victoria University of Wellington, Wellington.

Bell EA 2016. Maud Island frog (Leiopelma pakeka) forest census resurvey: September to November 2016. Unpublished report to the Department of Conservation Maud Island Field Base, Waitohi/Picton Office and National Frog Recovery Group.

Bell EA, Bell BD 1994. Local distribution, habitat and numbers of the endemic terrestrial frog Leiopelma hamiltoni on Maud Island, New Zealand. New Zealand Journal of Zoology 21: 437-442.

Bell WJ 1991. Searching behaviour: The behavioural ecology of finding resources. Chapman and Hall, London.

Benhamou S 2004. How to reliably estimate the tortuosity of an animal's path: Straightness, sinuosity, or fractal dimension? Journal of Theoretical Biology 229: 209-220.

Berec M, Klapka V, Zemek R 2016. Effect of an alien turtle predator on movement activity of European brown frog tadpoles. Italian Journal of Zoology 83: 68-76.

Berger L, Marantelli G, Skerratt LF, Speare R 2005. Virulence of the amphibian chytrid fungus Batrachochytrium dendrobatidis varies with the strain. Diseases of Aquatic Organisms 68: 47-50.

Birchfield GL, Deters JE 2005. Movement paths of displaced Northern Green Frogs (Rana clamitans melanota). Southeastern Naturalist 4: 63-76. 
BirdLife International 2013. State of the world's birds: indicators for our changing world. BirdLife International, Cambridge.

Bishop PJ, Angulo A, Lewis JP, Moore RD, Rabb GB, Garcia Moreno J 2012. The amphibian extinction crisis - what will it take to put the action into the Amphibian Conservation Action Plan? SAPIENS 5: 97-111.

Bishop PJ, Daglish LA, Haigh AJM, Marshall LJ, Tocher MD, McKenzie KL 2013. Native frog (Leiopelma spp.) recovery plan, 2013-2018. Threatened Species Recovery Plan 63. Department of Conservation, Wellington.

Blaustein AR 1994. Chicken Little or Nero's fiddle? A perspective on declining amphibian populations. Herpetologica 50: 85-97.

Blaustein AR, Kiesecker JM 2002. Complexity in conservation: Lessons from the global decline of amphibian populations. Ecology Letters 5: 597-608.

Blaustein AR, Wake DB 1990. Declining amphibian populations: A global phenomenon? Trends in Ecology \& Evolution 5: 203-204.

Blaustein AR, Wake DB 1995. The puzzle of declining amphibian populations. Scientific American 272: 52-58.

Blaustein AR, Wake DB, Sousa WP 1994. Amphibian declines: Judging stability, persistence and susceptibility to local and global extinctions. Conservation biology 8: 60-71. 
Bleach I, Beckmann C, Brown GP, Shine R 2014. Effects of an invasive species on refuge-site selection by native fauna: The impact of cane toads on native frogs in Australian tropics. Austral Ecology 39: 50-59.

Bleach IT, Beckmann C, Both C, Brown GP, Shine R 2015. Noisy neighbours at the frog pond: Effects of invasive cane toads on the calling behaviour of native Australian frogs. Behavioral Ecology and Sociobiology 69: 675-683.

Blumstein DT, Fernández-Juricic E 2004. The emergence of conservation behaviour. Conservation Biology 15: 1175-1177.

Bogosian III V, Hellgren EC, Sears MW, Moody RW 2012. High-resolution niche models via a correlative approach: Comparing and combining correlative and process-based information. Ecological Modelling 237-238: 63-73.

Böhm et al. 2013. The conservation status of the world's reptiles. Biological conservation 157: 372-385.

Bosch J, Rincón PA, Boyero L, Martínez-Solano I 2006. Effects of introduced salmonids on a montane population of Iberian frogs. Conservation Biology 20: 180-189.

Božanić B, Hradílek Z, Machač O, Pižl V, Štáhlavský F, Tufová J, Véle A, Tuf IH 2013. Factors affecting invertebrate assemblages in bryophytes of the Litovelské Luhy National Nature Reserve, Czech Republic. Acta Zoologica Bulgarica 65: 197-206.

Bradford DF 1991. Mass mortality and extinction in a high-elevation population of Rana muscosa. Journal of Herpetology 25: 174-177. 
Bradford DF, Graber DM, Tabatabai F 1994. Population declines of the native frog, Rana muscosa, in Sequoia and Kings Canyon National Parks, California. Southwestern Naturalist 39: 323-327.

Bridgman L 2015. Whareorino Archey's frog monitoring update (2013/2014 data). Unpublished report, Department of Conservation, Te Kuiti.

Brown JL 1975. Social organization: The social context of behaviour and natural selection. In: Brown JL (Ed.): The evolution of behaviour. WW Norton and Company Inc., New York.

Browne CL, Paszkowski CY 2014. The influence of habitat composition, season and gender on habitat selection by Western toads (Anaxyrus boreas). Herpetological Conservation and Biology 9: 417-427.

Bucciarelli GM, Blaustein AR, Garcia TS, Kats LB 2014. Invasion complexities: The diverse impacts of nonnative species on amphibians. Copeia 4: 611-632.

Buchholz R 2007. Behavioural biology: An effective and relevant conservation tool. Trends in Ecology \& Evolution 22: 401-407.

Bulger JB, Scott NJ, Seymour RB 2003. Terrestrial activity and conservation of adult California red-legged frogs Rana aurora draytonii in coastal forests and grasslands. Biological Conservation 110: 85-95.

Bull EL, Hayes MP 2001. Post-breeding season movements of Columbia spotted frogs (Rana luteiventris) in Northeastern Oregon. Western North American Naturalist 61: 119-123. 
Burnham KP, Anderson DR 2002. Model selection and multimodel inference: A practical information-theoretic approach. Springer Scientific, New York.

Butts SR, McComb WC 2000. Associations of forest-floor vertebrates with coarse woody debris in managed forest of western Oregon. Journal of Wildlife Management 64: 95-104.

Catenazzi A 2015. State of the world's amphibians. Annual Review of Environment and Resources 40: 91-119.

Clobert J, Le Galliard JF, Cote J, Meylan S, Massot M 2009. Informed dispersal, heterogeneity in animal dispersal syndromes and the dynamics of spatially structured populations. Ecology Letters 12: 197-209.

Cohen MP, Alford RA 1996. Factors affecting diurnal shelter use by the cane toad, Bufo marinus. Herpetologica 52: 172-181.

Collins JP, Storfer A 2003. Global amphibian declines: Sorting the hypotheses. Diversity and Distributions 9: 89-98.

Craig J, Anderson S, Clout M, Creese B, Mitchell N, Ogden J, Roberts M, Ussher G 2000. Conservation issues in New Zealand. Annual Review of Ecology and Systematics 3: 61-78.

Cree A 1986. Water relations of the endemic New Zealand frogs Leiopelma archeyi, L. hamiltoni and L. hochstetteri. Unpublished PhD thesis, University of Waikato, Hamilton.

Cree A 1989. Relationship between environmental conditions and nocturnal activity of the terrestrial frog, Leiopelma archeyi. Journal of Herpetology 23: 61-68. 
D’Amore A, Kirby E, McNicholas M 2009. Invasive species shifts ontogenetic resource partitioning and microhabitat use of a threatened native amphibian. Aquatic Conservation: Marine and Freshwater Ecosystems 19: 534-541.

Daugherty CH, Sheldon AL 1982. Age-specific movement patterns of the frog Ascaphus truei. Herpetologica 38: 468-474.

Department of Conservation 2016. Maud Island predator-free again. Department of Conservation, media release, 11 October.

Dewhurst P 2003. Survival of a translocated population of the Maud Island frog (Leiopelma pakeka) and morphometric comparisons to the source population. Unpublished MSc thesis, Victoria University, Wellington.

Dole JW 1965. Summer movements of adult leopard frogs, Rana pipiens Schreber, in northern Michigan. Ecology 46: 236-255.

Domingos FMCB, Arantes IC, Cavalcanti DR, Jotta PACV 2015. Shelter from the sand: Microhabitat selection by the bromelicolous tree frog Scinax cuspidatus (Anura: Hylidae) in a Brazilian restinga. North-Western Journal of Zoology 11: 27-33.

Dowding JE, Murphy EC 1994. Ecology of ship rats (Rattus rattus) in a kauri (Agathis australis) forest in Northland, New Zealand. New Zealand Journal of Ecology 18: 19-28.

Drost CA, Fellers GM 1996. Collapse of a regional frog fauna in the Yosemite area of the California Sierra Nevada, USA. Conservation Biology 10: 414-425. 
Duellman WE, Trueb L 1994. Biology of amphibians. Johns Hopkins University Press, Baltimore.

EDGE 2016. Top 100 EDGE Amphibians. Zoological Society of London. <http://www.edgeofexistence.org/amphibians/default.php>.

Eggers KE 1998. Morphology, ecology and development of Leiopelmatid frogs (Leiopelma spp.) in Whareorino forest, New Zealand. Unpublished MSc thesis, Massey University, Palmerston North.

Eggert C 2002. Use of fluorescent pigments and implantable transmitters to track a fossorial toad (Pelobates fuscus). Herpetological Journal 12: 69-74.

Evans AM, Clinton PW, Allen RB, Frampton CM 2003. The influence of logs on the spatial distribution of litter-dwelling invertebrates and forest floor processes in New Zealand forests. Forest Ecology and Management 184: 251-262.

Farallo VR, Miles DB 2016. The importance of microhabitat: A comparison of two microendemic species of Plethodon to the widespread P. cinerus. Copeia 104: 67-77.

Firle S, Bommarco R, Ekbom B, Natiello M 1998. The influence of movement and resting behavior on the range of three carabid beetles. Ecology 79: 2113-2122.

Fitzgerald BM, Campbell DJ 2003. Examination of eight Leiopelma frogs from Whareorino Forest for signs of predation. Unpublished report, Ecological Research Associates of New Zealand, Wellington. 
Fritts SR, Grodsky SM, Hazel DW, Homyack JA, Castleberry SB, Moorman CE 2015. Quantifying multi-scale habitat use of woody biomass by southern toads. Forest Ecology and Management 346: 81-88.

Frog Recovery Group 2013. Frog advice - mouse incursion on Maud Island. Internal Department of Conservation Report, Wellington.

Garner JL 2006. Movement and habitat-use of the Great Basin spadefoot (Spea intermontana) at its northern range limit. Unpublished MSc thesis, Thompson Rivers University, British Columbia.

Garnham JI, Stockwell MP, Pollard CJ, Pickett EJ, Bower DS, Clulow J, Mahony MJ 2015. Winter microhabitat selection of a threatened pond amphibian in constructed urban wetlands. Austral Ecology 40: 816-826.

Gautier P, Olgun K, Uzum B, Miaud C 2006. Gregarious behaviour in a salamander: Attraction to conspecific chemical cues in burrow choice. Behavioral Ecology and Sociobiology 59: 836-841.

Germano JM 2006. Responses of the Maud Island frog, Leiopelma pakeka, to artificial displacement. Unpublished MSc thesis, University of Otago, Dunedin.

Germano JM, Cree A, Bishop PJ 2011. Ruling out boys from the girls: Can subtle morphological differences identify sex of the apparently monomorphic frog, Leiopelma pakeka? New Zealand Journal of Zoology 38: 161-171.

Germano JM, Molina FC, Bishop PJ, Bell BD, Cree A 2012. Urinary hormone metabolites identify sex and imply unexpected winter breeding in an endangered, subterranean-nesting frog. General and Comparative Endocrinology 175: 464-472. 
Gibbs G 2006. Ghosts of Gondwana: The history of life in New Zealand. Craig Putton Publishing, Nelson.

Gibbs GW 1998. Why are some weta (Orthoptera: Stenopelmatidae) vulnerable yet others are common? Journal of Insect Conservation 2: 161-166.

Gillespie GR 2001. The role of introduced trout in the decline of the spotted tree frog (Litoria spenceri) in southeastern Australia. Biological Conservation 100: 187-198.

Gonser RA, Woolbright LL 1995. Homing behaviour of the Puerto Rican frog, Eleutherodactylus coqui. Journal of Herpetology 29: 481-484.

Gorman NI 1996. A baseline study of Kapiti Island lizard fauna, prior to rat eradication. Unpublished MSc thesis, Victoria University of Wellington, Wellington.

Graeter GJ 2005. Habitat selection and movement patterns of amphibians in altered forest habitats. Unpublished MSc thesis, University of North Carolina-Chapel Hill, Georgia.

Graeter GJ, Rothermel BB 2007. The effectiveness of fluorescent powdered pigments as tracking technique for amphibians. Herpetological Review 38: 162-166.

Graves BM, Summers CH, Olmstead KL 1993. Sensory mediation of aggregation among postmetamorphic Bufo cognatus. Journal of Herpetology 27: 315-319.

Green DM 1988. Antipredator behaviour and skin glands in the New Zealand native frogs, genus Leiopelma. New Zealand Journal of Zoology 15: 39-45. 
Green DM 2003. The ecology of extinction: Population fluctuation and decline in amphibians. Biological Conservation 111: 331-343.

Green DM, Cannatella DC 1993. Phylogenetic significance of the amphicoelous frogs, Ascaphidae and Leiopelmatidae. Ethology, Ecology \& Evolution 5: 233-245.

Greenberg CH, Tanner GW 2005. Spatial and temporal ecology of eastern spadefoot toads on a Florida landscape. Herpetologica 61: 20-28.

Griffiths RA, Schley L, Sharp PE, Dennis JL, Román A 1998. Behavioural responses of Mallorcan midwife toad tadpoles to natural and unnatural snake predators. Animal Behaviour 55: 207-214.

Haddad NM 1999. Corridor use predicted from behaviors at habitat boundaries. American Naturalist 153: 215-227.

Haigh A, Pledger S, Holzapfel S 2007. Population monitoring programme for Archey's frog (Leiopelma archeyi): Pilot studies, monitoring design and data analysis. Department of Conservation Research \& Development Series 278, Wellington.

Heatwole H 1961. Habitat selection and activity of the wood frog, Rana sylvatica Le Conte. The American Midland Naturalist 66: 301-313.

Hecnar SJ, M'Closkey RT 1997. The effects of predatory fish on amphibian species richness and distribution. Biological Conservation 79: 123-131.

Heemeyer JL, Williams PJ, Lannoo MJ 2012. Obligate crayfish burrow use and core habitat requirements of crawfish frogs. The Journal of Wildlife Management 76: 1081-1091. 
Hoare JM 2006. Novel predators and naïve prey: How introduced mammals shape behaviours and populations of New Zealand lizards. Unpublished PhD thesis, Victoria University of Wellington, Wellington.

Hobson JA, Goin OB, Goin CJ 1968. Electrographic correlates of behaviour in tree frogs. Nature 220: 386-387.

Hodgkinson S, Hero JM 2001. Daily behaviour and microhabitat use of the waterfall frog, Litoria nannotis in Tully Gorge, Eastern Australia. Journal of Herpetology 35: 116-120.

Hoffman AS, Heemeyer JL, Williams PJ, Robb JR, Karns DR, Kinney VC, Engbrecht NJ, Lannoo MJ 2010. Strong site fidelity and a variety of imaging techniques reveal around-the-clock and extended activity patterns in crawfish frogs (Lithobates areolatus). BioScience 60: 829-834.

Holyoake A, Waldman B, Gemmell NJ 2001. Determining the species status of one of the world's rarest frogs: A conservation dilemma. Animal Conservation 4: 29-35.

Huey RB 1982. Temperature, physiology, and the ecology of reptiles. In: Gans C, Pough FH (Eds.): Biology of the Reptilia. Physiology (C), Academic Press, London.

Huey RB 1991. Physiological consequences of habitat selection. The American Naturalist 137: S92-S115.

Huey RB, Peterson CR, Arnold SJ, Porter WP 1989. Hot rocks and not-so-hot rocks: Retreat site selection by garter snakes and its thermal consequences. Ecology 70: 931-944. 
Huntley AC, Donnelly M, Cohen HB 1978. Sleep in the western toad, Bufo boreas. Sleep Research 7: 141

Hussain QA, Pandit AK 2012. Global amphibian declines: A review. International Journal of Biodiversity and Conservation 4: 348-357.

Indermaur L, Winzeler T, Schmidt BR, Tockner K, Schaub M 2008. Differential resource selection within shared habitat types across spatial scales in sympatric toads. Ecology 90: 3430-3444.

IUCN 2017. The IUCN Red List of Threatened Species. Version 2017-1. <http://www.iucnredlist.org>.

Jaeger RG 1978. Plant climbing by salamanders: Periodic availability of plant-dwelling prey. Copeia 1978: 686-691.

Jaeger RG, Hailman JP 1973. Effects of intensity on the phototactic responses of adult anuran amphibians: A comparative survey. Zeitschrift für Tierpsychologie 33: 352-407.

Johansson TSK 1959. Tracking honey bees in cotton fields with fluorescent pigments. Journal of Economic Entomology 52: 572-577.

Johnson CR 1969. Aggregation as a means of water conservation in juvenile Limnodynastes from Australia. Herpetologica 25: 275-276.

Jørgensen CB 1997. 200 years of amphibian water economy, from Robert Townsend to the present. Biology Review 72: 153-237. 
Karst TM 2013. Mortality mitigation of a translocated rare New Zealand frog Leiopelma pakeka. Unpublished MSc thesis, Victoria University of Wellington, Wellington.

Kats LB, Ferrer RP 2003. Alien predators and amphibian declines: Review of two decades of science and the transition to conservation. Diversity and Distributions 9: 99-110.

Kays R, Crofoot MC, Jetz W, Wikelski M 2015. Terrestrial animal tracking as an eye on life and planet. Science 348: aaa2478.

Kearney M, Porter W 2009. Mechanistic niche modelling: Combining physiological and spatial data to predict species' ranges. Ecology Letters 12: 334-350.

Kearney M, Predavec M 2000. Do nocturnal ectotherms thermoregulate? A study of the temperate gecko Christinus marmoratus. Ecology 81: 2984-2996.

Kiesecker JM 2003. Invasive species as a global problem: Insights towards understanding the worldwide decline of amphibians. In: Semlitsh RD (Ed.): Amphibian conservation. Smithsonian Press, Washington, DC.

Kiesecker JM, Blaustein AR 1997. Population differences in responses of red-legged frogs (Rana aurora) to introduced bullfrogs. Ecology 78: 1752-1760.

Kiesecker JM, Blaustein AR 1998. Effects of introduced bullfrogs and smallmouth bass on microhabitat use, growth and survival of native red-legged frogs (Rana aurora). Conservation Biology 12: 776-787. 
Kluber MR, Olson DH, Puettmann KJ 2009. Downed wood microclimates and their potential impact on Plethodontid salamander habitat in Oregon coast range. Northwest Science 83: 25-34.

Knapp RA, Matthews KR 2000. Non-native fish introductions and the decline of the mountain yellow-legged frog from within protected areas. Conservation Biology 14: 428-438.

Langkilde T, Alford RA 2002. The tail wags the frog: harmonic radar transponders affect movement behaviour in Litoria lesueuri. Journal of Herpetology 36: 711-715.

Langkilde T, Shine R 2004. Competing for crevices: Interspecific conflict influences retreat-site selection in montane lizards. Behavioural Ecology 140: 684-691.

Laskowski KL, Pearish S, Bensky M, Bell AM 2015. Chapter four - Predictors of individual variation in movement in a natural population of threespine stickleback (Gasterosteus aculeatus). Advances in Ecological Research 52: 65-90.

Le Roux J 2008. The remnant Leiopelma pakeka (Anura: Leiopelmatidae) population on Maud Island: Population size, distribution and morphology. Unpublished MSc thesis, Victoria University of Wellington, Wellington.

Le Roux J, Bell BD 2007. A re-estimation of the population size of Leiopelma pakeka (Anura: Leiopelmatidae) in its remnant forest habitat on Maud Island. New Zealand Journal of Zoology 34: 265-266.

Lee J, Waldman B 2002. Communication by faecal chemo signals in an archaic frog, Leiopelma hamiltoni. Copeia 2002: 679-686. 
Lemckert FL 2004. Variations in anuran movements and habitat use: Implications for conservation. Applied Herpetology 1: 165-181.

Lemen CA, Freeman PW 1985. Tracking mammals with fluorescent pigments: A new technique. Journal of Mammalogy 66: 134-136.

Lima SL 1998. Nonlethal effects in the ecology of predator-prey interactions: What are the ecological effects of anti-predator decision-making? Bioscience 48: 25-34.

Lima SL, Dill LM 1990. Behavioral decisions made under the risk of predation: A review and prospectus. Canadian Journal of Zoology 68: 619-640.

Lima SL, Zollner PA 1996. Towards a behavioural ecology of ecological landscapes. Trends in Ecology \& Evolution 11: 131-135.

Long ZL, Prepas EE 2012. Scale and landscape perception: The case of refuge use by Boreal Toads (Anaxyrus boreas boreas). Canadian Journal of Zoology 90: 1015-1022.

Lövei GL, Stringer IAN, Devine CD, Cartellieri M 1997. Harmonic radar - a method using inexpensive tags to study invertebrate movement on land. New Zealand Journal of Ecology 21: 187-193.

Lukis K 2009. Returning an endemic frog to the New Zealand mainland: Transfer and adaptive management of Leiopelma pakeka at Karori Sanctuary, Wellington. Unpublished MSc thesis, Victoria University of Wellington, Wellington. 
Matthews KR 2003. Response of mountain yellow-legged frogs, Rana muscosa, to short distance translocation. Journal of Herpetology 37: 621-626.

McCallum ML 2007. Amphibian decline or extinction? Current declines dwarf background extinction rate. Journal of Herpetology 41: 483-91.

McGlone MS 1989. The Polynesian settlement of New Zealand in relation to environmental and biotic changes. New Zealand Journal of Ecology 12: 115-129.

Meyer-Rochow VB, Pehlemann FW 1990. Retinal organisation in the native New Zealand frogs Leiopelma archeyi, L. hamiltoni, and L. hochstetteri (Amphibia: Anura; Leiopelmatidae). Journal of the Royal Society of New Zealand 20: 349-366.

Milne T, Bull CM 2000. Burrow choice by individuals of different sizes in the endangered pygmy blue tongue lizard Tiliqua adelaidensis. Biological Conservation 95: 295-301.

Ministry for the Environment 2016. Climate change projection for New Zealand snapshot. INFO 765, Wellington.

Morales JM, Ellner SP 2002. Scaling up animal movements in heterogeneous landscapes: The importance of behavior. Ecology 83: 2240-2247.

Morey SR 1990. Microhabitat selection and predation in the Pacific treefrog, Pseudacris regilla. Journal of Herpetology 24: 292-296.

Morris DW 2003. Toward an ecological synthesis: A case for habitat selection. Oecologia 136: 113. 
Mullican TR 1988. Radio telemetry and fluorescent pigments: A comparison of techniques. Journal of Wildlife Management 52: 627-631.

Nathan R 2008. An emerging movement ecology paradigm. Proceedings of the National Academy of Science 105: 19050-19051.

Nathan R, Getz WM, Revilla E, Holyoak M, Kadmon R, Saltz D, Smouse PE 2008. A movement ecology paradigm for unifying organismal movement research. Proceedings of the National Academy of Sciences 105: 19052-19059.

Newman DG 1977. Some evidence of the predation of Hamilton's frog (Leiopelma hamiltoni (McCulloch)) by tuatara (Sphenodon punctatus (Gray)) on Stephens Island. Proceedings of the New Zealand Ecological Society 24: 43-47.

Newman DG 1990. Activity, dispersion, and population densities of Hamilton's frog (Leiopelma hamiltoni) on Maud and Stephens Islands, New Zealand. Herpetologica 46: 319-330.

Newman DG, Bell BD, Bishop PJ, Burns R, Haigh A, Hitchmough RA 2013. Conservation status of New Zealand frogs. New Zealand Threat Classification Series 5. Department of Conservation, Wellington.

Newman DG, Bell BD, Bishop PJ, Burns R, Haigh A, Hitchmough RA, Tocher M 2010. Conservation status of New Zealand frogs, 2009. New Zealand Journal of Zoology 37: 121-130.

Nunes AL, Richter-Boix A, Laurila A, Rebelo R 2013. Do anuran larvae respond behaviourally to chemical cues from an invasive crayfish predator? A community-wide study. Oecologia 171: 115127. 
Orlofske SA, Grayson KL, Hopkins WA 2009. The effects of fluorescent tracking powder on oxygen consumption in salamanders using either cutaneous or bimodal respiration. Copeia 2009: 623627.

Oromí N, Sanuy D, Sinsch U 2010. Thermal ecology of natterjack toads (Bufo calamita) in a semiarid landscape. Journal of Thermal Biology 35: 34-40.

Osbourn MS, Connette GM, Semlitsch RD 2014. Effects of fine-scale forest habitat quality on movement and settling decisions in juvenile pond-breeding salamanders. Ecological Applications 24: 1719-1729.

Paoletti DJ, Olson DH, Blaustein AR 2011. Responses of foothill yellow-legged frog (Rana boylii) larvae to an introduced predator. Copeia 1: 161-168.

Patrick DA, Harper EB, Hunter ML Jr, Calhoun AJ 2008. Terrestrial habitat selection and strong density-dependent mortality in recently metamorphosed amphibians. Ecology 89: 2563-2574.

Pearl CA, Adams MJ, Schuytema GS, Nebeker AV 2003. Behavioural responses of anuran larvae to chemical cues of native and introduced predators in the Pacific northwestern United States. Journal of Herpetology 37: 572-576.

Peterman WE, Semlitsch RD 2013. Fine-scale habitat associations of a terrestrial salamander: The role of environmental gradients and implications for population dynamics. PLoS One 8: e62184.

Pittman SE, Osbourn MS, Semlitsch RD 2014. Movement ecology of amphibians: A missing component for understanding population declines. Biological Conservation 169: 44-53. 
Pittman SE, Semlitsch RD 2013. Habitat type and distance to edge affect movement behaviour of juvenile pond-breeding salamanders. Journal of Zoology 291: 154-162.

Pledger S 2011. Analysis and recommendations for Archey's frog monitoring in Whareorino Forest and the Coromandel Peninsula. Unpublished report, Victoria University of Wellington, Wellington.

Pledger S 2013. Brief report to the Department of Conservation Waikato Conservancy. Unpublished report, Victoria University of Wellington, Wellington.

Preisser EL, Bolnick DI, Benard MF 2005. Scared to death? The effects of intimidation and consumption in predator-prey interactions. Ecology 86: 501-509.

Price-Rees AM, Brown GP, Shine R 2014. Activity patterns and movement of free-ranging bluetongue lizards (Tiliqua scincoides and Tiliqua multifasciata) in the Australian wet-dry tropics. Journal of Herpetology 48: 298-305.

R Core Team 2015. R: A language and environment for statistical computing. R Foundation for Statistical Computing, Vienna, Austria. <https://www.r-project.org>.

Ramirez EA, Puglis HJ, Ritzenthaler A, Boone M 2012. Terrestrial movement and habitat preferences of male cricket frogs on a golf course. Copeia 2012: 191-196.

Ramírez PA, Bell BD, Germano JM, Bishop PJ, Nelson NJ 2017. Tracking a small cryptic amphibian with fluorescent powders. New Zealand Journal of Ecology 41: 134-138. 
Reaney LT, Backwell PRY 2007. Temporal constraints and female preference for burrow width in the fiddler crab, Uca mjoebergi. Behavioral Ecology and Sociobiology 61: 1515-1521.

Reilly S, Essner R Jr, Wren S, Easton L, Bishop PJ 2015. Movement patterns in leiopelmatid frogs: Insights into the locomotor repertoire of basal anurans. Behavioural Processes 121: 43-53.

Resetarits WJ, Wilbur HM 1989. Choice of oviposition site by Hyla chrysoscelis: role of predators and competitors. Ecology 70: 220-228.

Revilla E, Wiegand T, Palomares F, Ferreras P, Delibes M 2004. Effects of matrix heterogeneity on animal dispersal: From individual behaviour to metapopulation-level parameters. The American Naturalist 164: E130-E153.

Rittenhouse TAG, Altnether TT, Semlitsch RD 2006. Fluorescent powder pigments as a harmless tracking method for ambystomatids and ranids. Herpetological Review 37: 188-191.

Rittenhouse TAG, Doyle MC, Mank CR, Rothermel BB, Semlitsch RD 2004. Substrate cues influence habitat selection by Spotted Salamanders. The Journal of Wildlife Management 68: 1151-1158.

Roe AW, Grayson KL 2008. Terrestrial movement and habitat use of juvenile and emigrating adult easterner-spotted newts, Notophthalmus viridescens. Journal of Herpetology 42: 22-30.

Roelants K, Bossuyt F 2005. Archaeobatrachian paraphyly and Pangaean diversification of crowngroup frogs. Systematic Biology 54:11-126.

Row JR, Blouin-Demers G 2006. Kernels are not accurate estimators of home-range size for herpetofauna. Copeia 4: 797-802. 
Rowley JJ, Alford RA 2007. Techniques for tracking amphibians: The effects of tag attachment, and harmonic direction finding versus radio telemetry. Amphibia-Reptilia 28: 367-376.

Roznik EA, Johnson SA 2009. Burrow use and survival of newly metamorphosed gopher frogs (Rana capito). Journal of Herpetology 43: 431-437.

Rufaut CG 1995. A comparative study of the Wellington tree weta, Hemideina crassidens (Blachard, 1851), in the presence and absence of rodents. Unpublished MSc thesis, Victoria University of Wellington, Wellington.

Salo P, Korpimäki E, Banks PB, Nordström M, Dickman CR 2007. Alien predators are more dangerous than native predators to prey populations. Proceedings of the Royal Society B 274: $1237-1243$

Scheffers BR, Edwards DP, Diesmos A, Williams SE, Evans TA 2014. Microhabitats reduce animal's exposure to climate extremes. Global Change Biology 20: 495-503.

Schwarzkopf L, Alford RA 1996. Desiccation and shelter-site use in a tropical amphibian: Comparing toads with physical models. Functional Ecology 10: 193-200.

Seebacher F, Alford RA 1999. Movement and microhabitat use of a terrestrial amphibian (Bufo marinus) on a Tropical island: Seasonal variation and environmental correlates. Journal of Herpetology 33: 208-214.

Seebacher F, Alford RA 2002. Shelter microhabitats determine body temperature and dehydration rates of a terrestrial amphibian (Bufo marinus). Journal of Herpetology 36: 69-75. 
Shaw S, Haigh A, Bishop PJ, Skeratt LF, Speare R, Bell BD, Berger L 2008. Distribution and prevalence of Batrachochytrium dendrobatidis in New Zealand. In: Conference Proceedings for the Australasian Wildlife Disease Association Conference, Kioloa.

Shaw SD, Skerratt LF, Haigh A, Bell BD, Daglish L, Bishop PJ, Summers R, Moreno V, Meltzer S, Ohmer M, Herbert S, Gleeson D, Rowe L, Speare R 2013. The distribution and host range of Batrachochytrium dendrobatidis in New Zealand, 1930-2010. Ecology 94: 2108-2111.

Shaw SD, Skerratt LF, Kleinpaste R, Daglish L, Bishop PJ 2012. Designing a diet for captive native frogs from the analysis of stomach contents from free-ranging Leiopelma. New Zealand Journal of Zoology 39: 47-56.

Sih A, Bolnick DI, Luttbeg B, Orrock JL, Peacor SD, Pintor LM, Preisser E, Rehage JS, Vonesh JR 2010. Predator-prey naïveté, antipredator behaviour, and the ecology of predator invasions. Oikos 119: 610-621.

Sinervo B, Calsbeek R, Comendant T, Both C, Adamopoulou C, Clobert J 2006. Genetic and maternal determinants of effective dispersal: The effect of sire genotype and size at birth in sideblotched lizards. American Naturalist 168: 88-99.

Sinsch U 1990. Migration and orientation in anuran amphibians. Ethology, Ecology \& Evolution 2: 65-79.

Sinsch U 1991. Mini-review: The orientation behaviour of amphibians. Herpetological Journal 1: 541-544. 
Sinsch U 2014. Movement ecology of amphibians: From individual migratory behaviour to spatially structured populations in heterogeneous landscapes. Canadian Journal of Zoology 92: 491-502.

Skidds DE, Golet FC, Paton PW, Mitchell JC 2007. Habitat correlates of reproductive effort in wood frogs and spotted salamanders in an urbanizing watershed. Journal of Herpetology 41: 439-450.

Smith MA, Green DM 2005. Dispersal and the metapopulation paradigm in amphibian ecology and conservation: Are all amphibian populations metapopulations? Ecography 28: 110-128.

Smith MA, Green DM 2006. Sex, isolation and fidelity: Unbiased long-distance dispersal in a terrestrial amphibian. Ecography 29: 649-658.

Smith GR, Todd A, Rettig JE, Nelson F 2003. Microhabitat selection by northern cricket frogs (Acris crepitans) along a west-central Missouri creek: Field and experimental observations. Journal of Herpetology 37: 383-385.

Sokal RR, Rohlf FJ 1995. Biometry: The principles and practice of statistics in biological research. WH Freeman \& Company, New York.

Spotila JR 1972. Role of temperature and water in the ecology of lungless salamanders. Ecological Monographs 42: 95-125.

Stamps JA 1988. Conspecific attraction and aggregation in territorial species. American Naturalist 131: 329-347.

Stephenson EM 1961. New Zealand native frogs. Tuatara 8: 99-106. 
Stephenson EM, Stephenson NG 1957. Field observations on the New Zealand frog, Leiopelma Fitzinger. Transactions of the Royal Society of New Zealand 84: 867-882.

Stephenson NG 1955. On the development of the frog, Leiopelma hochstetteri Fitzinger. Proceedings of the Zoological Society of London 124: 785-795.

Storfer A 2003. Amphibian declines: Future directions. Diversity and Distributions 9: 151-163.

Stuart SN, Chanson JS, Cox NA, Young BE, Rodrigues AS, Fischman DL, Waller RW 2004. Status and trends of amphibian declines and extinctions worldwide. Science 306: 1783-1786.

Sullivan BK, Kwiatkowski MA, Schuett GW 2004. Translocation of urban Gila Monsters: A problematic conservation tool. Biological Conservation 117: 235-242.

Thurley T 1996. A survey of native frogs (Leiopelma archeyi and L. hochstetteri) in Whareorino Forest, northern King Country. Unpublished MSc thesis, Victoria University of Wellington, Wellington.

Thurley T 2003. Emergency predator control for the Whareorino Forest Archey's frog population. Unpublished report, Department of Conservation, Te Kuiti.

Thurley T, Bell BD 1994. Habitat distribution and predation on a western population of terrestrial Leiopelma (Anura: Leiopelmatidae) in the northern King Country, New Zealand. New Zealand Journal of Zoology 21: 431-436.

Tocher M, Brown D 2004. Leiopelma hamiltoni (NCN.) homing. Herpetological Review 35: 259261. 
Tocher MD, Fletcher D, Bishop PJ 2006. A modelling approach to determine a translocation scenario for the endangered New Zealand frog Leiopelma hamiltoni. Herpetological Journal 16: 97-106.

Towns DR, Daugherty CH 1994. Patterns of range contractions and extinctions in the New Zealand herpetofauna following human colonisation. New Zealand Journal of Zoology 21: 325-339.

Towns DR, Parrish GR, Westbrooke I 2003. Inferring vulnerability to introduced predators without experimental demonstration: Case study of Suter's skink in New Zealand. Conservation Biology 17: 1361-1371.

Tozetti AM, Toledo LF 2005. Short-term movement and retreat sites of Leptodactylus labyrinthicus (Anura: Leptodactylidae) during the breeding season: A spool-and-line tracking study. Journal of Herpetology 39: 640-644.

Tracy CR 1976. A model of the dynamic exchanges of water and energy between a terrestrial amphibian and its environment. Ecological Monographs 46: 293-326.

Tracy R, Christian KA, O’Connor MP, Tracy CR 1993. Behavioral thermoregulation by Bufo americanus: The importance of the hydric environment. Herpetologica 49: 375-382.

Turchin P 1998. Quantitative analysis of movement: Measuring and modelling population redistribution in animals and plants. Sinauer Associates, Massachusetts.

Valenzuela-Sánchez A, Harding G, Cunningham AA, Chirgwin C, Soto-Azat C 2014. Home range and social analyses in a mouth brooding frog: Testing the coexistence of paternal care and male territoriality. Journal of Zoology 294: 215-223. 
Vardeman EA, Campbell JF, Arthur FH, Nechols JR 2007. Behavior of female Rhyzopertha dominica (Coleoptera: Bostrichidae) in a mono-layer of wheat treated with diatomaceous earth. Journal of Stored Products Research 43: 297-301.

Vitousek PM, Mooney HA, Lubchenco J, Melillo JM 1997. Human domination of Earth's ecosystems. Science 277: 494-499.

Vitt LJ, Caldwell JP 2009. Thermoregulation, performance and energetics. In: Vitt LJ, Caldwell JP (Eds.): Herpetology, an introductory biology of amphibians and reptiles. Academic Press, San Diego, California.

Voyles J, Young S, Berger L, Campbell C, Voyles WF, Dinudom A, Cook D, Webb R, Alford RA, Skerratt LF, Speare R 2009. Pathogenesis of chytridiomycosis, a cause of catastrophic amphibian declines. Science 326: 582-585.

Wake DB 1991. Declining amphibian populations. Science 253: 860.

Wake DB 1998. Action on amphibians. Trends in Ecology \& Evolution 13: 379-380.

Waldman B, Bishop PJ 2004. Chemical communication in an archaic anuran amphibian. Behavioural Ecology 15: 88-93.

Webster JT 2004. Individual identification, disease monitoring and home range of Leiopelma hamiltoni. Unpublished MSc thesis, University of Canterbury, Christchurch.

Wells KD 2007. The ecology and behaviour of amphibians. The University of Chicago Press, Chicago and London. 
Wiens JA, Stenseth NC, Van Horne B, Ims RA 1993. Ecological mechanisms and landscape ecology. Oikos 66: 369-380.

Wilmshurst JM, Higham TFG 2004. Using rat-gnawed seeds to independently date the arrival of Pacific rats and humans in New Zealand. The Holocene 14: 801-806.

Woody DR, Mathis A 1997. Avoidance of areas labelled with chemical stimuli from damaged conspecifics by adult newts, Notophthalmus viridescens, in a natural habitat. Journal of Herpetology 31: 316-318.

Woolbright LL 1985. Patterns of nocturnal movement and calling by the tropical frog Eleutherodactylus coqui. Herpetologica 41: 1-9.

Worthy TH 1987. Palaeoecological information concerning members of the frog genus Leiopelma: Leiopelmatid in New Zealand. Journal of the Royal Society of New Zealand 17: 409-420.

Worthy TH, Holdaway RN 1994a. Scraps from an owl's table - predator activity as a significant taphonomic process newly recognised from New Zealand fossil deposits. Alcheringa: An Australasian Journal of Palaeontology 18: 229-245.

Worthy TH, Holdaway RN 1994b. Quaternary fossil faunas from caves in Takaka valley and on Takaka Hill, northwest Nelson, South Island, New Zealand. Journal of the Royal Society of New Zealand 24: 297-391.

Worthy TH, Holdaway RN 2002. The lost world of the Moa: Prehistoric life of New Zealand. Indiana University Press, Indiana. 
Worthy TH, Tennyson AJD, Scofield RP, Hand SJ 2013. Early Miocene fossil frogs (Anura: Leiopelmatidae) from New Zealand. Journal of the Royal Society of New Zealand 43: 211-230.

Yeiser JM, Richter SC 2015. Microhabitat conditions influence mesohabitat associations and distribution of larval salamanders in headwater streams. Hydrobiologia 751: 175-187.

Yetman CA, Ferguson JWH 2011. Conservation implications of spatial habitat use by adult giant bullfrogs (Pyxicephalus adspersus). Journal of Herpetology 45: 56-62.

Young BE, Lips KR, Reaser JK, Ibáñez R, Salas AW, Cedeño JR, Coloma LA, Ron S, La Marca E, Meyer JR, Muñoz A, Bolaños F, Chaves G, Romo D 2008. Population declines and priorities for amphibian conservation in Latin America. Conservation Biology 15: 1213-1223.

Zavaleta ES, Hobbs RJ, Mooney HA 2001. Viewing invasive species removal in a whole-ecosystem context. Trends in Ecology \& Evolution 16: 454-459. 


\section{Appendix 1}

Home range estimates using $95 \%$ minimum convex polygon (MCP) method for $L$. archeyi with $\geq 8$ recaptures during 2005-2013 at Whareorino Forest. Age classes were assigned according to the age class that consecutively comprised $\geq 80 \%$ of the most recent recaptures $(A=$ adult, $\mathrm{SA}=$ sub-adult, ${ }^{*}=$ indeterminate age class).

Non-treatment grids

\begin{tabular}{|c|c|c|c|}
\hline Frog ID & Number of recaptures & Age class & $\operatorname{MCP}\left(\mathrm{m}^{2}\right)$ \\
\hline A107 & 13 & * & 12.35 \\
\hline A117 & 11 & $*$ & 8.63 \\
\hline A12 & 8 & A & 11.28 \\
\hline A120 & 11 & $*$ & 7.97 \\
\hline $\mathrm{A} 123$ & 13 & A & 3.95 \\
\hline A126 & 8 & SA & 0.87 \\
\hline A136 & 9 & $\mathrm{~A}$ & 1.58 \\
\hline A137 & 10 & SA & 1.19 \\
\hline A147 & 8 & SA & 1.20 \\
\hline A159 & 9 & $*$ & 2.60 \\
\hline A22 & 8 & A & 1.54 \\
\hline A23 & 8 & A & 3.29 \\
\hline A26 & 13 & A & 1.10 \\
\hline A28 & 17 & A & 8.48 \\
\hline A64 & 8 & A & 4.66 \\
\hline A80 & 16 & $*$ & 18.56 \\
\hline A83 & 12 & $*$ & 2.34 \\
\hline A88 & 13 & $*$ & 1.88 \\
\hline A89 & 9 & SA & 5.42 \\
\hline A95 & 8 & $*$ & 14.63 \\
\hline A98 & 8 & $*$ & 3.59 \\
\hline B120 & 10 & $*$ & 3.67 \\
\hline B136 & 9 & SA & 0.61 \\
\hline B165 & 10 & SA & 6.81 \\
\hline B169 & 9 & $*$ & 12.46 \\
\hline B171 & 9 & $*$ & 2.64 \\
\hline B180 & 11 & $*$ & 2.28 \\
\hline B185 & 8 & SA & 1.04 \\
\hline B196 & 9 & SA & 1.14 \\
\hline B306 & 9 & SA & 1.70 \\
\hline B58 & 25 & A & 7.47 \\
\hline B59 & 10 & SA & 2.91 \\
\hline B72 & 11 & $\mathrm{~A}$ & 5.75 \\
\hline B96 & 8 & $*$ & 3.92 \\
\hline
\end{tabular}


Rat control grids

\begin{tabular}{|c|c|c|c|}
\hline Frog ID & Number of recaptures & Age class & $\mathrm{MCP}\left(\mathrm{m}^{2}\right)$ \\
\hline C103 & 8 & $\mathrm{~A}$ & 3.14 \\
\hline C104 & 10 & $\mathrm{~A}$ & 1.63 \\
\hline C106 & 11 & $\mathrm{~A}$ & 5.89 \\
\hline C107 & 9 & $A$ & 4.29 \\
\hline C108 & 10 & $\mathrm{~A}$ & 2.54 \\
\hline C134 & 12 & $\mathrm{~A}$ & 8.00 \\
\hline C166 & 13 & $\mathrm{~A}$ & 12.22 \\
\hline C168 & 13 & $\mathrm{~A}$ & 1.18 \\
\hline $\mathrm{C} 17$ & 19 & $\mathrm{~A}$ & 5.24 \\
\hline $\mathrm{C} 171$ & 11 & $\mathrm{~A}$ & 2.39 \\
\hline C186 & 8 & $*$ & 3.33 \\
\hline C187 & 10 & $*$ & 6.81 \\
\hline C19 & 8 & $\mathrm{~A}$ & 3.57 \\
\hline $\mathrm{C} 211$ & 12 & $\mathrm{~A}$ & 6.80 \\
\hline $\mathrm{C} 219$ & 10 & $\mathrm{~A}$ & 17.63 \\
\hline $\mathrm{C} 250$ & 11 & $*$ & 0.63 \\
\hline $\mathrm{C} 258$ & 10 & A & 1.09 \\
\hline $\mathrm{C} 262$ & 8 & $*$ & 0.98 \\
\hline C317 & 9 & $*$ & 3.83 \\
\hline C399 & 11 & $*$ & 5.27 \\
\hline C51 & 9 & SA & 1.19 \\
\hline D102 & 9 & $\mathrm{~A}$ & 3.90 \\
\hline D119 & 16 & A & 4.94 \\
\hline D120 & 16 & A & 3.72 \\
\hline D130 & 14 & A & 2.36 \\
\hline D137 & 14 & A & 5.79 \\
\hline D154 & 10 & A & 1.94 \\
\hline D167 & 10 & $*$ & 5.79 \\
\hline D2 & 8 & A & 4.66 \\
\hline D200 & 17 & $*$ & 2.16 \\
\hline D203 & 8 & SA & 1.00 \\
\hline D256 & 8 & $*$ & 4.84 \\
\hline D258 & 10 & A & 1.89 \\
\hline D265 & 14 & $\mathrm{~A}$ & 7.25 \\
\hline D3 & 44 & A & 14.04 \\
\hline D327 & 10 & $*$ & 0.73 \\
\hline D333 & 8 & $*$ & 2.97 \\
\hline D353 & 12 & A & 9.22 \\
\hline D36 & 8 & $*$ & 1.28 \\
\hline D397 & 12 & $*$ & 3.47 \\
\hline D42 & 8 & A & 16.65 \\
\hline D421 & 9 & A & 10.18 \\
\hline D435 & 8 & $*$ & 0.99 \\
\hline
\end{tabular}


Rat control grids: Continuation

\begin{tabular}{lccc}
\hline Frog ID & Number of recaptures & Age class & MCP $\left(\mathrm{m}^{2}\right)$ \\
\hline D514 & 9 & SA & 2.23 \\
D52 & 15 & A & 3.19 \\
D548 & 9 & $*$ & 1.99 \\
D55 & 9 & $*$ & 3.69 \\
D561 & 10 & A & 2.45 \\
D60 & 18 & A & 3.99 \\
D62 & 20 & A & 5.51 \\
D71 & 8 & $*$ & 1.41 \\
D74 & 17 & A & 1.79 \\
D76 & 14 & A & 2.99 \\
D8 & 20 & A & 1.00 \\
D81 & 22 & A & 3.14 \\
D82 & 10 & A & 3.20 \\
D9 & 9 & A & 5.43 \\
\hline
\end{tabular}




\section{Appendix 2}

95\% minimum convex polygons (MCP) of $L$. archeyi with $\geq 8$ recaptures during 2005-2013 from the non-treatment (A-B) and rat control (C-D) grids in Whareorino Forest. Grid dimensions are $10 \times 10 \mathrm{~m}$.

Grid A

Frog: A12

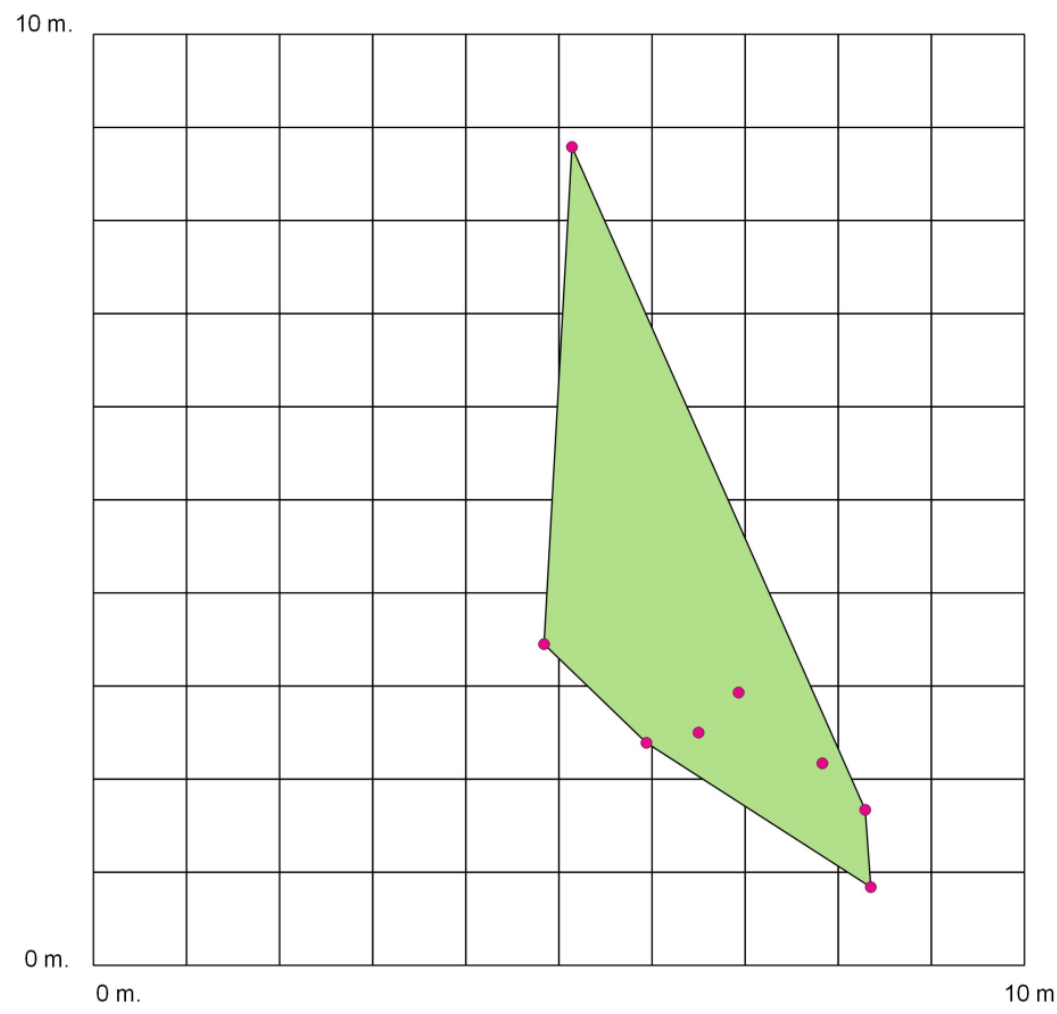


Frog: A22

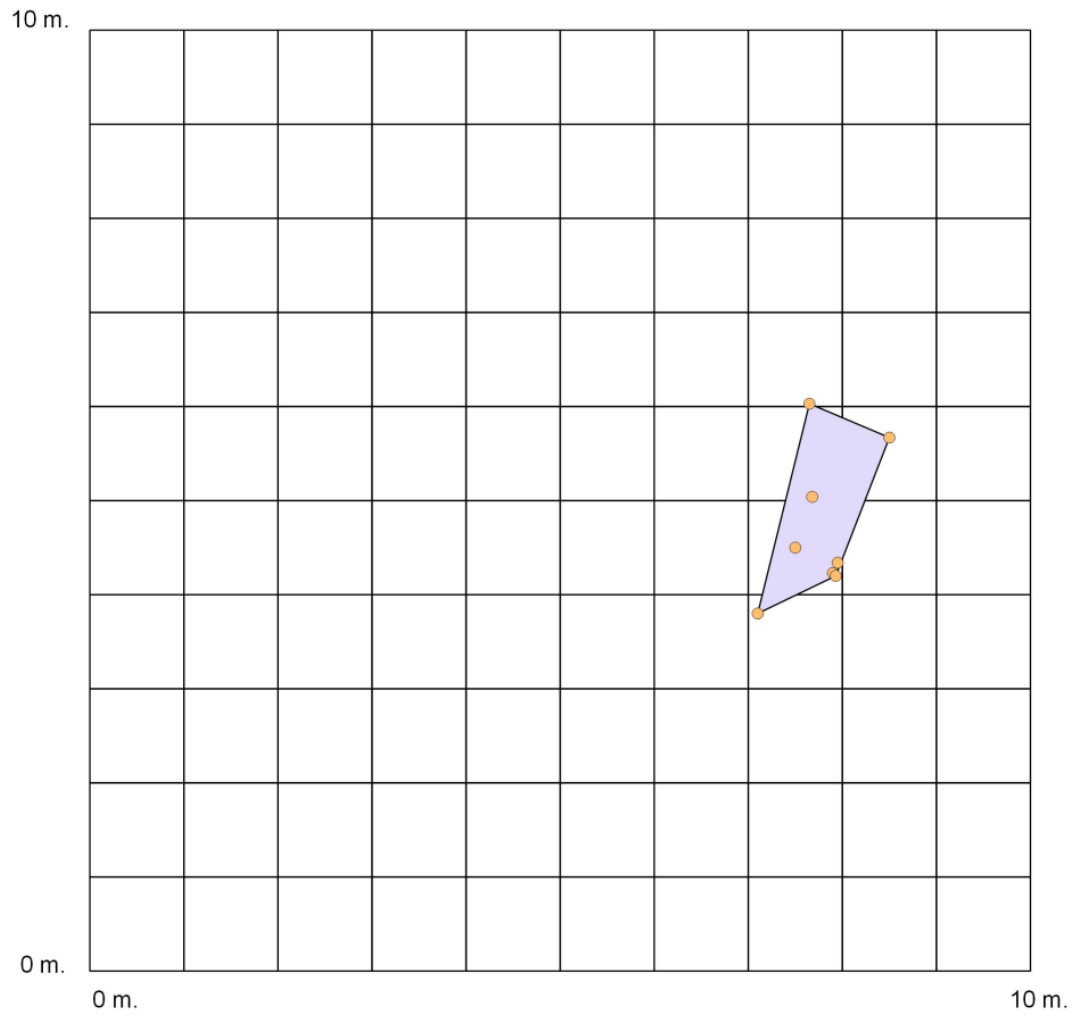

Frog: A23

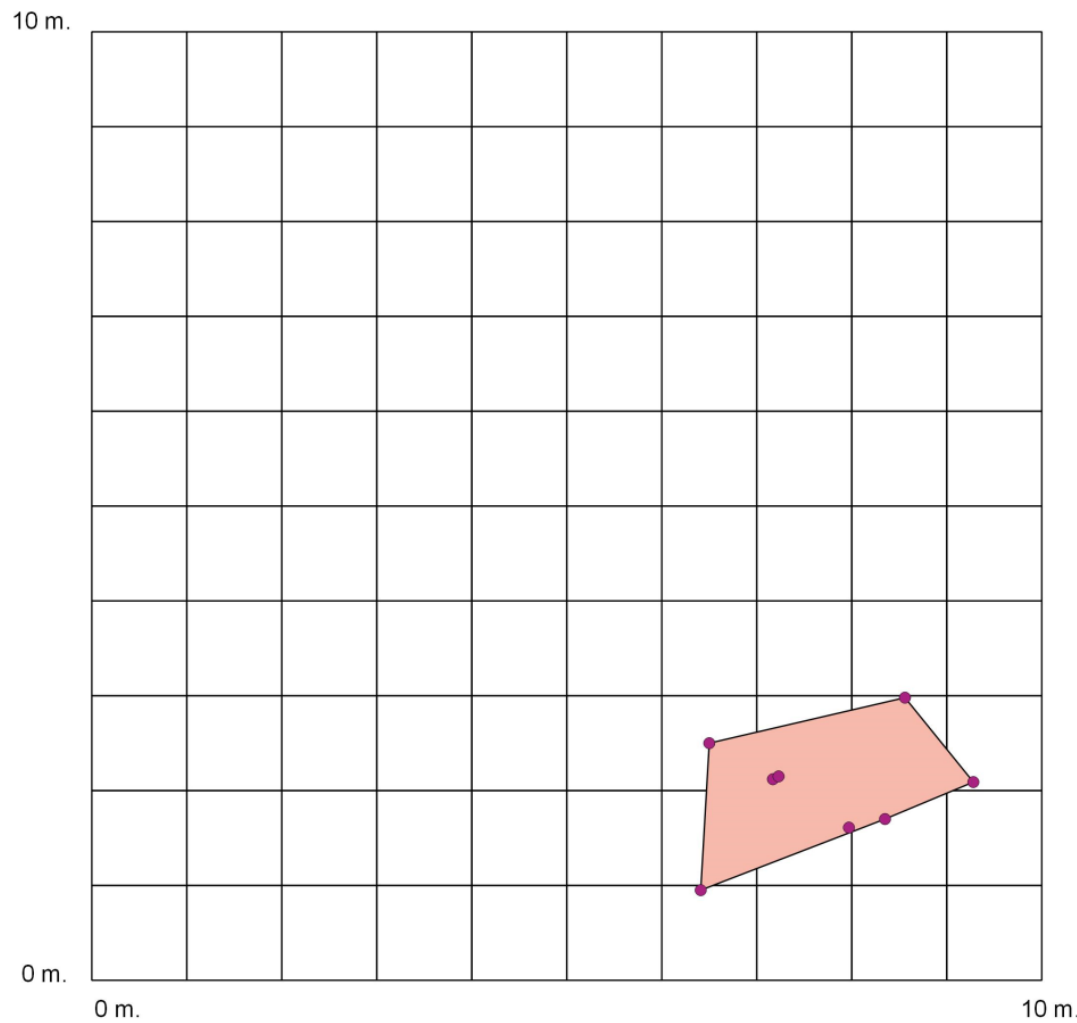


Frog: A26

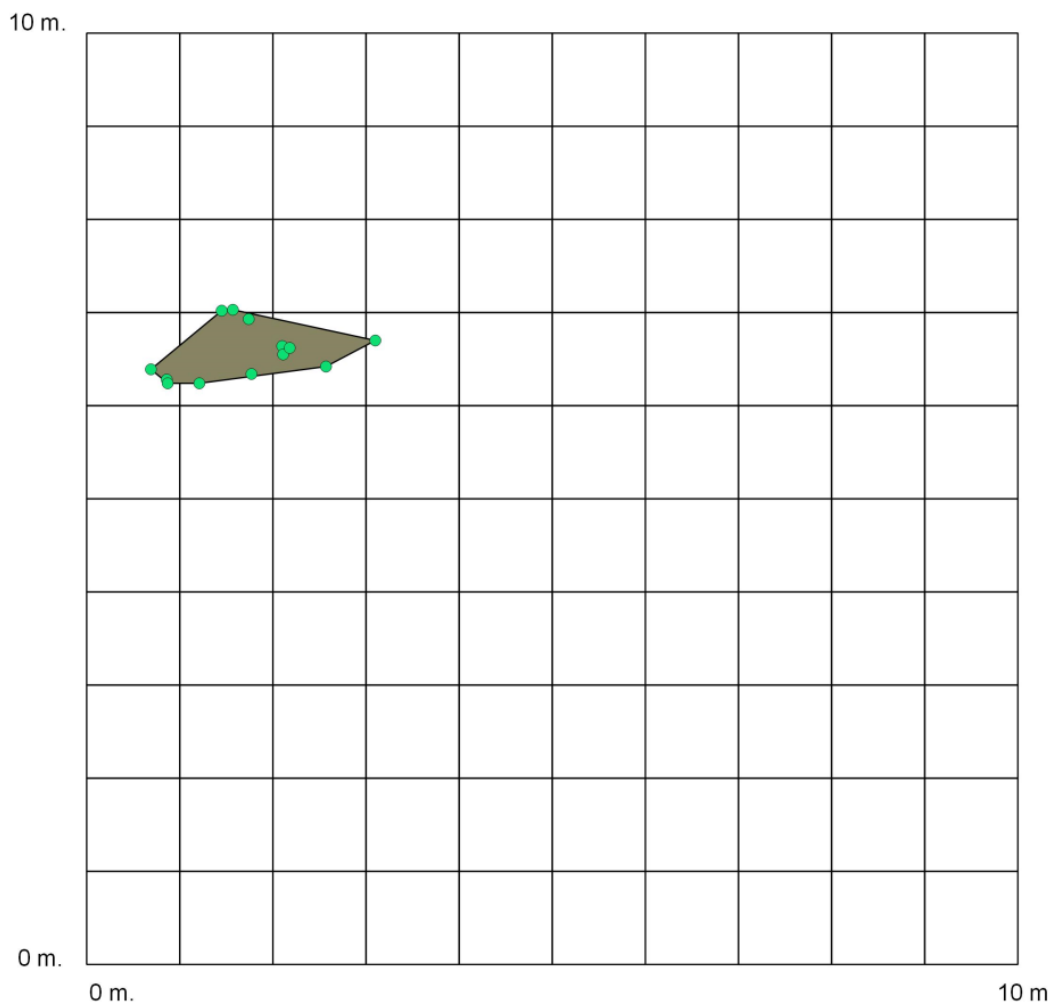

Frog: A28

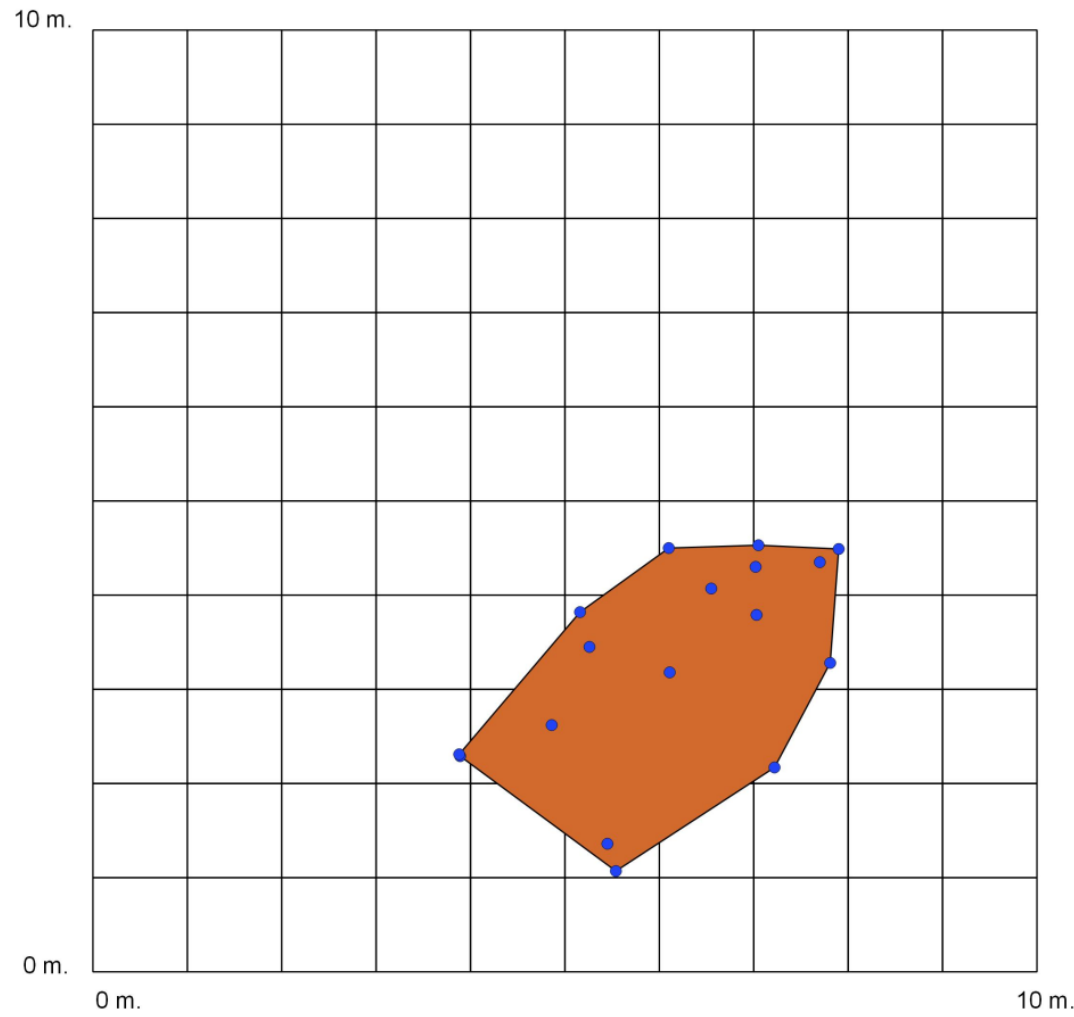


Frog: A64

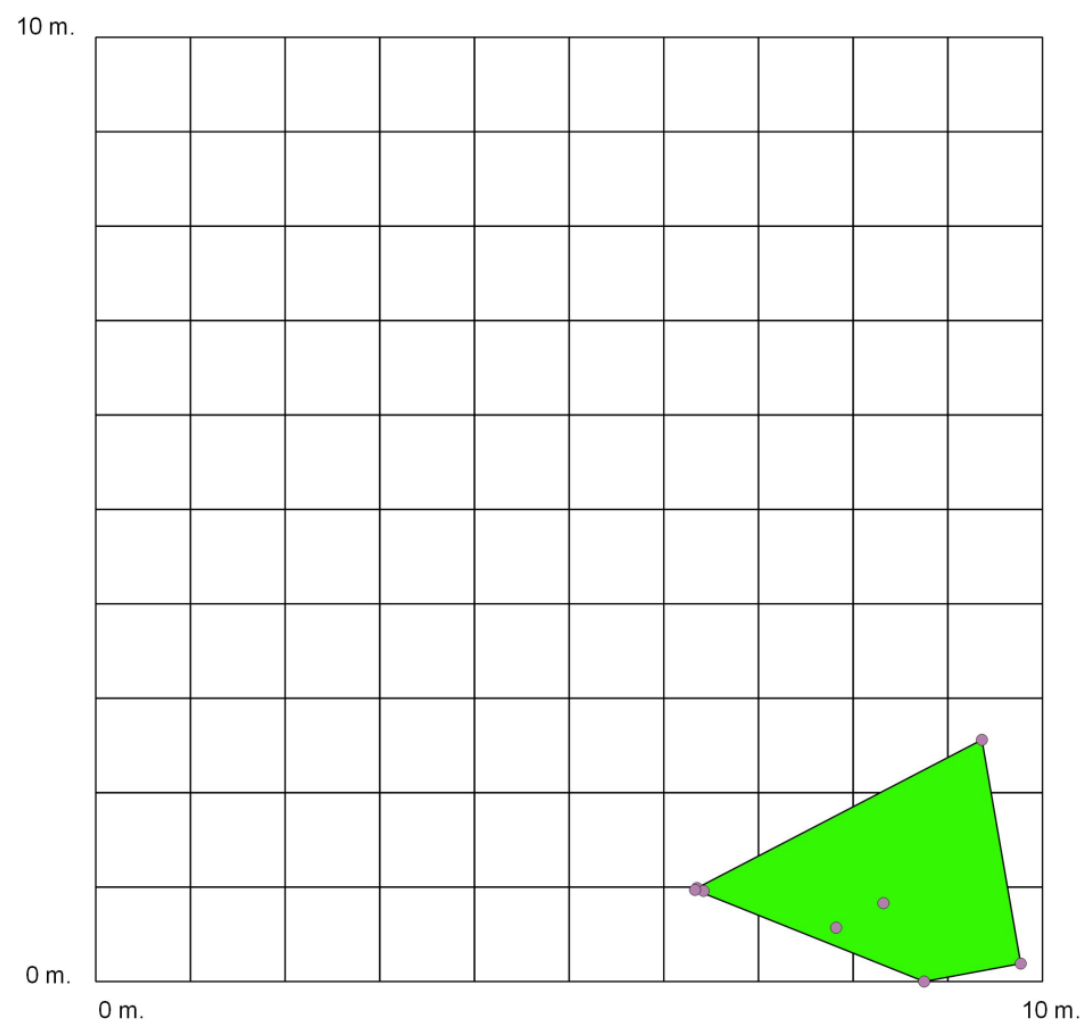

Frog: A80

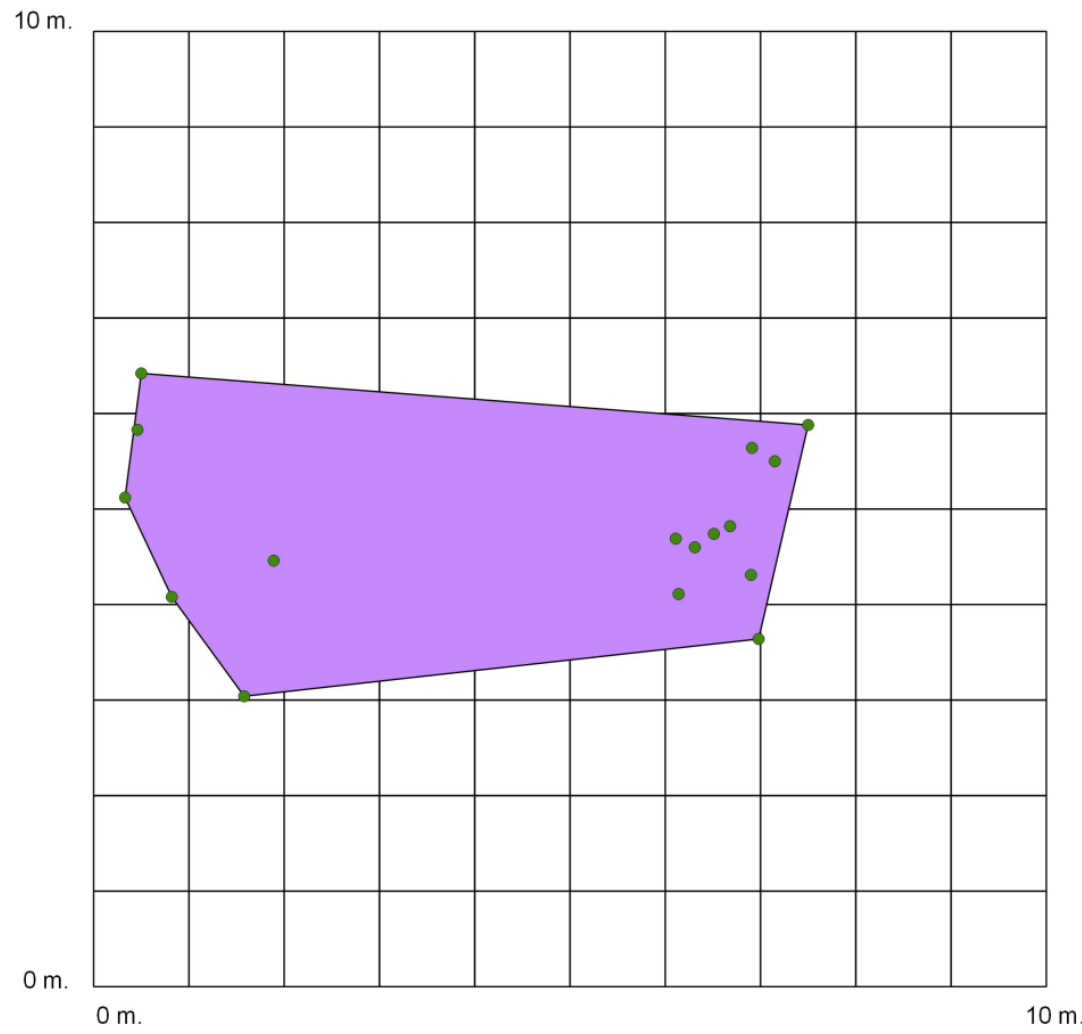


Frog: A83

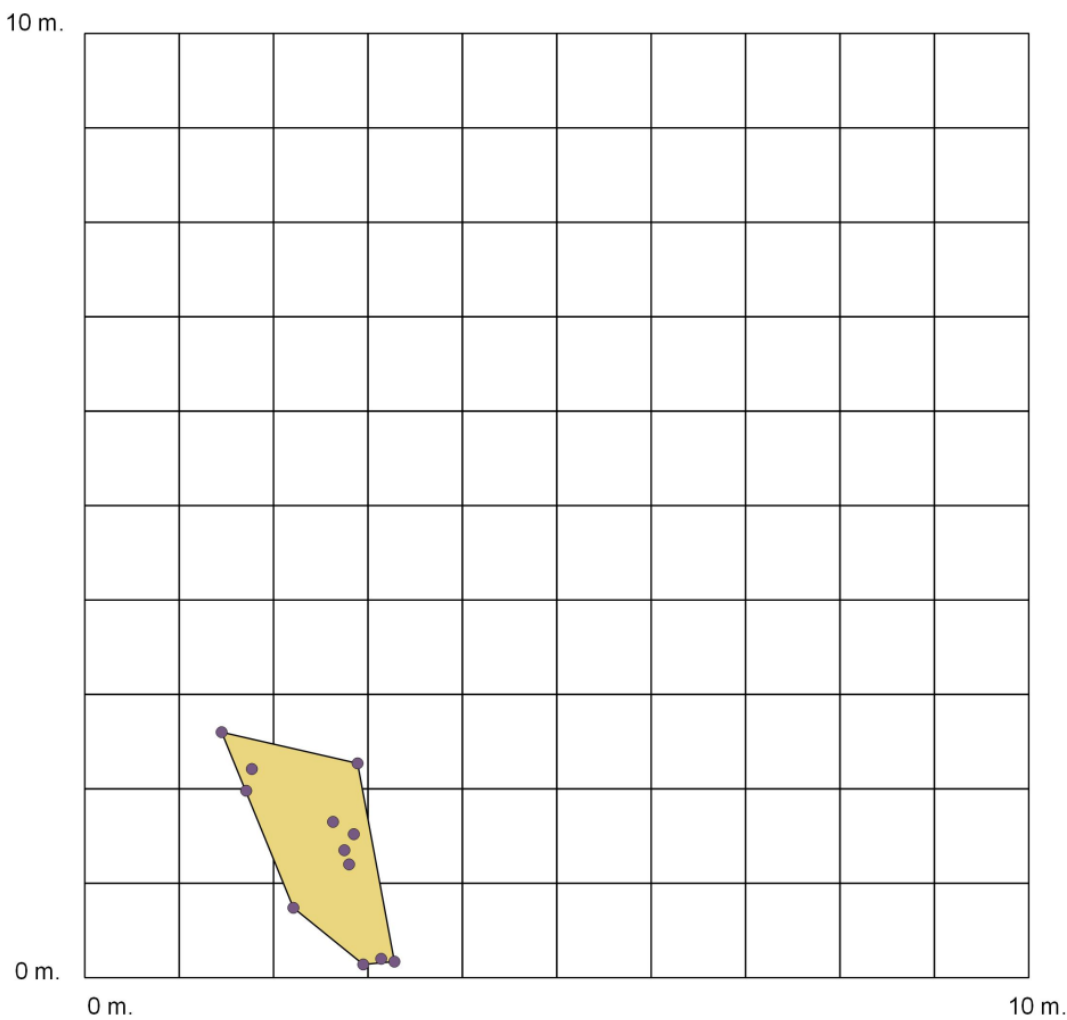

Frog: A88

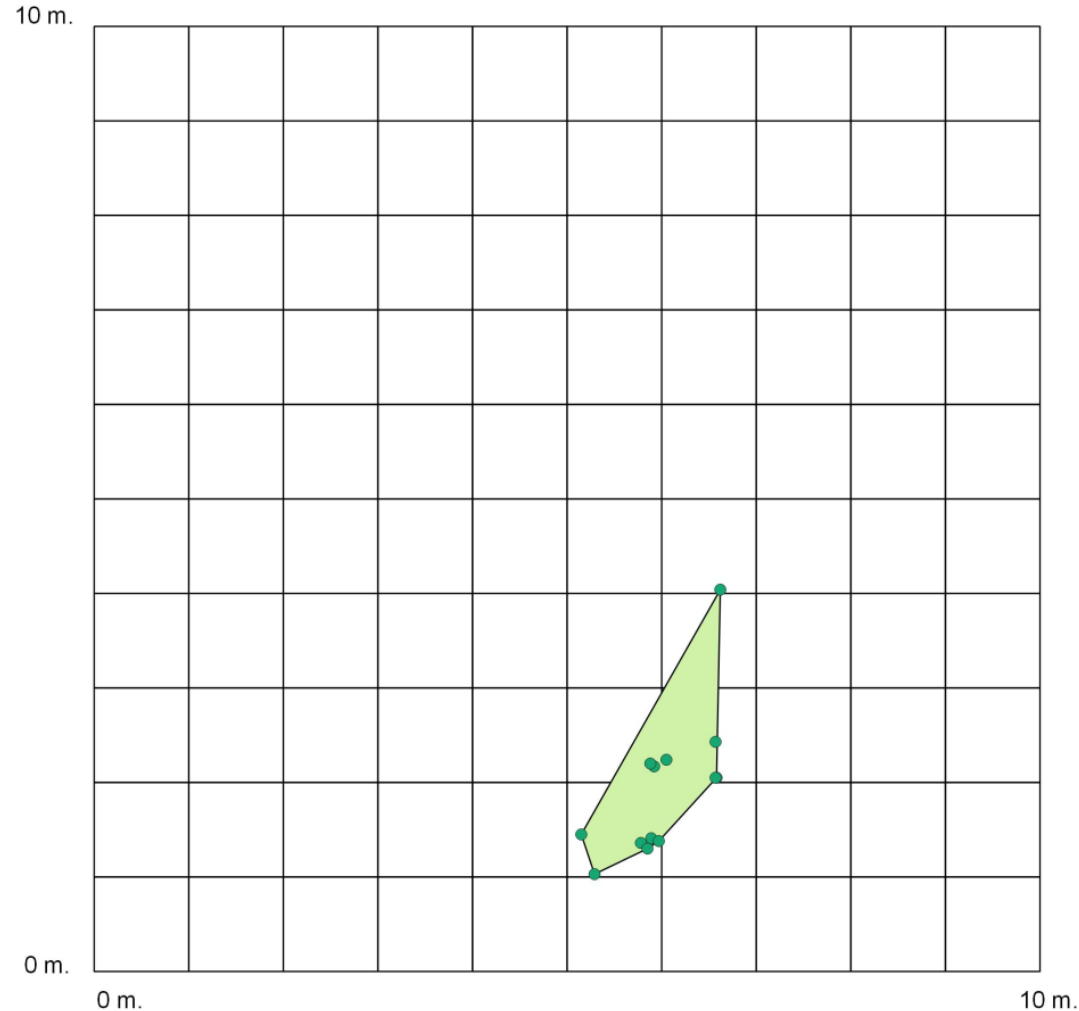


Frog: A89

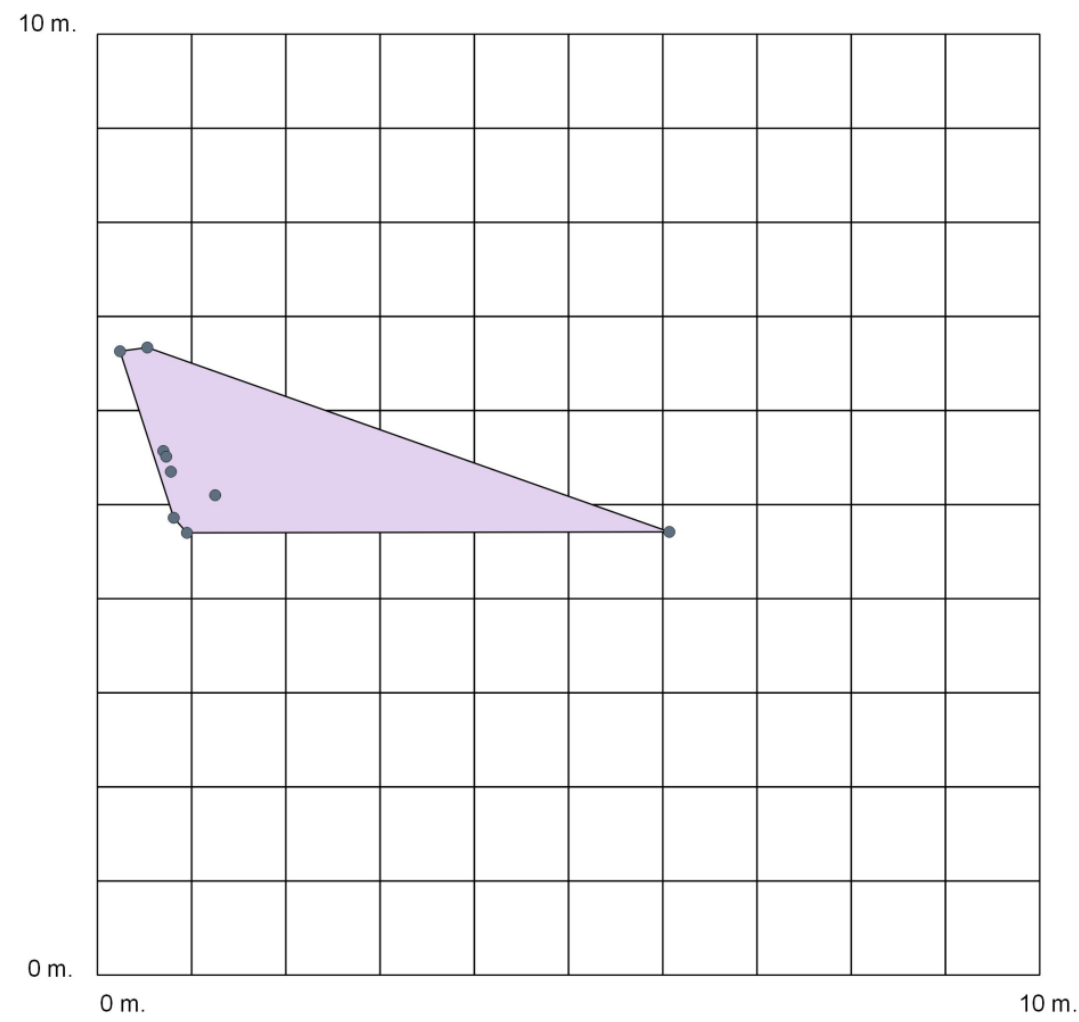

Frog: A95

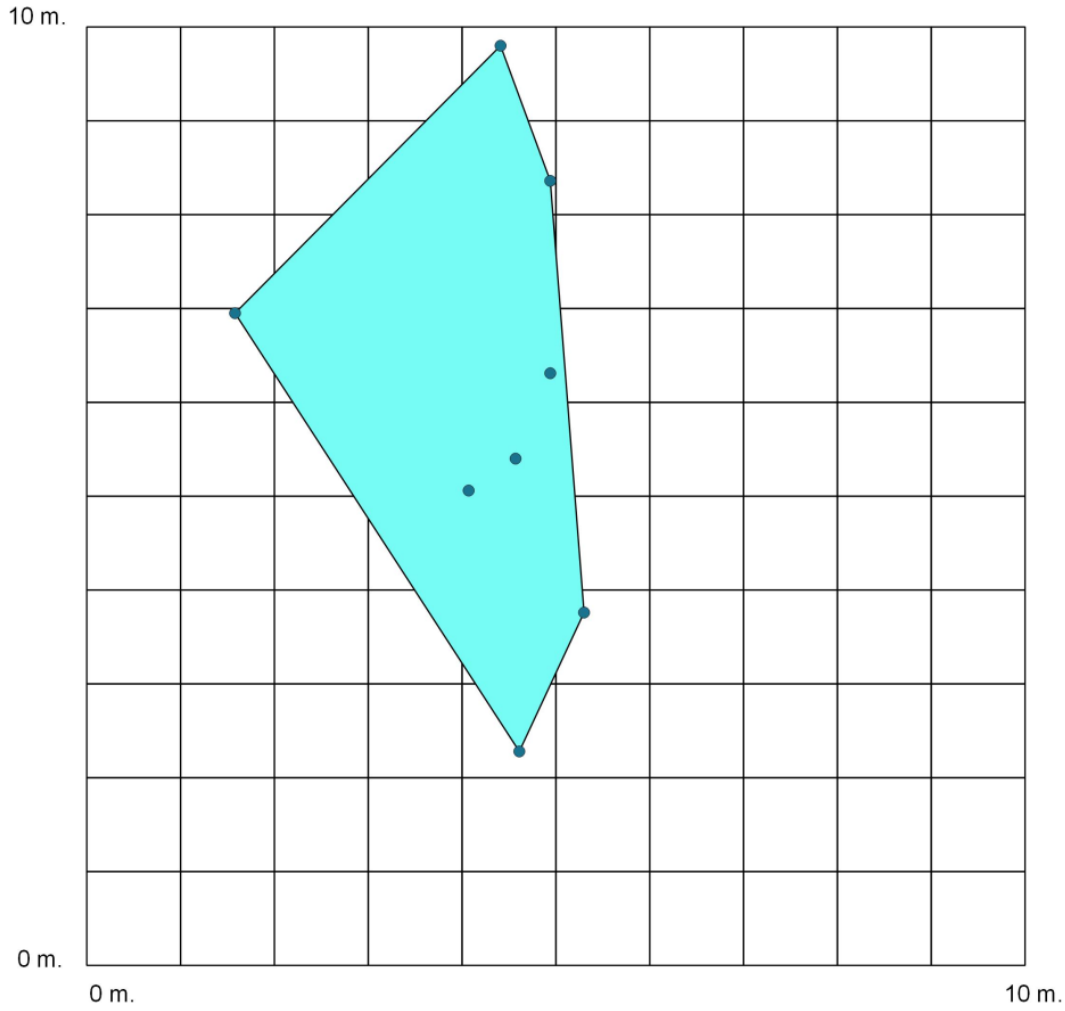


Frog: A98

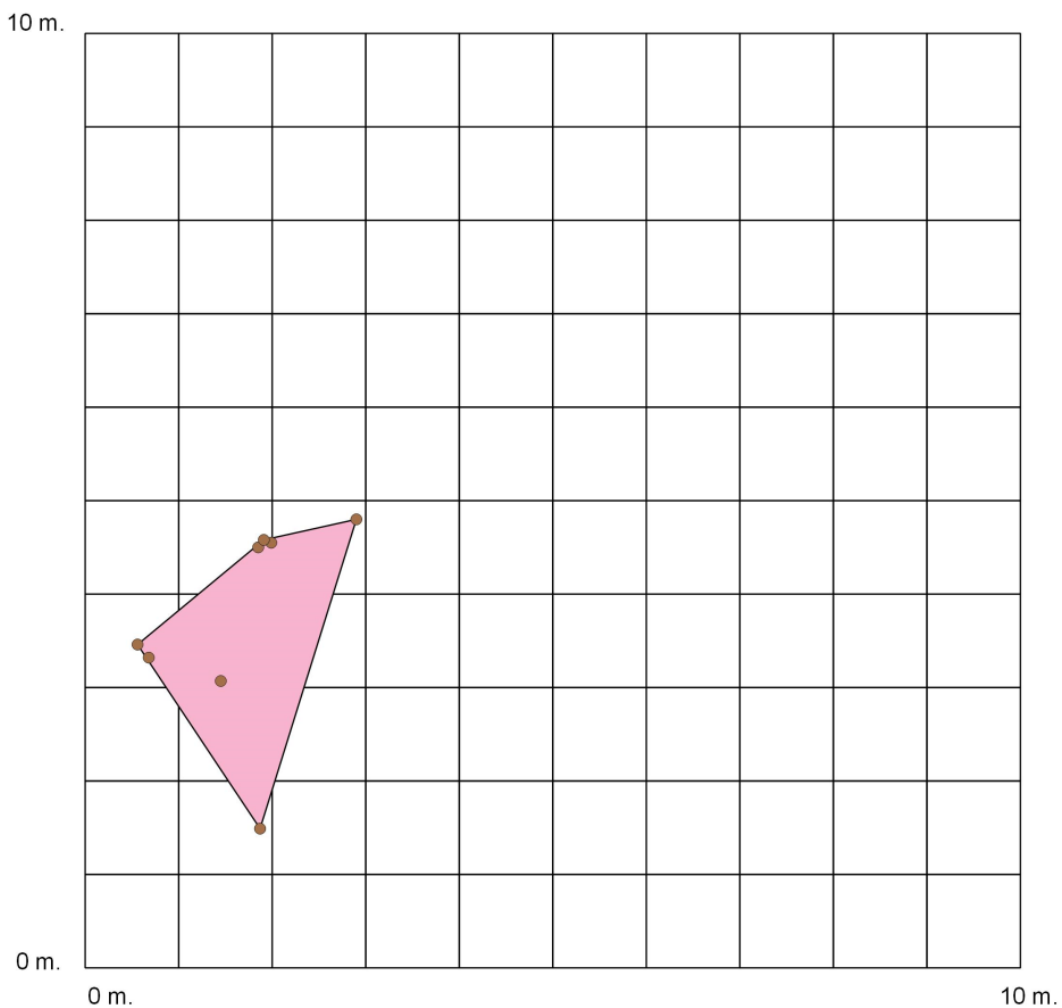

Frog: A107

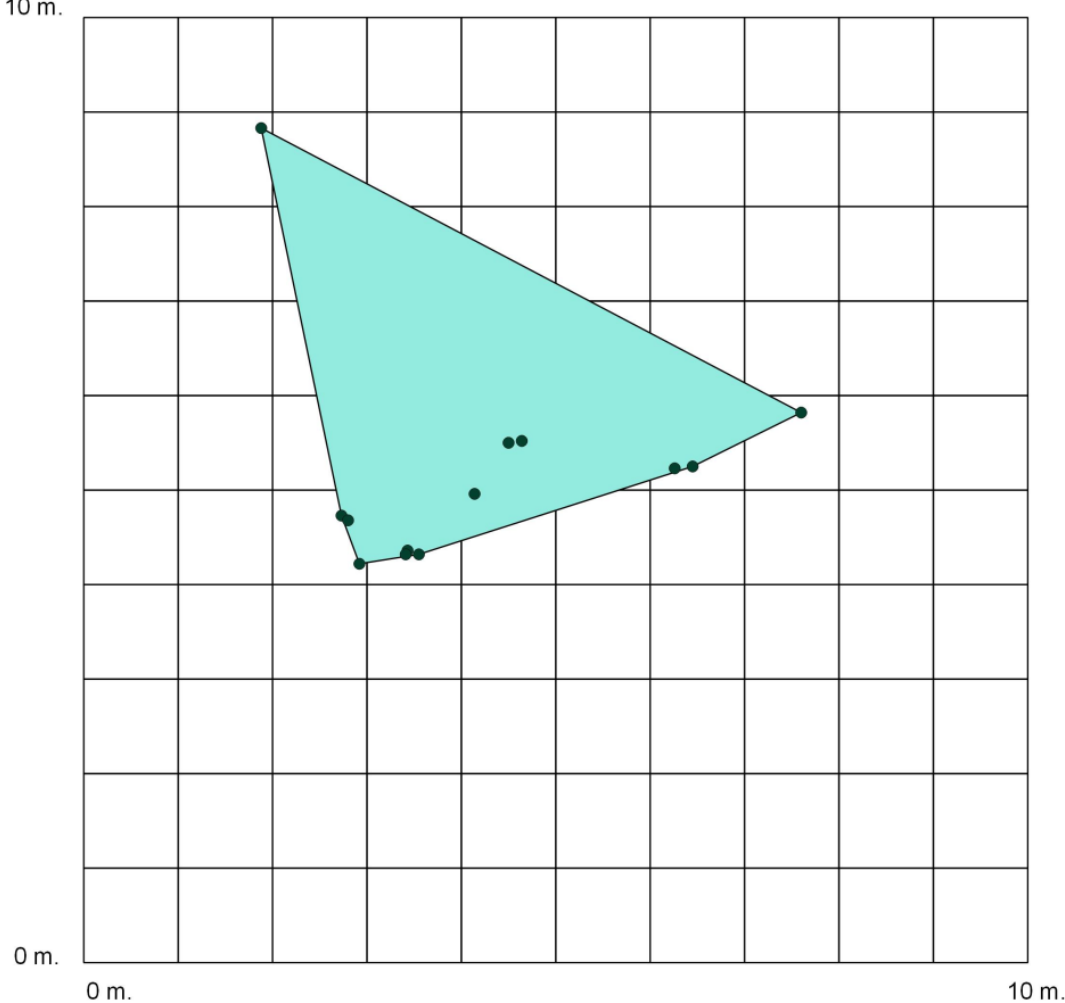


Frog: A117

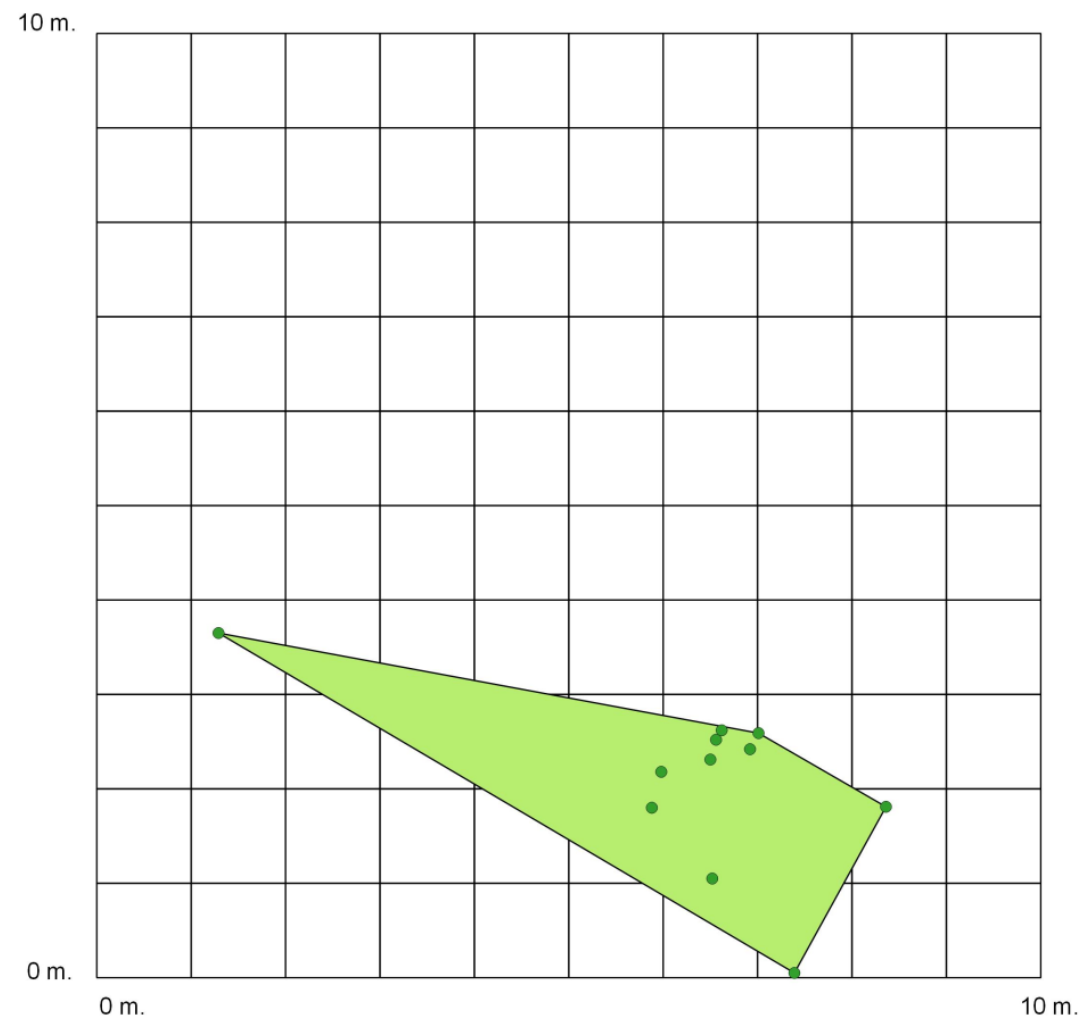

Frog: A120

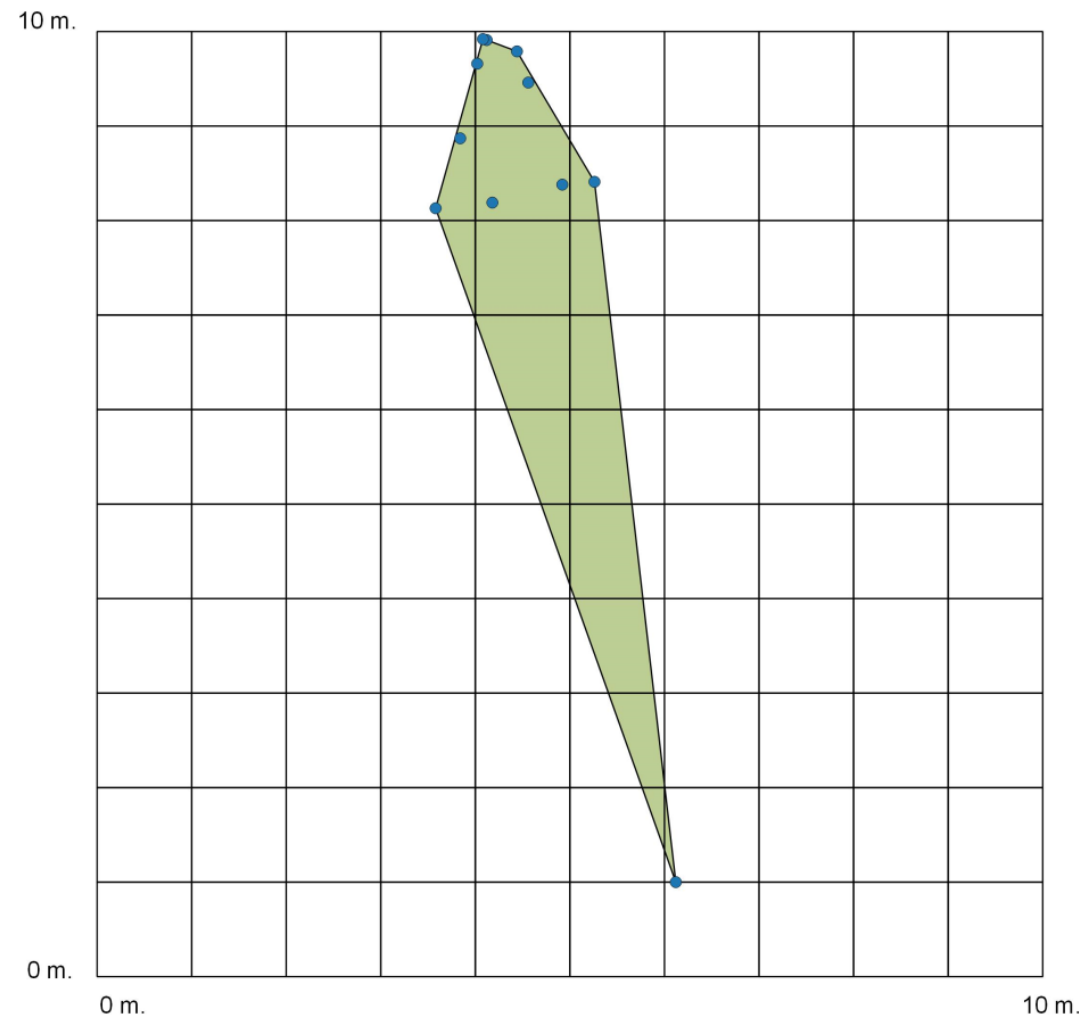


Frog: A123

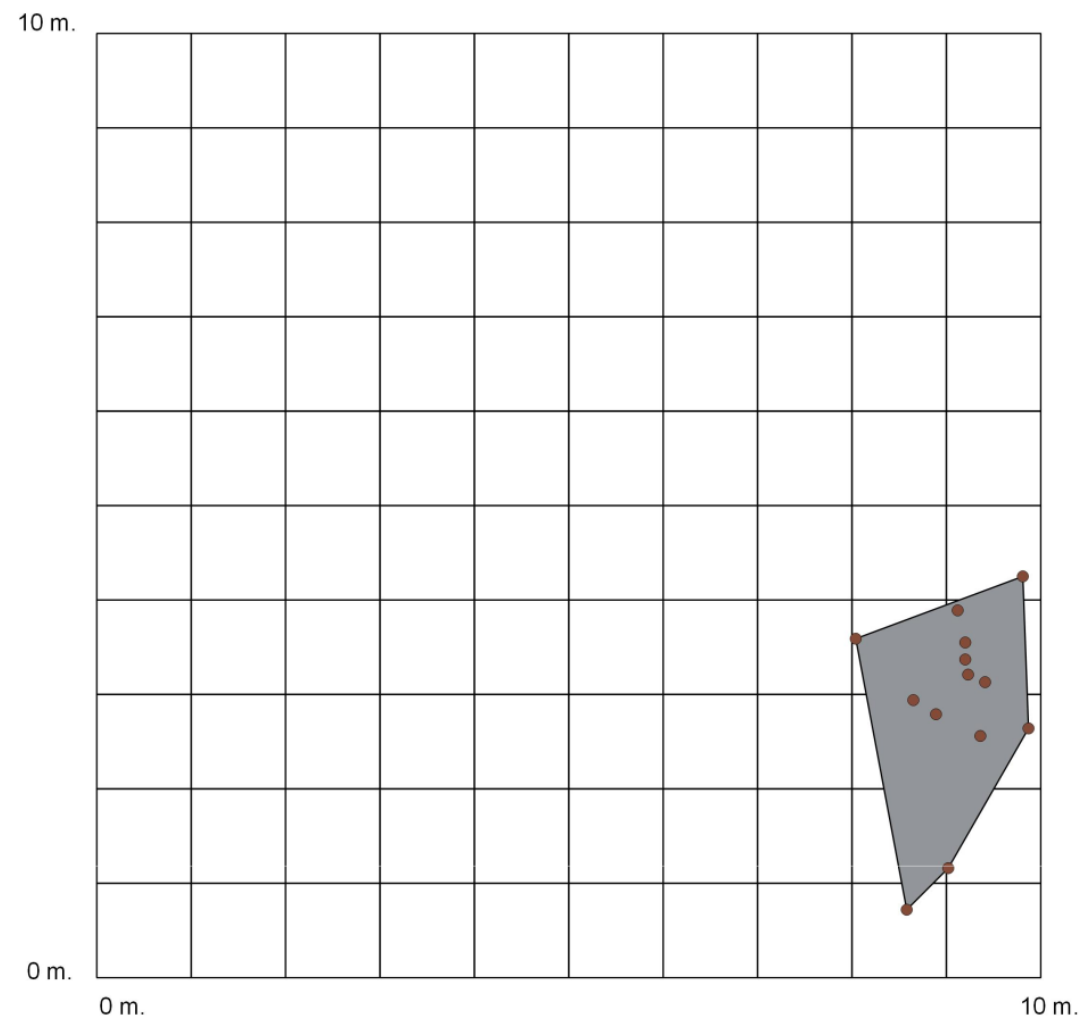

Frog: A126

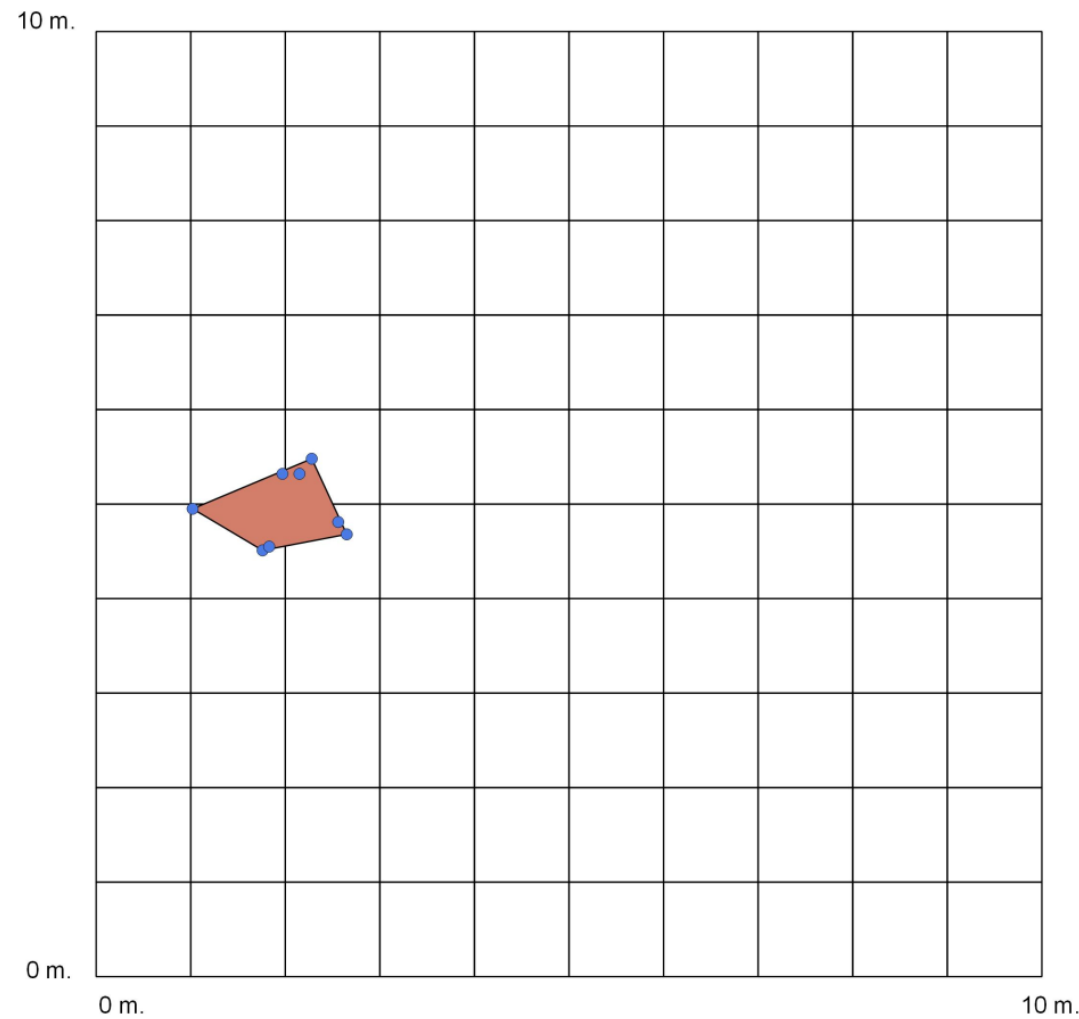


Frog: A136

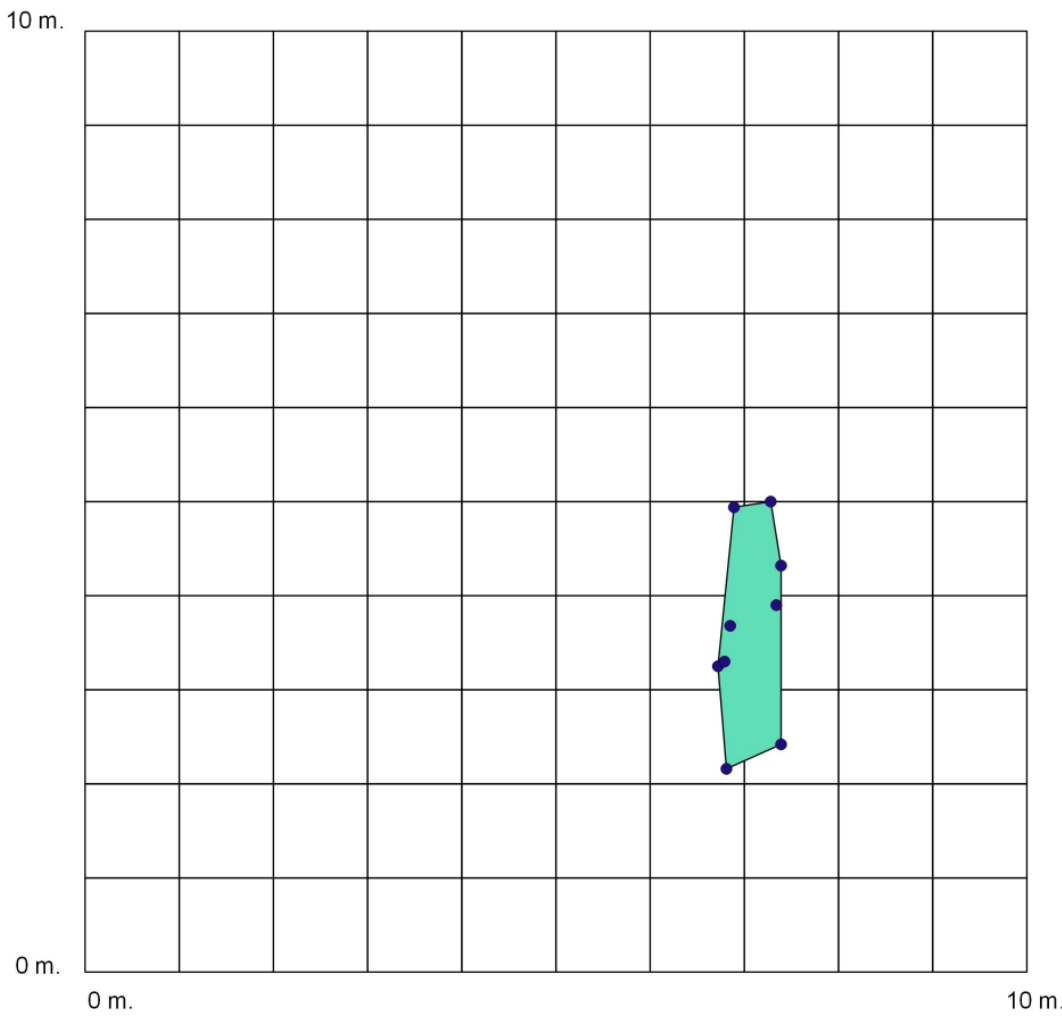

Frog: A137

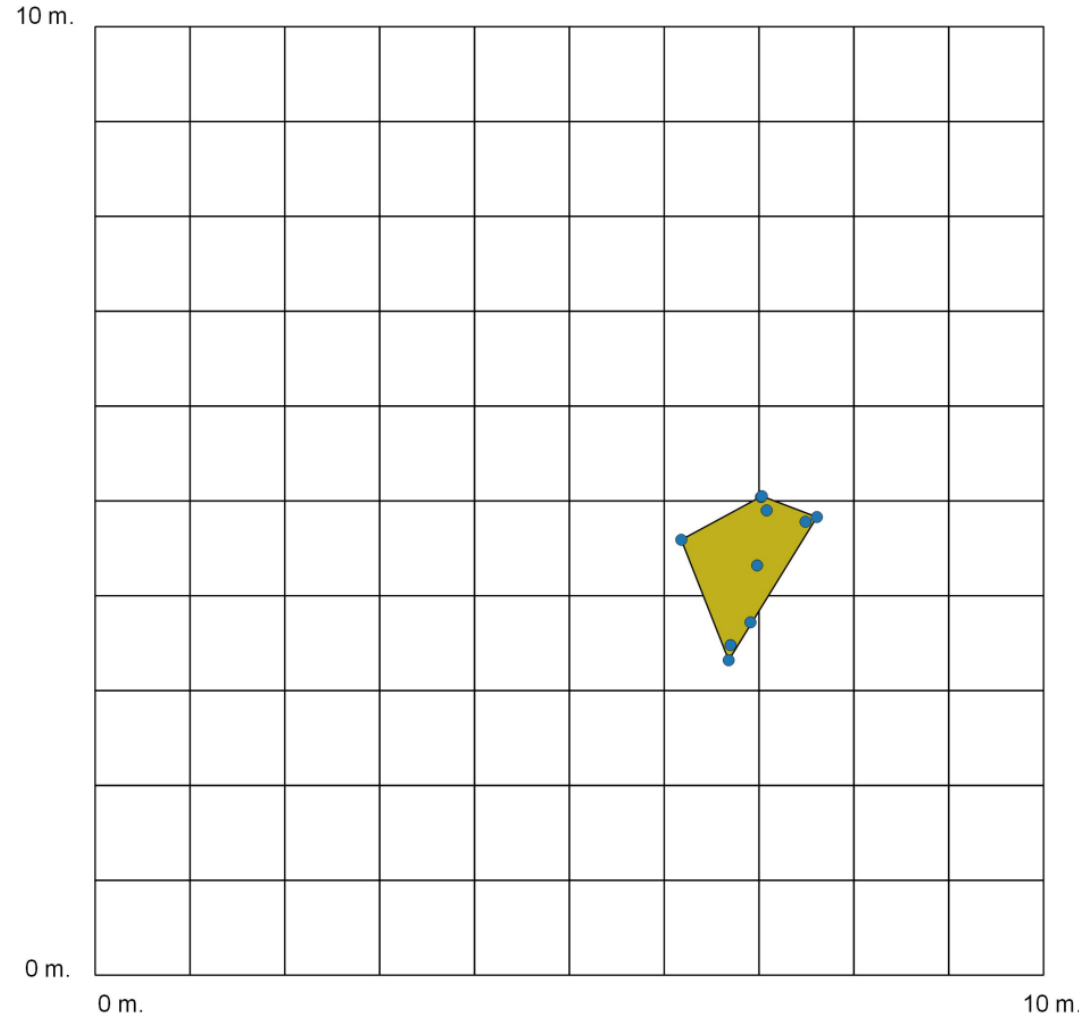


Frog: A147

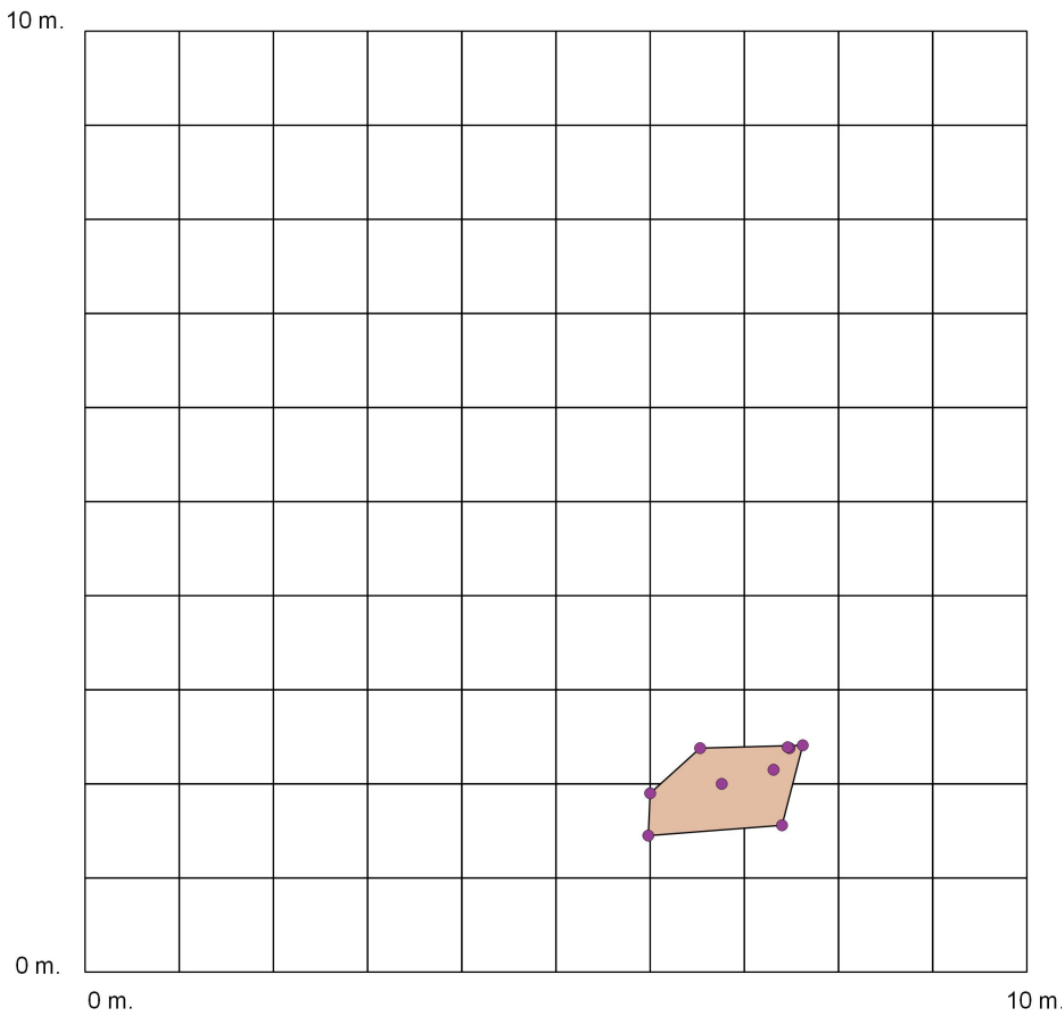

Frog: A159

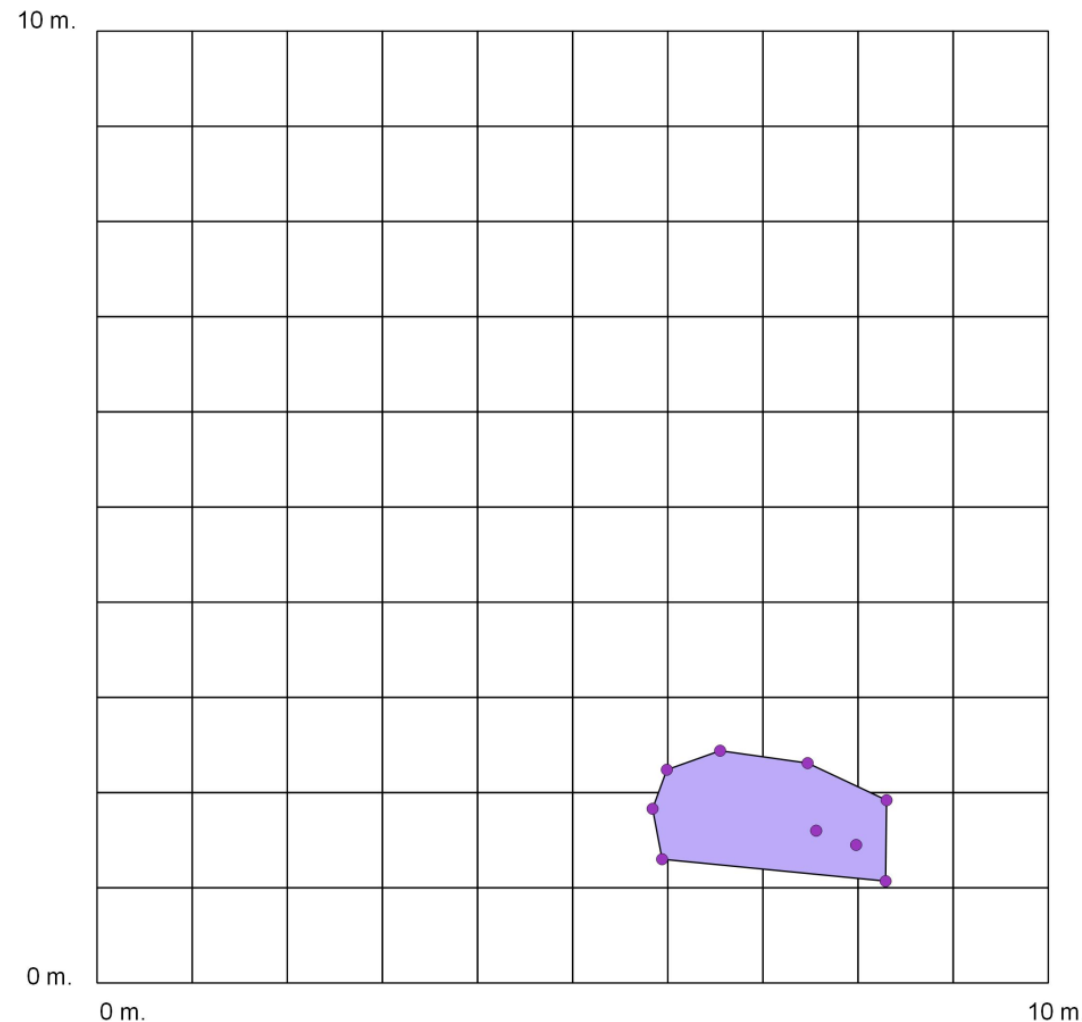


Grid B

Frog: B58

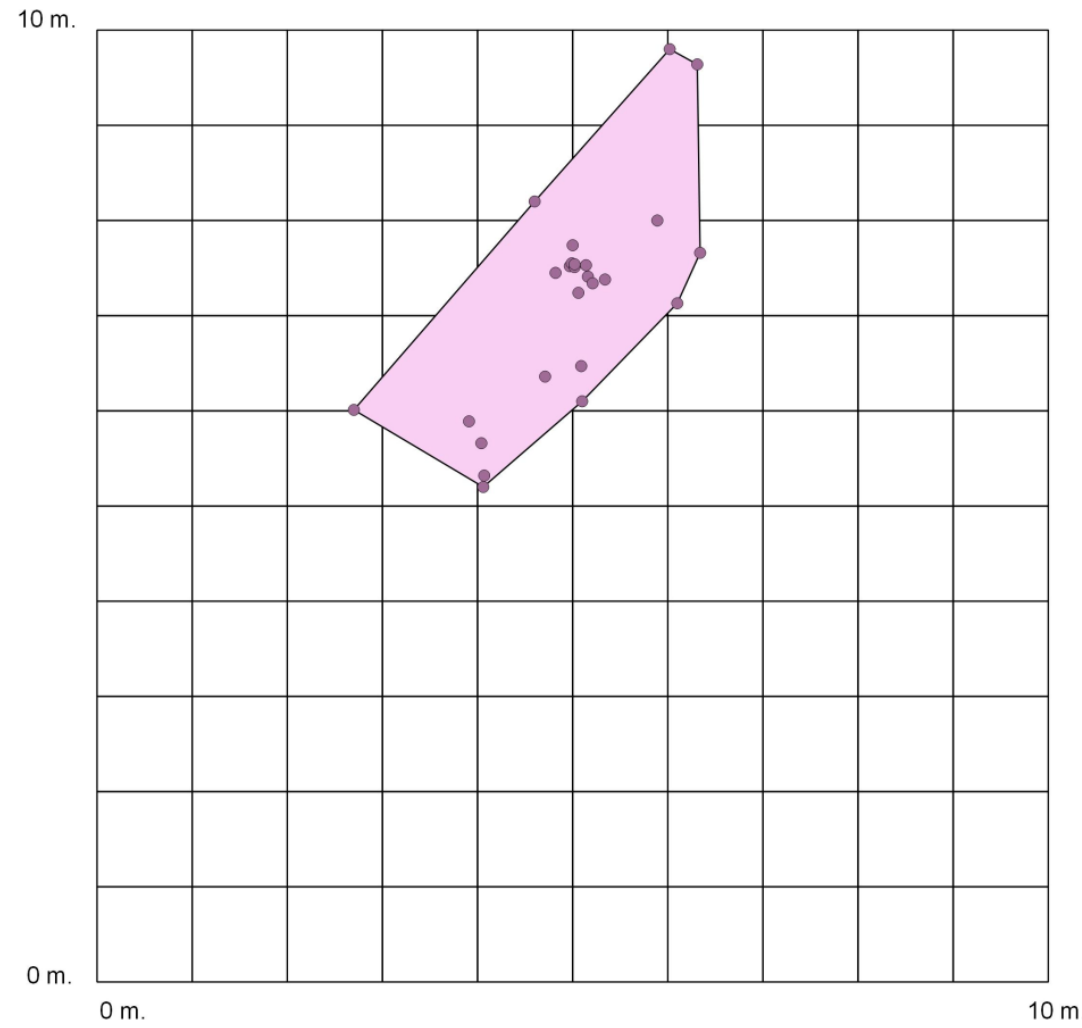

Frog: B59

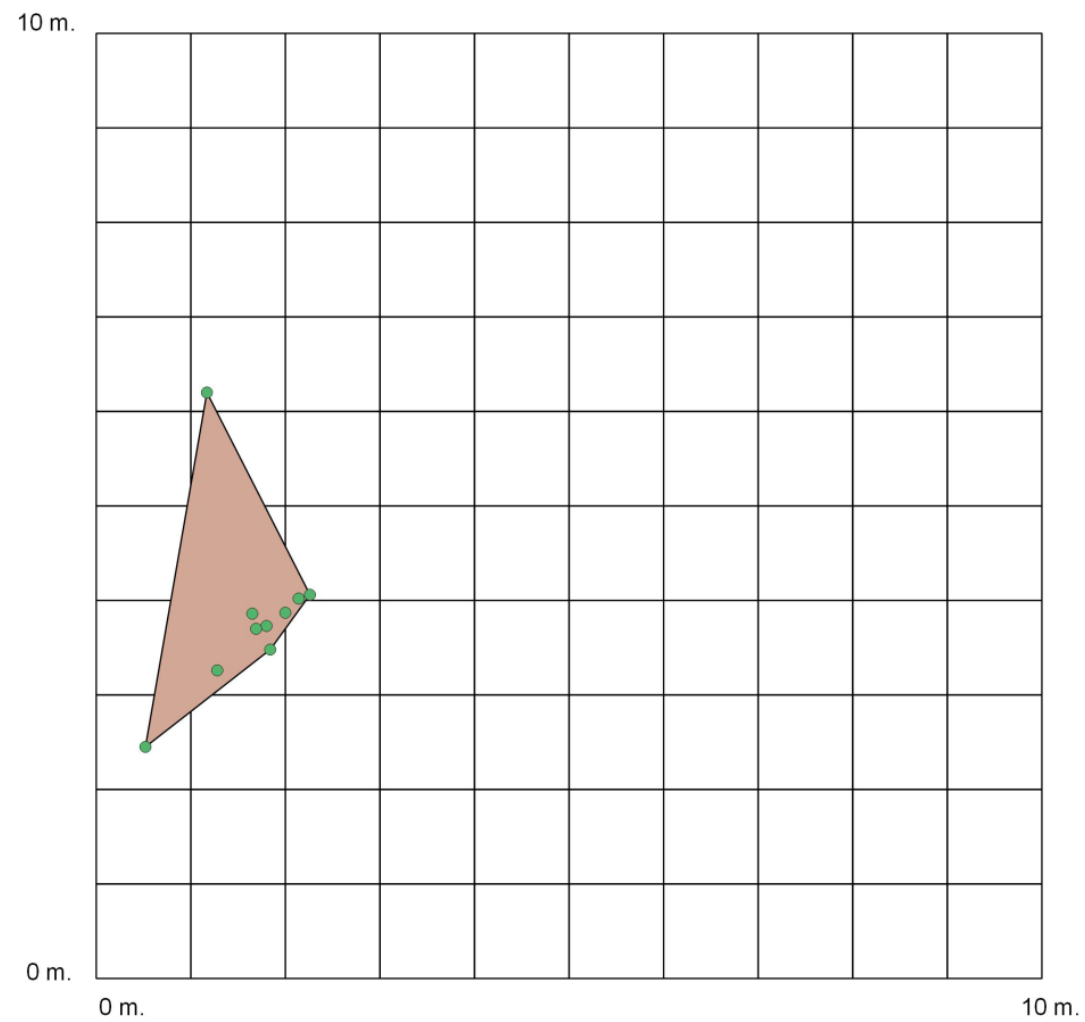


Frog: B72

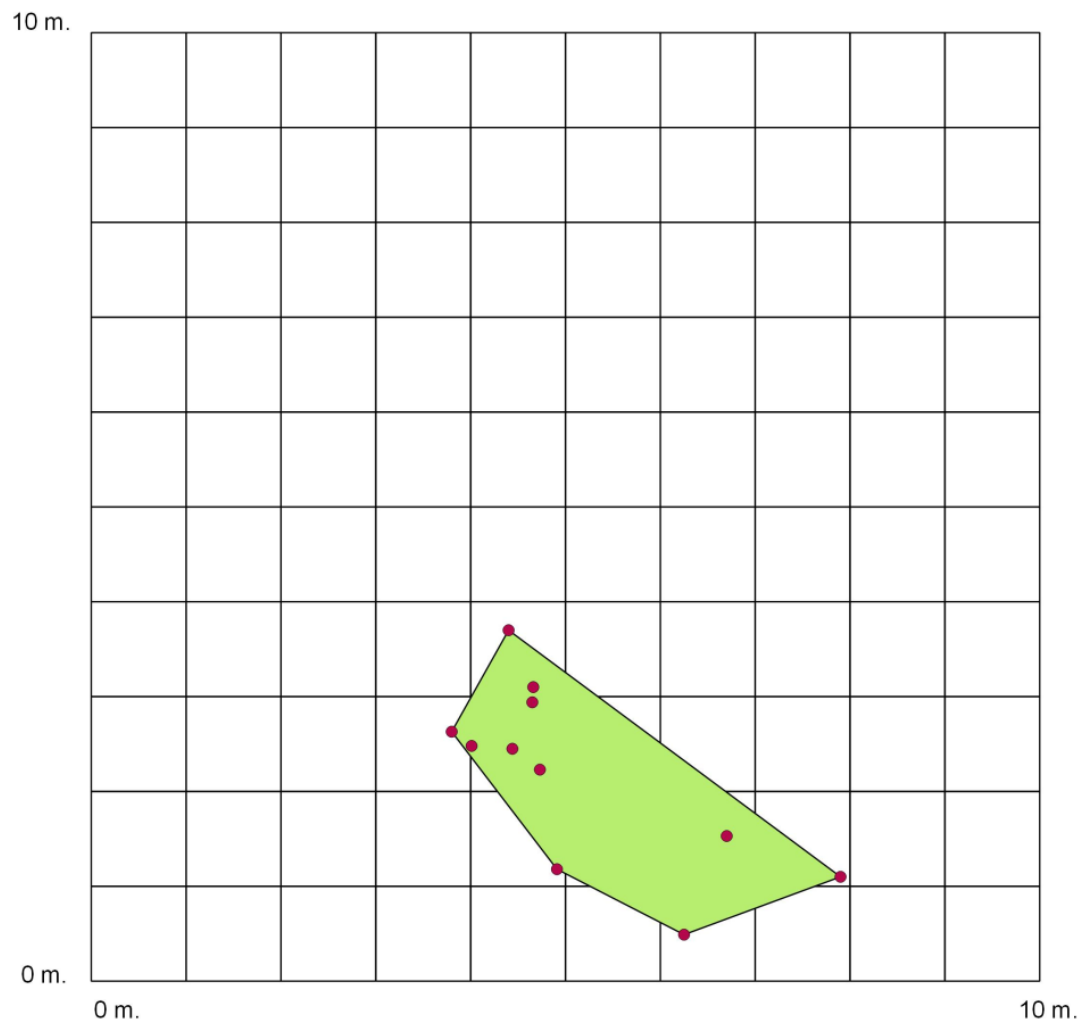

Frog: B96

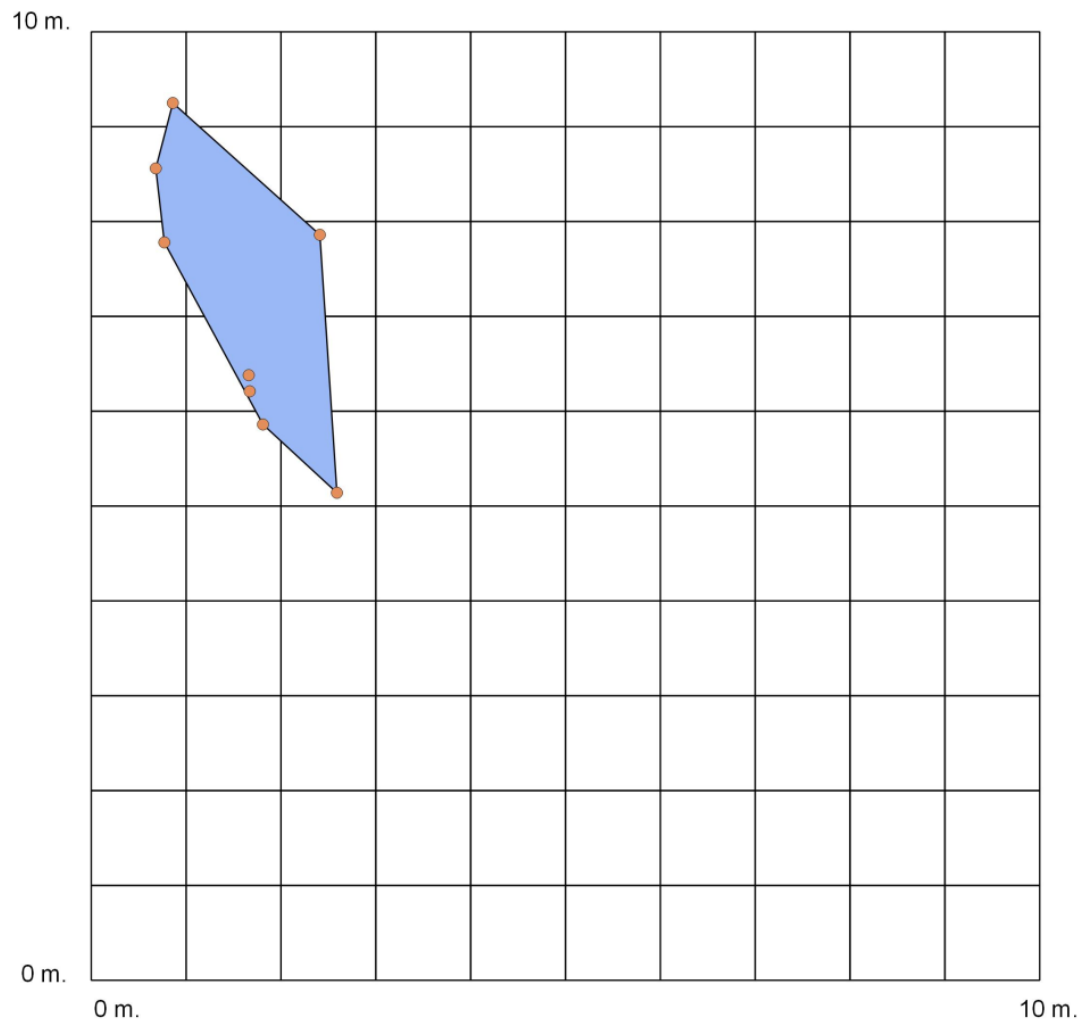


Frog: B120

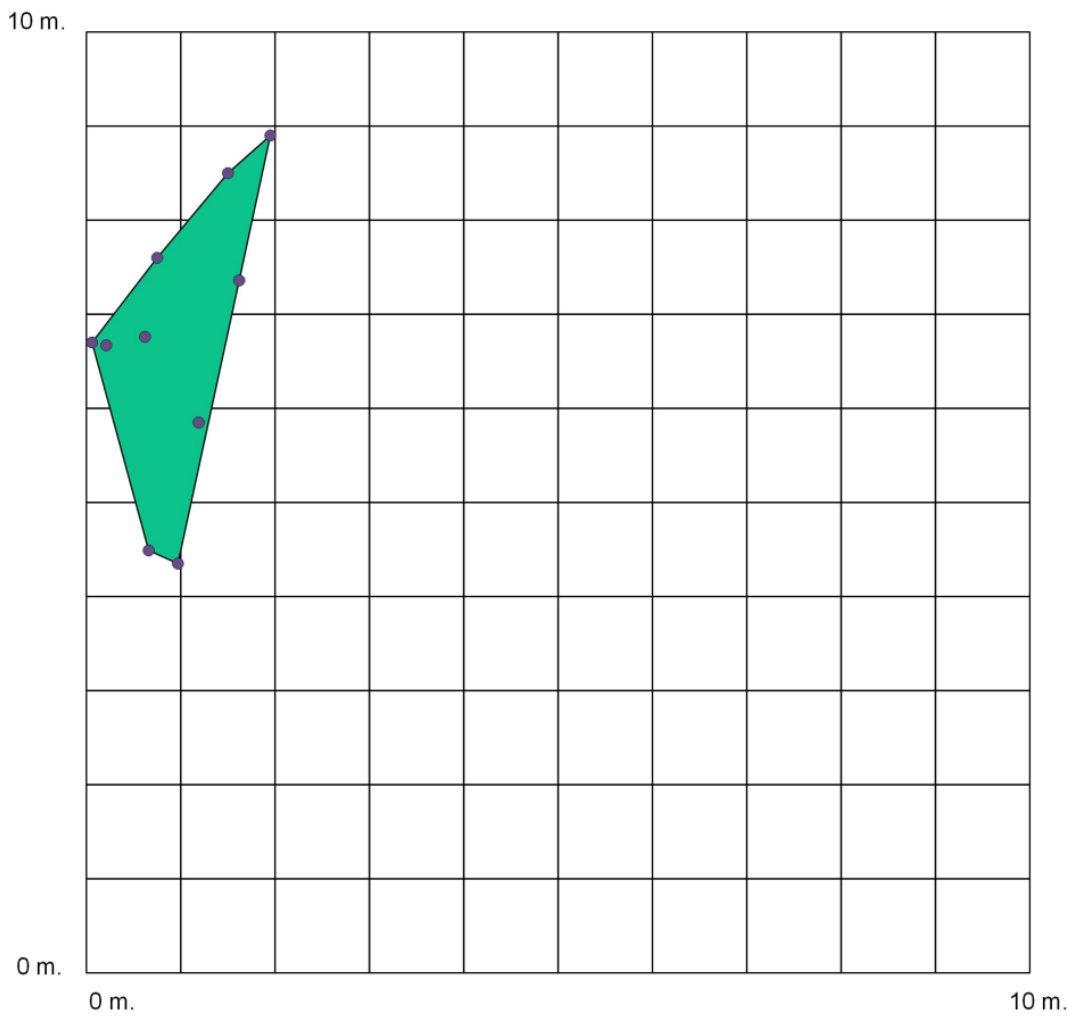

Frog: B136

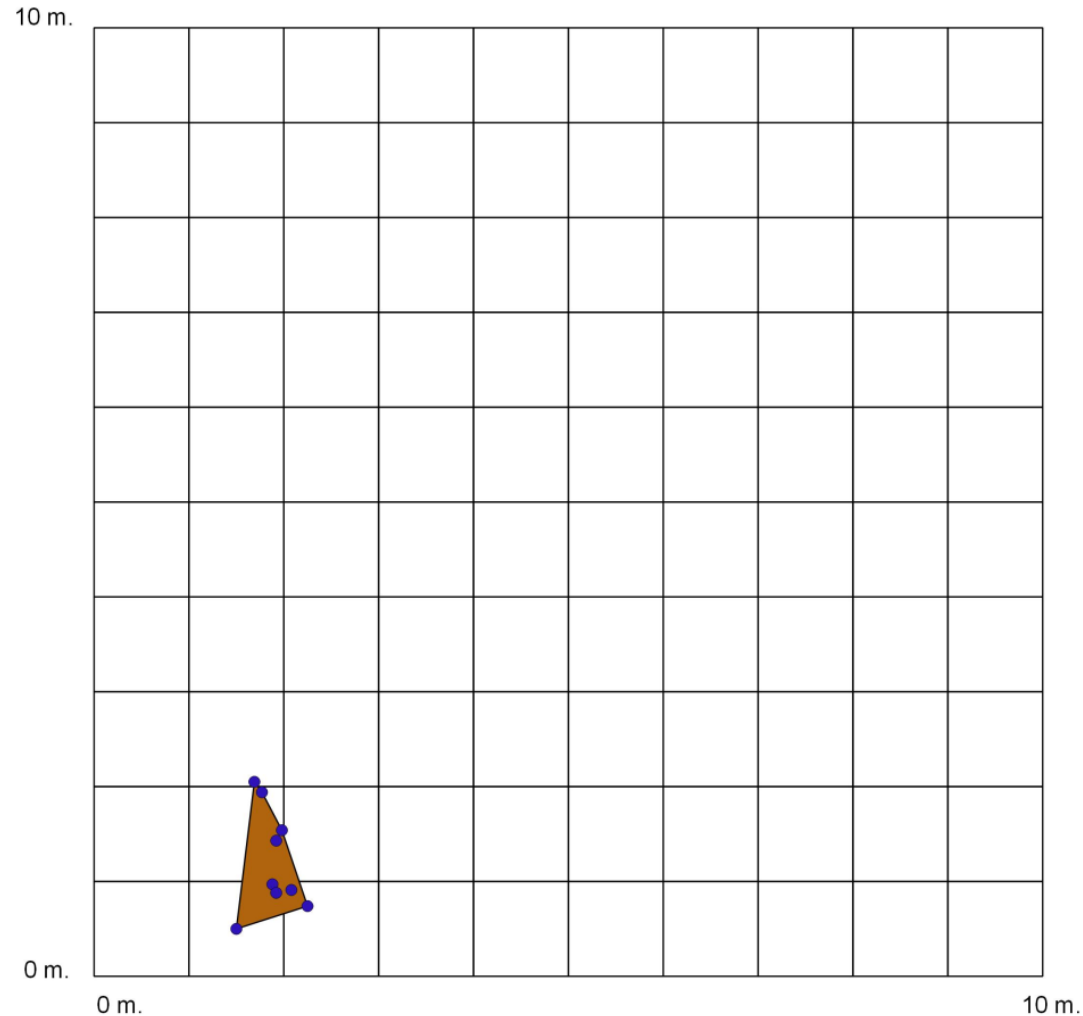


Frog: B165

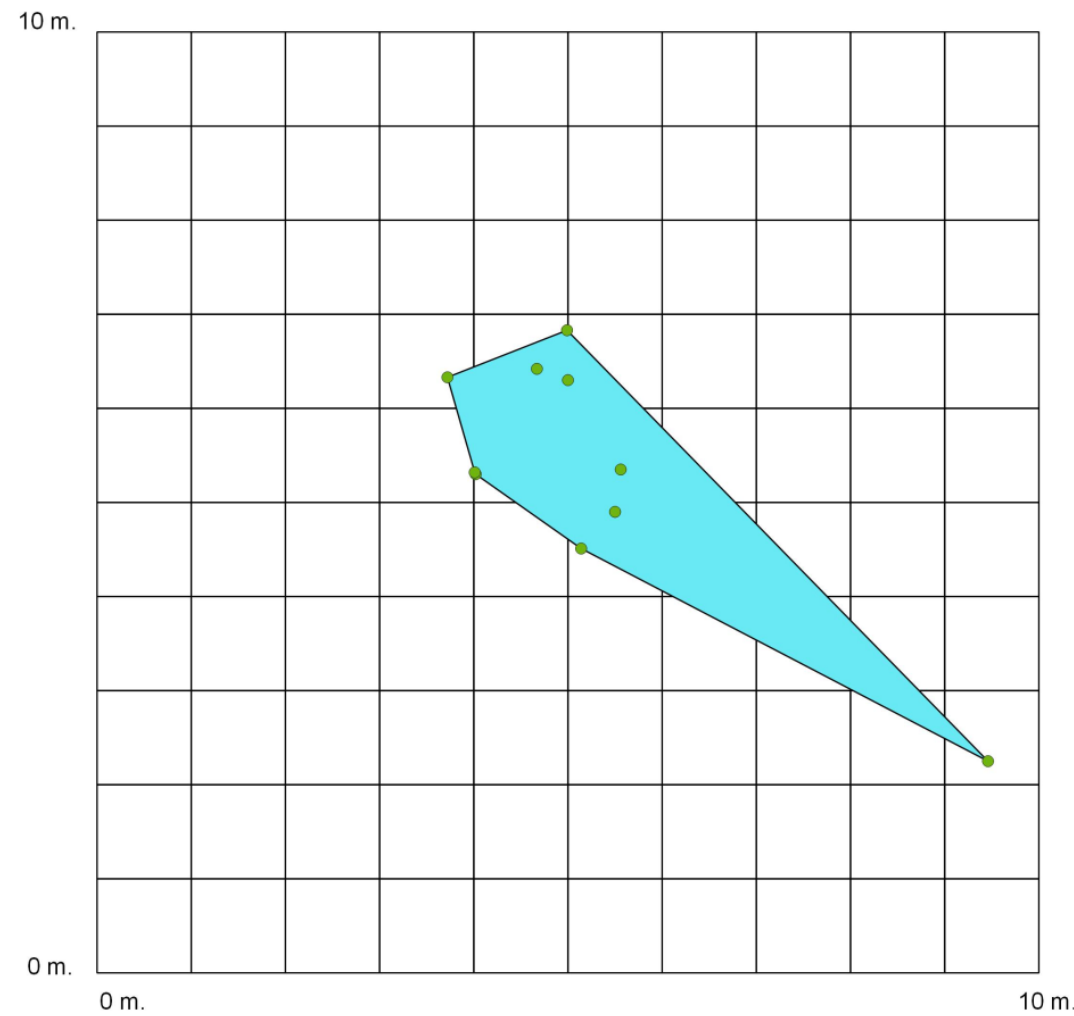

Frog: B169

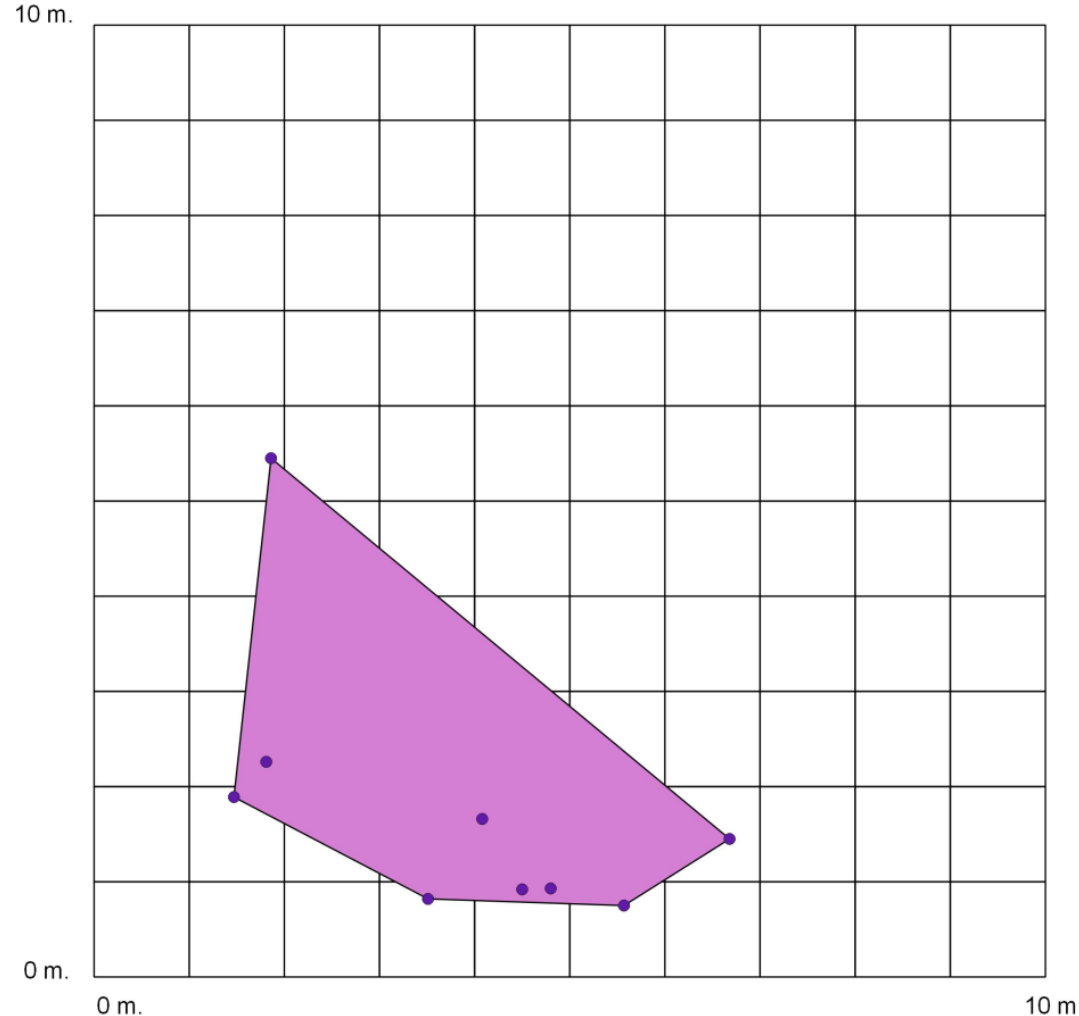


Frog: B171

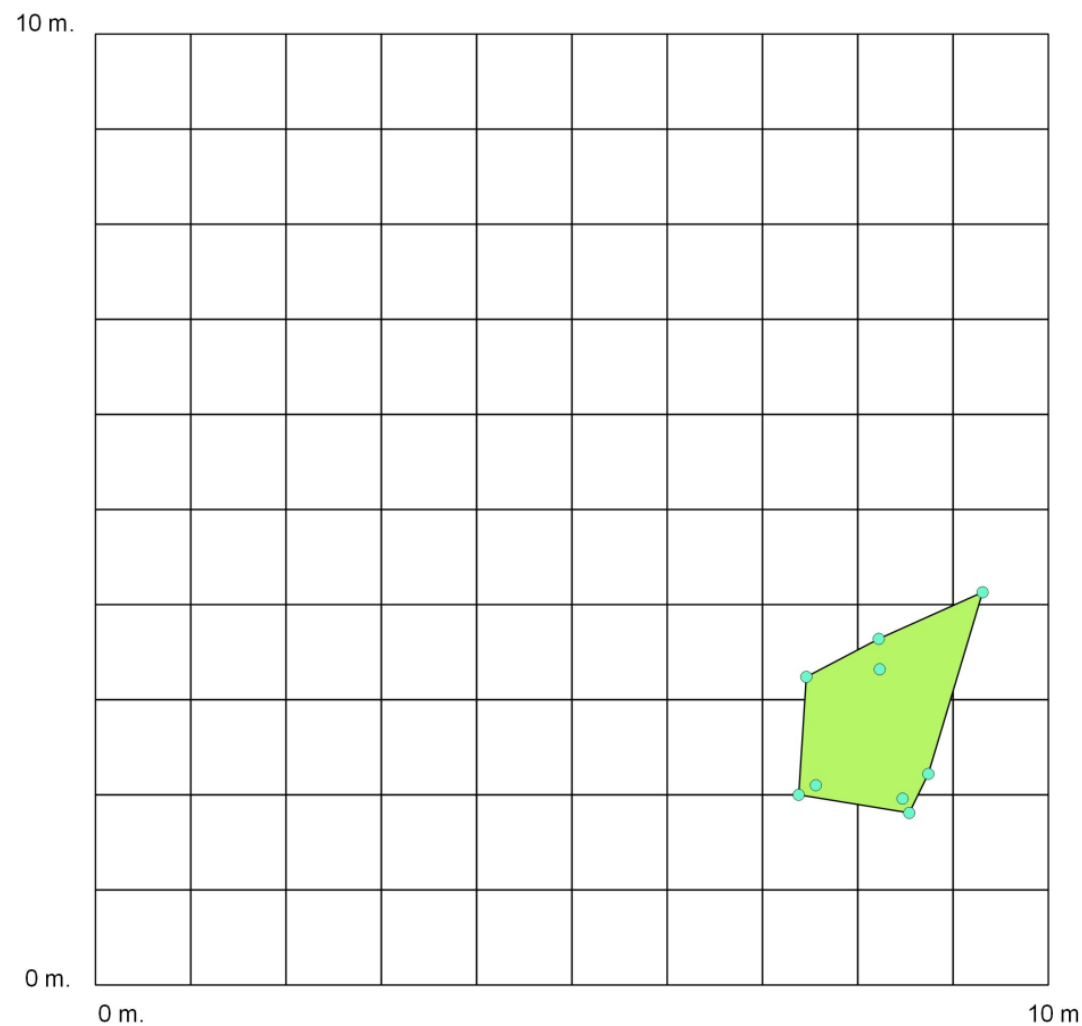

Frog: B180

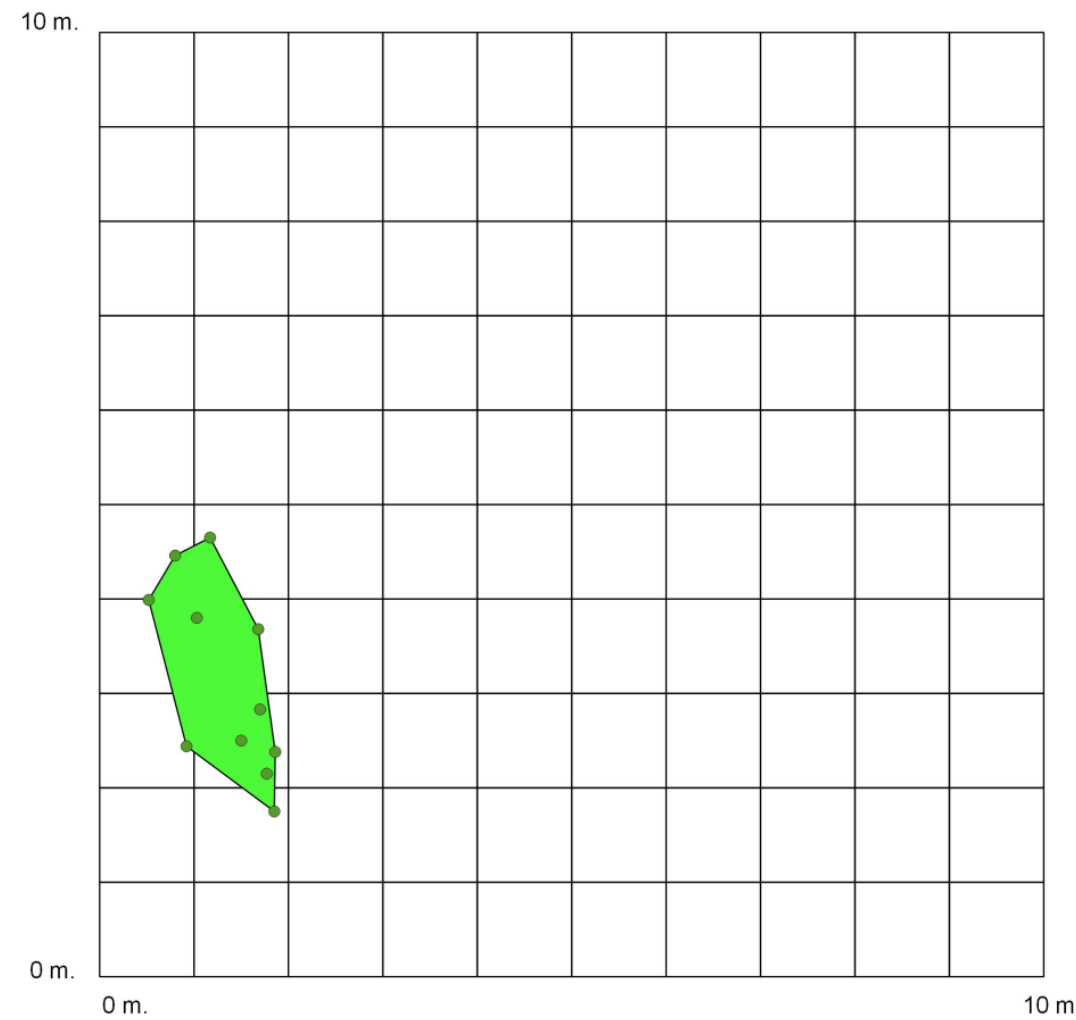


Frog: B185

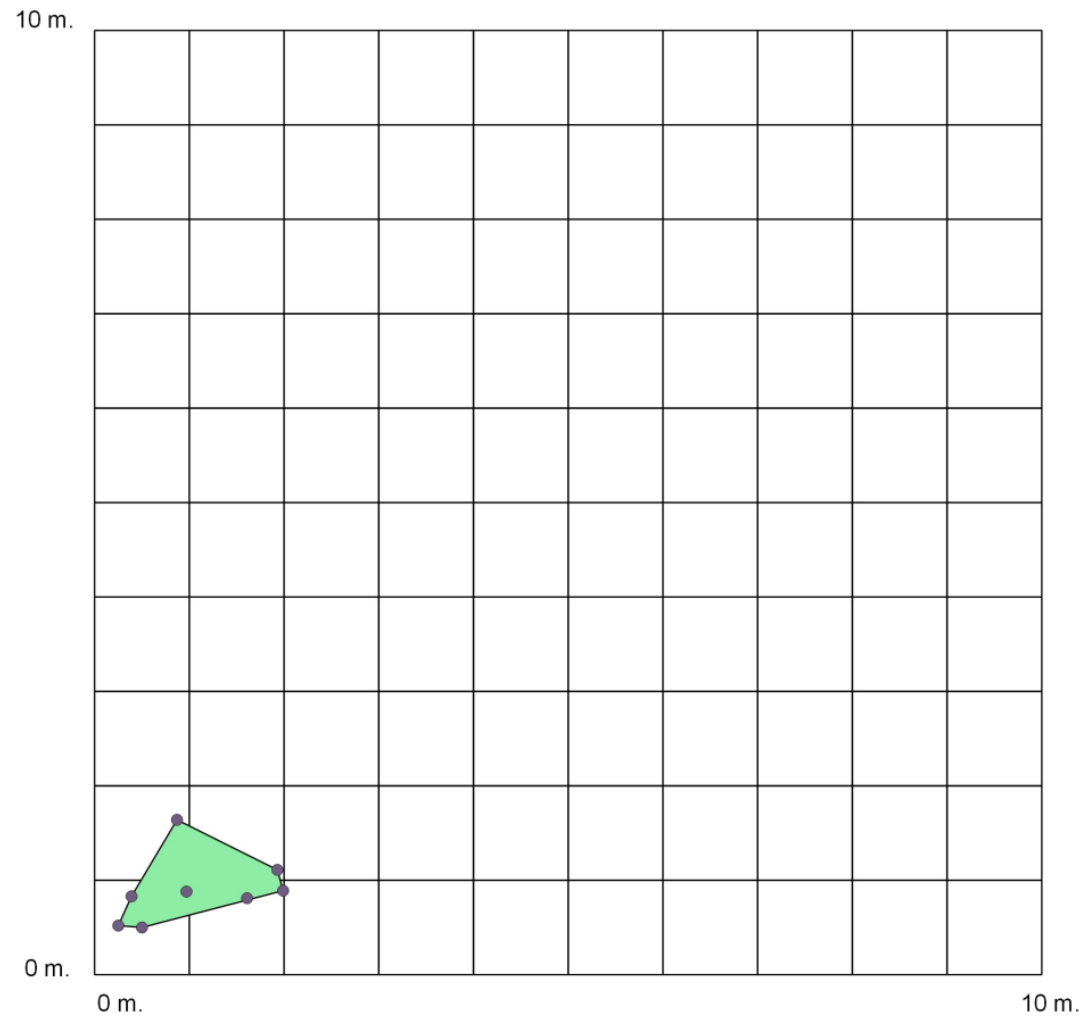

Frog: B196

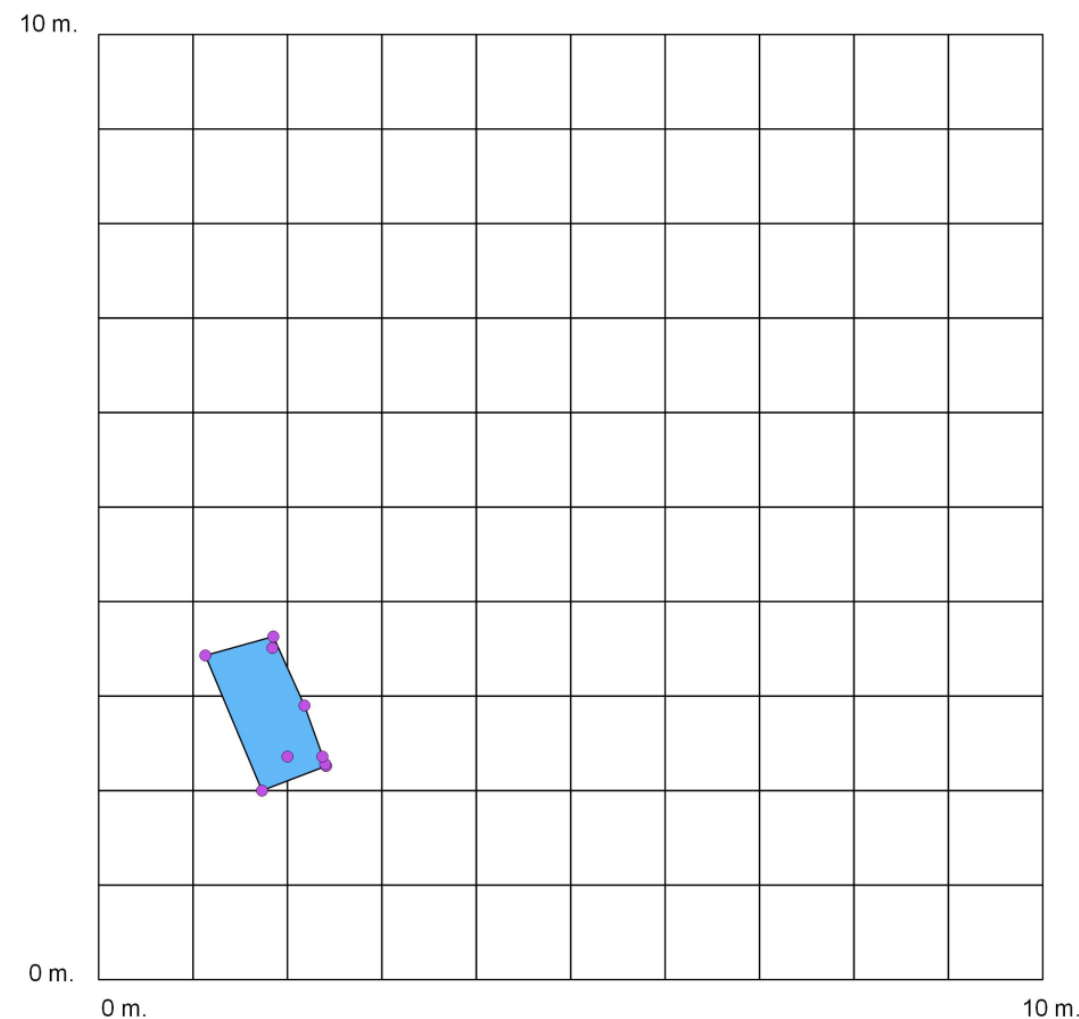


Frog: B306

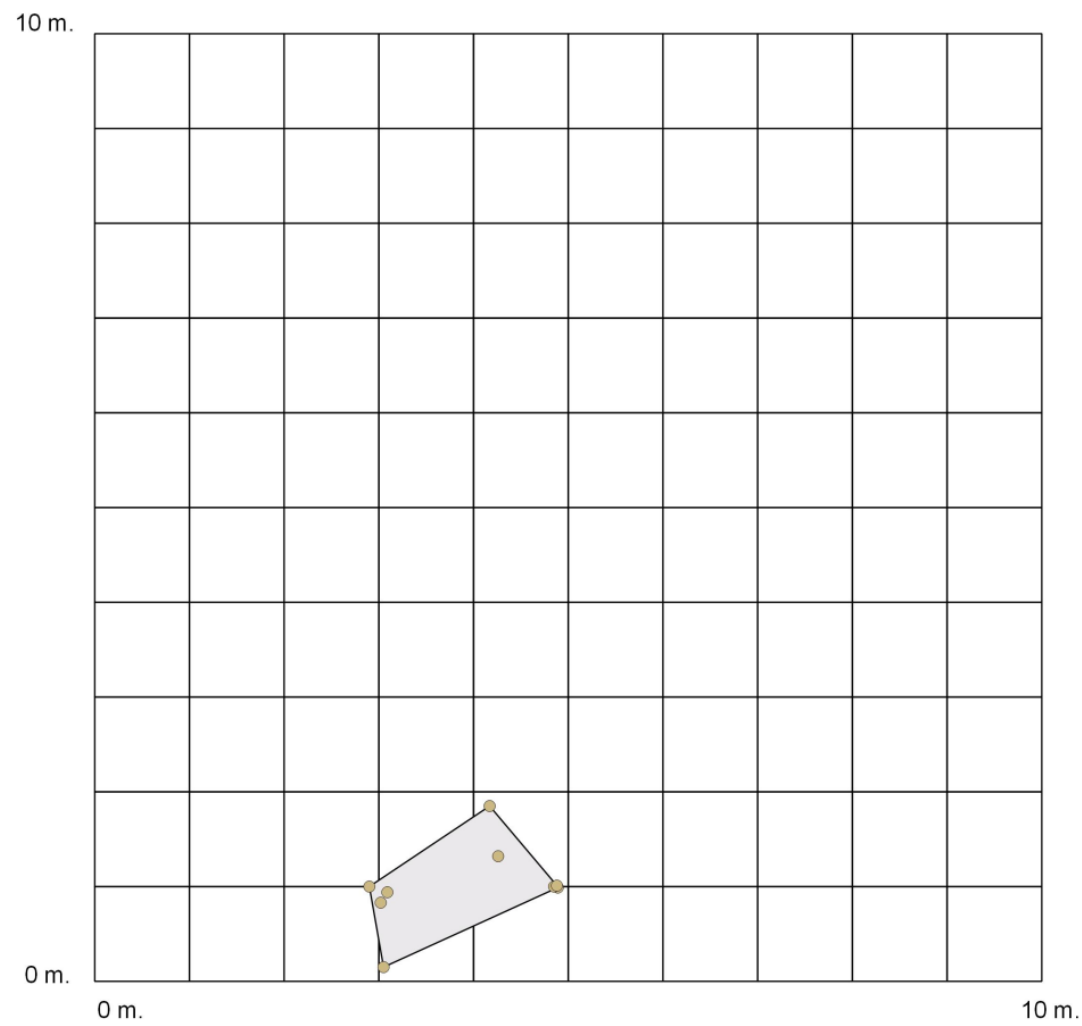


Grid C

Frog: C17

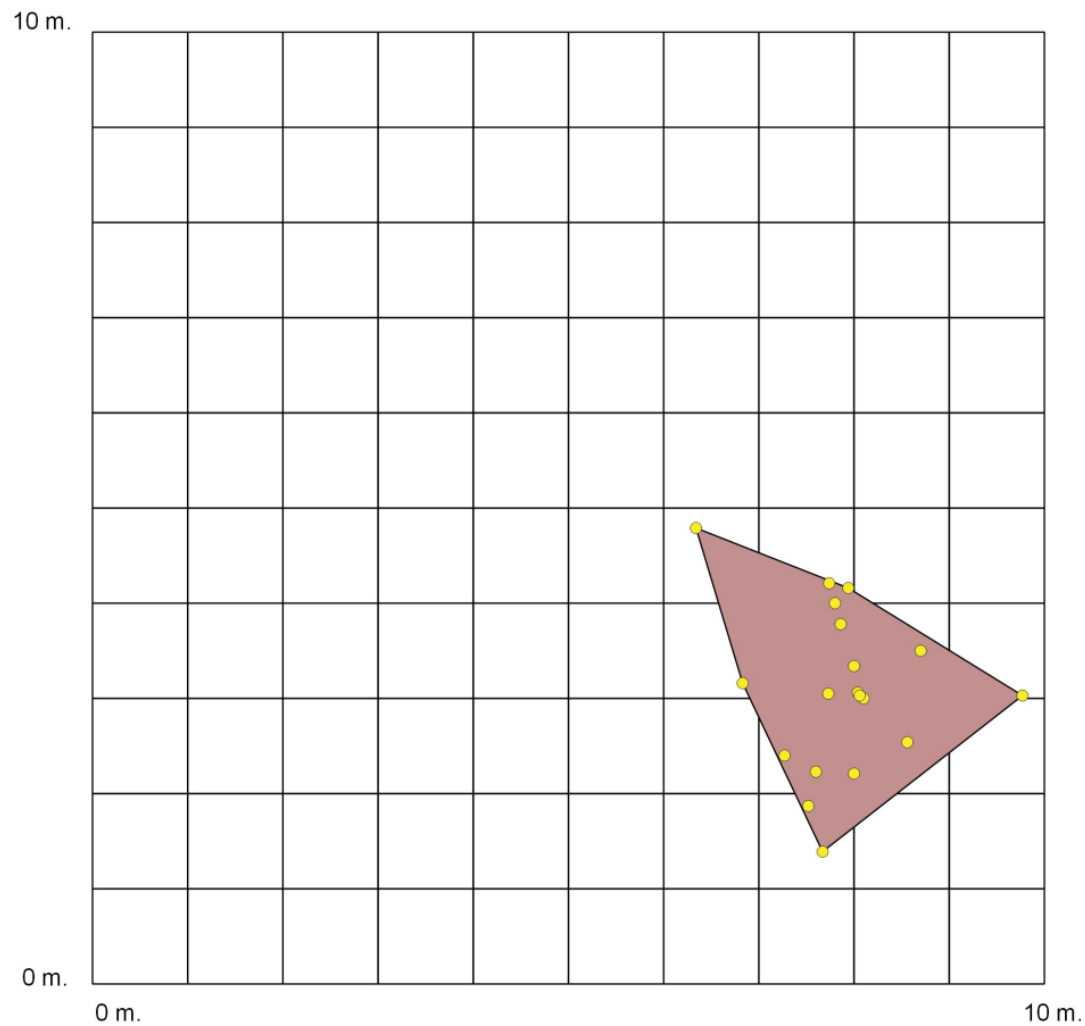

Frog: C19

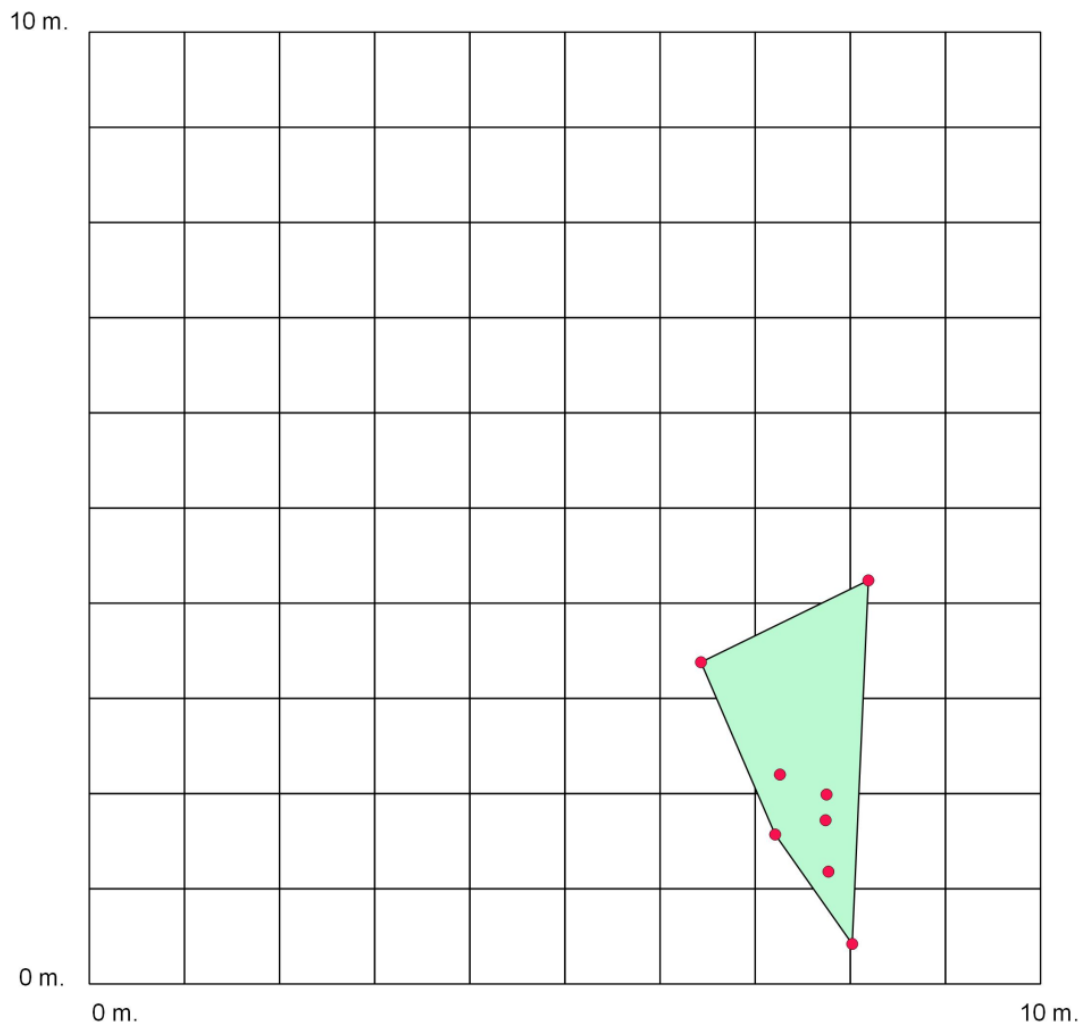


Frog: C51

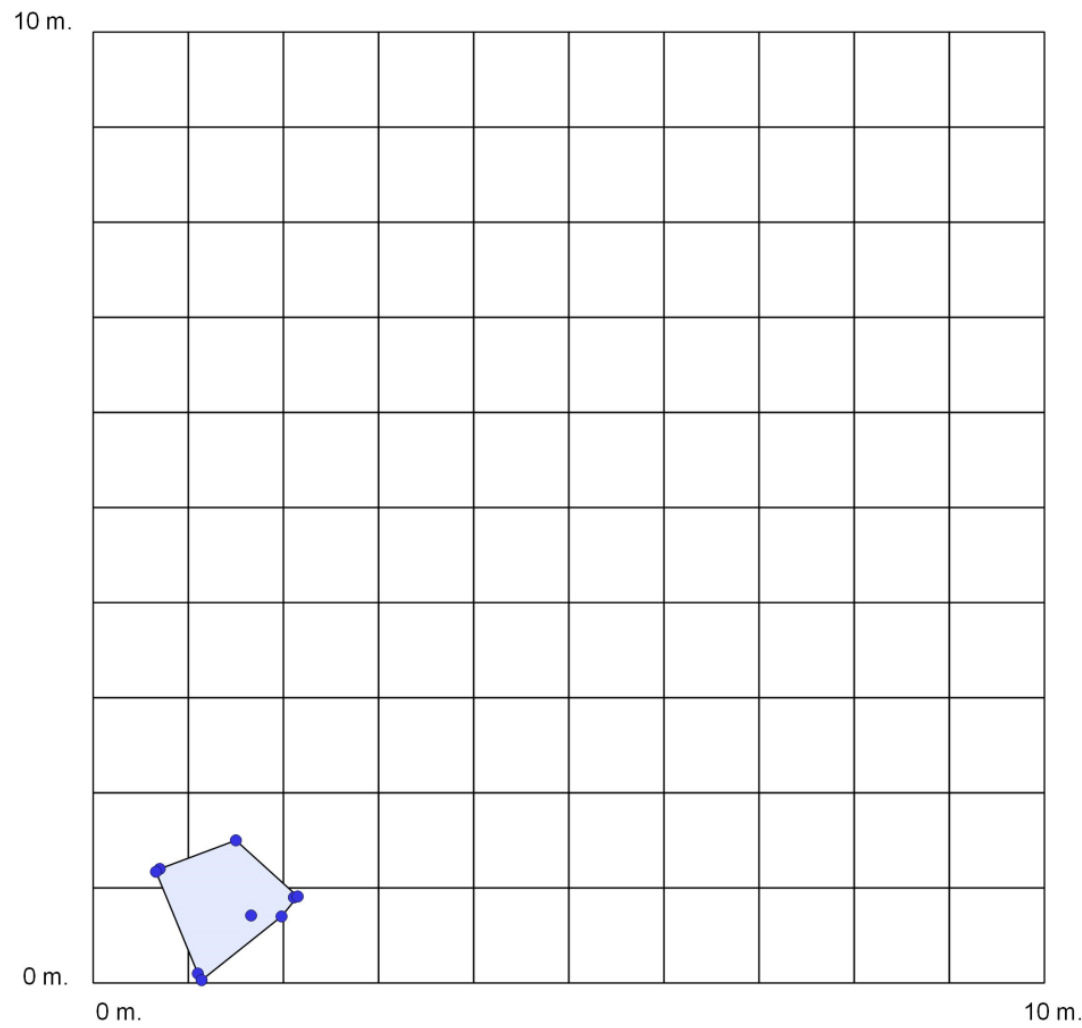

Frog: C81

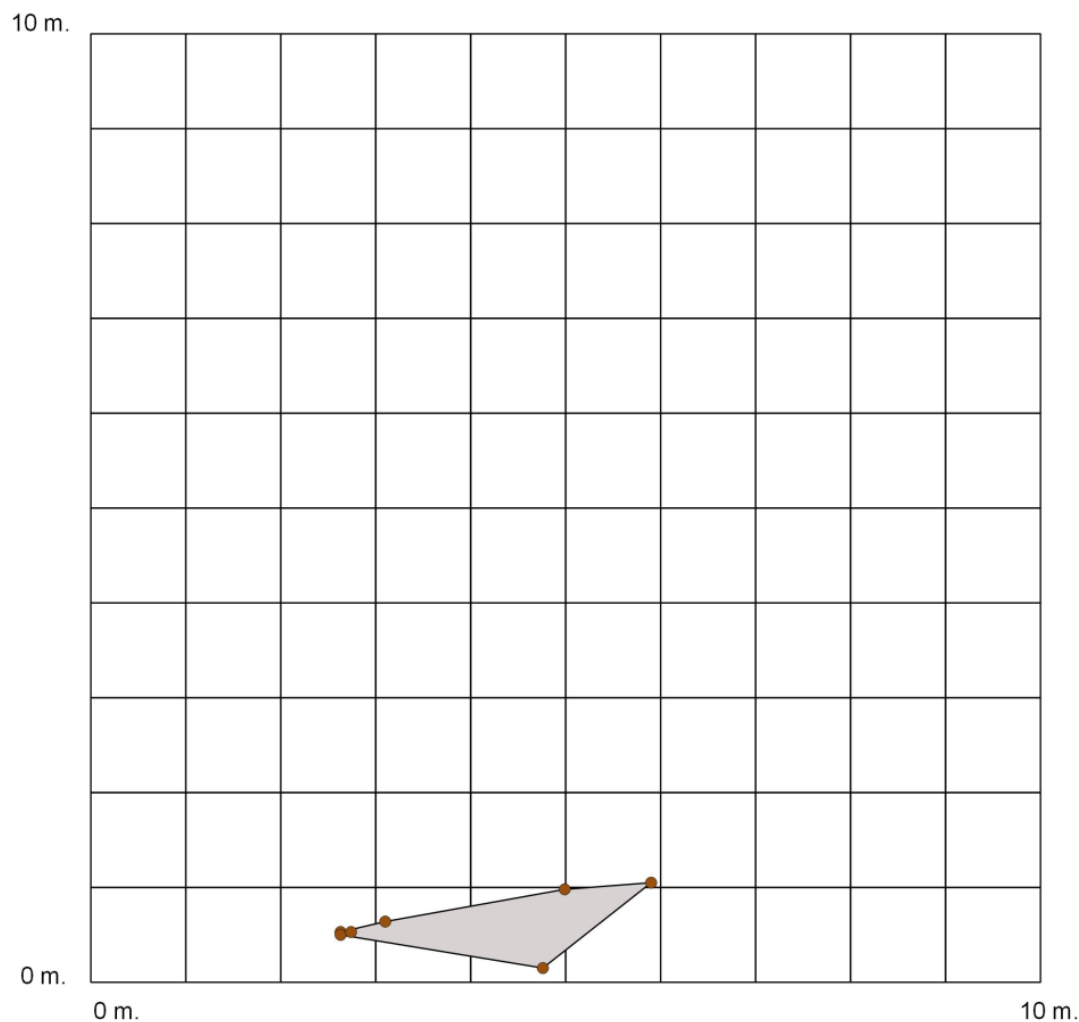


Frog: C103

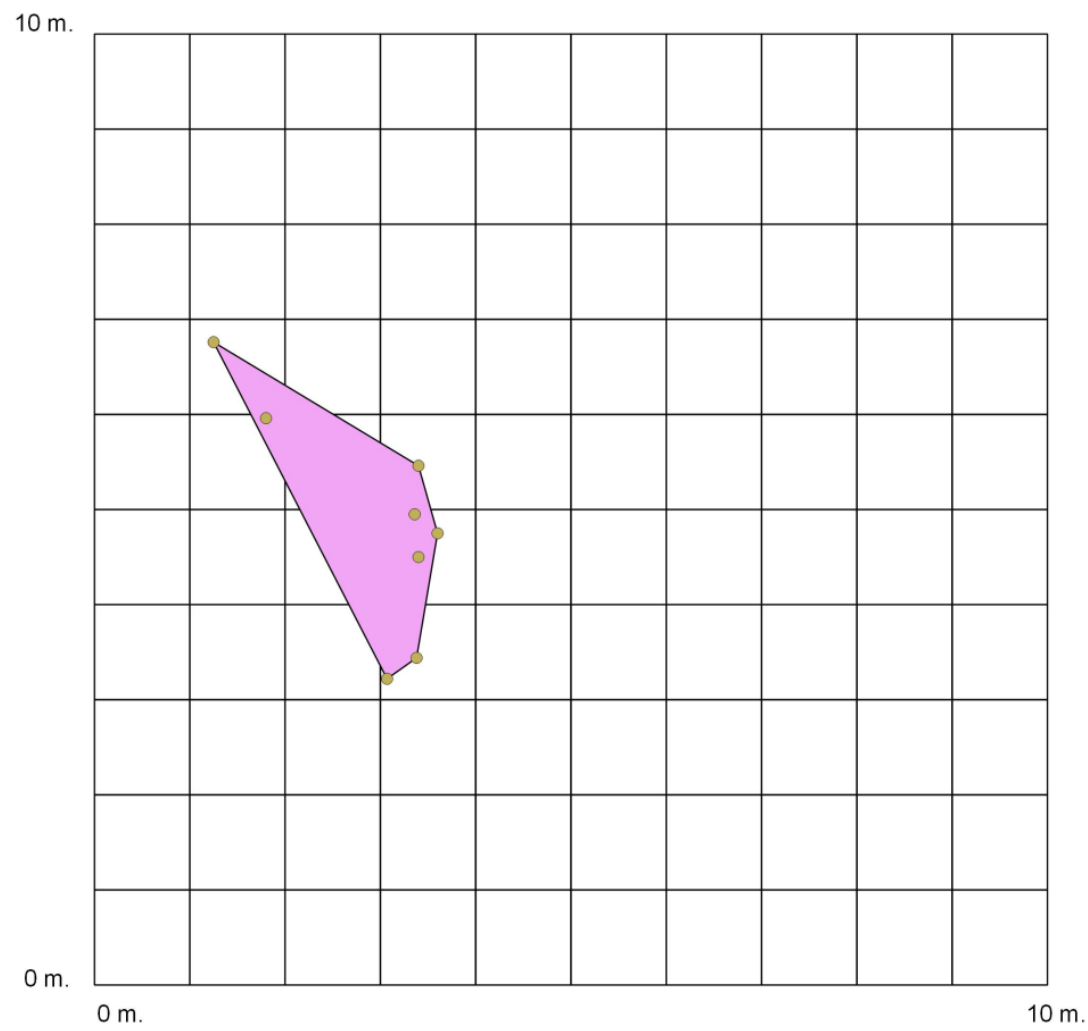

Frog: C104

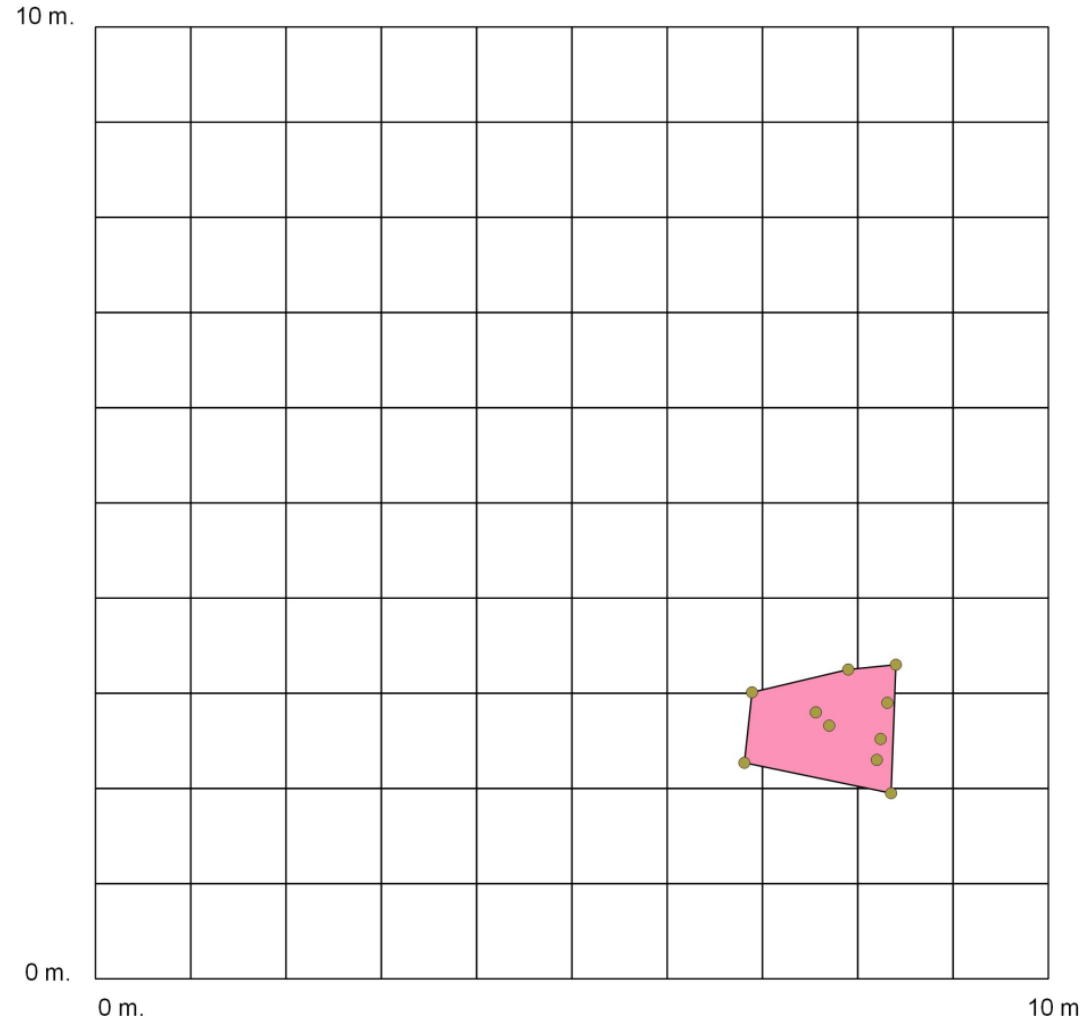


Frog: C106

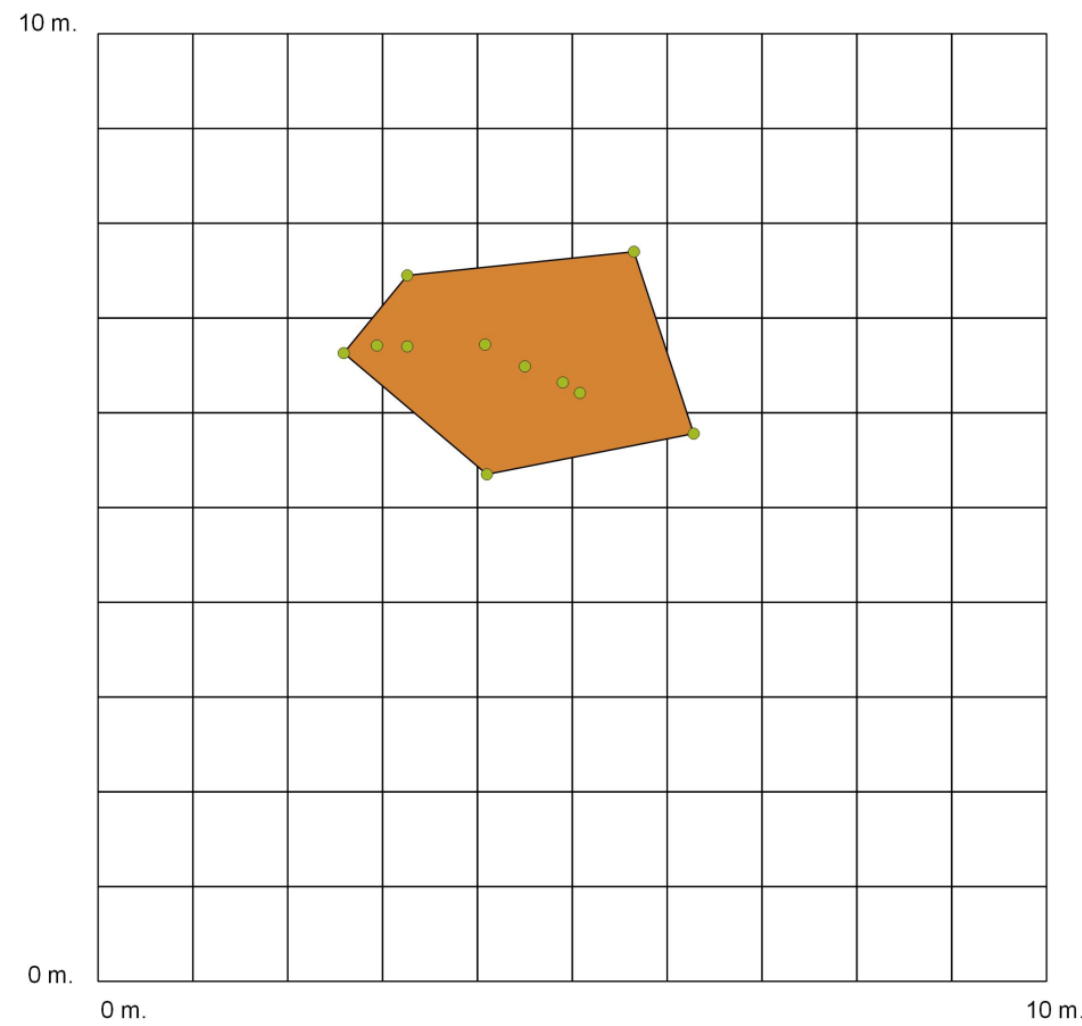

Frog: C107

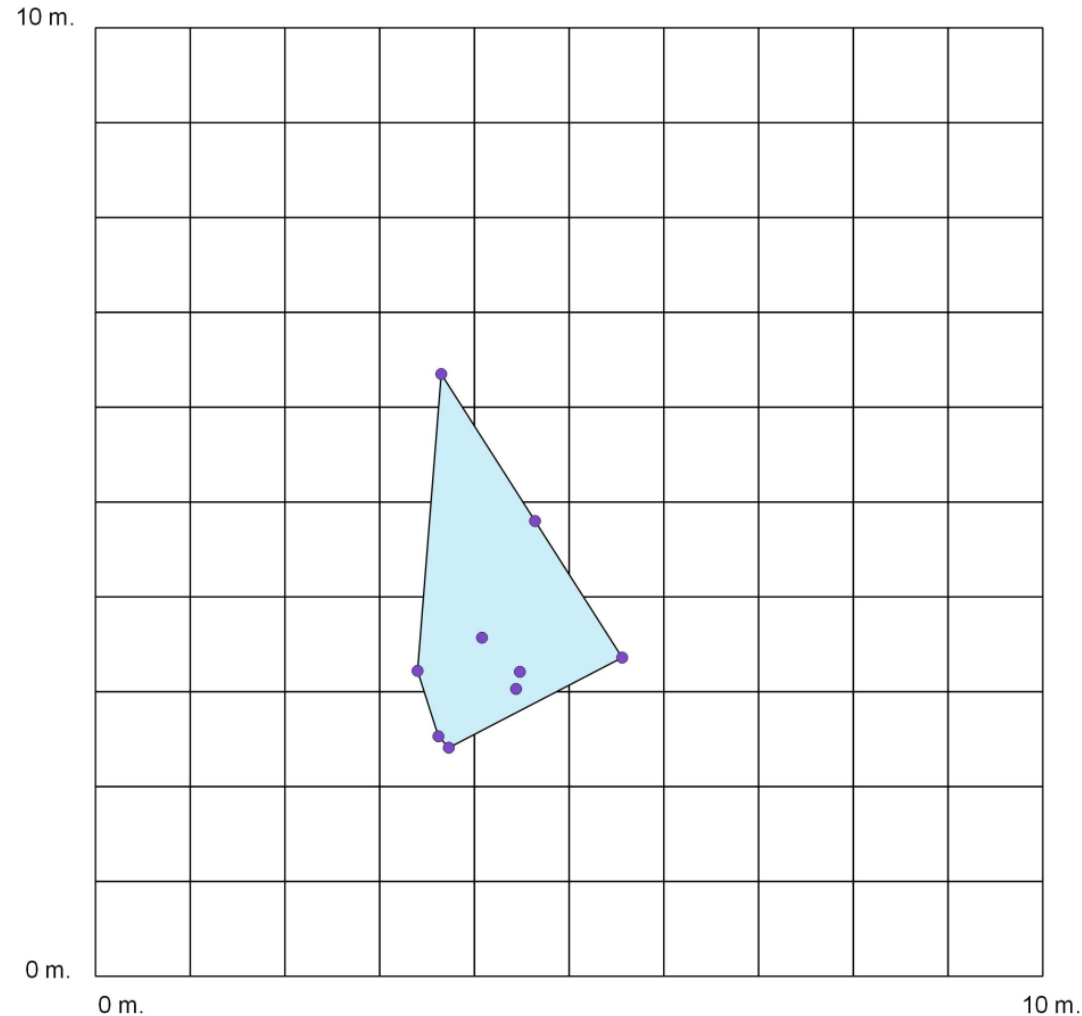


Frog: C108

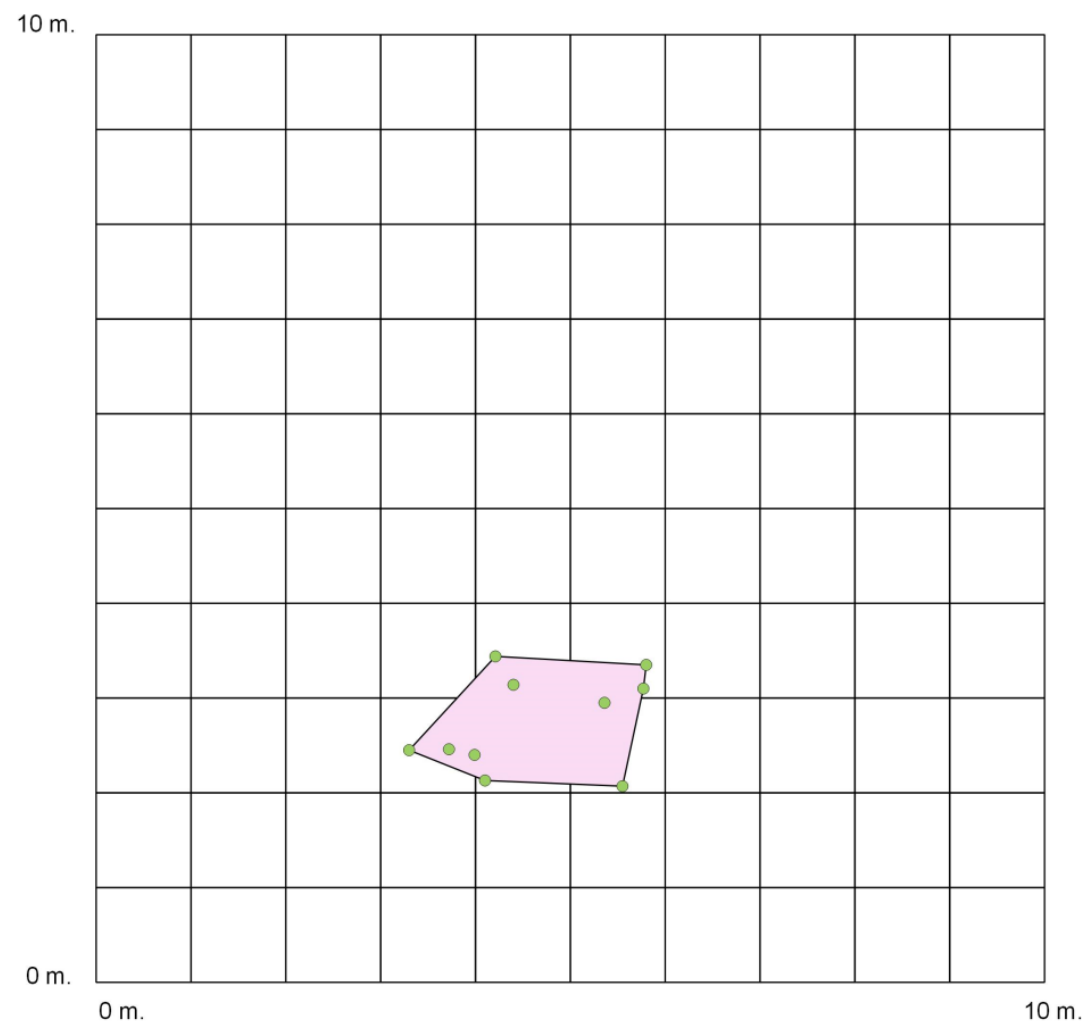

Frog: C134

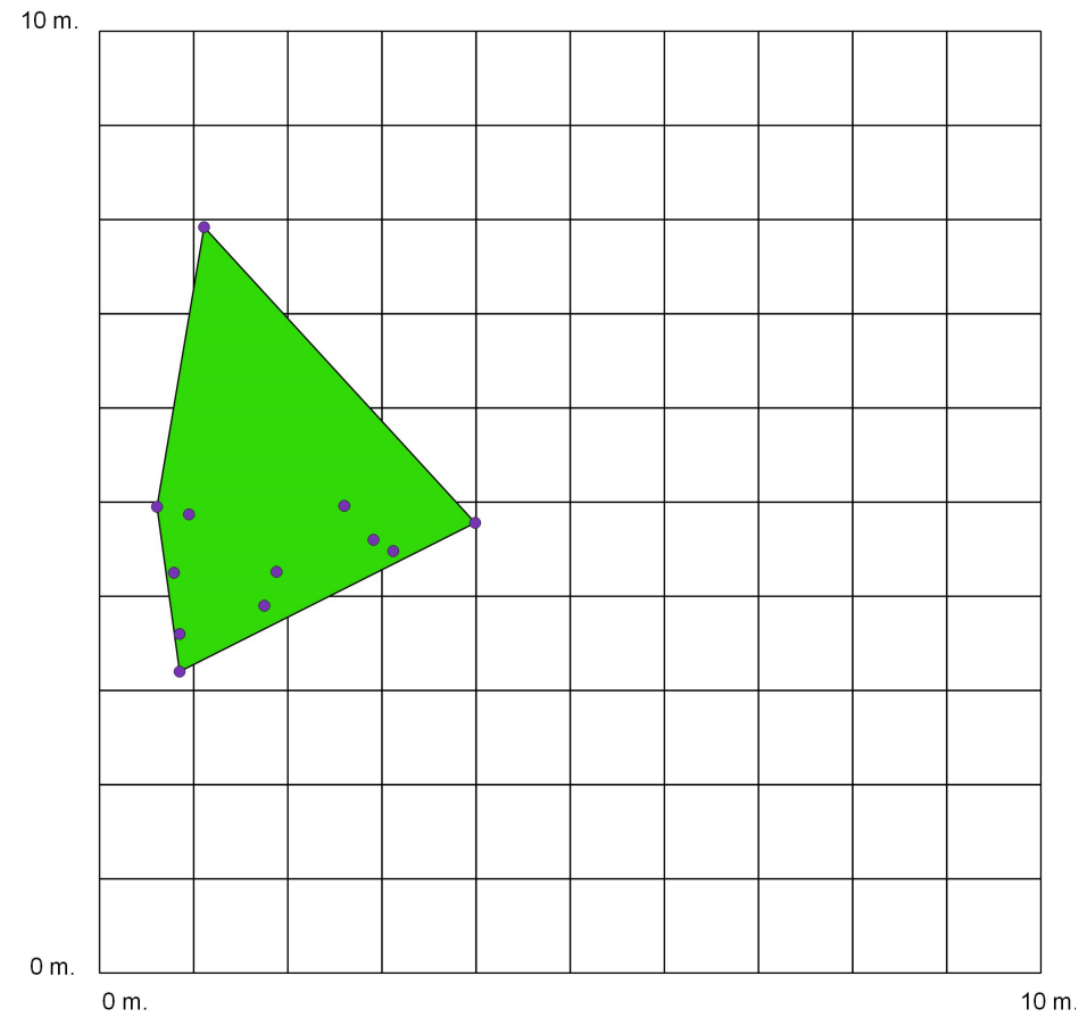


Frog: C166

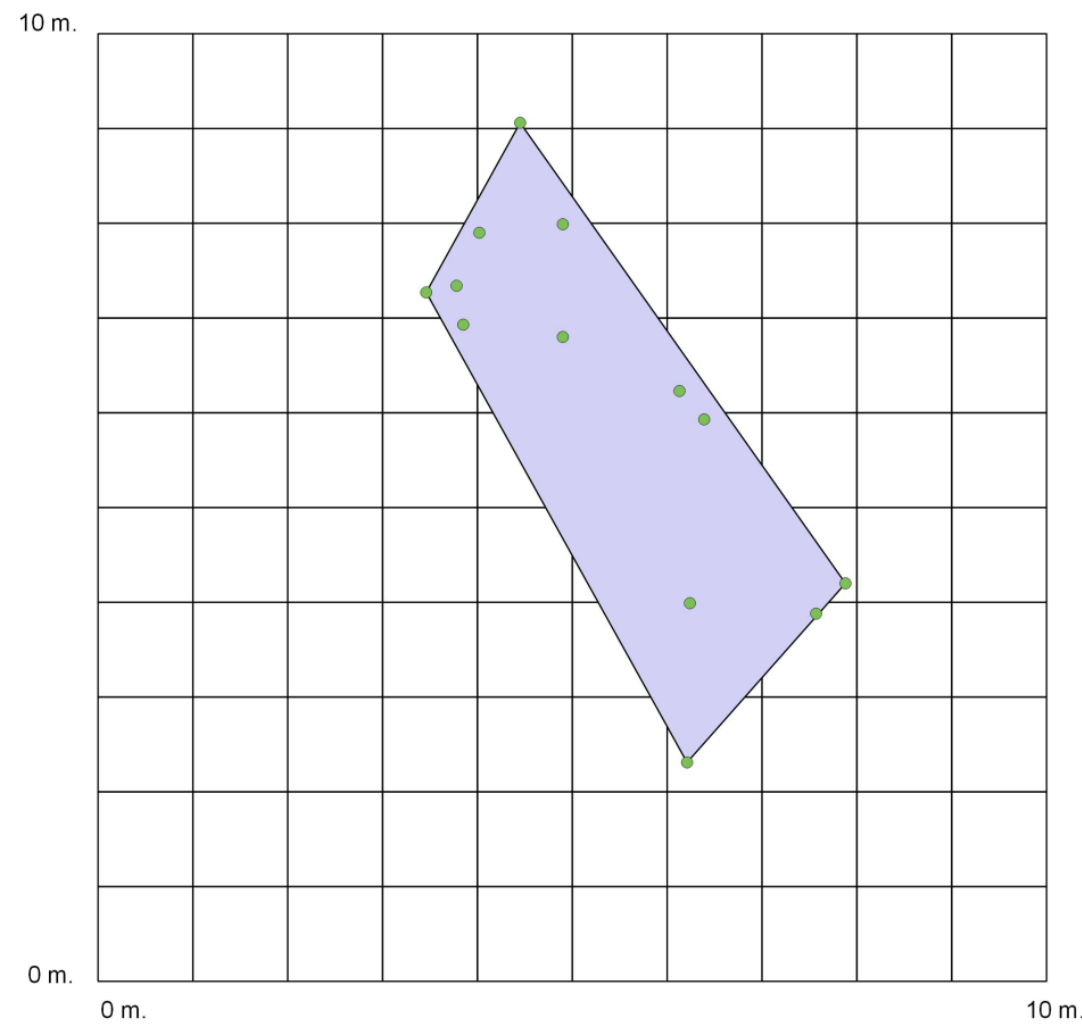

Frog: C168

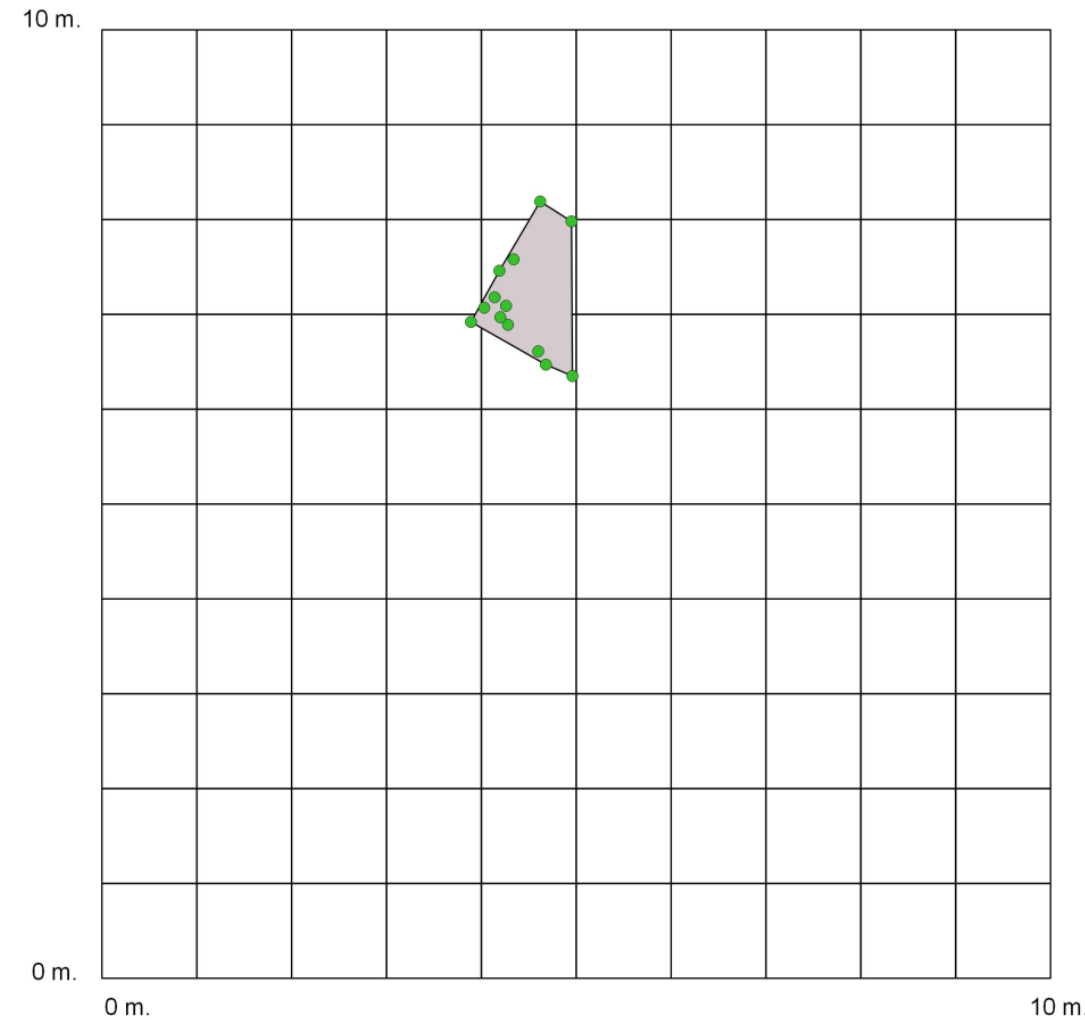


Frog: C171

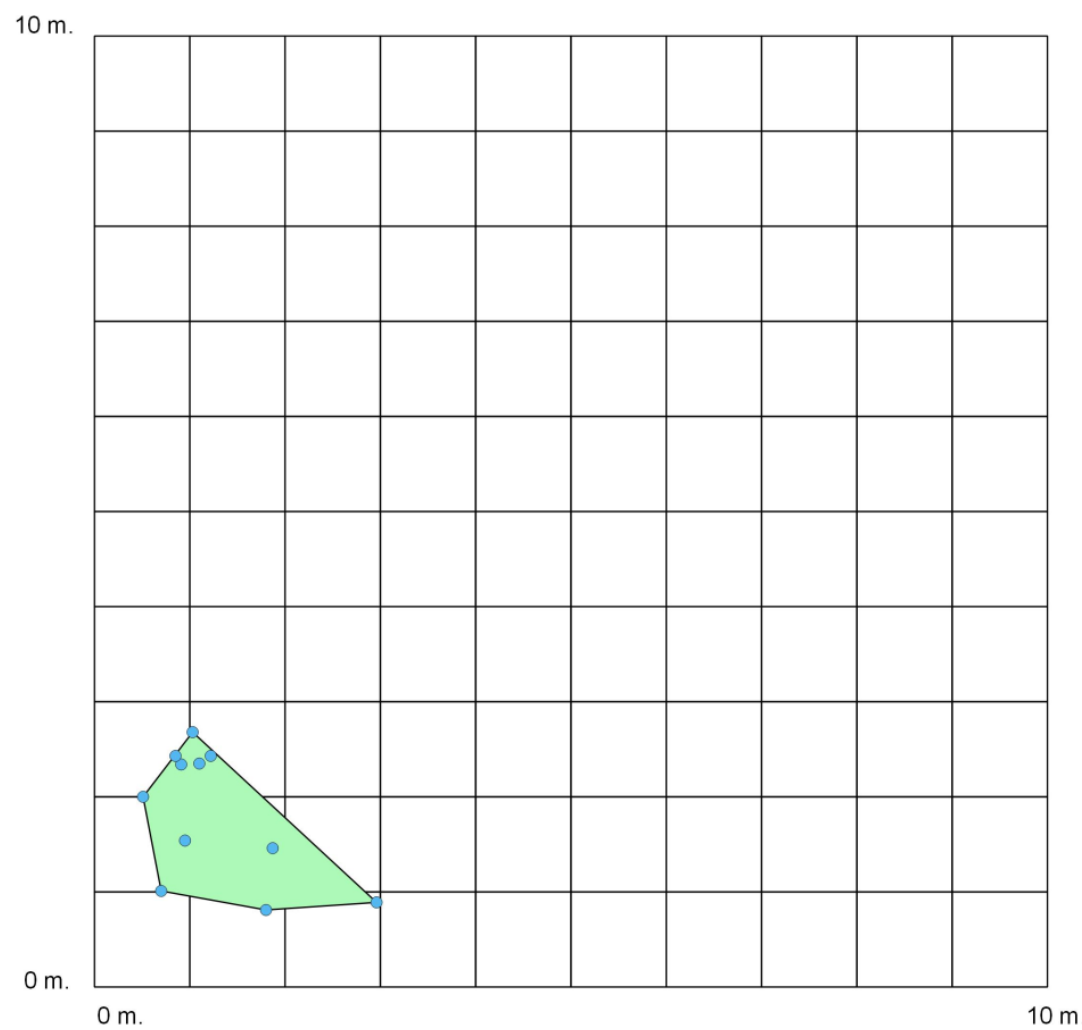

Frog: C186

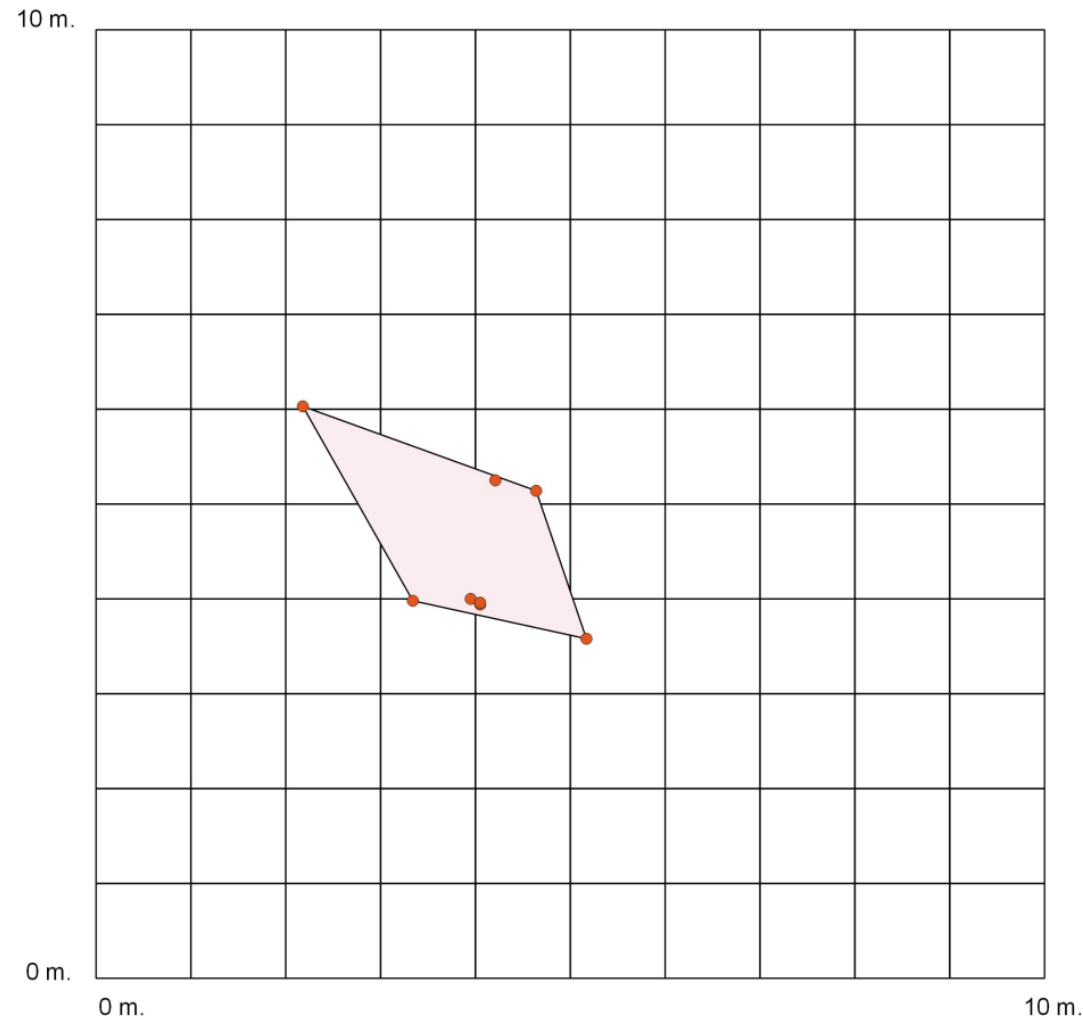


Frog: C187

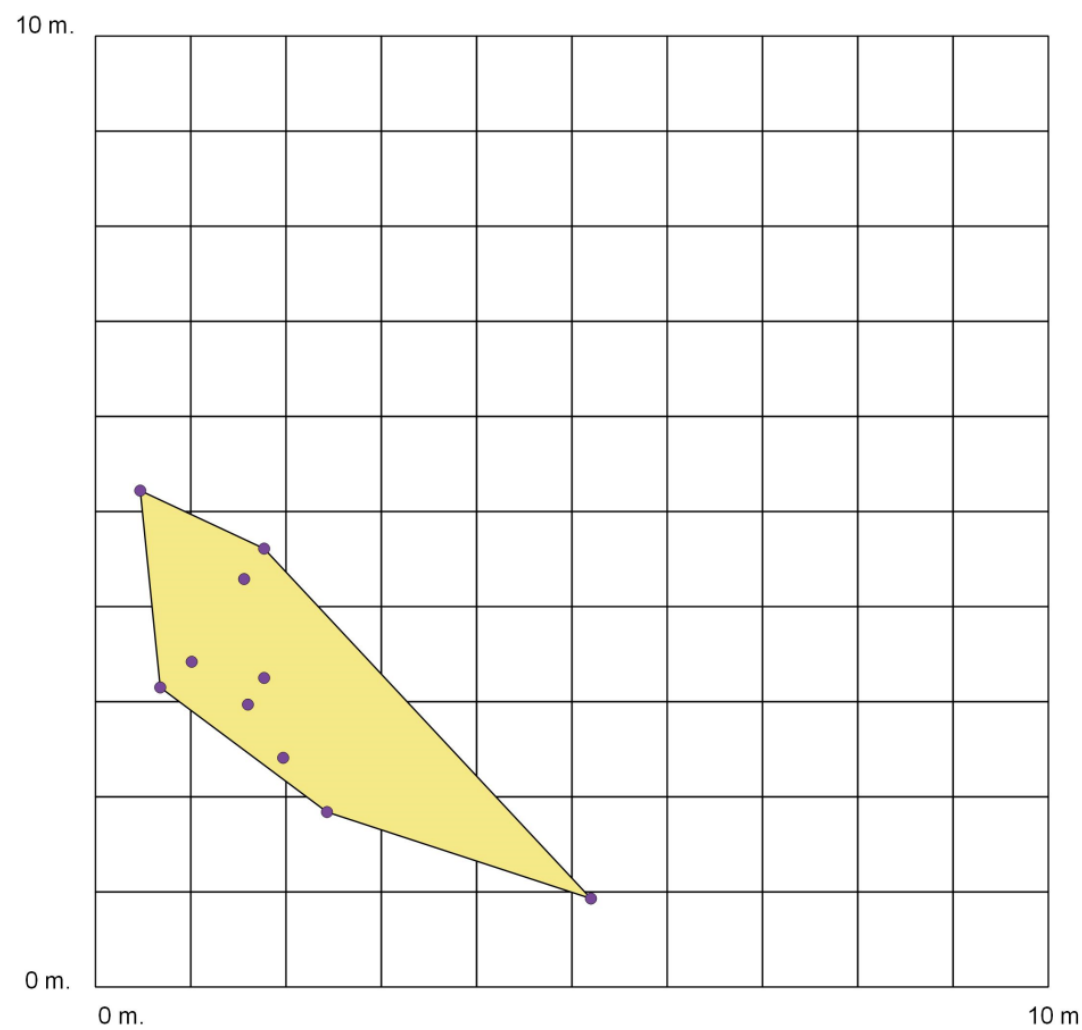

Frog: C250

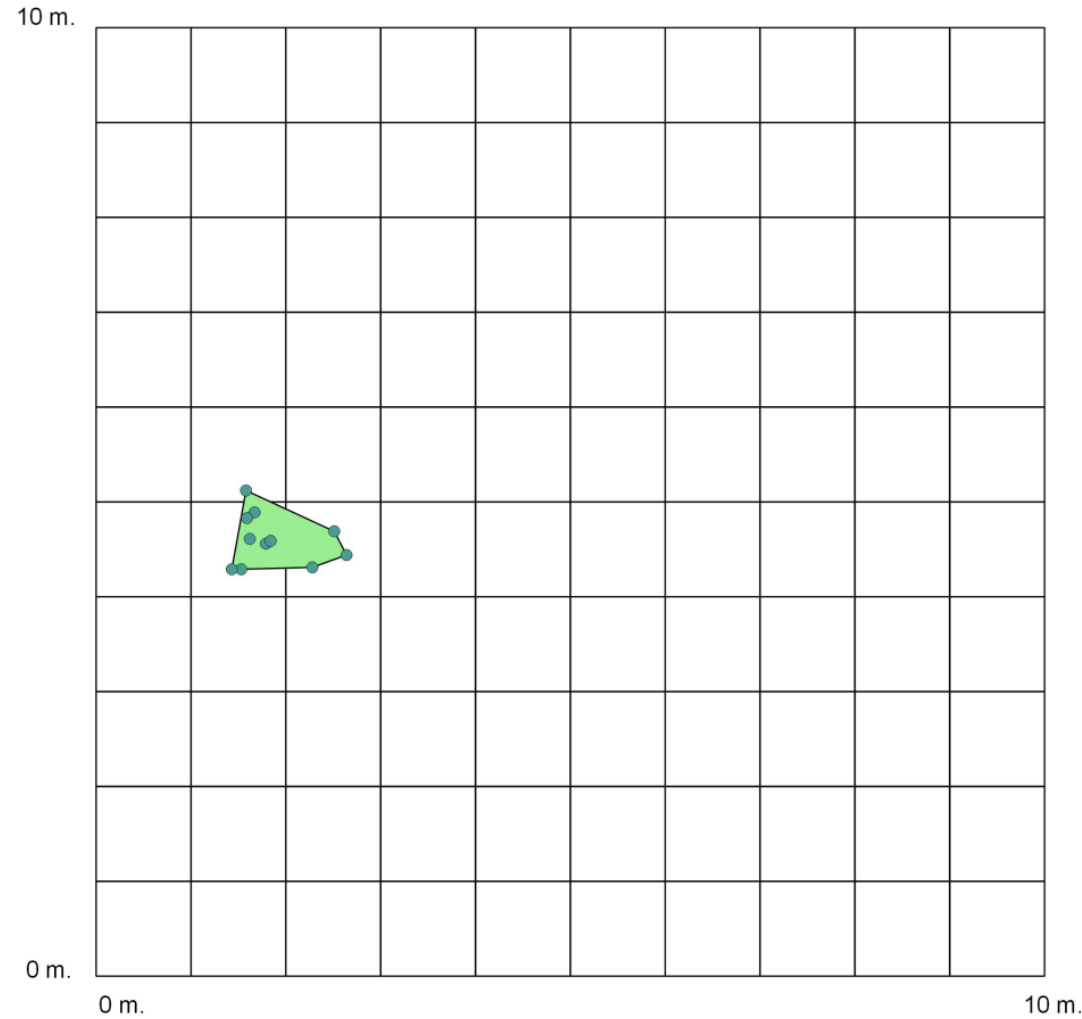


Frog: C258

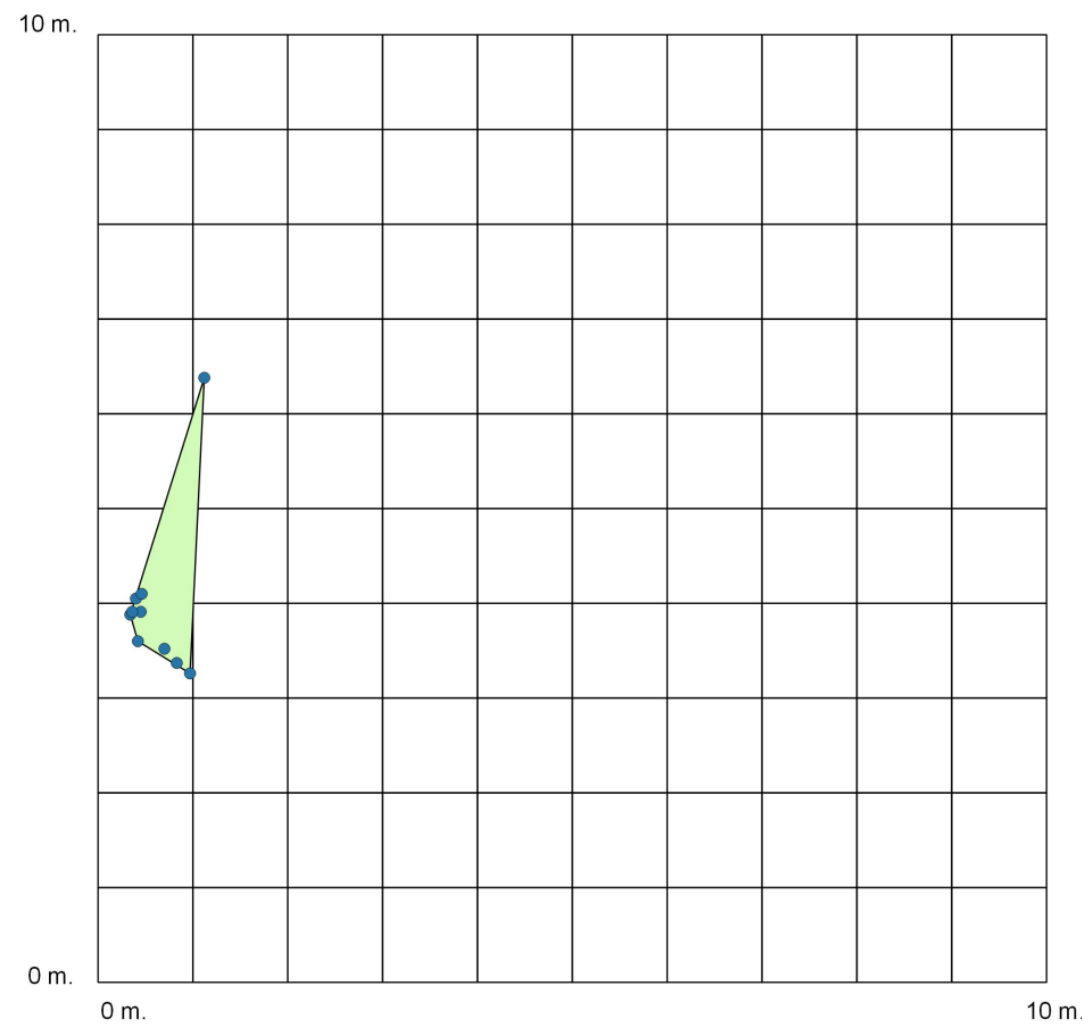

Frog: C262

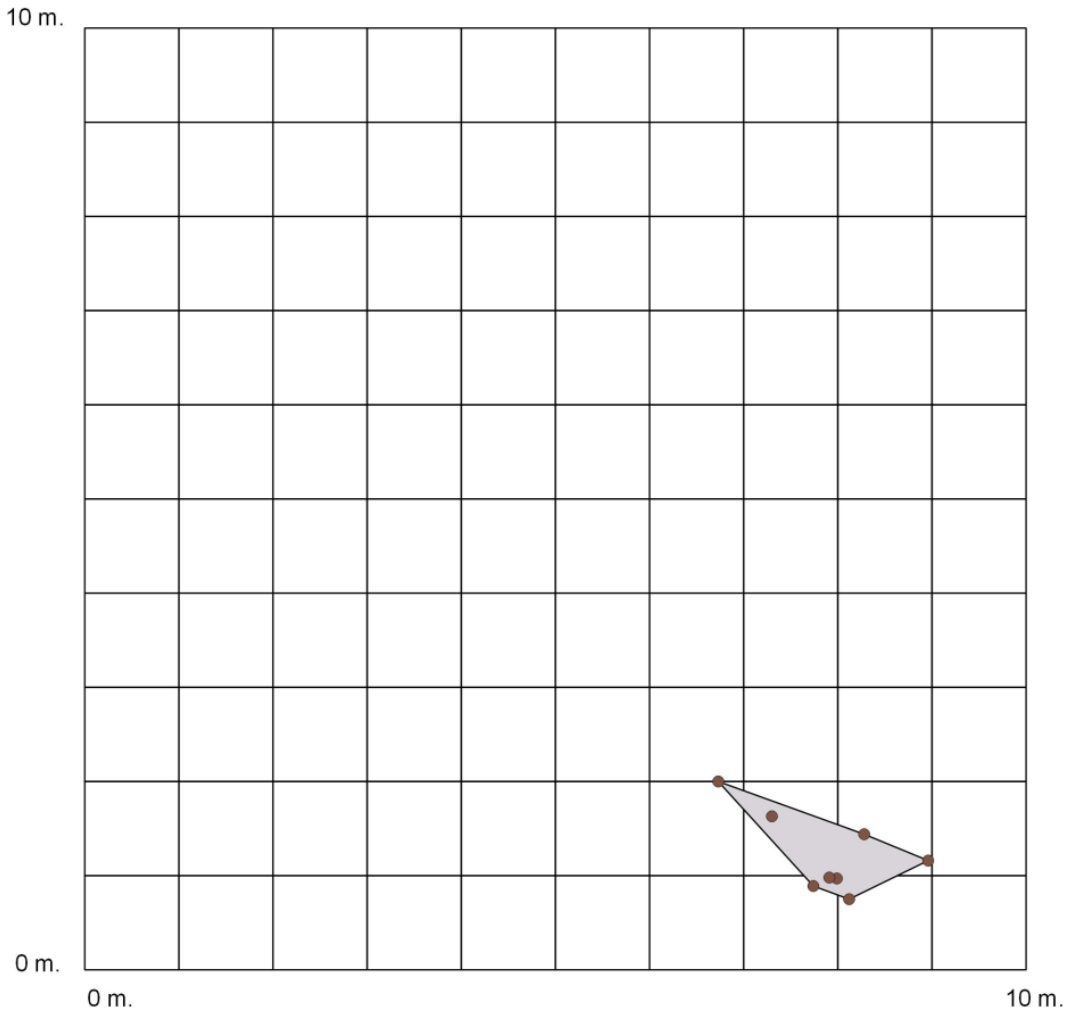


Frog: C317

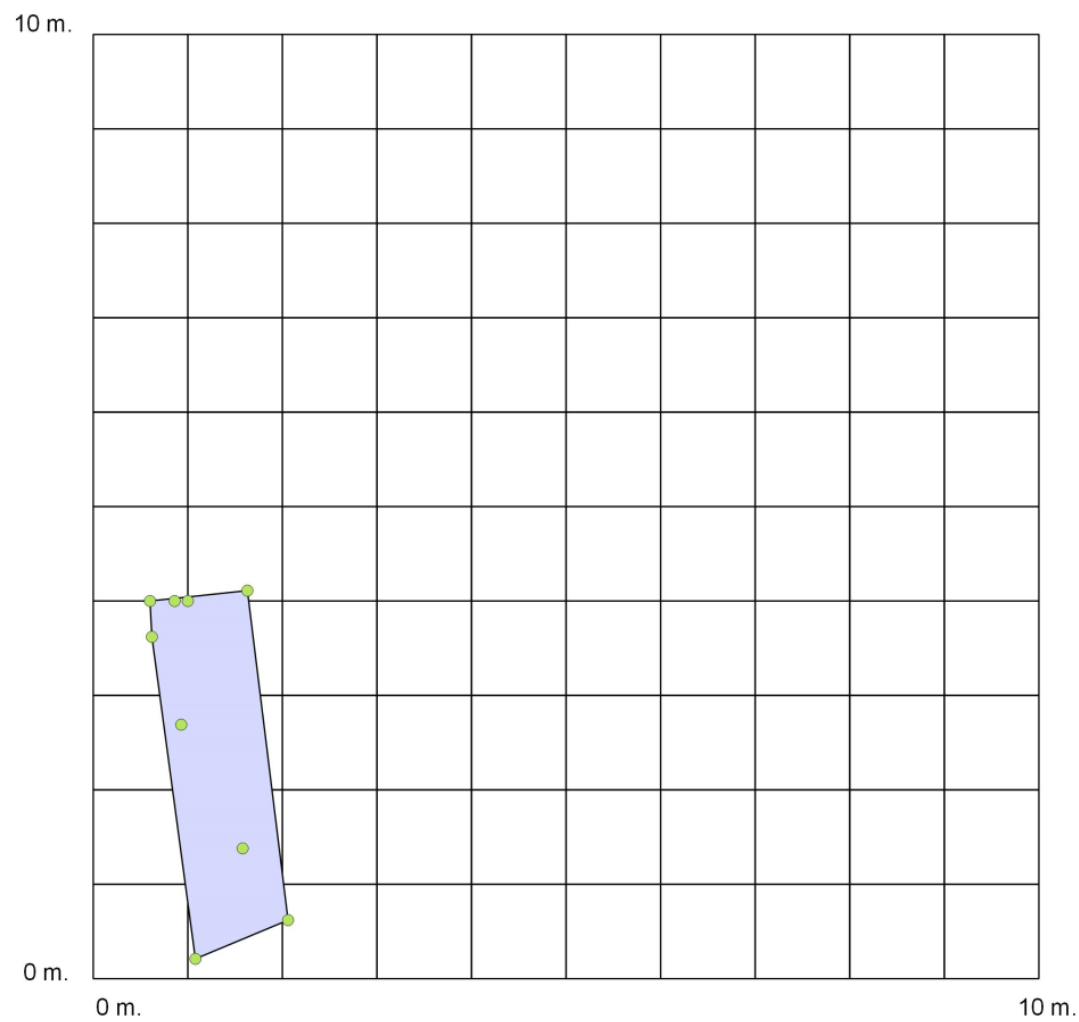

Frog: C399

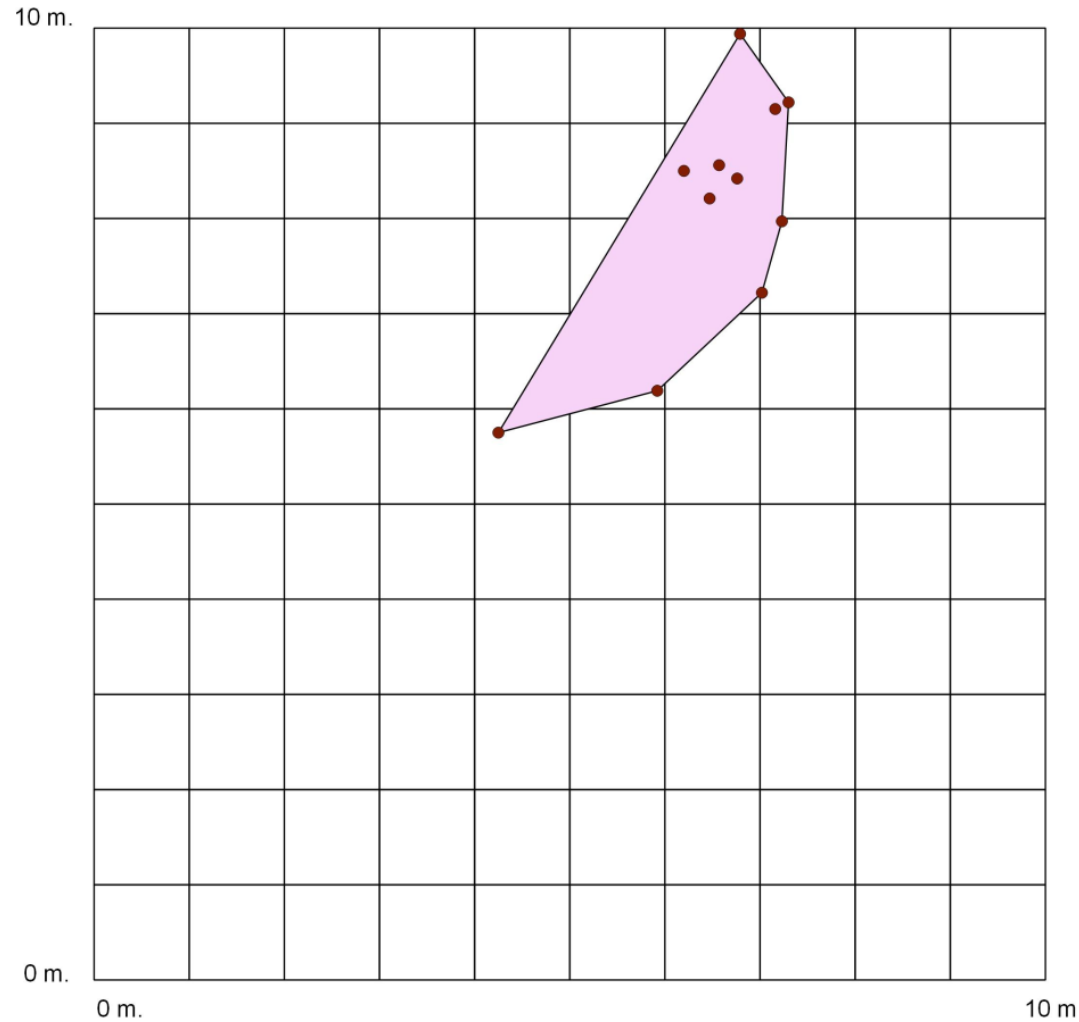


Grid D

Frog: D2

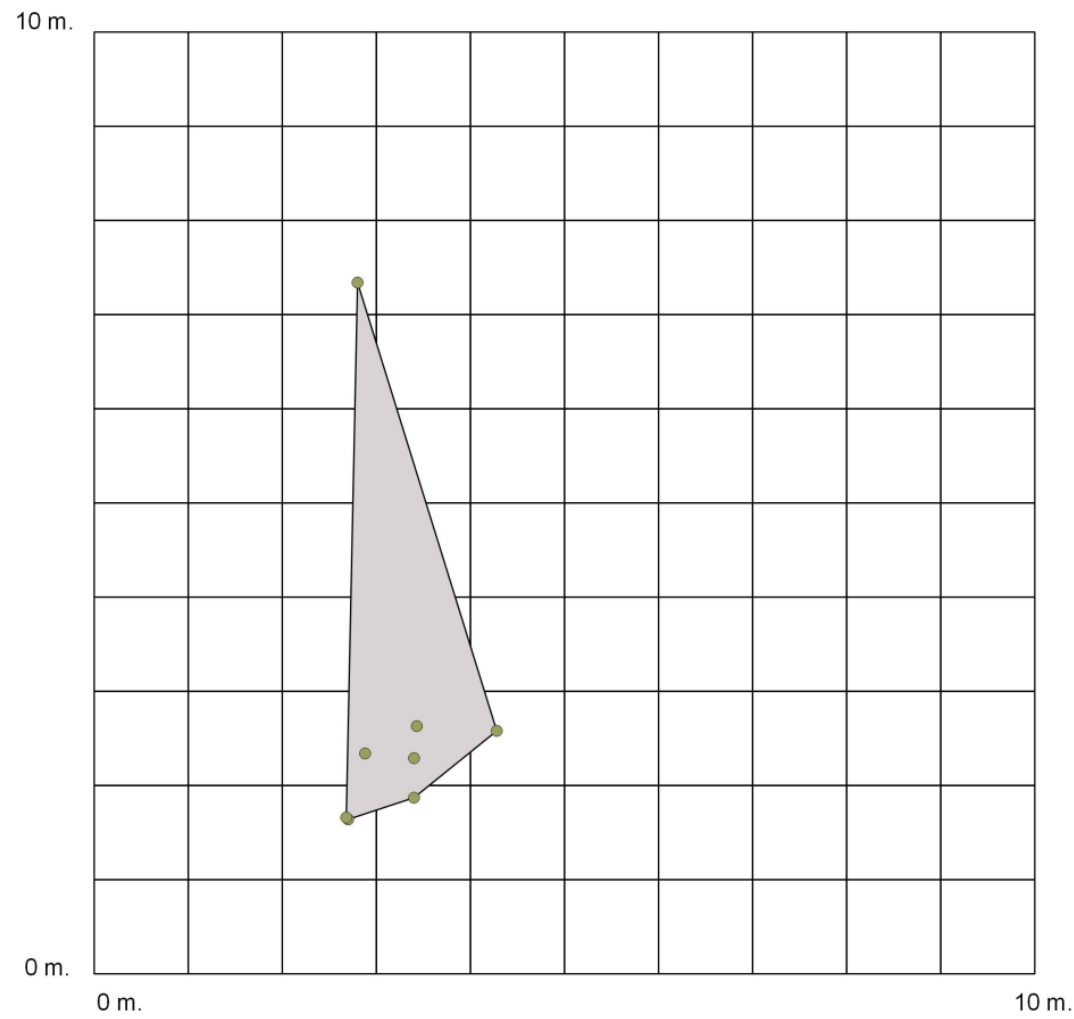

Frog: D3

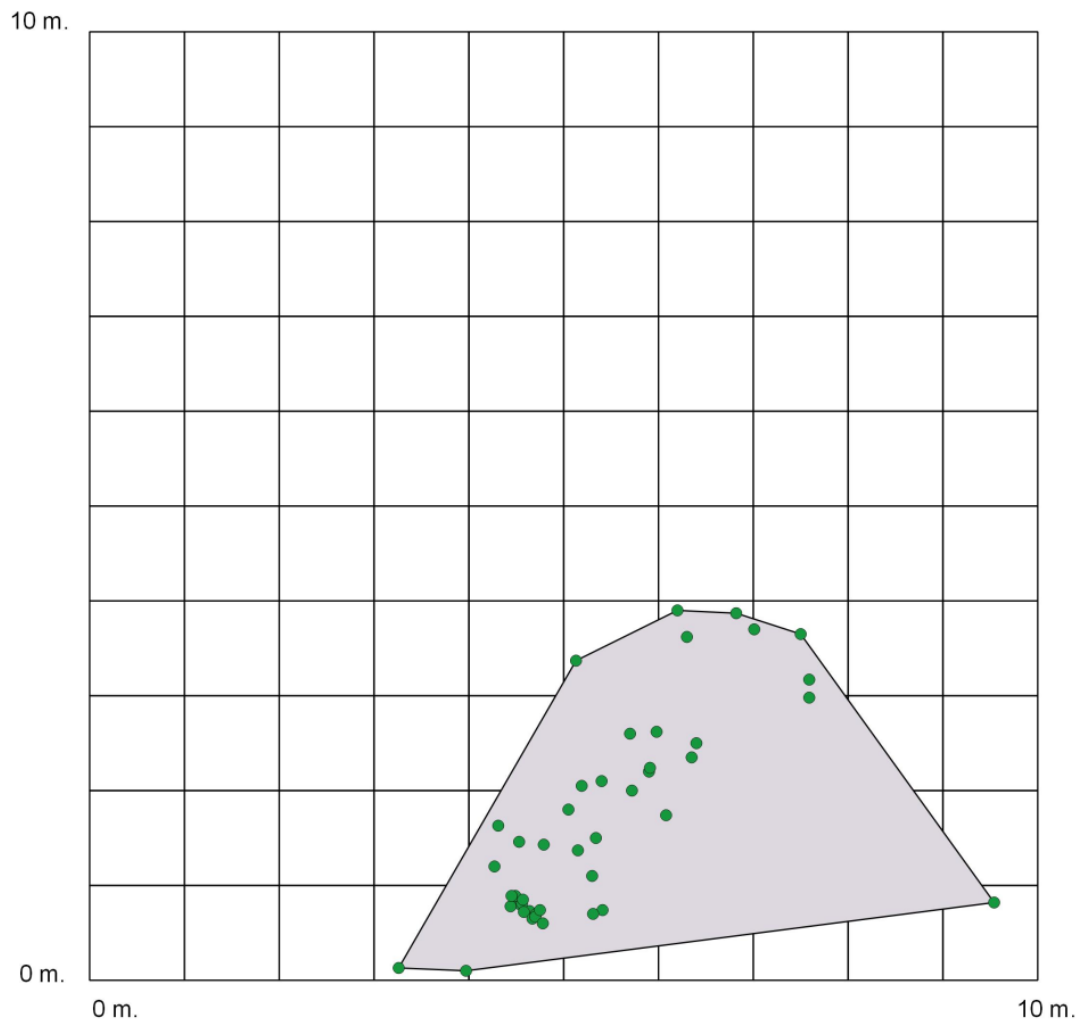


Frog: D8

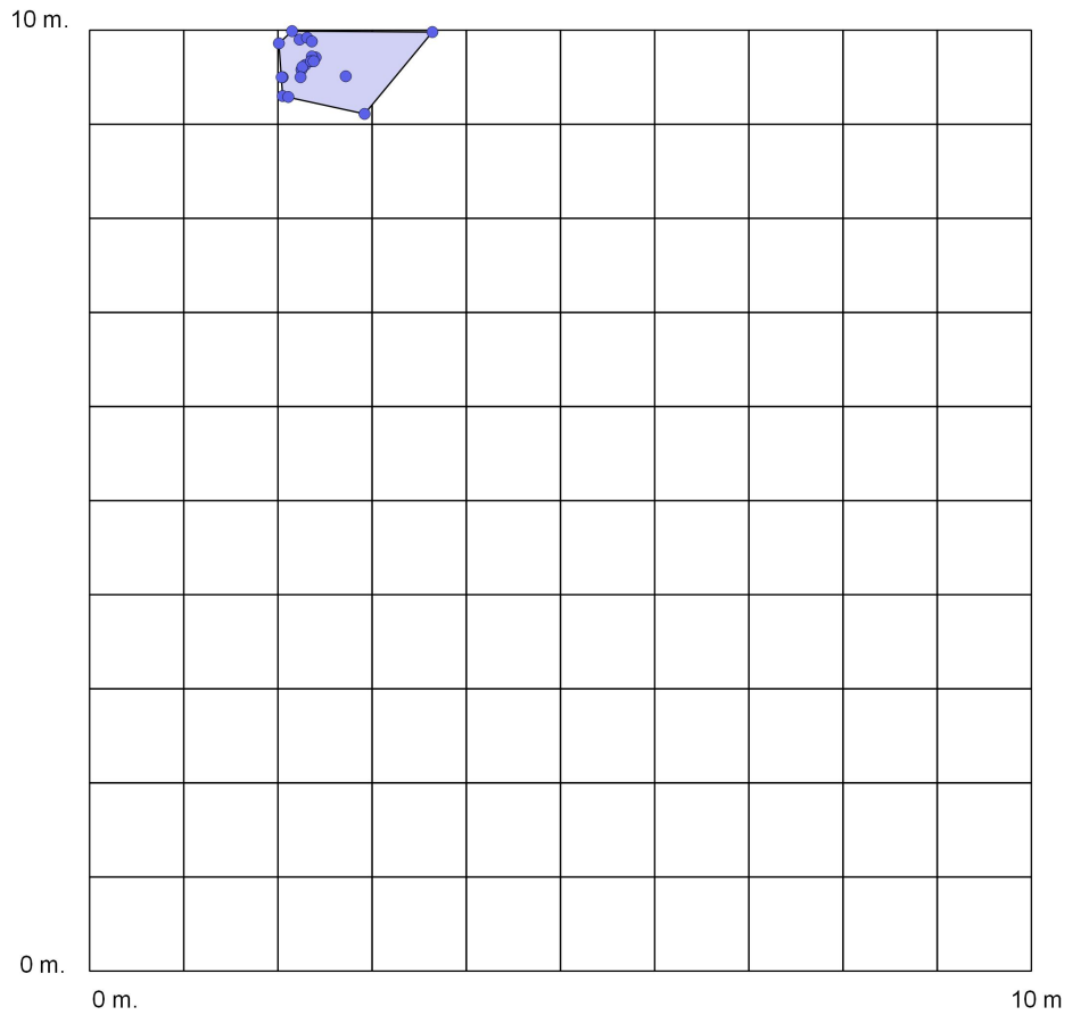

Frog: D9

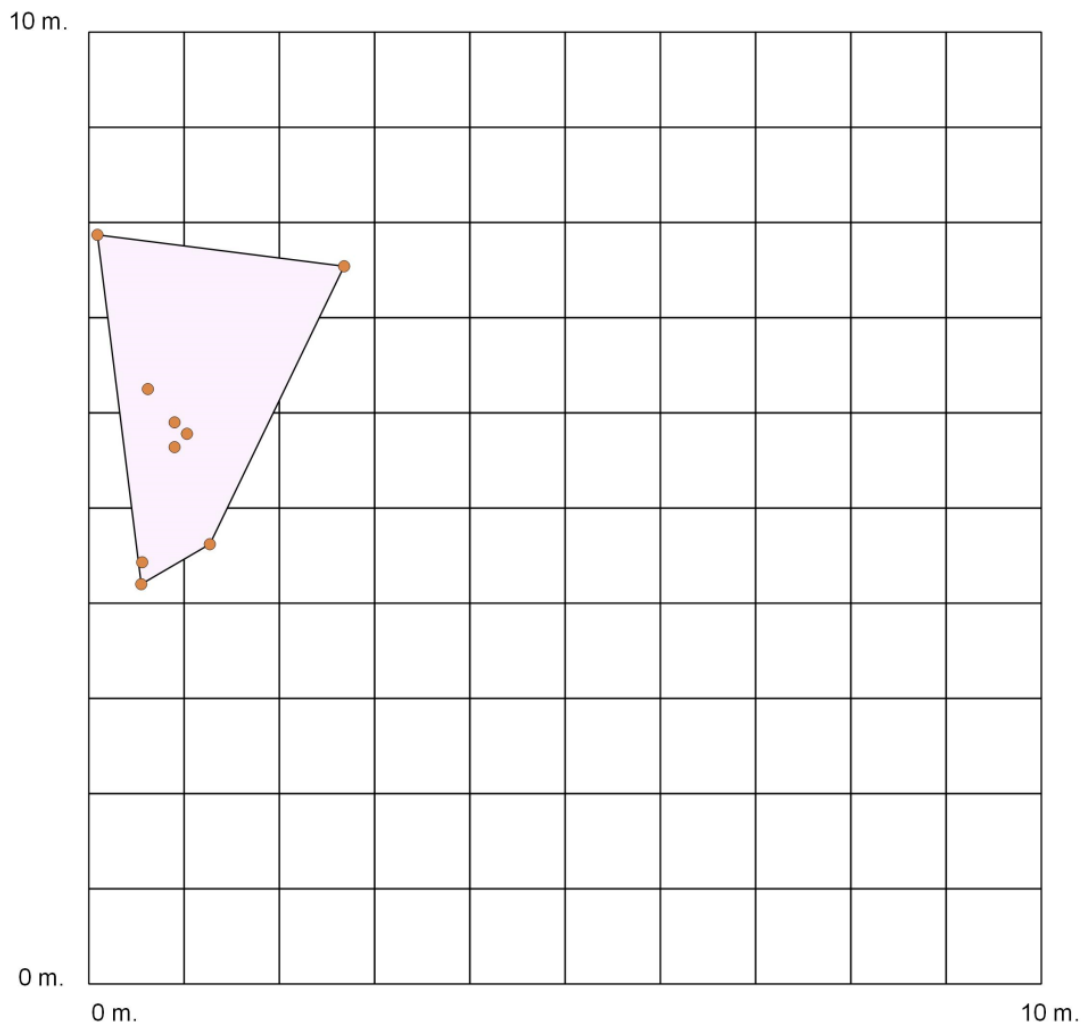


Frog: D36

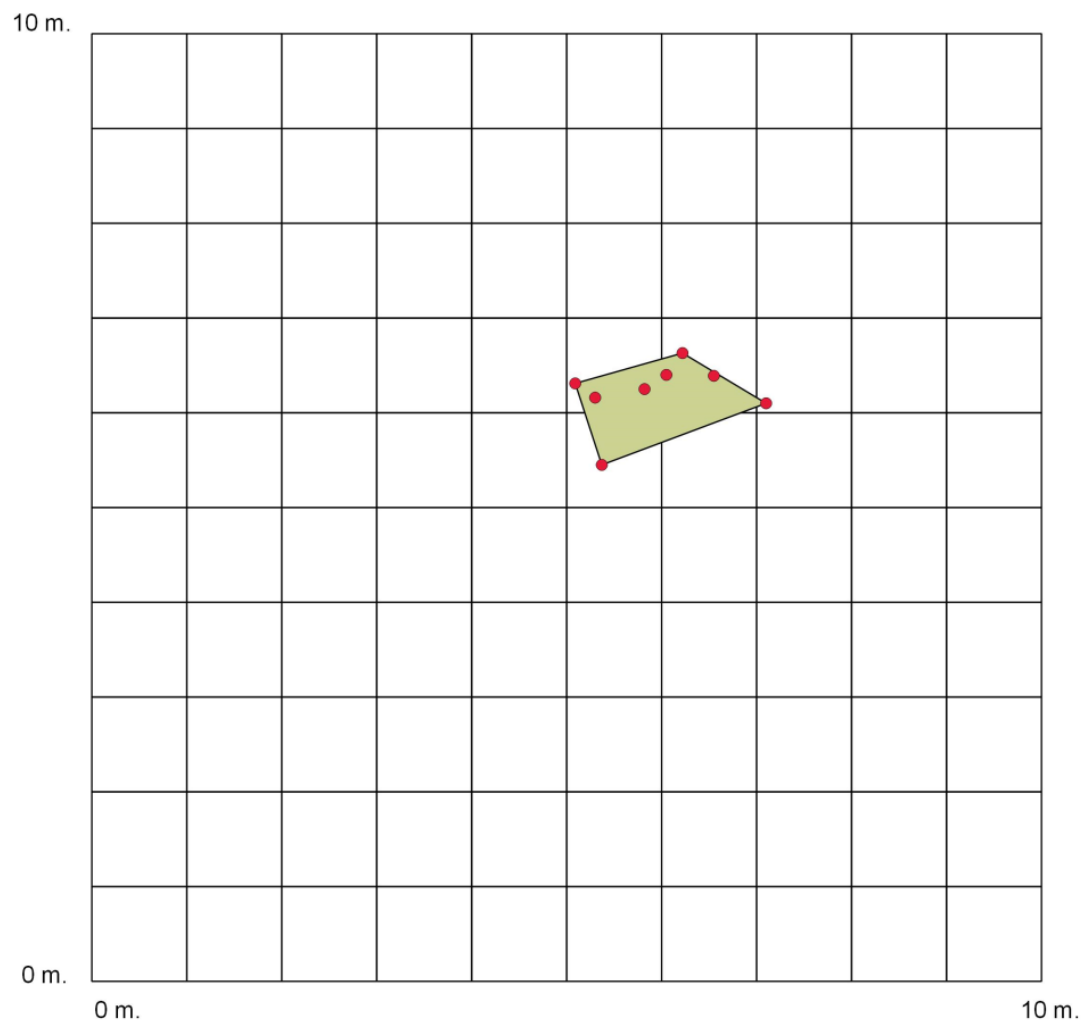

Frog: D42

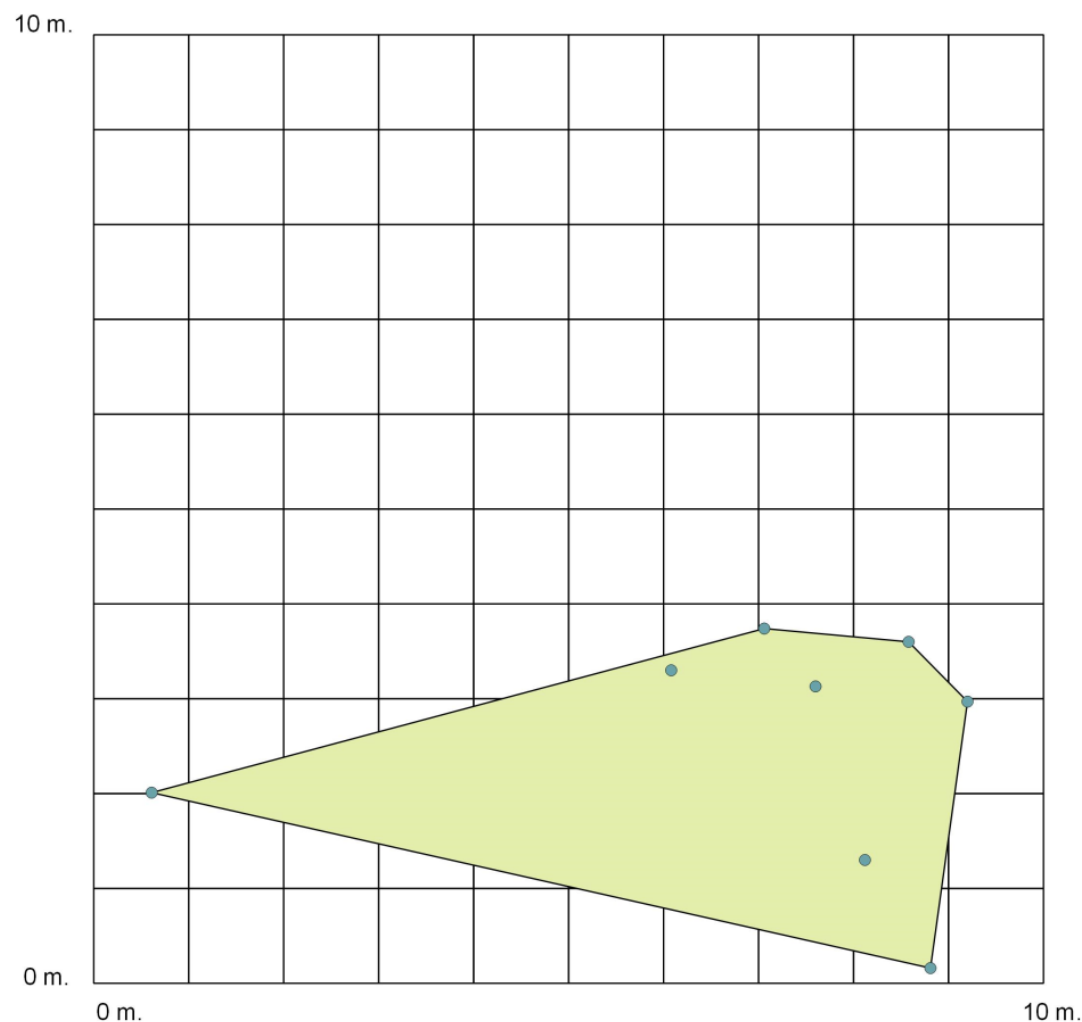


Frog: D52

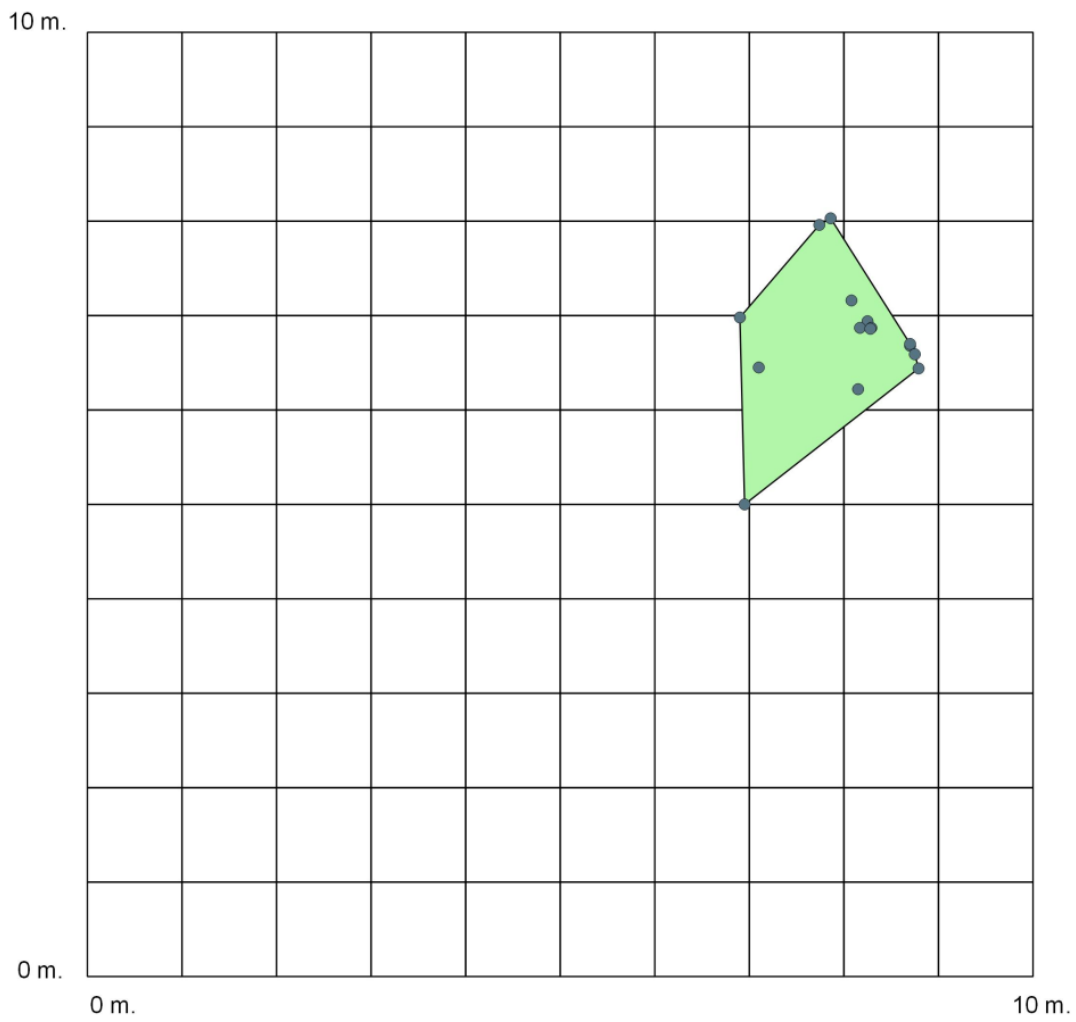

Frog: D55

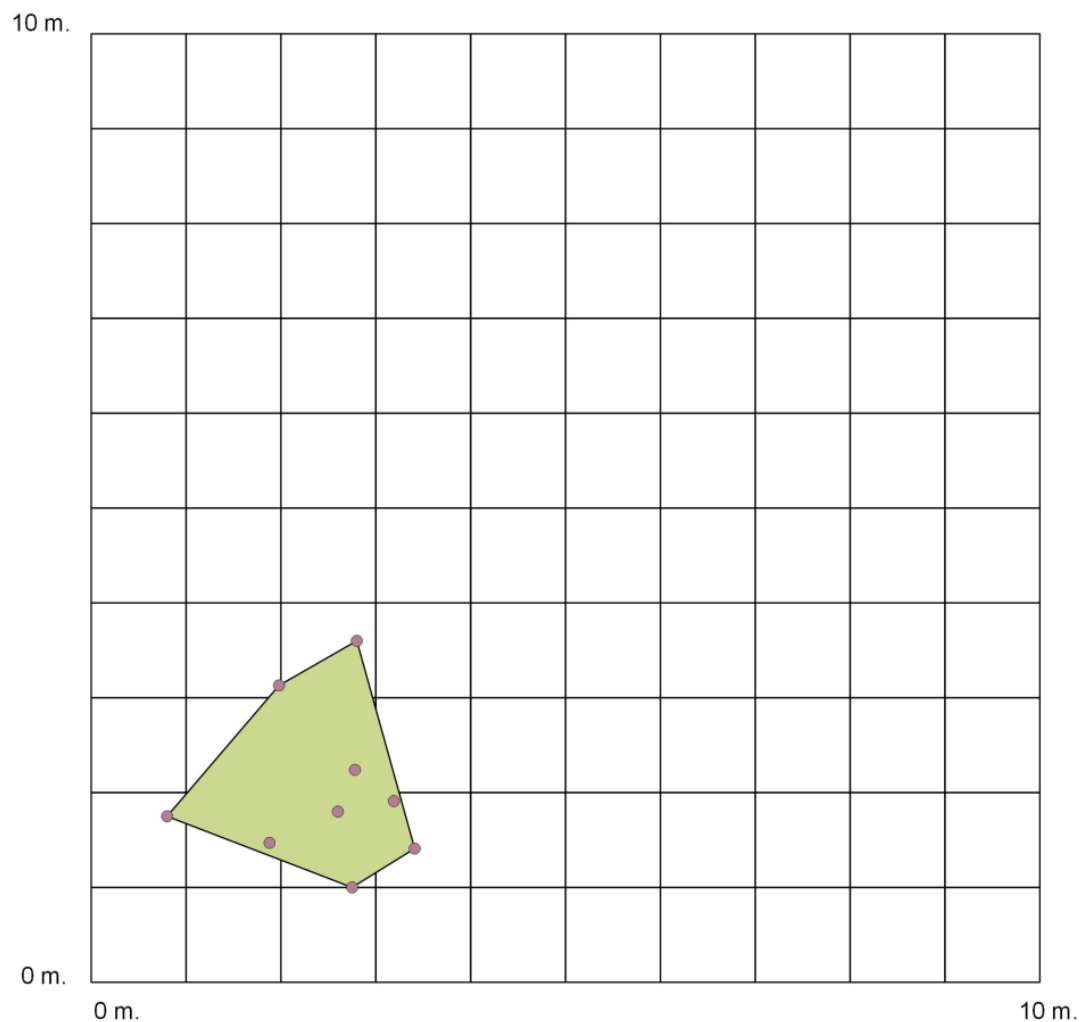


Frog: D60

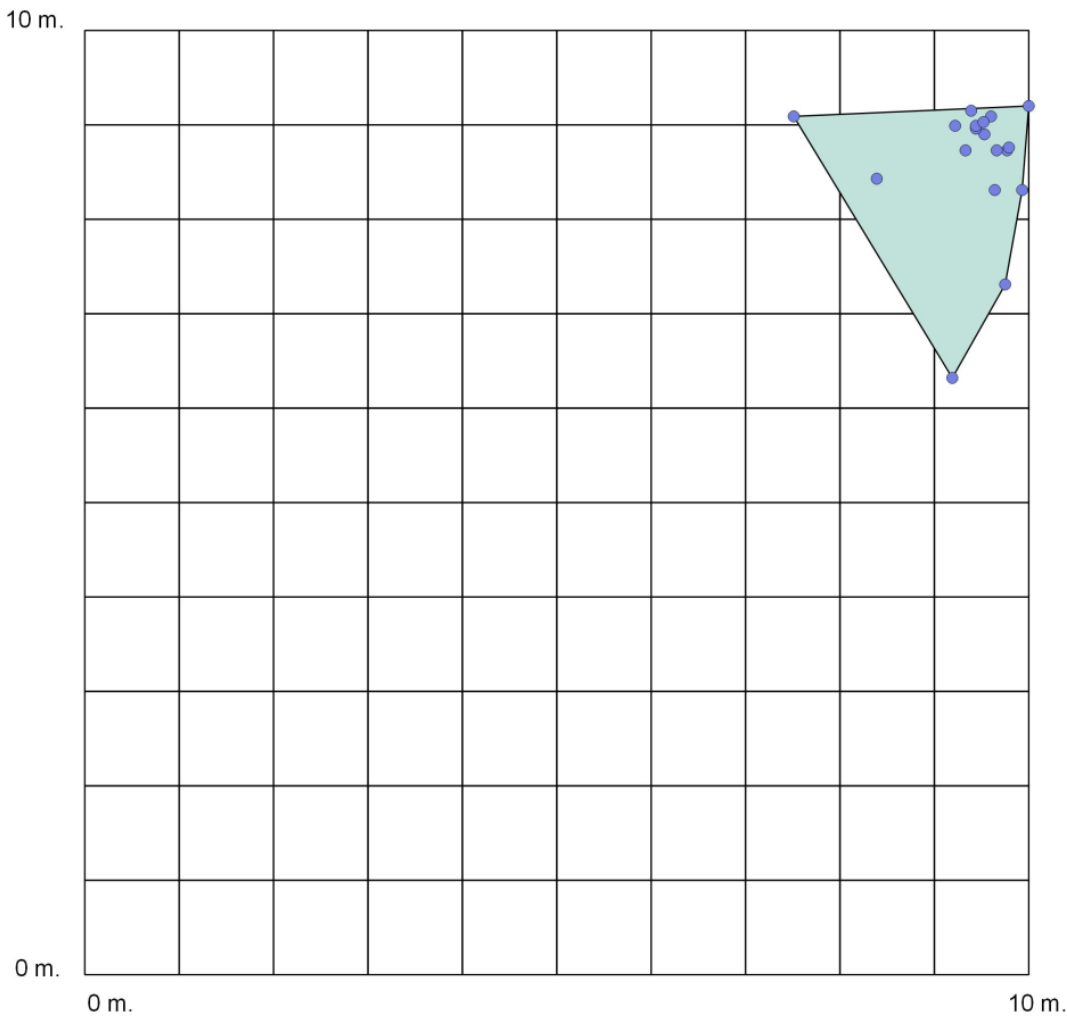

Frog: D62

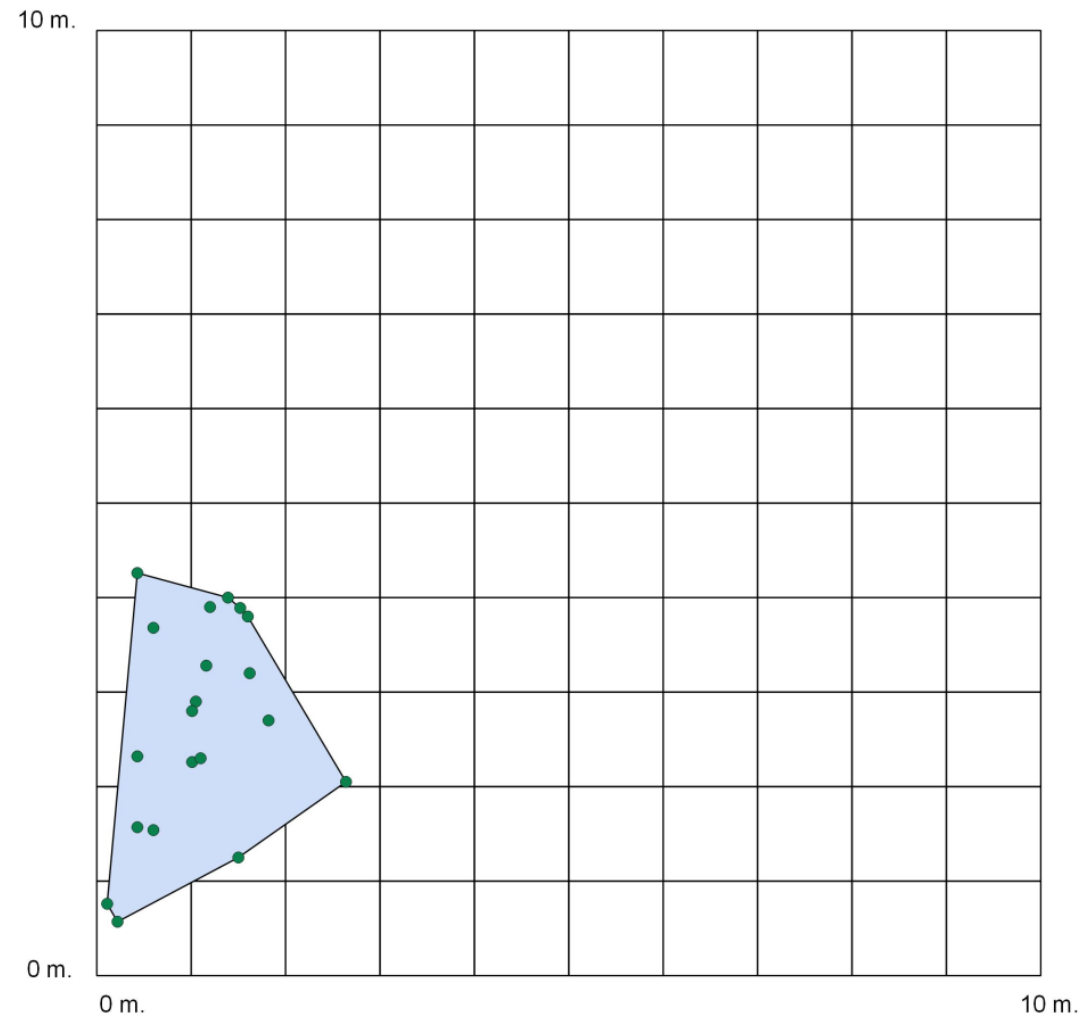


Frog: D71

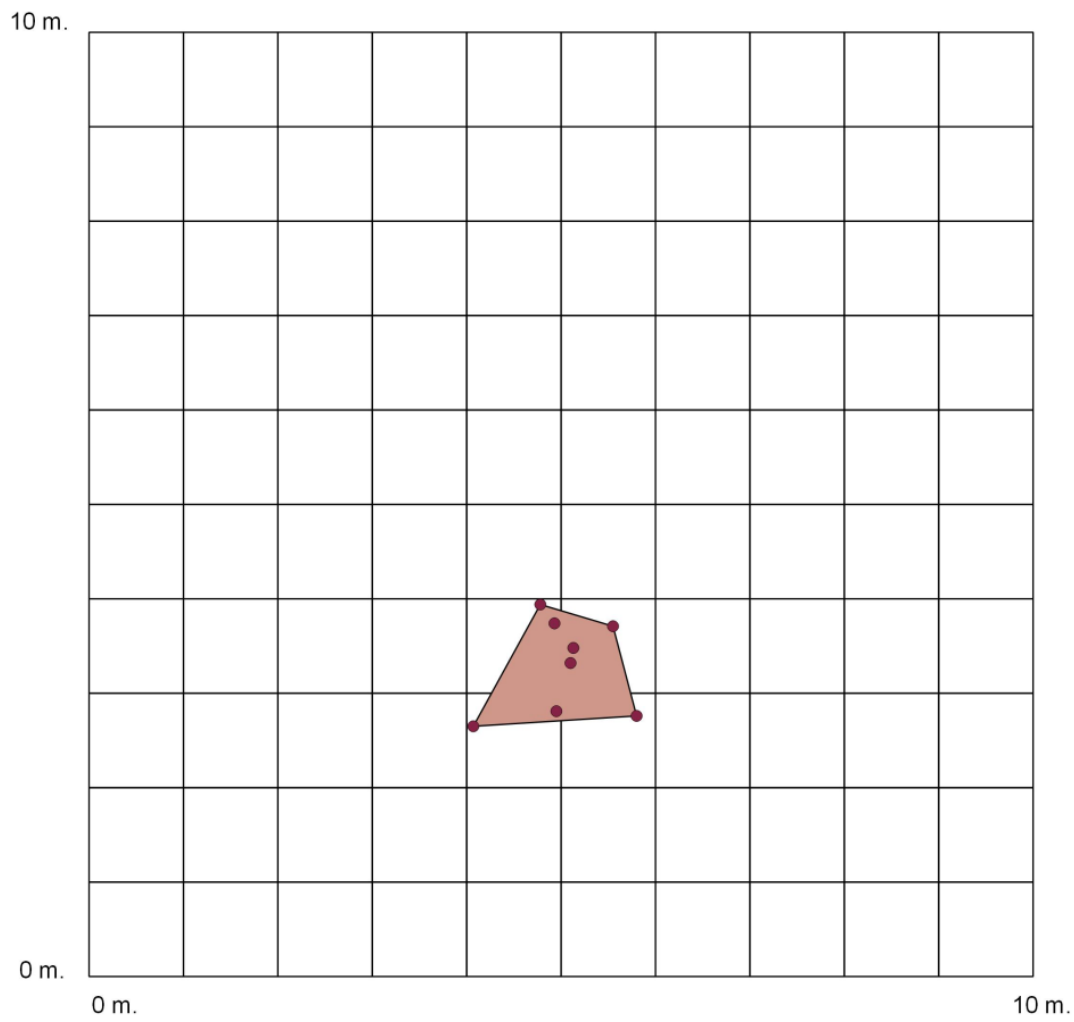

Frog: D74

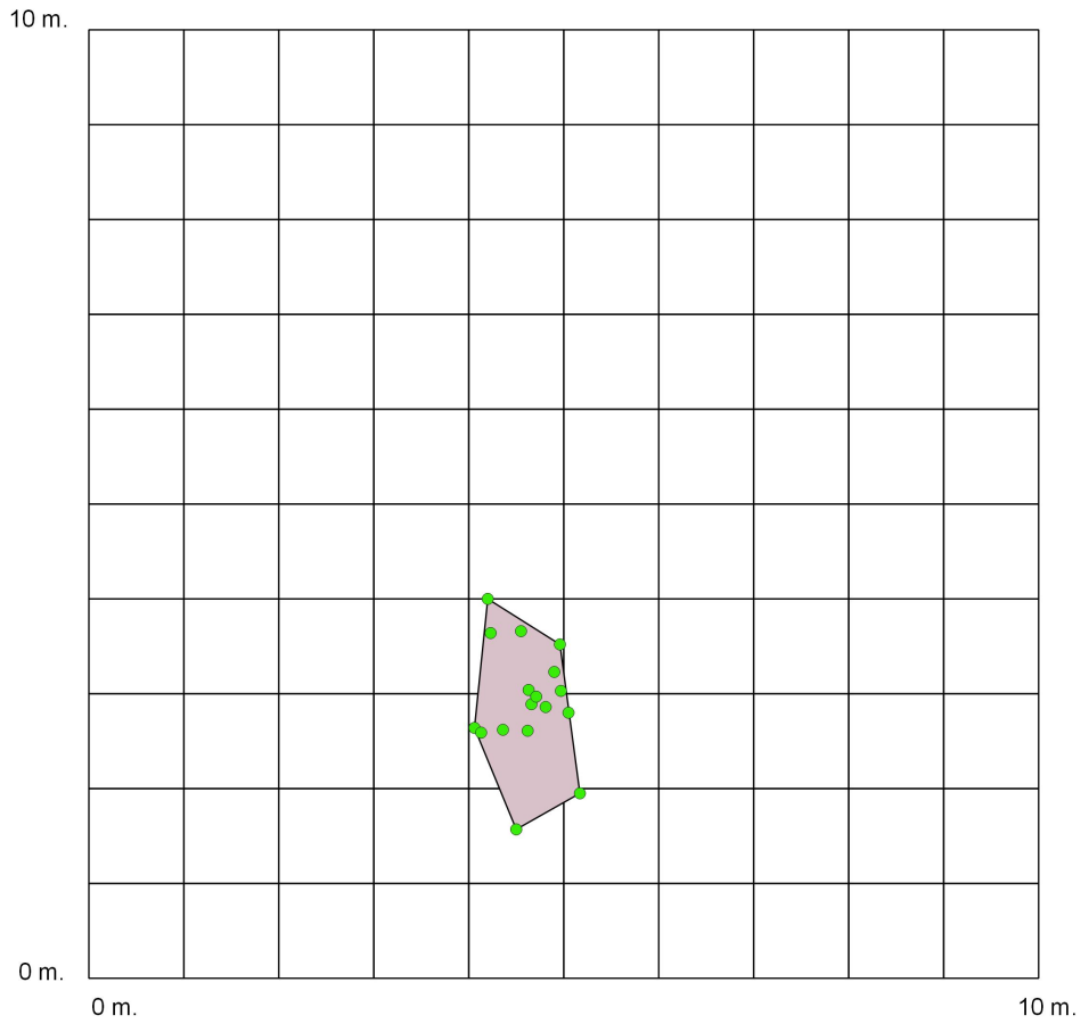


Frog: D76

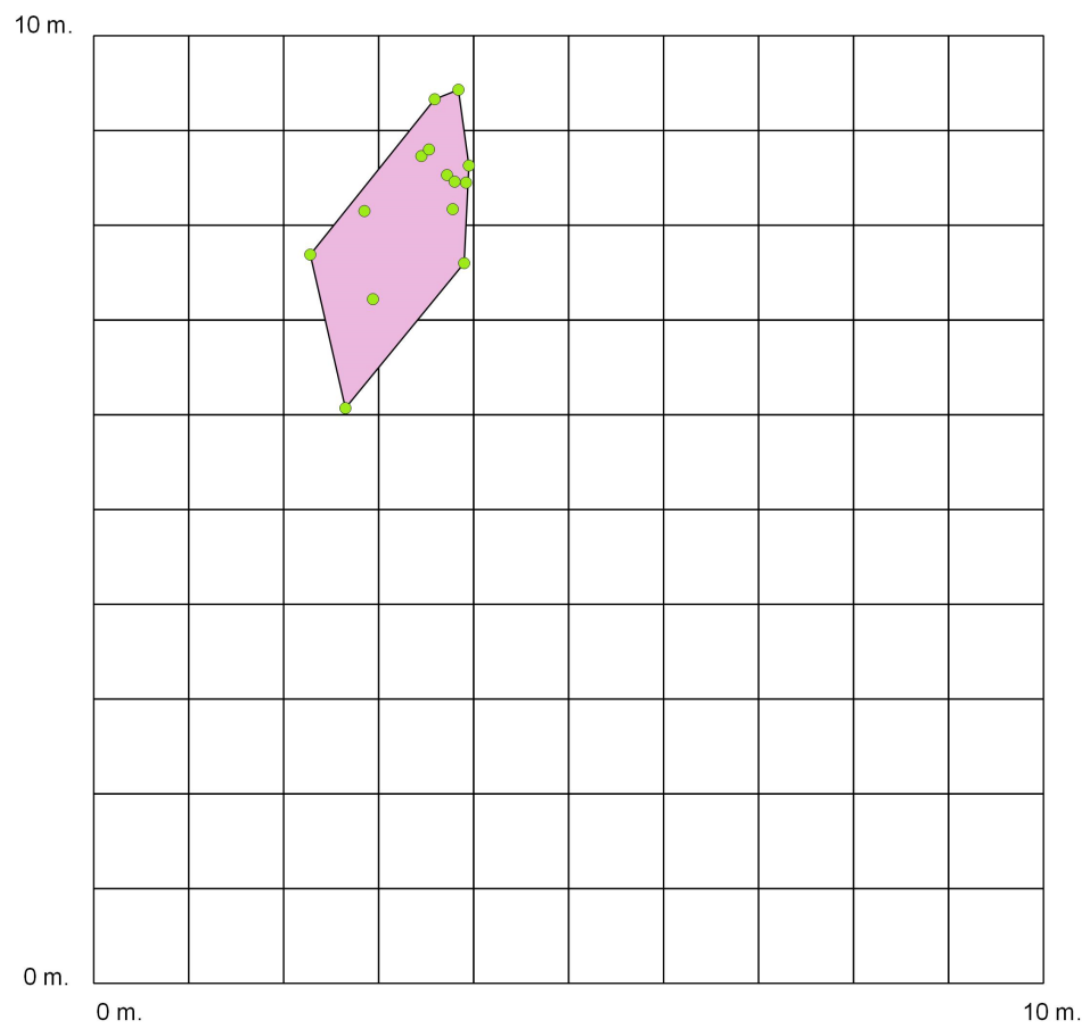

Frog: D81

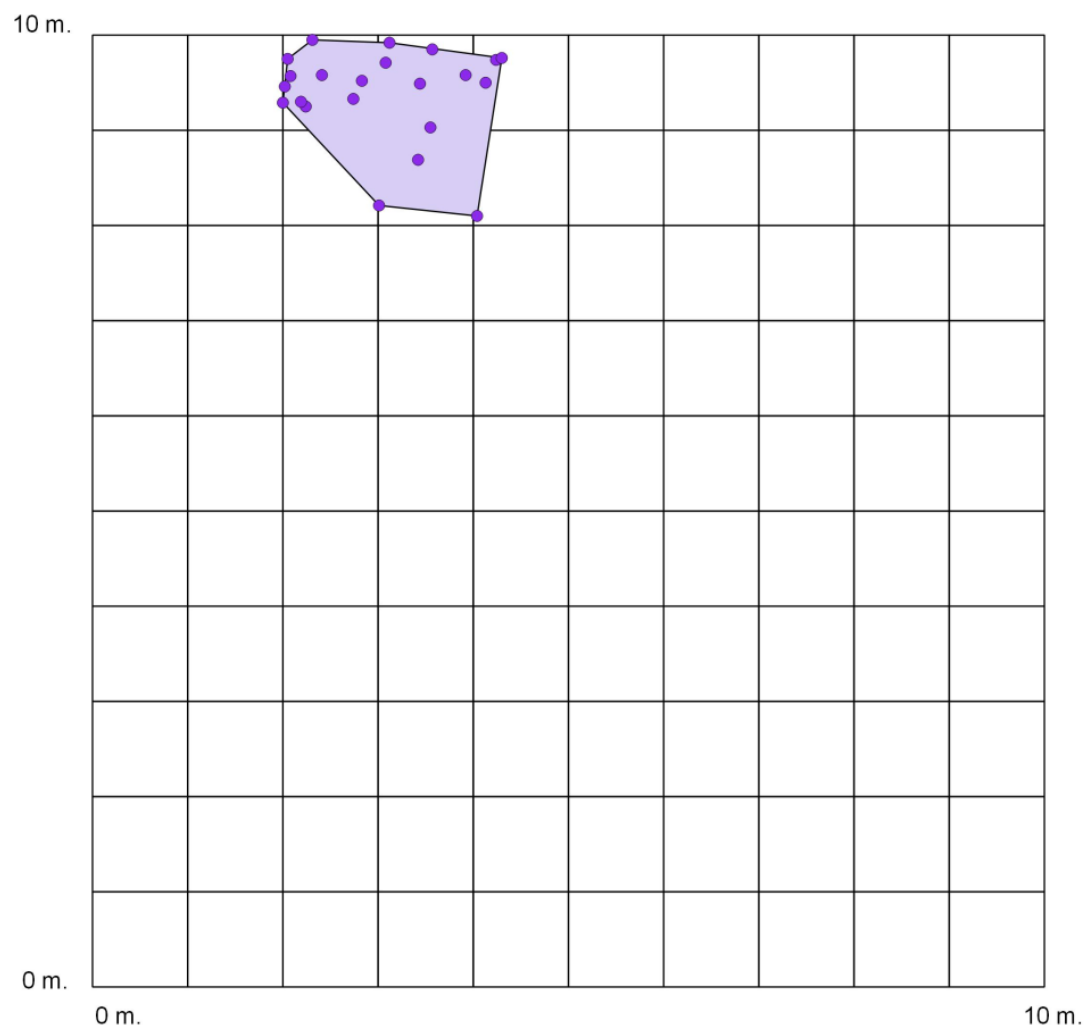


Frog: D82

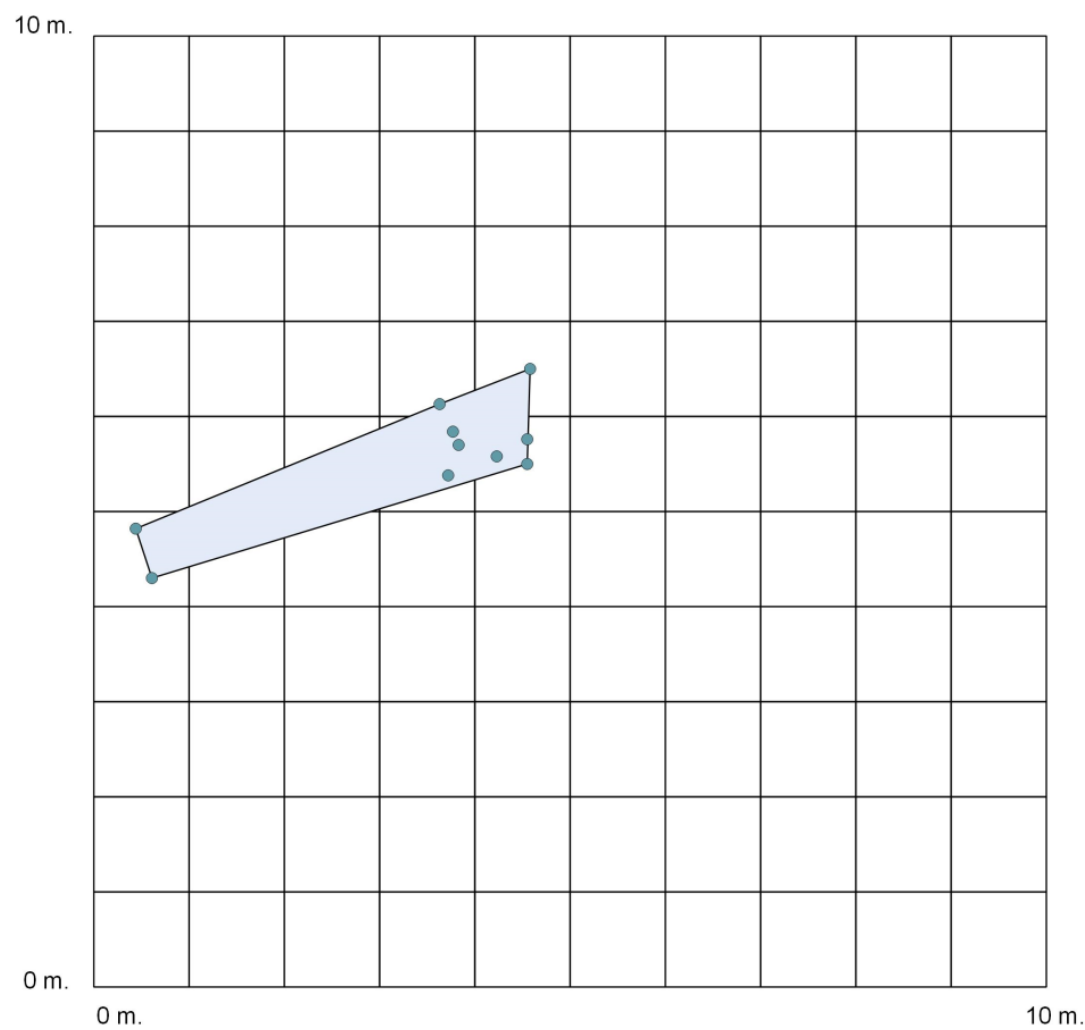

Frog: D102

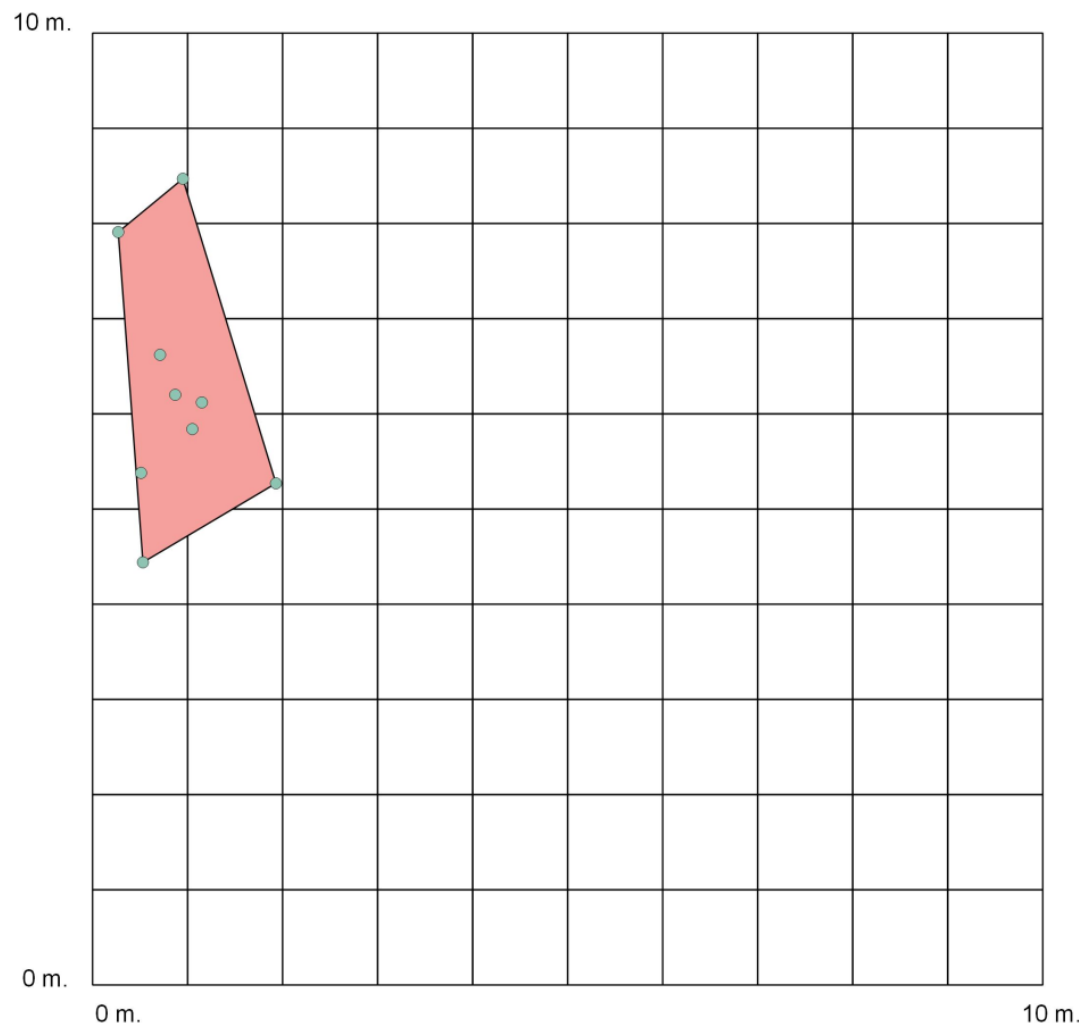


Frog: D109

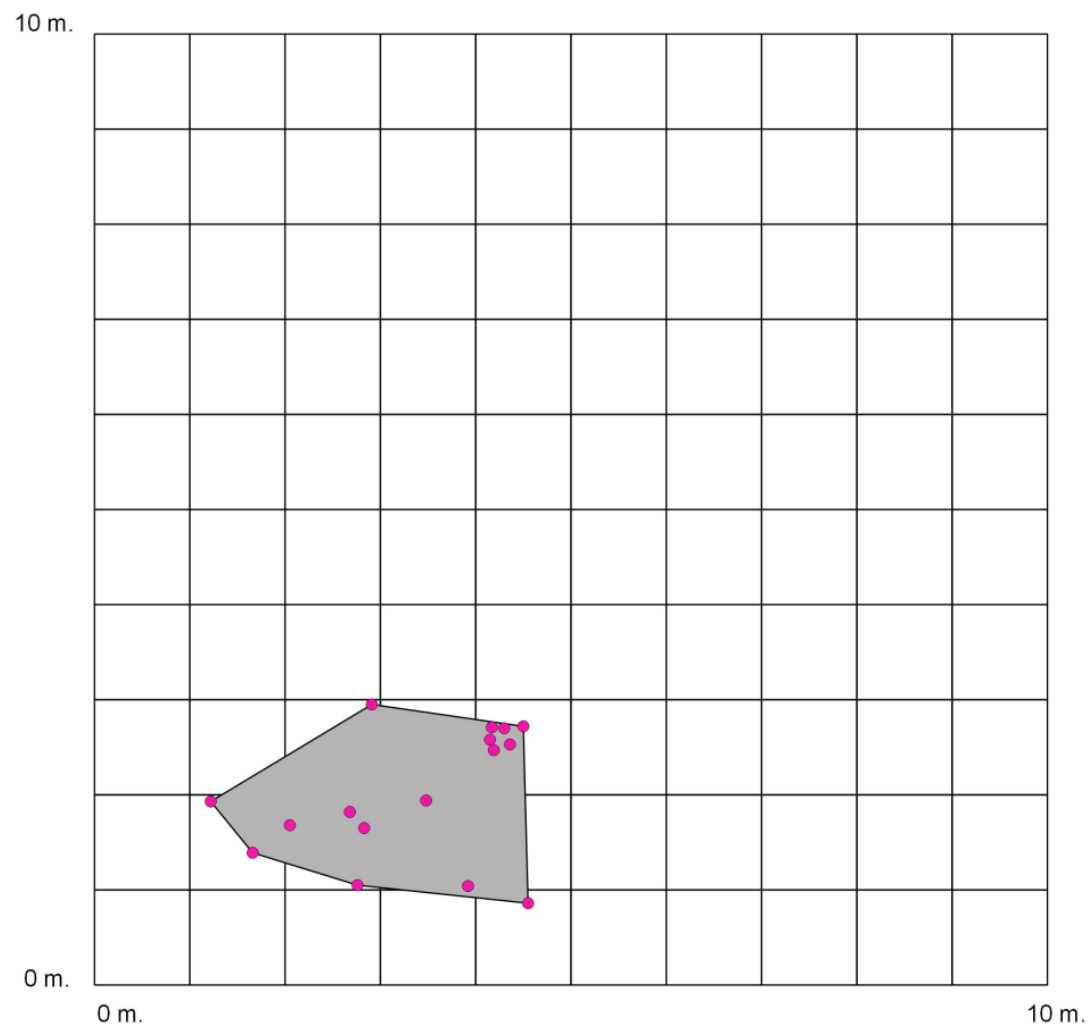

Frog: D120

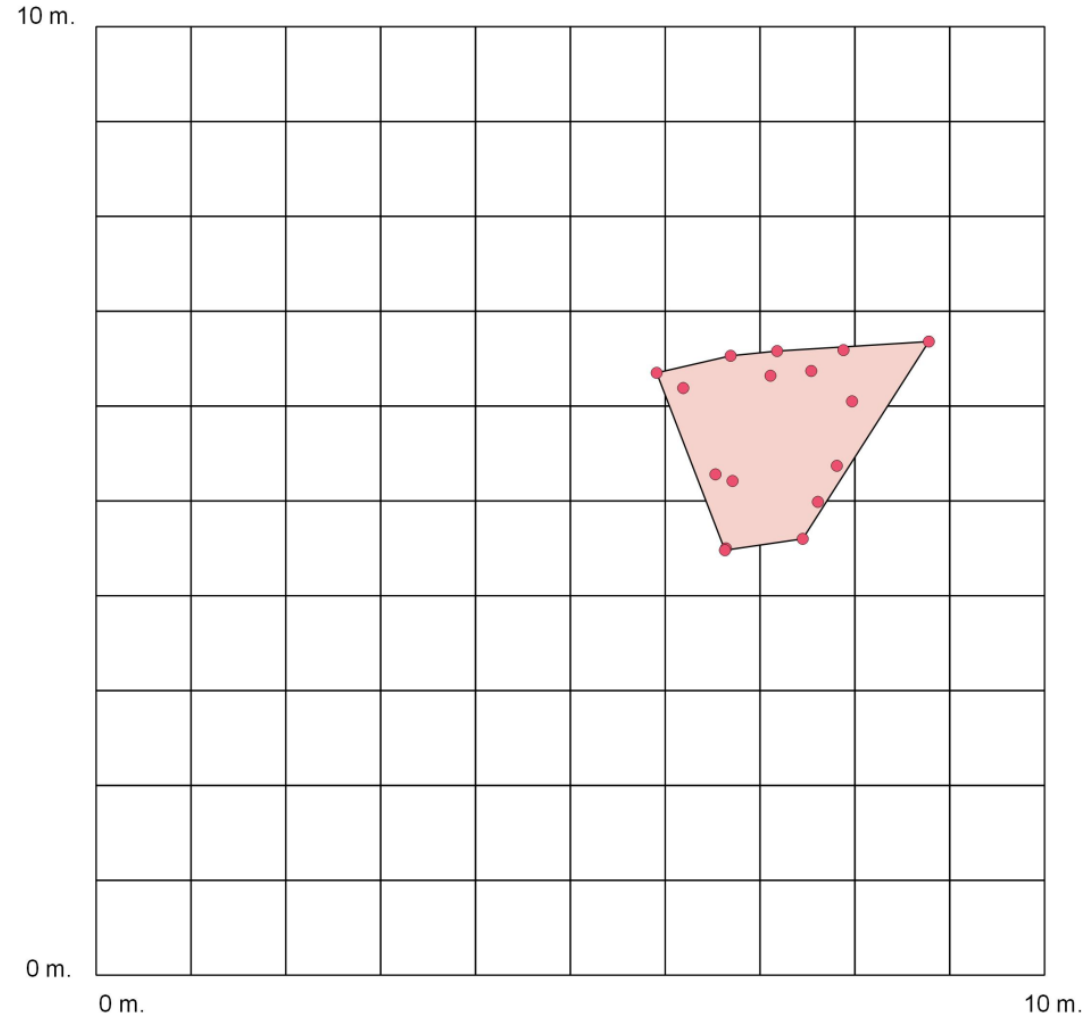


Frog: D130

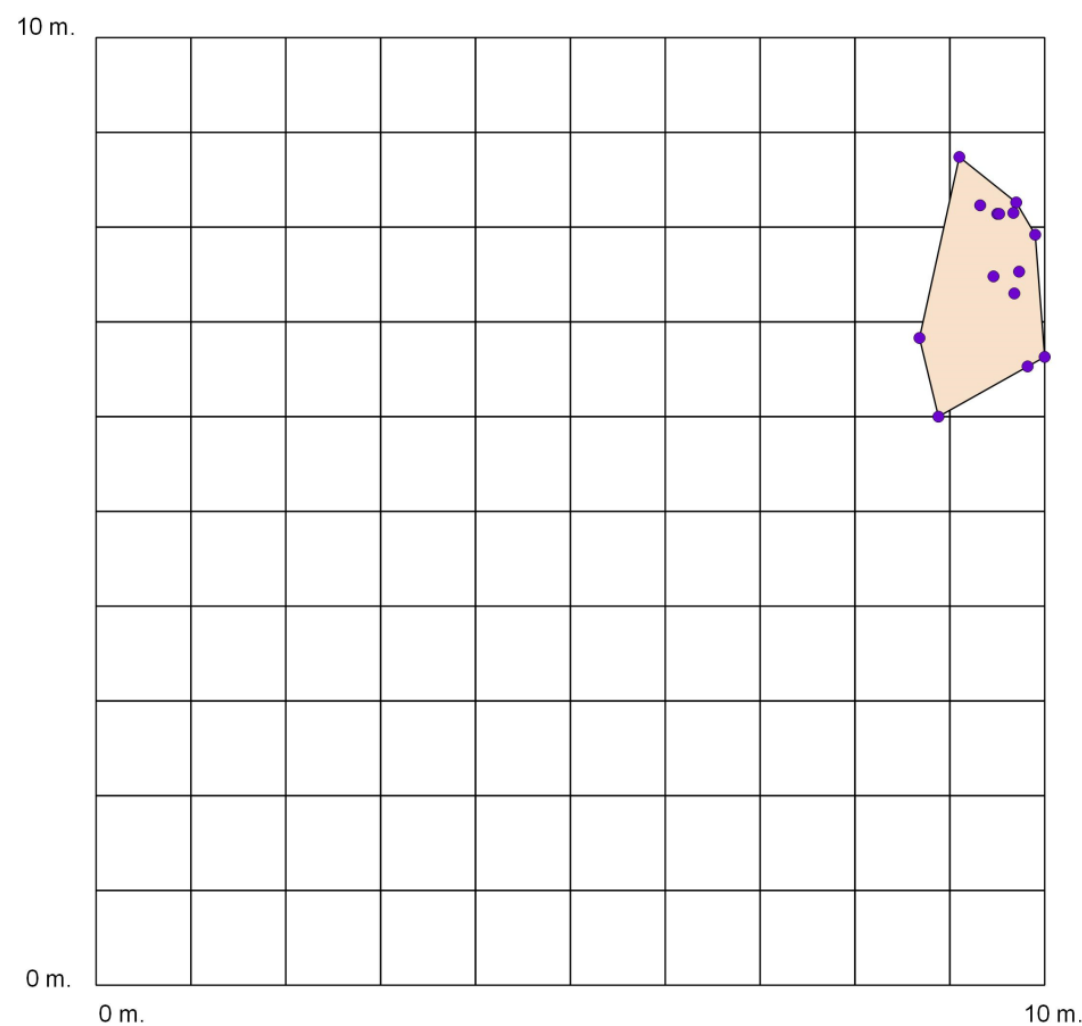

Frog: D137

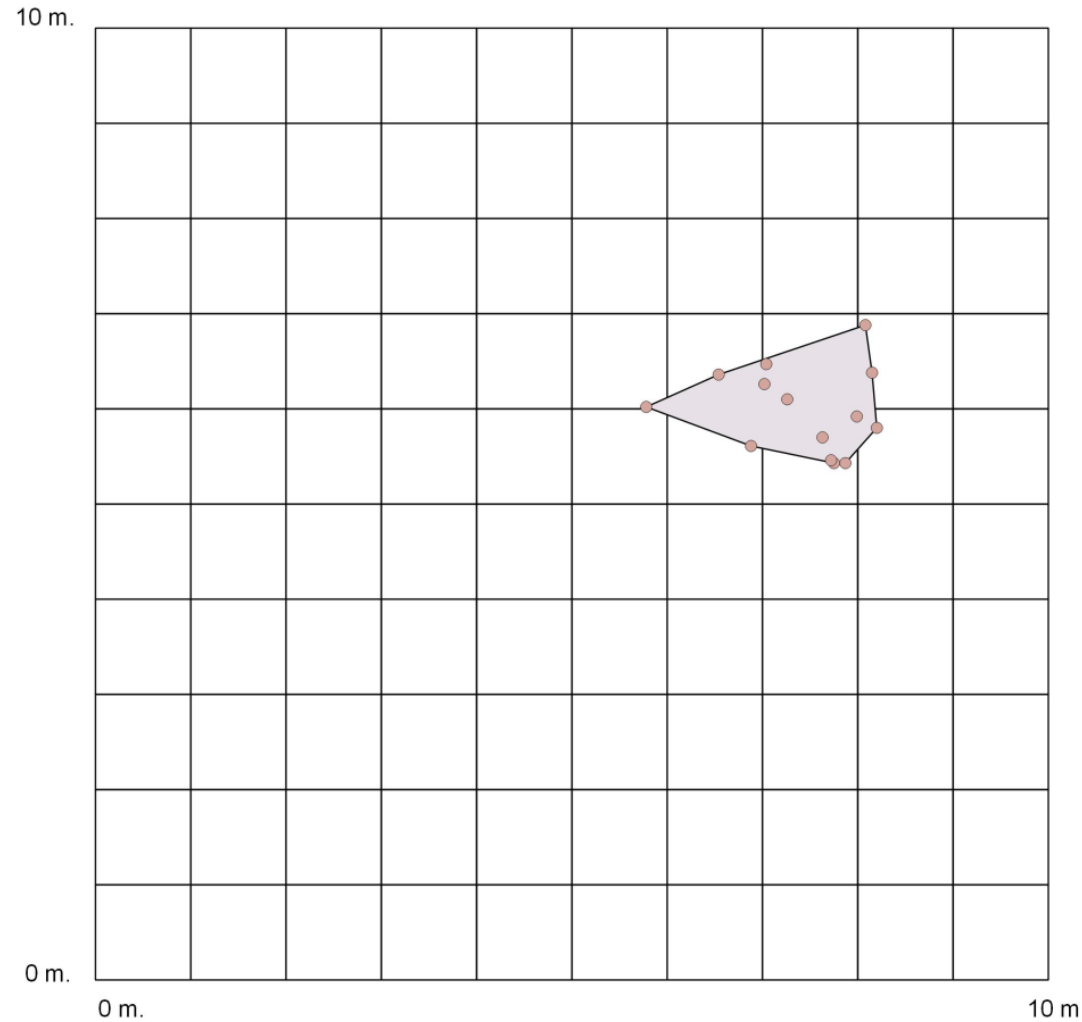


Frog: D154

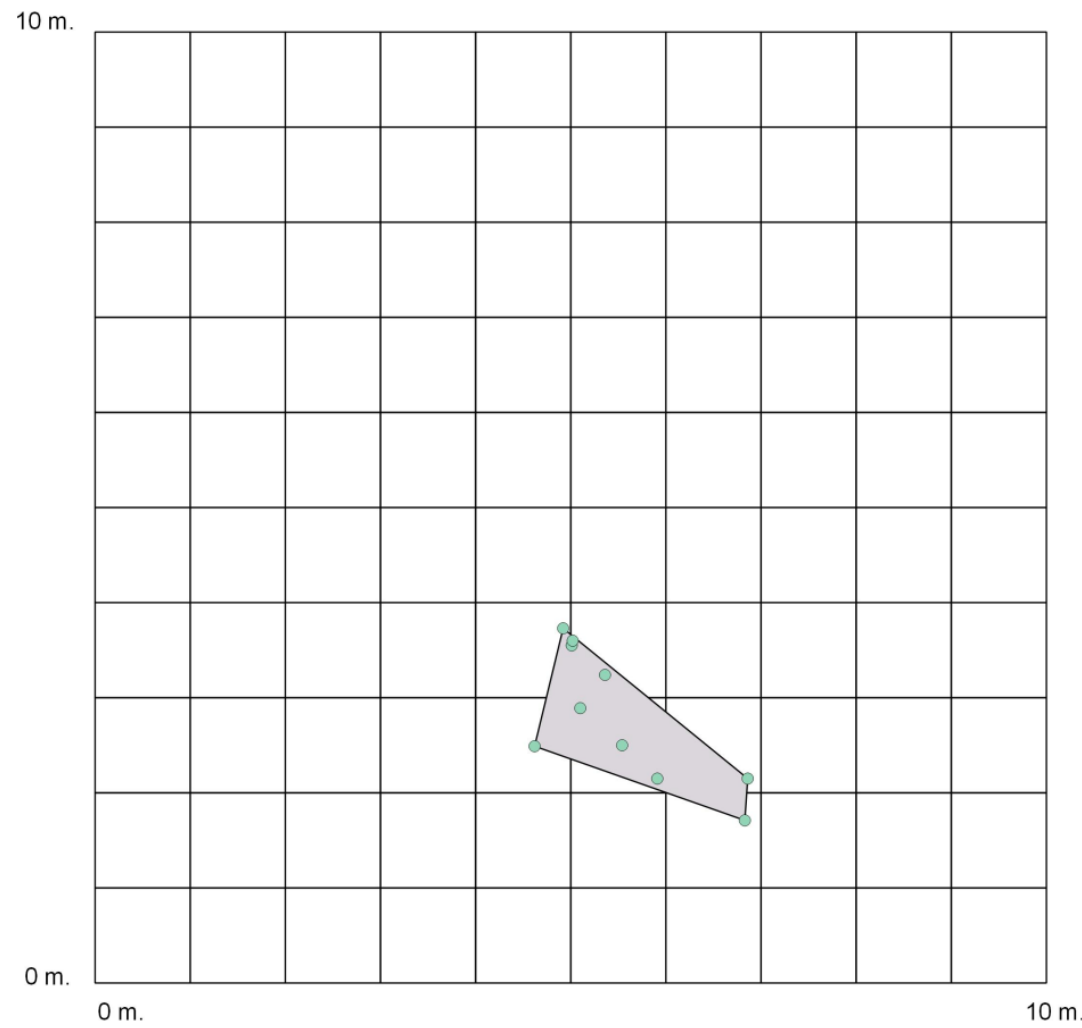

Frog: D167

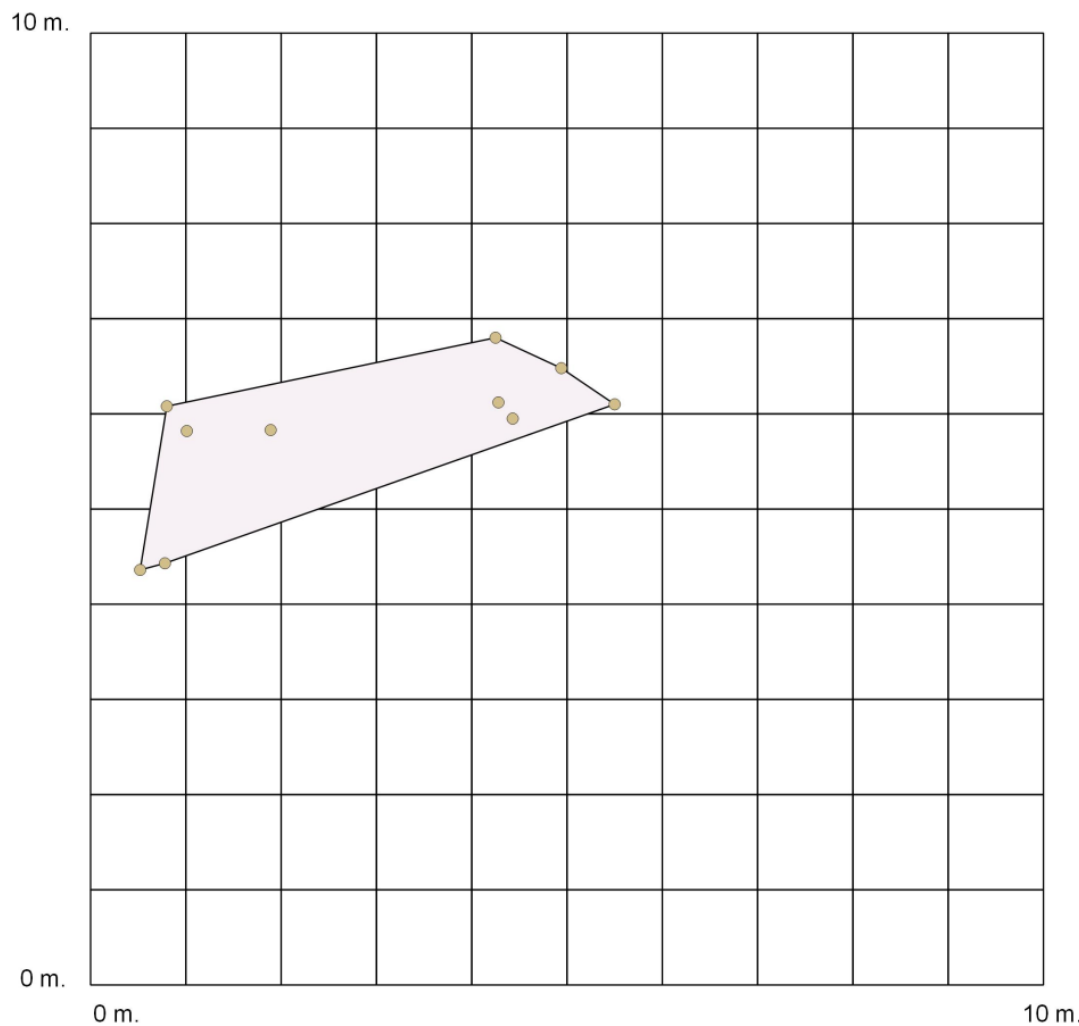


Frog: D200

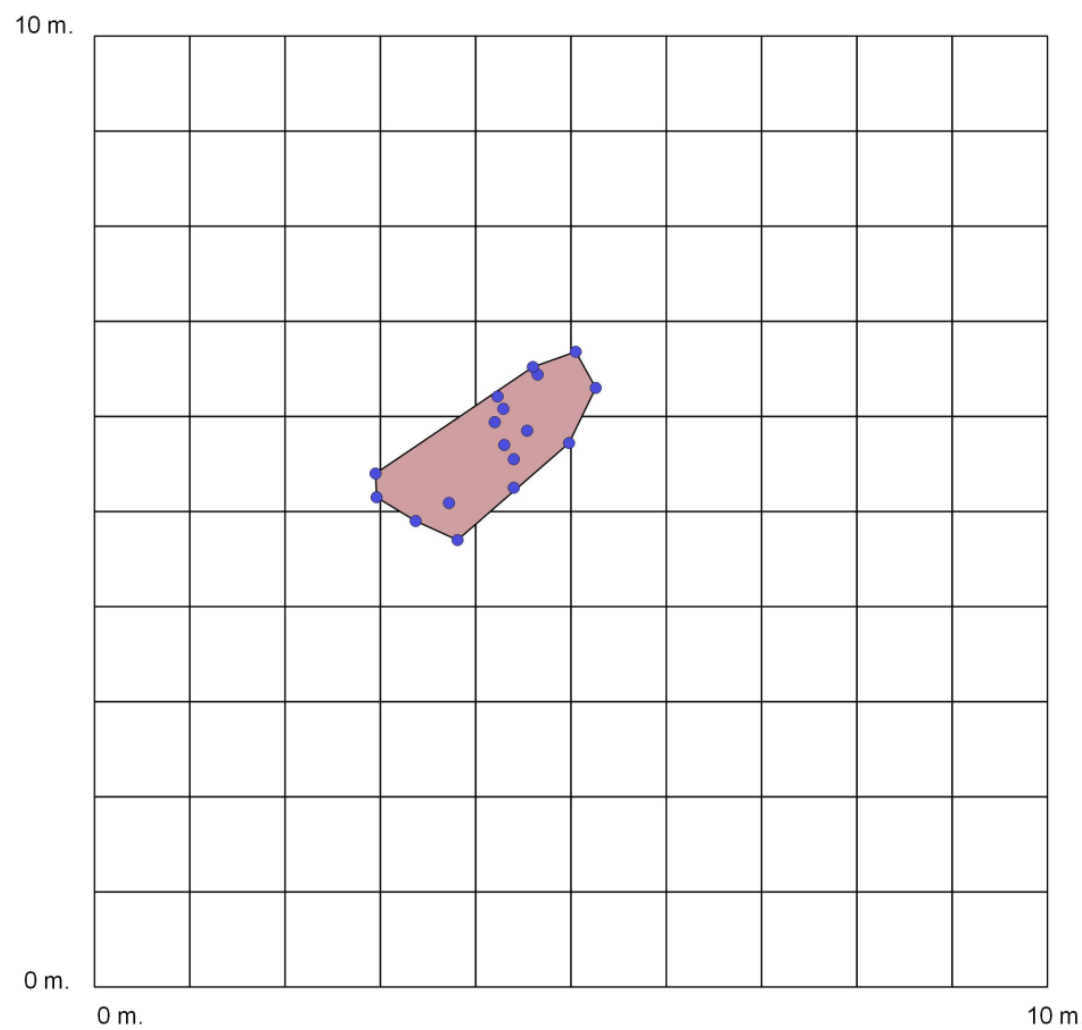

Frog: D203

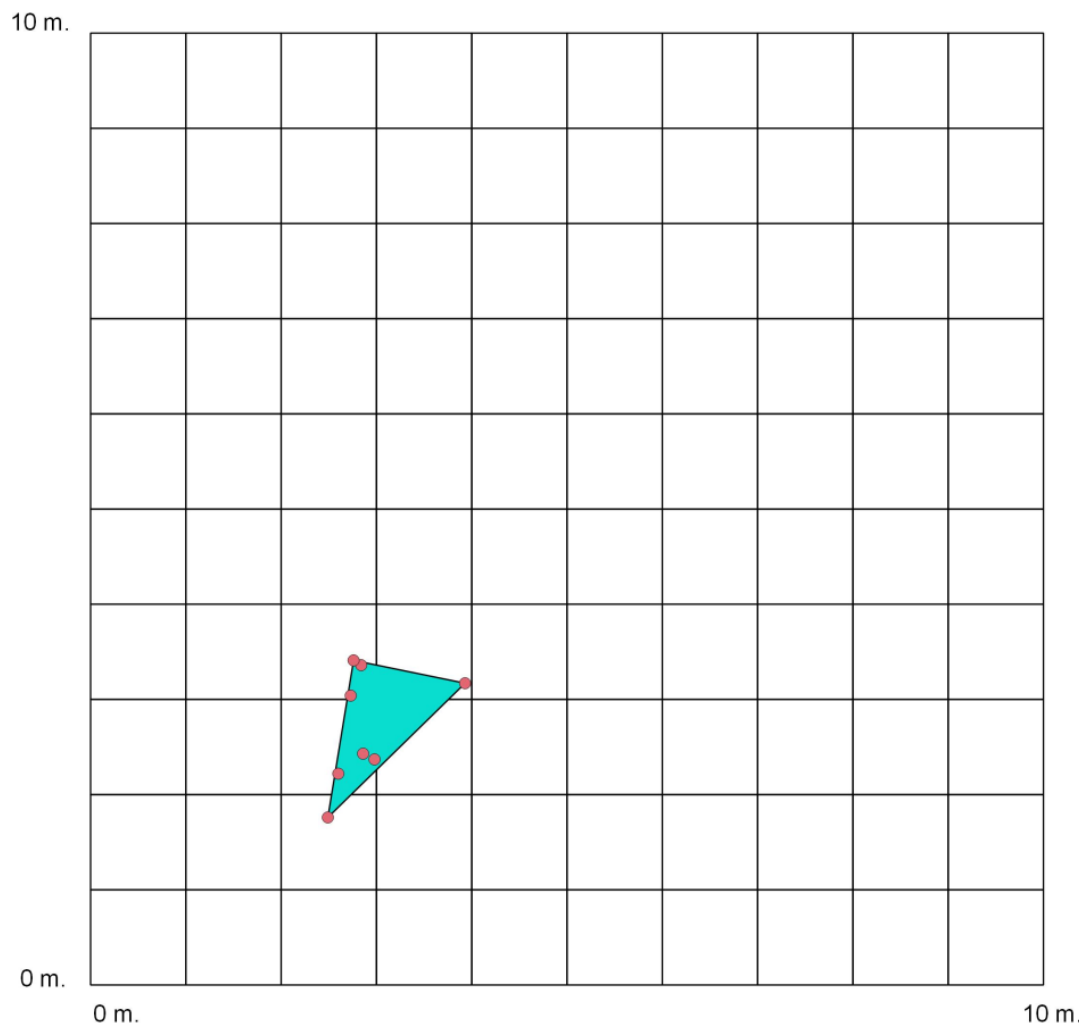


Frog: D256

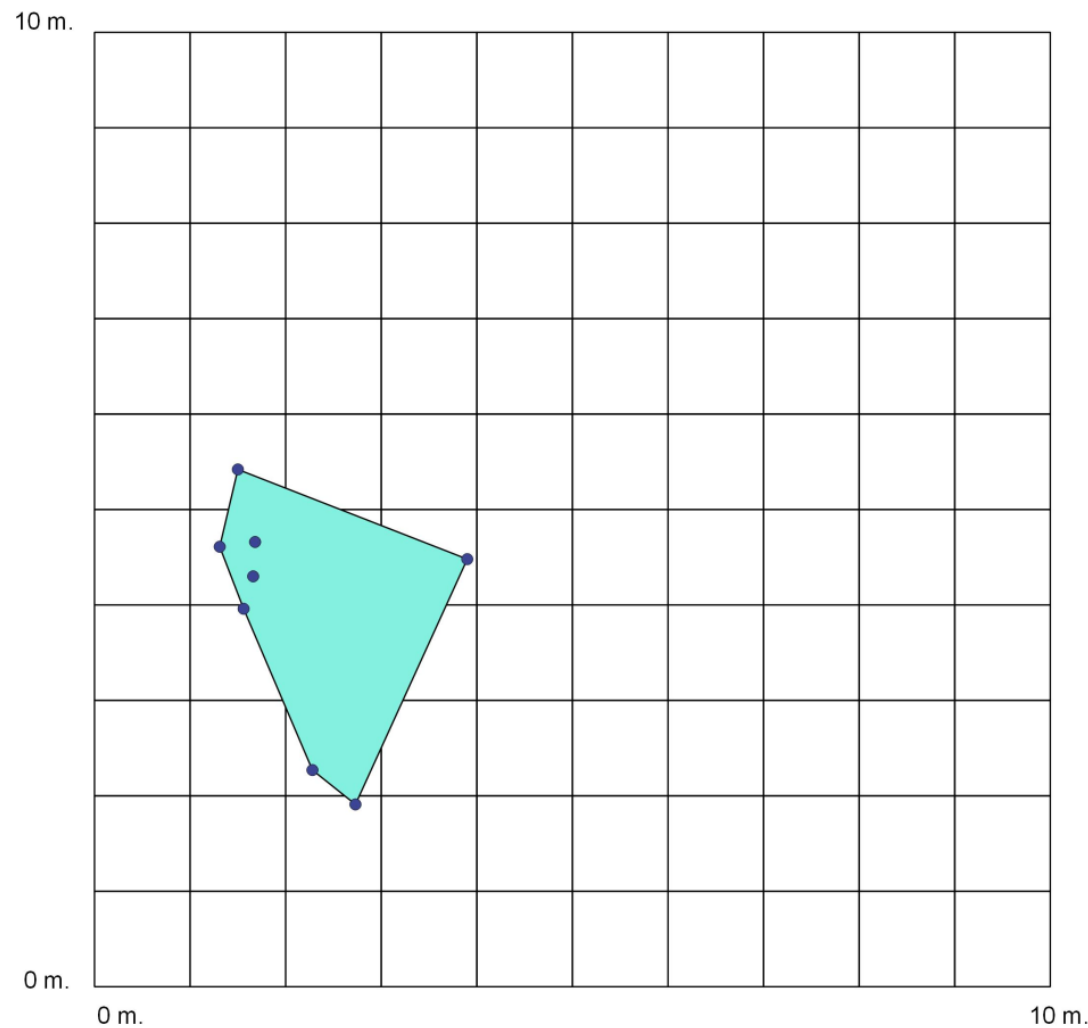

Frog: D258

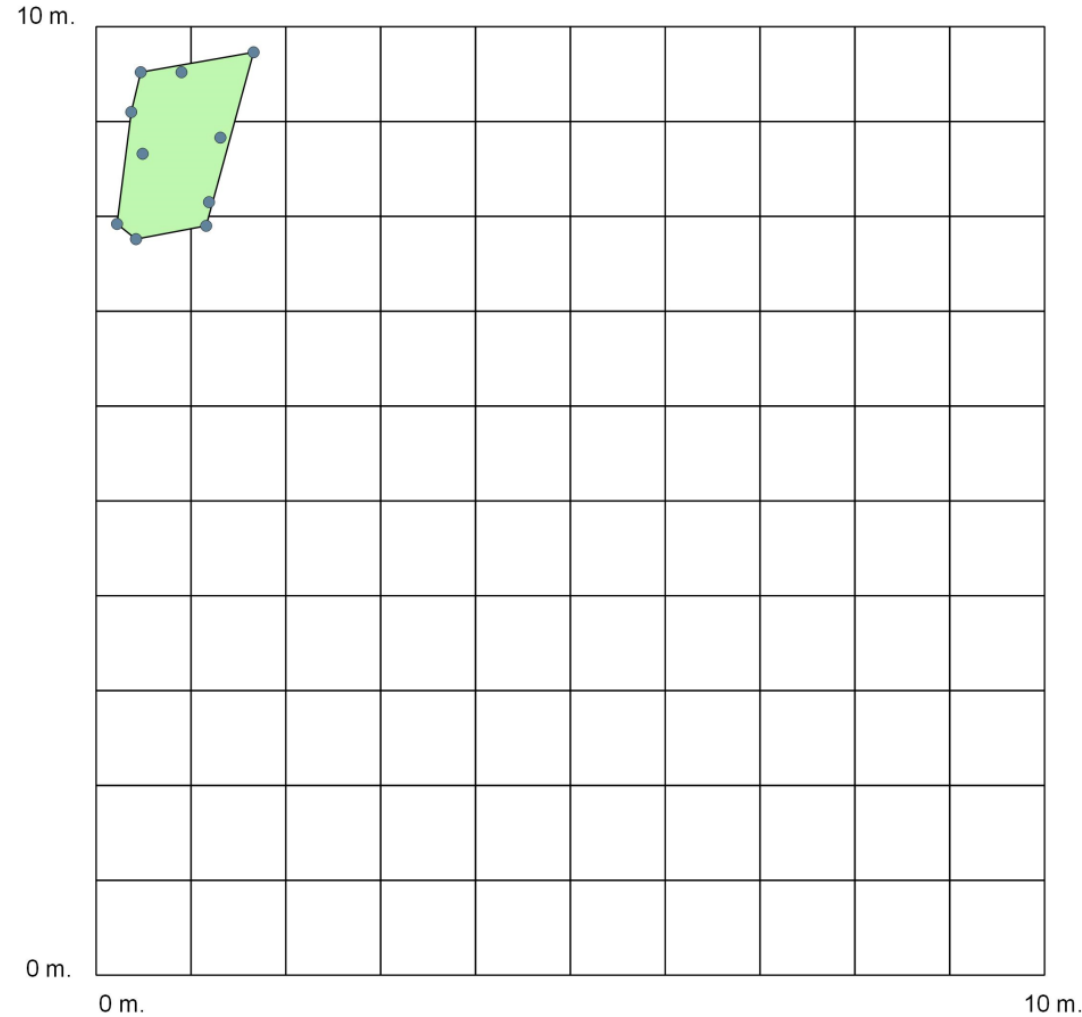


Frog: D265

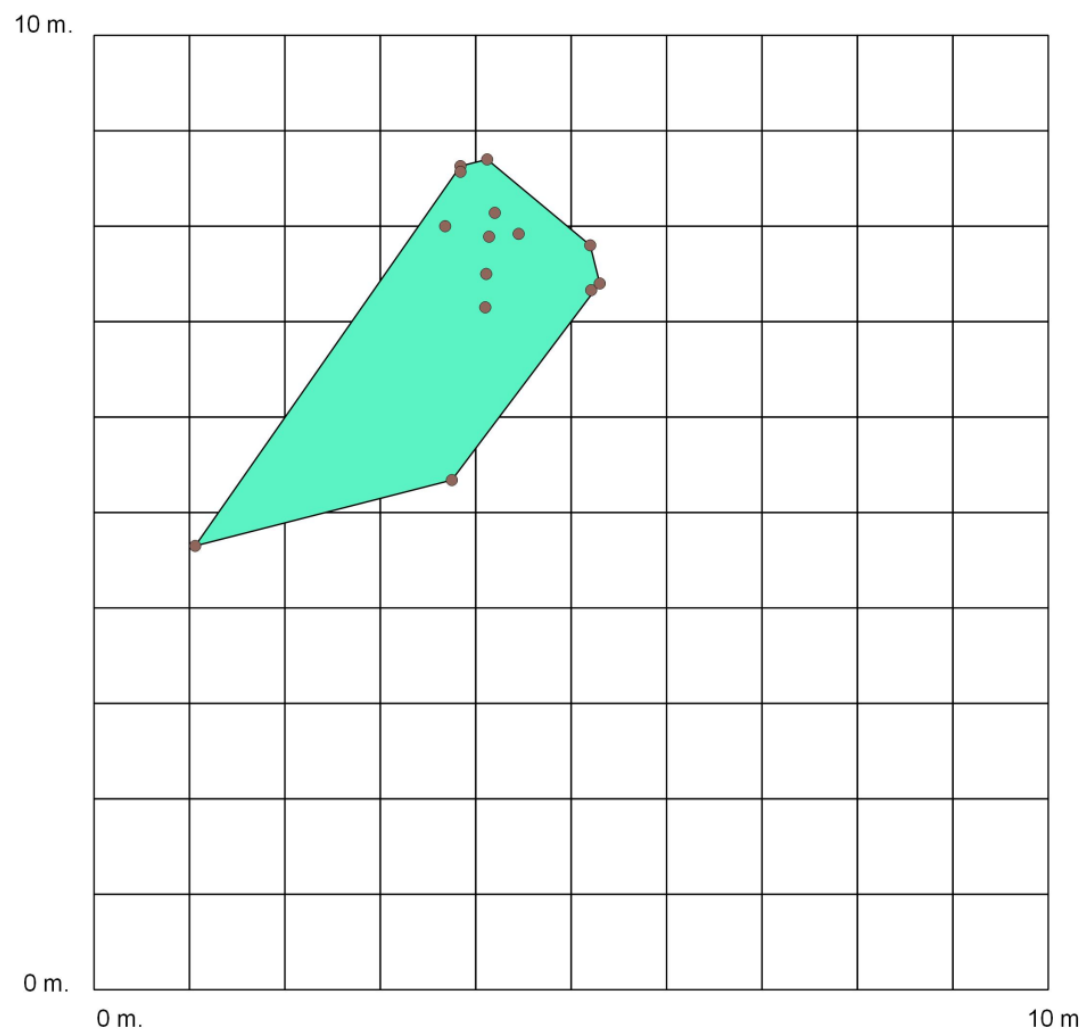

Frog: D327

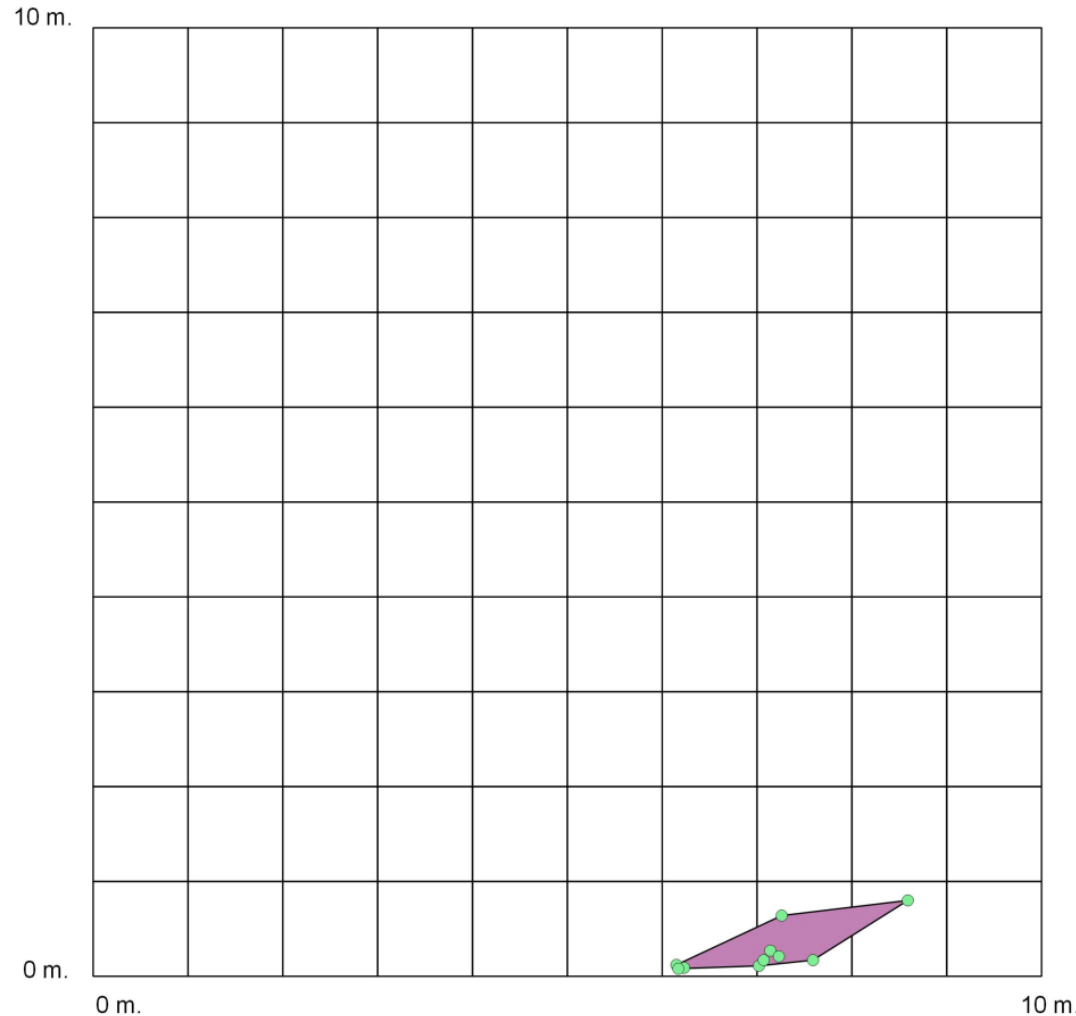


Frog: D333

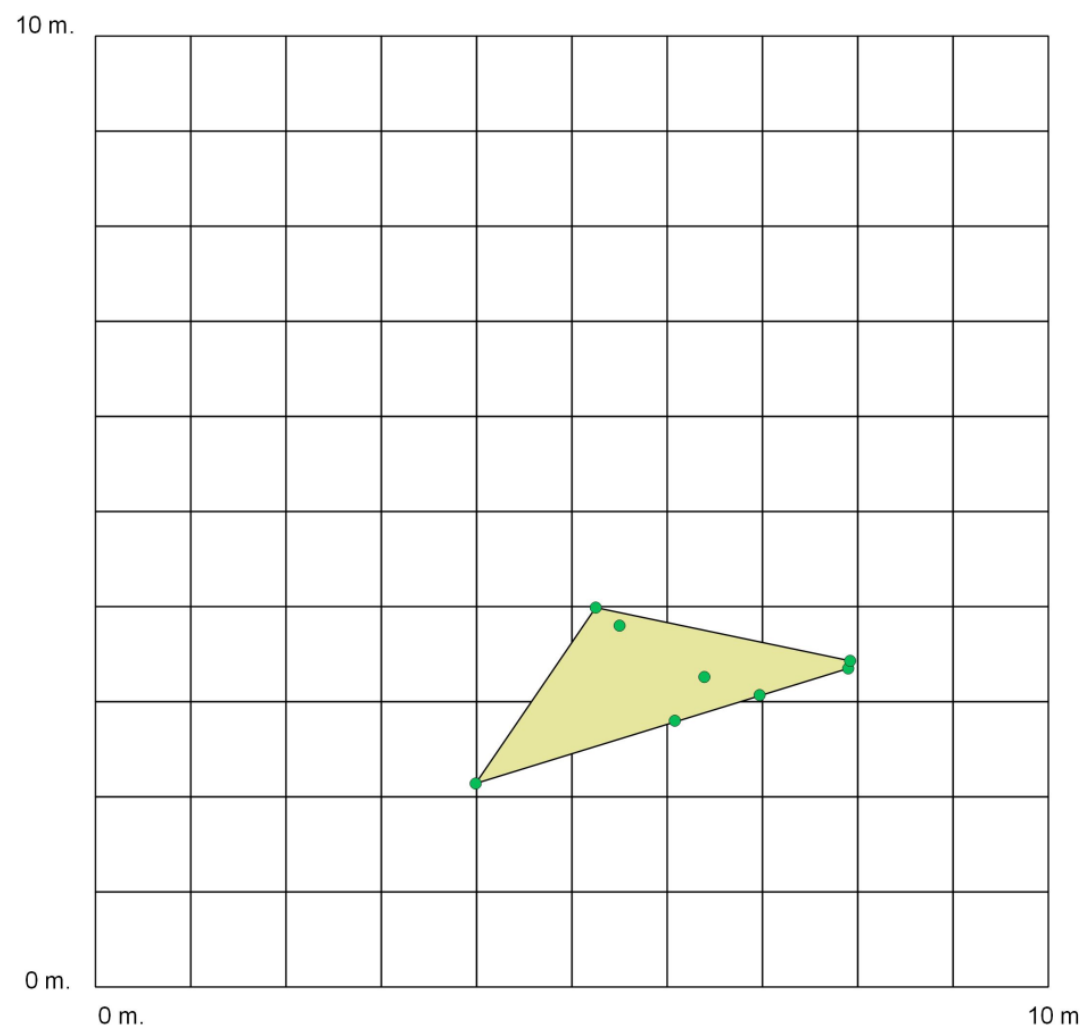

Frog: D353

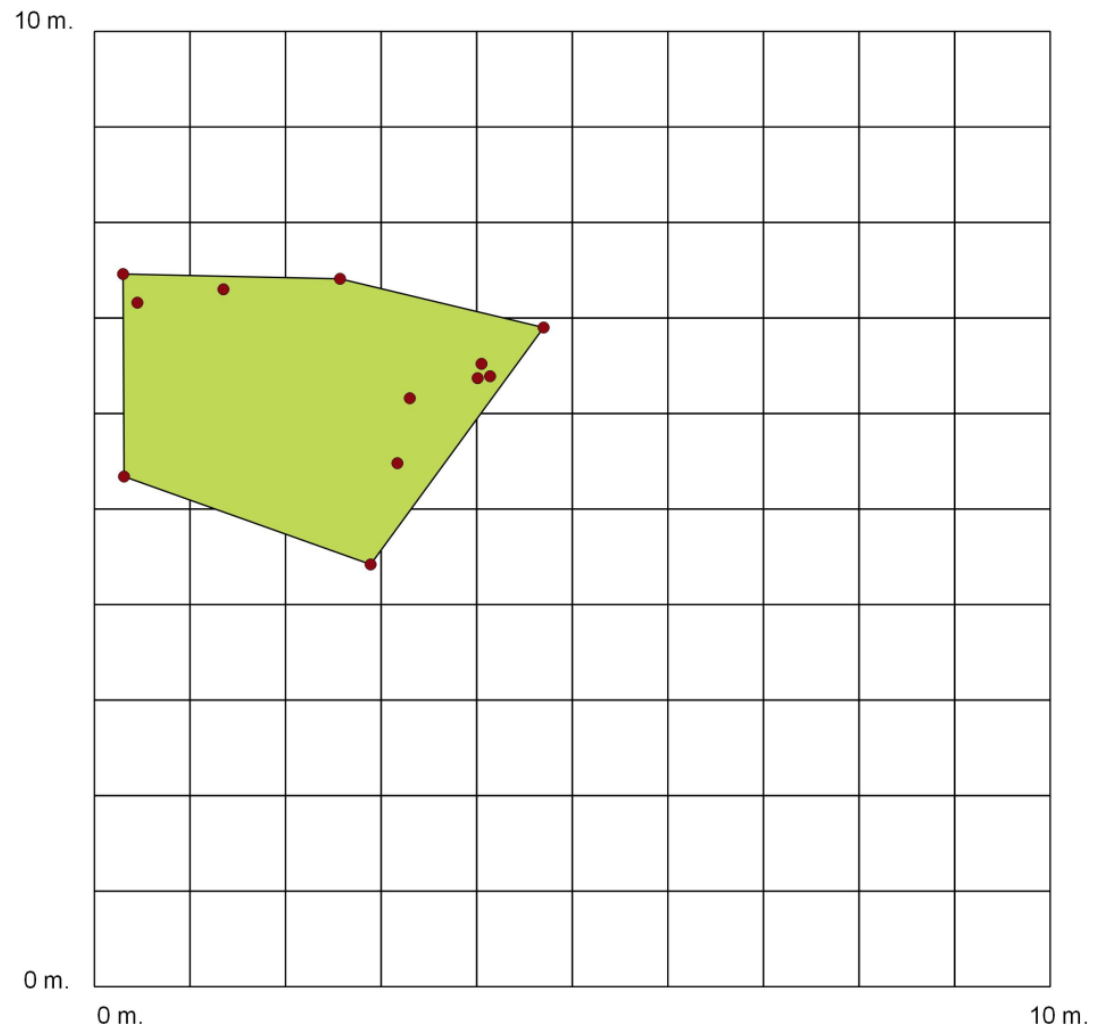


Frog: D397

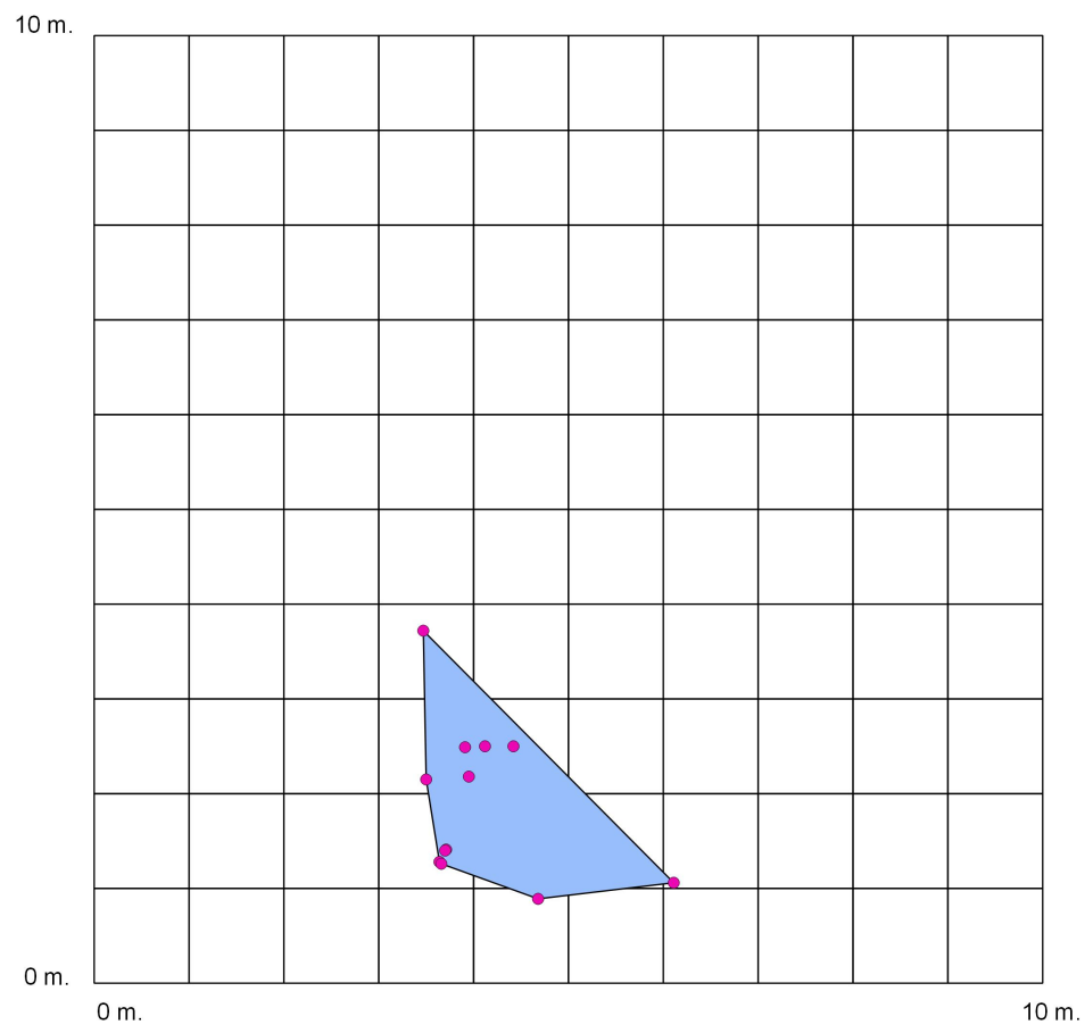

Frog: D421

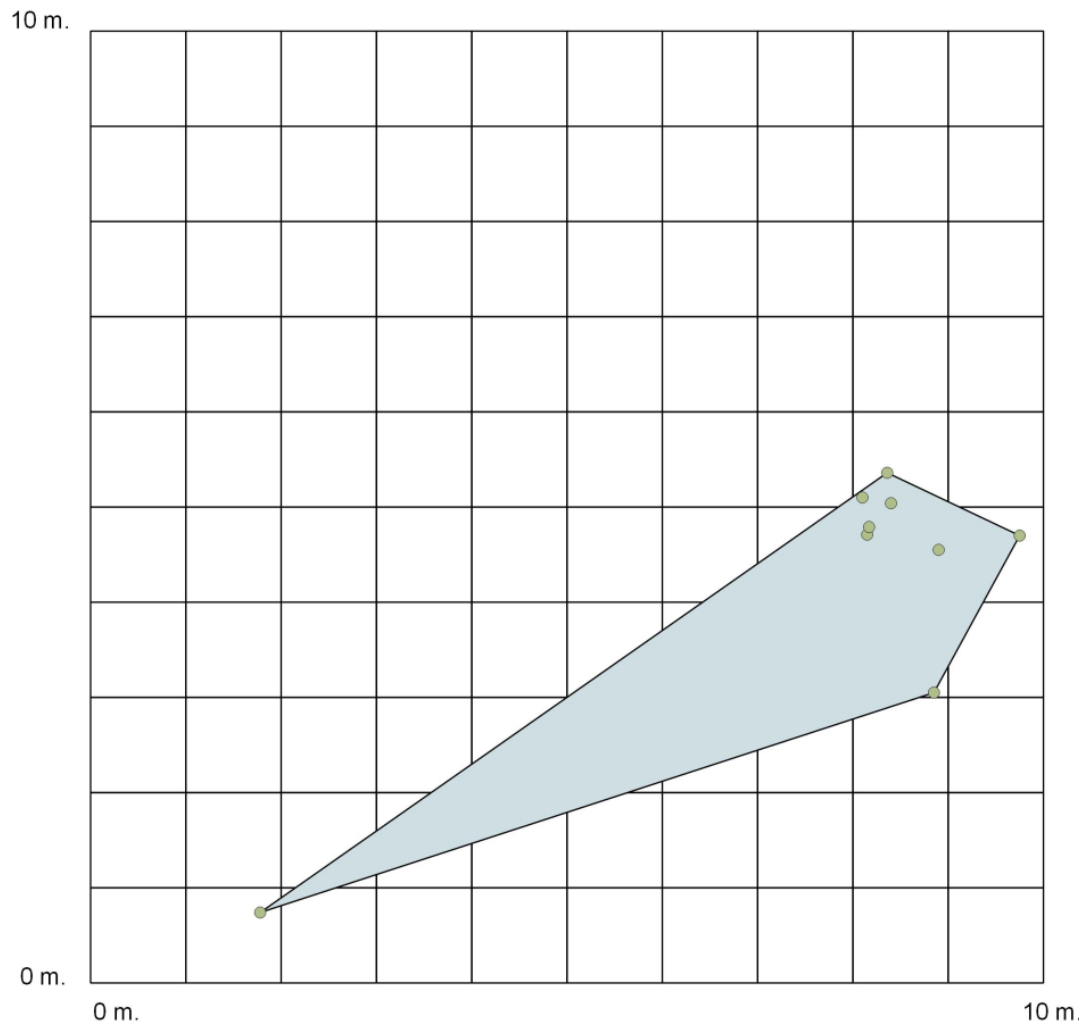


Frog: D435

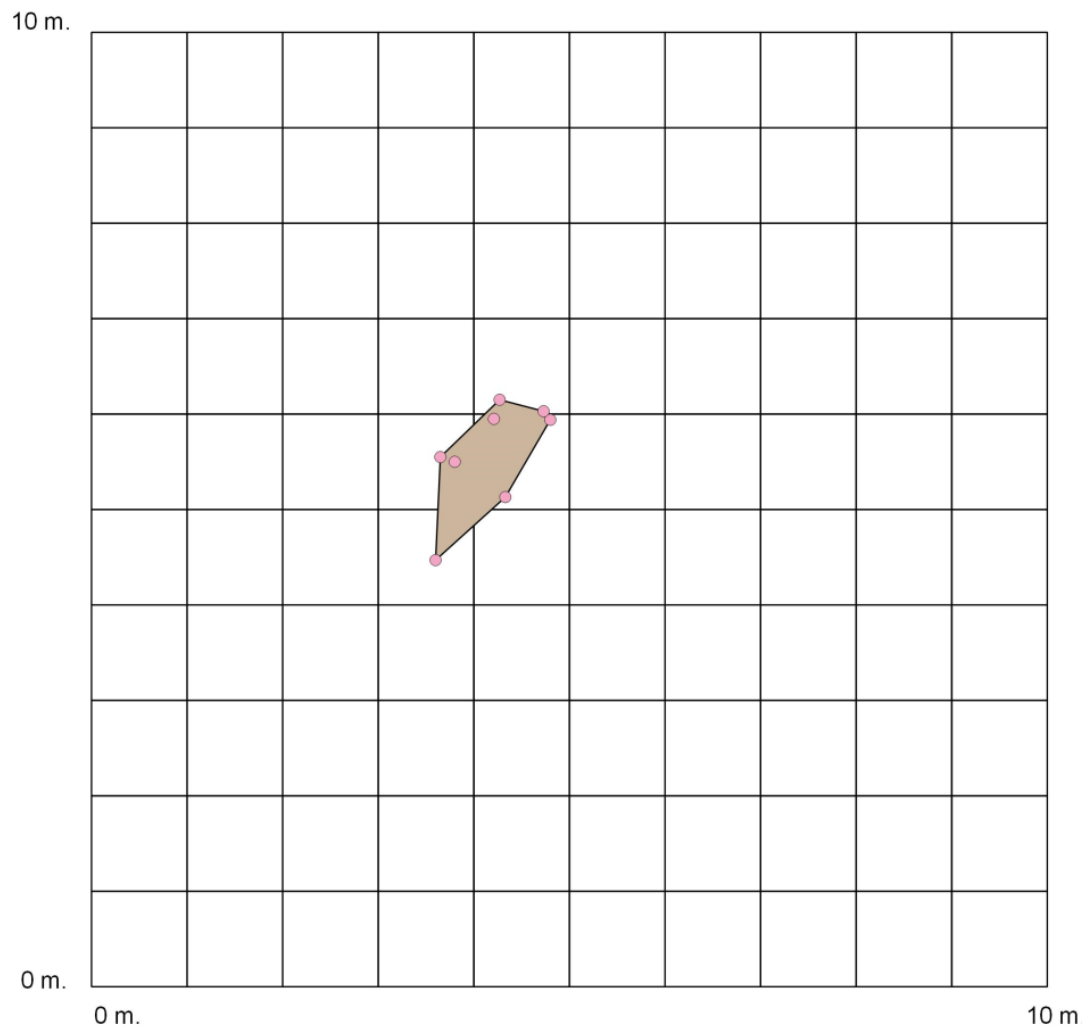

Frog: D514

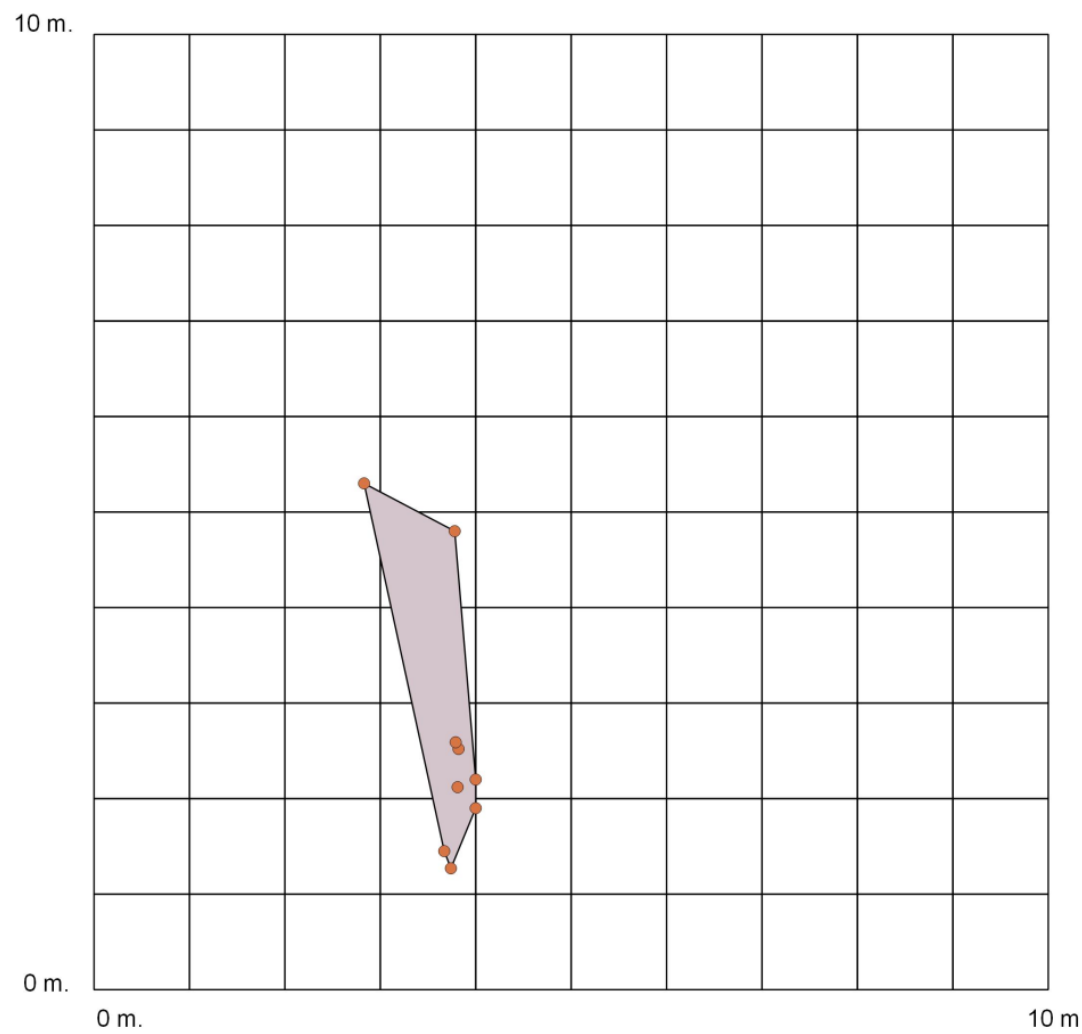


Frog: D548

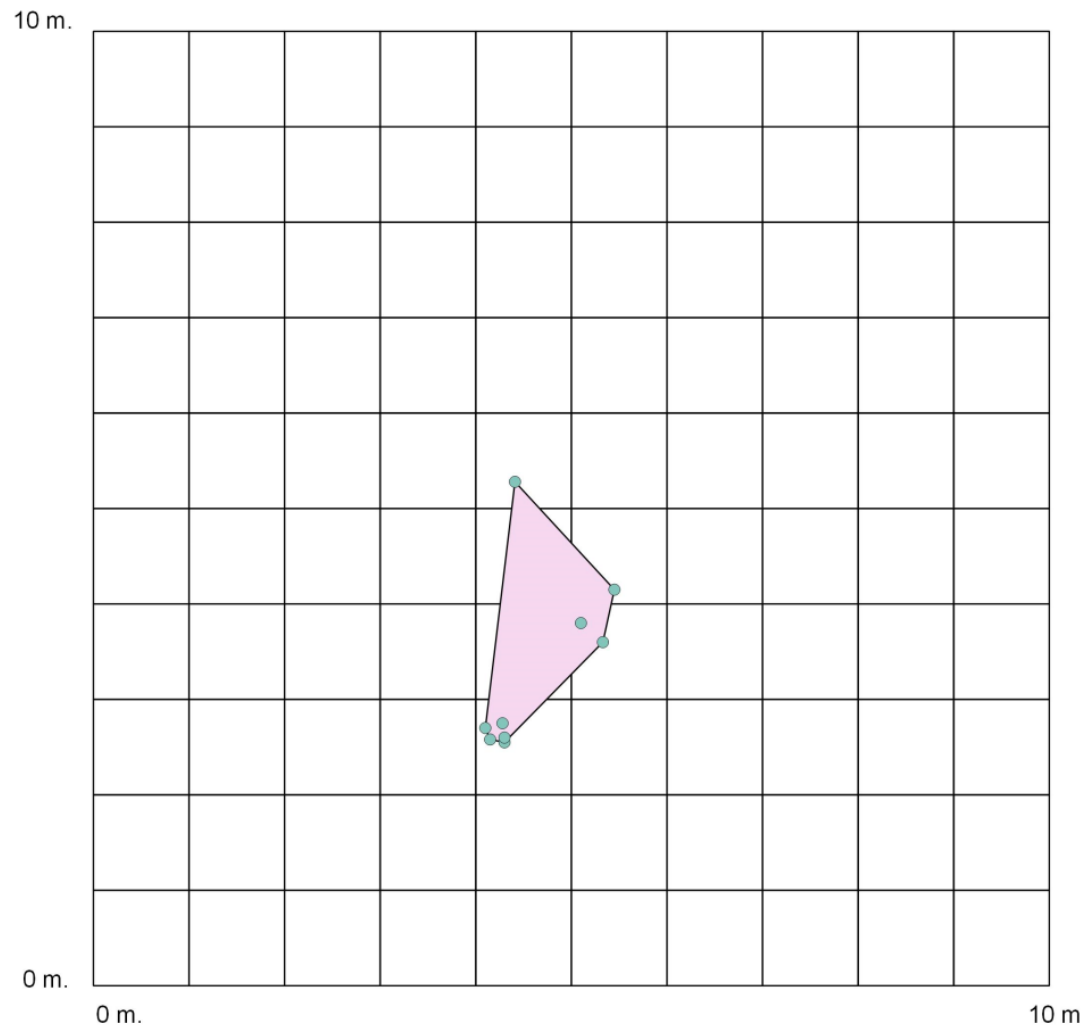

Frog: D561

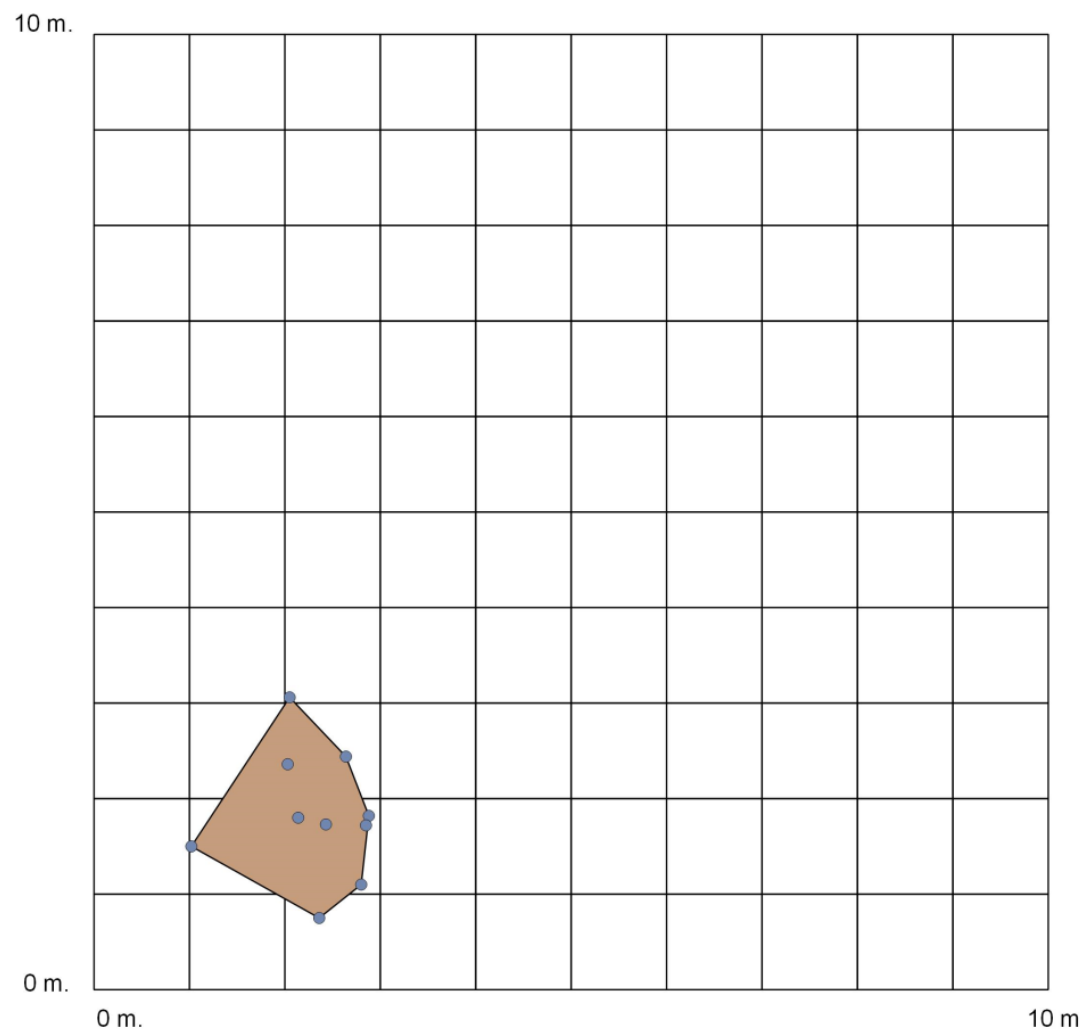

